\title{
Fernanda Lage
}

Aplicação da Tríade de Qualidade do Sedimento em análise espacial no reservatório Guarapiranga (SP, Brasil)

Sediment Quality Triad Approach applied to Guarapiranga Reservoir (SP, Brazil) in a spatial analysis

São Paulo

2013 


\section{Fernanda Lage}

Aplicação da Tríade de Qualidade do Sedimento em análise espacial no reservatório do Guarapiranga (SP, Brasil)

\section{Sediment Quality Triad Approach applied to Guarapiranga Reservoir (SP, Brazil) in a spatial analysis}

(versão corrigida segundo recomendação da banca)

São Paulo

2013 


\section{Fernanda Lage}

\section{Aplicação da Tríade de Qualidade do Sedimento em análise espacial no reservatório Guarapiranga (SP, Brasil)}

\section{Sediment Quality Triad Approach applied to Guarapiranga Reservoir (SP, Brazil) in a spatial analysis}

Tese apresentada ao Instituto de Biociências da Universidade de São Paulo, para a obtenção de Título de Doutor em Ecologia, na Área de Ecologia de Ecossistemas Terrestres e Aquáticos.

Orientador (a): Ana Lúcia Brandimarte

\section{São Paulo}


Lage, Fernanda

Aplicação da Tríade de Qualidade do Sedimento em análise espacial

na Represa do Guarapiranga (SP, Brasil) / Fernanda Lage ; orientadora

Ana Lucia Brandimarte. - São Paulo, 2013.

$118 \mathrm{f}$.

Tese (Doutorado) - Instituto de Biociências da Universidade de São

Paulo. Departamento de Ecologia.

1.Macroinvertebrados Bentônicos. 2. metais. 3. reservatório urbano. I.

Universidade de São Paulo. Instituto de

Biociências.

Departamento de Ecologia. II. Título.

\section{Comissão Julgadora:}

Prof (a). Dr(a).

Prof (a). Dr(a).

Prof (a). Dr(a).

Prof (a). Dr(a).

Prof (a). Dr(a).

Oirentador (a) 
À minha familia e noivo Roberto pelo amor, apoio e incentivo. 


\section{Agradecimentos}

“À Deus, que nos deu o dom da vida,

$\mathcal{N}$ os presenteou com a liberdade,

nos abençoou com a inteligência,

nos deu a graça de lutarmos,

para a conquista das nossas realizações!

A Ele cabe o Louvor e a Glória,

A nós só cabe agradecer."

(Rui Barbosa)

À minha querida orientadora, Ana Lúcia Brandimarte, por todo apoio e ensinamentos e pela valorosa orientação.

À Capes, pela bolsa de doutorado.

À todos os funcionários do Programa de Pós - Graduação do Departamento de Ecologia.

Ao Instituto de Biociências, e aos técnicos, secretárias e funcionários do Departamento de Ecologia (IB - USP).

À toda equipe do Laboratório de Limnologia (Instituto de Biociências - USP), alunos do Prof. Dr. Marcelo Luiz Mrtins Pompêo e Prof. Dra. Ana Lúcia Brandimarte, sem a ajuda de vocês não teria sido possível realizar este trabalho.

À doutoranda e amiga Sheila Cardoso da Silva, que esteve comigo durante todo o processo de análises químicas e análise de dados.

À toda a equipe do laboratório do Prof. Dr. Evaldo Luiz Gaeta Espíndola do CRHEA, Usp-São Carlos, pela ajuda com os testes ecotoxicológicos, em especial à Clarice Botta.

Ao Prof. Dr. Antonio Aparecido Mozeto do Departamento de Química da UFSCar e de sua equipe pela ajuda no processo dos testes ecotoxicológicos.

À Prof. Dra. Mercedes Marchese do INALI, em Santa Fé-Argentina, pela ajuda na identificação dos Oligochaeta.

Aos docentes do Departamento de Ecologia da USP-SP, Prof. Dr. Sérgio Rosso, Prof. Dr. Roberto Munehisa Shimizu e Prof. Sergio Tadeu Meireles pela ajuda com as análises estatísticas e delineamento amostral. E ao Prof. Dr. Marcelo Luiz Martins Pompêo pela ajuda em todos os momentos, desde a infraestrutura para realizar as coletas e as análises químicas até às conversas frequentes sobre o trabalho.

Ao PhD. Peter Chapman da empresa Golder Associates Ltd., do Canadá, pelos comentários e sugestões sobre o trabalho e em especial pelo convite a publicação na revista IEAM em que é editor.

Aos amigos Roberto, Cláudia Fileto e Maíra Nunes que me alojaram em São Carlos. À amiga Dra. Luciana Pinto Sartori por todo apoio para o ingresso no doutorado na USP.

À meu noivo Roberto e pais Armando e Neide, por todo apoio, fé, amor e paciênica. À todos que de alguma maneira ajudaram na realização deste trabalho. 
Índice

Introdução Geral $\quad 1$

Referências $\quad 4$

Capítulo 1. Variação temporal da comunidade de macroinvertebrados bentônicos no reservatório Guarapiranga (SP, Brasil)

$\begin{array}{ll}\text { Abstract/ Resumo } & 7\end{array}$

1.1. Introdução 9

1.2. Materiais e Métodos

$\begin{array}{ll}\text { 1.2.1. Área de estudo } & 10\end{array}$

1.2.2. Fonte de dados 13

1.2.3. Análise dos dados 13

1.3. Resultados $\quad 15$

1.4. Discussão 28

1.5. Referências 32

Capítulo 2. Aplicação da Tríade da Qualidade do Sedimento em análise espacial no reservatório Guarapiranga (SP, Brasil)

Abstract/ Resumo 37

2.1. Introdução

2.1.1. Influência antropogênica sobre o reservatório Guarapiranga 38

2.2.2. Tríade da Qualidade do Sedimento 39

2.2. Materiais e Métodos

2.2.1. Área de estudo $\quad 40$

2.2.2. Amostragem do sedimento e análise dos dados 42

2.2.2.1. Macroinvertebrados bentônicos $\quad 42$

2.2.2.2. Bioensaios 42

2.2.2.3. Análise granulométrica, teor de matéria orgânica no
concentração de nutrientes

$\begin{array}{rr}\text { sedimento, e concentração de nutrientes } & 43 \\ 2.2 .2 .4 & \text { Metais e caracterização física e química da água intersticial } \\ 43\end{array}$

2.2.2.5. Métricas e análises exploratórias 44

2.3. Resultados

2.4. Discussão $\quad 58$

2.5. Referências $\quad 63$

Capítulo 3. How do you deal with your organic sediment sample for benthic macroinvertebrate community analyses? $\quad 70$

Capítulo 4. Composição da comunidade de macroinvertebrados bentônicos em quatro estações amostrais de um lago raso em diferentes estações do ano

$\begin{array}{ll}\text { Abstract/Resumo } & 74\end{array}$

4.1. Introdução

4.2. Materiais e Métodos

$\begin{array}{ll}\text { 4.2.2. Amostragem } & 76\end{array}$

$\begin{array}{ll}\text { 4.2.2.1. Sedimento } & 77\end{array}$

4.2.2.2. Macroinvertebrados bentônicos 77

$\begin{array}{ll}\text { 4.2.3. Análises exploratórias } & 77\end{array}$

$\begin{array}{ll}\text { 4.3. Resultados } & 78\end{array}$ 
4.4. Discussão

4.5. Referências

Conclusão Geral

Resumo Geral

Abstract

Anexos 


\section{Introdução Geral}

As águas da Região Metropolitana de São Paulo (RMSP) podem ser consideradas como um dos elementos propulsores do seu desenvolvimento. No entanto, pela falta de planejamento em seu crescimento, a RMSP vem enfrentando problemas relacionados à poluição e ao possível esgotamento da água. Atualmente, verifica-se na região uma baixa disponibilidade hídrica por habitante, apesar dos índices pluviométricos na faixa de $1.400 \mathrm{~mm}$ por ano. A RMSP é constituída por grande área urbana, com tendência à expansão para as zonas periféricas das cidades, ocupadas principalmente pela população de baixa renda. Tal expansão desordenada agrava a degradação ambiental, especialmente nas áreas de proteção de mananciais e de várzeas, sujeitas a uma disposição inadequada de resíduos sólidos e à impermeabilização do solo (Matsuzaki, 2007).

O reservatório Guarapiranga, localizado na RMSP, foi formado pela Companhia Light \& Power entre 1906 e 1909, com a construção de barragens no Rio Guarapiranga e em seus afluentes, com finalidade energética. Mas, a partir de 1928, tornou-se a principal fonte de água para abastecimento público em São Paulo (Whately \& Cunha, 2006). Atualmente é o segundo principal sistema produtor de água de RMSP, pois foi suplantado pelo Sistema Cantareira que começou a ser construído em meados da década de 1970.

Com a ocupação do seu entorno por edificações residenciais, clubes, loteamentos residenciais, chácaras, marinas e instalações religiosas, o reservatório e as adjacências passaram a ser utilizados para lazer (Rocha, 1976). Logo na década de 1950, tal situação suscitou a construção de um coletor de esgotos na margem direita, para a população de Interlagos. E já no final dos anos 1980, os impactos da ocupação do entorno passaram a ser observados no reservatório, como uma grande mortalidade de peixes (Whately \& Cunha, 2006).

Na década de 1990, o governo estadual elaborou um programa de recuperação ambiental da região, conhecido como Programa Guarapiranga, que investiu na construção de redes de esgoto e na reurbanização de favelas. Investimentos esses insuficientes, uma vez que a qualidade da água piorou ao longo dos anos e a quantidade de água disponível encontra-se cada vez mais comprometida em função da retirada de grandes volumes de água do reservatório para abastecimento e dos diversos processos de degradação existentes na bacia, entre eles erosão, assoreamento, poluição e desmatamento.

No ano 2000, com o objetivo de regularizar a vazão do Guarapiranga, que vinha sendo explorado acima de sua capacidade ao longo dos anos, foi construída a interligação do braço Taquacetuba do reservatório Billings, com o Rio Parelheiros, afluente da margem direita do reservatório Guarapiranga. Em função dos períodos de estiagem dos últimos anos, o Taquacetuba também vinha sendo utilizado no limite máximo de sua capacidade até 2010, quando o nível do Guarapiranga voltou a subir e a reversão foi interrompida.

Em 2003, mais da metade da área da Bacia Hidrográfica da Guarapiranga já se encontrava alterada por atividades humanas. Da área degradada, $16 \%$ dizem respeito aos usos urbanos e o restante a atividades agrícolas, campo antrópico, mineração (caulim, argila, areia e granito), reflorestamento, indústrias e áreas de lazer. No mesmo ano, áreas com vegetação remanescente de Mata Atlântica ocupavam apenas 37\% da área da bacia, dos quais somente 1,2\% estavam legalmente protegidos sob forma de unidade de conservação de proteção integral (Whately \& Cunha, 2006).

Nas regiões adjacentes aos tributários do reservatório foi observada, no ano de 2005, mineração ativa no Embu-Mirim e ao longo de todo o Braço Parelheiros. Além disso, toda a área adjacente ao remanso do rio Embu-Guaçu já obteve concessão para a exploração de minérios. Caso todos os processos cheguem à fase de concessão de lavra ou regime de licenciamento, a Bacia Hidrográfica do Guarapiranga terá 32,6\% de seu território sob algum tipo de exploração mineral, o que contribui ainda mais para a redução da qualidade da água e ocasiona desmatamento, erosão e assoreamento nos tributários do reservatório (Whately \& Cunha, 2006).

Atualmente, o esgoto e a poluição difusa, inclusive por metais, constituem as principais fontes de poluição do reservatório, e têm íntima ligação com a deficiência dos serviços de 
saneamento, em especial de rede de coleta, afastamento e tratamento do esgoto produzido pela população da bacia (Whately \& Cunha, 2006).

Estes problemas não são recentes e o reservatório tem sido considerado eutrófico desde 1960. Matsuzaki (2007) classifica o Guarapiranga, de acordo com os valores de fósforo total, como supereutrófico a hipereutrófico. Além disso, a presença de metais-traço e a concentração de nutrientes no sedimento também indicam forte contaminação antropogênica (Rocha, 1976; Beyruth, 2000; Mozeto et al., 2001; Mozeto et al. 2003; Menezes \& Beyruth, 2003). Richter e colaboradores (2007) também observaram metais nas águas do reservatório, embora, alguns em concentrações aceitáveis, mas com certa variação sazonal. Observaram ainda, no sedimento, assim como Mozeto e colaboradores (2001; 2003), concentrações de metais e nutrientes que indicam forte contaminação antropogênica no braço Embu-Guaçu quando comparado a pontos próximos à barragem. Corroborando esses resultados, Padial (2008) encontrou no sedimento de grande parte do reservatório Guarapiranga, valores de concentração de metais muito acima do sugerido para proteção da vida aquática e acima do que seria de ocorrência natural.

A concentração de elementos poluentes no sedimento ocorre, entre outros fatores, em consequência de alterações hidrológicas como diminuição da corrente, o que facilita a sedimentação, tanto de material autóctone como alóctone, resultando na formação bancos de lodo, nos quais, além da matéria orgânica, podem ser acumulados sais minerais nutrientes e metais-traço aderidos a este material (Alden, 1992).

Do ponto de vista ecotoxicológico, os metais-traço são os mais preocupantes, porque em pequenas concentrações são capazes de provocar efeitos tóxicos graves nos organismos. Um dos fatores que afetam a biodisponibilidade dos metais é o tamanho dos grãos do sedimento, já que quanto menor a partícula, maior a capacidade de adsorção de metais. O destino desses metais-traço passa a ser dependente do destino da fase com a qual estão complexados: a formação de complexos insolúveis precipita tais elementos; por outro lado, elementos-traço incorporados ou adsorvidos são liberados na coluna d'água quando sua fase complexadora é destruída ou solubilizada ou ainda quando há mudanças no pH (Santischi et al., 1990). No entanto, uma questão difícil é determinar se a presença de contaminantes está surtindo efeito adverso na biota, uma vez que outros fatores podem afetá-la de forma negativa (Araújo, 2005; Mariani, 2006).

Além dos processos físicos e químicos, a fauna bentônica também é um importante agente transformador do sedimento, pois, através de sua atividade mecânica (biorrevolvimento), altera características físicas e químicas do sedimento, além de promover a liberação de nutrientes para a coluna d'água. Além disso, estes organismos têm um papel fundamental no fluxo de energia e na ciclagem de nutrientes dos ecossistemas aquáticos, decorrente do fato de participarem indiretamente no processo de decomposição da matéria orgânica, ao reduzirem o tamanho das partículas detritais, aumentando a área de atuação dos microrganimos decompositores, e por fazerem parte da dieta de vários organismos aquáticos (Margalef, 1983; Kalff, 2003).

Como se vê, o sedimento apresenta importância no metabolismo de sistemas aquáticos pois é um local de intensa deposição de materiais particulados e de decomposição de matéria orgânica. Assim, integra e reflete todos os processos que ocorrem neste ambiente (Kalff, 2003). Portanto, sua composição pode ser indicativa de seu estado trófico e da presença de contaminantes, devendo ser estudada com maior detalhe (Carmouze, 1994). Desta forma, estudos das características físicas e químicas do sedimento, aliados a bioensaios toxicológicos e à estrutura da fauna bentônica, conhecidos como tríade de qualidade do sedimento, podem avaliar a concentração de contaminantes e seus efeitos sobre a comunidade zoobentônica, além de descrever relações ecológicas entre esta fauna e as propriedades do sedimento, identificando riscos à sua integridade (Chapman, 1992).

Uma vez que o sedimento é o destino final de muitos poluentes, e que a fauna bentônica tem tão íntima relação com este, é de se esperar que esta seja indicadora dos impactos sobre os ecossistemas aquáticos. Os chamados indicadores biológicos são organismos que refletem a integridade ecológica dos ecossistemas onde vivem, pois respondem a diferentes agentes estressantes; refletem o histórico de degradação e devem, sempre que possível, fazer parte de Programas de Monitoramento Ambiental. Alguns dos principais métodos de monitoramento 
envolvem a avaliação da estrutura de comunidades, a identificação de espécies indicadoras, efeitos populacionais, estudos ecotoxicológicos e bioacumuladores (Callisto et al., 2005).

O uso de macroinvertebrados bentônicos como indicadores biológicos apresenta várias vantagens, dentre as quais, o fato de representarem não somente os efeitos imediatos dos fatores ambientais, mas também a interação dos efeitos prévios. Além disso, podem indicar o estado trófico passado e presente e os efeitos de descargas orgânicas e de poluentes nos corpos d'água, armazenando informação por períodos mais longos que as comunidades planctônicas e nectônicas. Por estes motivos, a comunidade bentônica vem sendo utilizada de forma crescente como indicadora da qualidade da água (Menezes \& Beyruth, 2003).

Neste contexto, este trabalho visa analisar a qualidade do sedimento do reservatório do Guarapiranga e a comunidade de macroinvertebrados que o habita. A partir do observado nos trabalhos de Rocha (1976) e Rocha (1999), que retraram baixa densidade de organismos e riqueza de taxa, surgiu o interesse de realizar uma análise da variação temporal da comunidade de macroinvertebrados bentônicos no reservatório do Guarapiranga, apresentada no Capítulo 1 desta tese. Além disso, já conhecendo seu histórico de poluição orgânica (Beyruth, 2000) e por metais (Patella, 1998; Mozeto et al. 2003; Padial, 2008), optou-se por aplicar a Tríade de Qualidade do Sedimento para a avaliação do reservatório, a qual é apresentada no Capítulo 2.

Uma questão interessante, surgida no decorrer da triagem dos invertebrados bentônicos, foi a ocorrência de uma ‘associação’ entre Oligochaeta Naidinae e o substrato formado por macrófitas aquáticas em decomposição. Chamou especial atenção a densidade expressiva da espécie Haemonais waldvogeli dentro de caules da macrófita Polygonum, fato foi observado somente em um ponto amostral. Assim, ao se conversar sobre esta tese, com o pesquisador Peter Chapman, durante o 'SETAC North America', em Long Beach, California, a autora foi convidada a publicar uma nota, um 'Learned Discourse', sobre esta questão na revista IEAM e, dessa forma apresenta-se o Capítulo 3, cujo conteúdo será publicado provavelmente em meados de julho de 2013. E por fim, conhecendo as diferenças de densidades de taxa do zoobentos, entre períodos de verão e inverno, apresentadas nos trabalhos de Rocha (1976) e Rocha (1999), e já que havia sido realizada uma coleta piloto no verão para testar as metodologias empregadas no presente trabalho, apresenta-se no Capítulo 4 a análise da comunidade e das variáveis físicas e químicas do sedimento em 4 regiões do reservatório Guarapiranga, em períodos de verão e inverno. 


\section{Referências}

ALDEN, RW. Uncertainty and sediment quality assessments: I. confidence limits for the triad. Environmental Toxicology and Chemistry, v.11, p. 637-644. 1992.

ARAÚJO, R.P.A. Teste de toxicidade como instrumento na avaliação dos sedimentos de água doce do Estado de São Paulo. 2005. 283 f. Tese (Doutorado em Ecologia) - Instituto de Biociências, Universidade de São Paulo, São Paulo. 2005.

BEYRUTH, Z. Periodic disturbance, trophic gradient and phytoplankton characteristics related to cyanobacterial growth in Guarapiranga Reservoir, São Paulo State, Brazil. Hydrobiologia, v. 424, p. 51-65, 2000.

CALLISTO, M. et al. Biodiversity assessment of benthic macroinvertebrates along a reservoir cascade in the lower São Francisco river (Northeastern Brazil). Brazilian Journal of Biology, v. 65, n. 2, p.1-6, 2005.

CARMOUZE, J. P. Metabolismo do meio bentônico e reciclagem dos nutrientes. In: O metabolismo dos ecossistemas aquáticos: fundamentos teóricos, métodos de estudos e análises químicas. São Paulo: Editora Edgard Blücher - FAPESP. 1994. p.103-128.

CHAPMAN, P.M. Sediment Quality Triad Approach. In: Sediment Classification Methods Compendium. EPA 823-R-92-006. Washington, DC. 1992. p. 10-1 - 10-18.

KALFF, J. Limnology: inland water ecosystems. New Jersey: Prentice Hall. 2003. 592 p.

MARGALEF, R. Limnología. Barcelona, Espanha: Ediciones Omega, S.A. 1983. 1010 p.

MARIANI, C.F. Reservatório Rio Grande: caracterização limnológica da água e biodisponibilidade de metais-traço no sedimento. 2006. 123 f. Dissertação (Mestrado em Ecologia) - Instituto de Biociências, Universidade de São Paulo. São Paulo. 2006.

MATSUZAKI, M. Transposição das águas do braço Taquacetuba da represa Billings para a represa Guarapiranga: aspectos relacionados à qualidade de água para abastecimento. 2007. $183 \mathrm{f}$. Tese (Doutorado em Saúde Pública) - Faculdade de Saúde Pública, Universidade de São Paulo, São Paulo. 2007.

MENEZES, L.C.B.; BEYRUTH, Z. Impactos da aquicultura em tanques-rede sobre a comunidade bentônica da represa de Guarapiranga - São Paulo- SP. Boletim do Instituto de Pesca, São Paulo, v. 29, n. 1, p.77-86, 2003.

MOZETO, A.A.; SILVÉRIO, P.F.; SOARES, A. Estimates of benthic fluxes of nutrientes across the sediment-water interface (Guarapiranga reservoir, São Paulo, Brazil). The Science of the Total Environment, v. 266, p. 135-142, 2001.

MOZETO, A.A. et al. Weakly-bound metals and total nutriente concentrations of bulk sediments from some water reservoirs in São Paulo state, SE Brazil. Sediment Quality Assessment and Manegement: Insight and Progress. Burlington, Canadá: M. Munawar, p. 221-339, 2003.

PADIAL, P. R. Qualidade, heterogeneidade espacial e biodisponibilidade de metais no sedimento de um reservatório tropical urbano eutrofizado (Reservatório Guarapiranga, SP). 2008. 109f. 
Dissertação (Mestrado em Ecologia) - Instituto de Biociências, Universidade de São Paulo, São Paulo. 2008.

PATELLA, E. Caracterização biogeoquímica dos estoques de metais pesados contaminantes $e$ nutrientes de testemunhos de sediment e particulados do reservatório do Guarapiranga, São Paulo. 31/07/1998. 89f. Dissertação (Mestrado em Ciência da Engenharia Ambiental) - Escola de Engenharia de São Carlos, Universidade de São Paulo, São Carlos. 1998.

RICHTER, E.M. et al. Avaliação da composição química de águas do sistema Guarapiranga: estudo de caso nos anos de 2002 e 2003. Química. Nova, v.30, n. 5, p. 1147-1152, 2007.

ROCHA, AA. A limnologia, os aspectos ecológicos-sanitários e a macrofauna bentônica da represa do Guarapiranga na Região Metropolitana de São Paulo. 1976. 194 f. Tese (Doutorado em Zoologia) - Instituto de Biociências, Universidade de São Paulo, São Paulo. 1976.

ROCHA, S.M. Macroinvertebrados bentônicos como indicadores de poluição na Represa do Guarapiranga - SP. 1999. 200 f. Dissertação (Mestrado em Saúde Pública) - Faculdade de Saúde Pública, Universidade de São Paulo, São Paulo. 1999.

SANTISCHI, P.H. et al. Chemical processes at the sediment-water interface. Marine Chemistry, v. 30, p.269-315, 1990.

WHATELY, M.; CUNHA, PM. Guarapiranga 2005: como e porque São Paulo está perdendo este manancial: resultados do diagnóstico socioambiental participativo da bacia hidrográfica da Guarapiranga. São Paulo: Instituto Socioambiental, 2006, 51 p. 
Capítulo 1: Variação temporal da comunidade de macroinvertebrados bentônicos no reservatório Guarapiranga (SP, Brasil) de 1936 a 2010 


\title{
Variação temporal da comunidade de macroinvertebrados bentônicos no reservatório do Guarapiranga (SP, Brasil) de 1936 a 2010
}

\begin{abstract}
This study aimed to know if benthic macroinvertebrate community suffered temporal variation over 100 years after the formation of Guarapiranga reservoir, now an eutrophic urban public water supply reservoir. We analyzed five papers besides this study, all of them conducted during winter in four medium-profundal regions of the reservoir (main body / dam - Guarapiranga and in the regions where the three main tributaries enter in the reservoir - Embu-Mirim, Embu-Guaçu and Parelheiros rivers) over the years 1936, 1974, 1996 and 2010. The density of Oligochaeta showed an increase over the years as well as Chaoboridae. On the other hand, Chironomidae that had $30 \%$ of the total of individuals in 1974 almost disappeared in 2010. The trophic index presented by the relation Oligochaeta / Chironomidae + Oligochaeta indicated maximum organic enrichment in 2010 for the entire reservoir. The most abundant genera of Oligochaeta are all tolerant to high levels of organic pollution and hypoxia as Limnodrilus, Dero and Haemonais. The increase in the concentrations of metals in the sediment was relevant from the 1990s in this reservoir and demonstrated anthropogenic origin mainly for $\mathrm{Cu} \mathrm{Cr} N \mathrm{Zn}$ and $\mathrm{Pb}$. Despite high concentrations of metals, these are regulated by sulfide present in the sediment and thus are not bioavailable. Tolerance to metals enables survival and reproduction of Limnodrilus hoffmeisteri and explains its high and increasing density even if metals are bioavailable. The great industrial and urban growth in the region, especially from the 1970s, has great influence on the chemical characteristics of the reservoir sediments and water and consequently on the benthic macroinvertebrate community. Organic enrichment and dissolved oxygen concentration showed a strong and inverse Pearson correlation $(\mathrm{r}$ $=-0.92$ ), selecting tolerant organisms to organic pollution and hypoxia. To conclude, organic enrichment and presence of metals in the reservoir are the results of uncontrolled urbanization and the associated diffuse pollution. These features changed the structure of the benthic macroinvertebrates community, favouring the occurrence of organisms with tolerance to organic pollution, hypoxia and toxic elements as trace metals and sulfides.
\end{abstract}

\section{Resumo}

Com o intuito de saber se a comunidade bentônica sofreu variação temporal ao longo de 100 anos de criação do reservatório Guarapiranga, hoje um reservatório urbano de abastecimento público eutrofizado, este trabalho foi desenvolvido. Foram analisados cinco trabalhos além dos dados do presente trabalho, realizados no período de inverno em quatro regiões médio-profundal do reservatório (corpo principal/barragem - Guarapiranga, e na desembocadura dos principais tributários no reservatório - rios Embu-Mirim, Embu-Guaçu e Parelheiros) ao longo dos anos, 1936, 1974, 1996 e 2010. A densidade de Oligochaeta apresentou aumento ao longo dos anos, assim como a de Chaoboridae. Por outro lado, Chironomidae que apresentava 30\% em 1974 é pouco representativo em 2010. O índice trófico apresentado na relação Oligochaeta/Oligochaeta + Chironomidae indica enriquecimento orgânico máximo em 2010 para todo o reservatório, e ainda os gêneros de Oligochaeta mais abundantes são todos tolerantes a altos níveis de poluição orgânica e a hipoxia, como Limnodrilus, Dero e Haemonais. O aumento nas concentrações de metais no sedimento foi relevante a partir da década de 1990 neste reservatório e demonstrou origem antrópica principalmente para $\mathrm{Cu}, \mathrm{Cr}, \mathrm{Ni}, \mathrm{Zn}$ e $\mathrm{Pb}$. Apesar das altas concentrações de metais, estes estão presos ao sulfeto presente no sedimento e portanto não-biodisponíveis. Salienta-se a alta e crescente densidade de Limnodrilus hoffmeisteri, conhecido também por sua tolerância a metais, 
que o permite sobreviver e se reproduzir mesmo na presença de metais biodisponíveis. $\mathrm{O}$ grande crescimento industrial e urbano na região a partir principalmente da década de 1970 passou a ter grande influência nas características químicas do sedimento e da água do reservatório e consequentemente na comunidade de macroinverterados bentônicos, como enriquecimento orgânico e depleção na concentração de oxigênio dissolvido, cuja correlação de Pearson foi forte e inversa ( $\mathrm{r}$ $=-0.92$ ), selecionando grupos de organismos tolerantes a poluição orgânica e hipoxia. Concluiu-se que o crescimento urbano desordenado, e a consequente poluição difusa no reservatório, proporcionou o enriquecimento orgânico de suas águas e sedimento. Este fato juntamente com a entrada de metais-traço no corpo d'água resultou na alteração da estrutura comunidade de macroinvertebrados bentônicos favorecento a ocorrência de uma fauna tolerante à hipoxia, poluição orgânica e presença de elementos tóxicos como metais-traço e sulfetos. 


\subsection{Introdução}

O século XX foi caracterizado pelo desenvolvimento industrial em grande parte do mundo, quando os corpos hídricos se tornaram essenciais à sociedade e a seu desenvolvimento, impulsionado pela construção de reservatórios. O Brasil passou por esse mesmo processo de desenvolvimento industrial e crescimento populacional nas grandes cidades, onde corpos d'água foram barrados a fim de gerar energia ou abastecer a população. Em São Paulo, a maior cidade do país, o reservatório Guarapiranga foi criado em 1909 com a finalidade de gerar energia e anos depois seria o principal manancial de abastecimento público da região metropolitana (Whately \& Cunha, 2006).

Em São Paulo, devido ao crescimento populacional impulsionado pelo desenvolvimento industrial e econômico da cidade, o meio urbano foi se expandindo para as áreas periféricas até alcançar seus mananciais de abastecimento, inclusive o reservatório Guarapiranga, os quais deveriam ter suas áreas de proteção respeitadas, já que suas águas servem para consumo humano. A SABESP, companhia responsável pelo abastecimento de água na cidade começou a registrar florações de algas no Guarapiranga já no final da década de 1970 e estas se tornaram mais recorrentes depois de 1982. Em 1985, algicidas já eram aplicados no reservatório devido às florações. Segundo Beyruth (1992), meses seguidos com florações de algas no reservatório causaram problemas ao abastecimento público em 1990.

Problemas como os observados no Guarapiranga são de ocorrência global e levam à necessidade de um gerenciamento cuidadoso dos reservatórios a fim de que seus usos sejam garantidos. Entre as principais ferramentas para a avaliação da qualidade ambiental destes e de outros ecossistemas aquáticos está a comunidade de invertebrados bentônicos.

A fauna bentônica é um importante agente transformador do sedimento, pois, através de sua atividade mecânica (biorrevolvimento), altera características físicas e químicas do sedimento, além de promover a liberação de nutrientes para a coluna d'água. Além disso, estes organismos têm um papel fundamental no fluxo de energia e na ciclagem de nutrientes dos ecossistemas aquáticos, decorrente do fato de participarem indiretamente no processo de decomposição da matéria orgânica, ao reduzirem o tamanho das partículas detritais aumentando a área de atuação dos microrganimos decompositores, e por fazerem parte da dieta de vários organismos aquáticos (Margalef, 1983; Rosenberg \& Resh, 1993).

A concentração de elementos poluentes no sedimento ocorre, entre outros fatores, como conseqüência de alterações hidrológicas como diminuição da corrente, o que facilita a sedimentação, tanto de material autóctone como alóctone, o que forma bancos de lodo, nos quais, além da matéria orgânica, podem ser acumulados sais minerais nutrientes e metais-traço aderidos a este material (Adams \& Rowland, 2003; Alden, 1992).

No reservatório Guarapiranga, análises da comunidade de macroinvertebrados bentônicos começaram a ser desenvolvidas na década de 30, juntamente com estudos sobre o fitoplâncton, o zooplâncton e as características físicas e químicas da coluna d'água. Em um estudo desenvolvido por Wright (1936) foi registrada uma grande depleção de oxigênio no fundo. Kleerekoper (1939), autor do primeiro trabalho sobre zoobentos no reservatório, chamou atenção para a grande dificuldade na coleta e análise de dados da fauna bentônica, e atribuiu isso em parte à falta de pesquisadores interessados nesse trabalho e,consequentemente, ao conhecimento escasso sobre esta.

Uma análise dos macroinvertebrados bentônicos no reservatório voltou a ocorrer pouco mais de 30 anos depois por Rocha (1976). Neste trabalho, o autor utilizou um coletor condizente com o tipo de sedimento, mas se mostrava inseguro sobre o delineamento amostral. Desenvolveu seu trabalho utilizando diversas estações amostrais no reservatório, buscando uma abordagem de monitoramento ao longo de 4 anos além de fornecer dados qualitativos ainda com identificação a baixos níveis taxonômicos, porém já com dados quantitativos.

Duas décadas depois foi realizado um estudo sobre a fauna bentônica (Rocha, 1999) utilizando as mesmas estações amostrais que Rocha (1976). Nota-se que pesquisas da década de 1990 compartilhavam a preocupação mundial com a boa qualidade e conservação do meio ambiente 
e investigavam quais seriam as medidas para recuperar o que se havia perdido. Com esse objetivo, em 1990, já com um corpo d'água bem deteriorado, pesquisadores desenvolveram outro estudo sobre a fauna bentônica, com melhor delineamento amostral, padronização de metodologia e análise qualitativa a um nível taxonômico pouco maior que o trabalho de 1976, além de análise quantitativa e utilização de índices ecológicos para comunidade como riqueza, diversidade, dominância e outros (Rocha, 1999; Menezes \& Beyruth, 2003; CETESB 2007). Naquele ano, o reservatório apresentava certo incremento orgânico e crescentes concentrações de nitrogênio e fósforo em suas águas (Caleffi, 1994). Trinta anos antes, Palmer (1960) já havia alertado para estes problemas que haviam sido sentidos, já na década de 1950, pela população de Interlagos, bairro localizado na margem direita do reservatório. $\mathrm{Na}$ época, esta situação chamou a atenção para a necessidade de instalação de coletores de esgoto.

Posteriormente, Patella (1998) e Mozeto e colaboradores (2003) realizaram a caracterização biogeoquímica dos estoques de metais pesados contaminantes e nutrientes no sedimento e de particulados do reservatório Guarapiranga. Mozeto e colaboradores (2001) também estudaram o fluxo bentônico de nutrientes na interface sedimento-água.

Em 2002 a CETESB (Companhia de Tecnologia de Saneamento Ambiental) passou a realizar análises mensais no sedimento deste reservatório e a realizar monitoramento da fauna bentônica, em uma única estação de coleta a $2 \mathrm{~km}$ da barragem, onde é realizada tomada de água de fundo para posterior tratamento e abastecimento público pela SABESP (Secretaria de Abastecimento de Água do Estado de São Paulo) (CETESB, 2004). Neste monitoramento, observase um aperfeiçoamento, ao longo dos anos, na metodologia utilizada para analisar o sedimento e a fauna bentônica. Os dados da fauna são qualitativos a altos níveis taxonômicos e também quantitativos. Com o objetivo de monitorar o corpo d'água para os demais fins do reservatório, a CETESB somente analisa alguns pontos no reservatório: alguns na zona litorânea (regiões utilizadas pela população para lazer), um ponto na zona profundal, próximo à tomada de água, e outro no tributário Parelheiros, o qual, até 2010 recebia água transposta do reservatório Billings. Padial (2008) e Cardoso-Silva (2008) observaram ainda a existência de heterogeneidade espacial no sedimento e na água do reservatório Guarapiranga, respectivamente.

Utilizando dados de cinco dos trabalhos citados anteriomente, além dos dados do presente trabalho, este capítulo foi desenvolvido com o objetivo de testar as hipóteses nulas de que a comunidade de macroinvertebrados bentônicos do reservatório Guarapiranga não sofreu alteração na estrutura entre os anos de 1930 e 2010; e que a comunidade zoobentônica não sofre influência das características físicas e químicas do sedimento do reservatório.

\subsection{Materiais e Métodos}

\subsection{1. Área de estudo}

O reservatório Guarapiranga, localizado a $23^{0} 43^{\prime}$ Sul e $46^{0} 32$ ' Oeste a uma altitude de 742 m, é uma sub-bacia da Bacia do Alto Tietê (Figura 1). Considerado um reservatório urbano, sua bacia abrange cinco municípios da Grande São Paulo: São Paulo $\left(211 \mathrm{~km}^{2}\right)$, Itapecerica da Serra $\left(183 \mathrm{~km}^{2}\right)$, Embu-Guaçu $\left(162 \mathrm{~km}^{2}\right)$, Embu $\left(41 \mathrm{~km}^{2}\right)$ e Cotia $\left(33 \mathrm{~km}^{2}\right)$. O município de São Paulo contorna toda a margem direita do reservatório e parte da margem esquerda, abrangendo $70 \%$ do perímetro do reservatório, sendo o restante limitado aos municípios de Embu-Guaçu (27\%) e Itapecerica da Serra (3\%) (Whately \& Cunha, 2006). O reservatório Guarapiranga tem como principais tributários os rios Embu-Mirim, Embu-Guaçu e Parelheiros (Whately \& Cunha, 2006). Apresenta um nível operacional mínimo de 726,37 m e máximo de 736,62 m (Helou \& Silva, 1987), profundidade máxima, próximo à barragem, de $13 \mathrm{~m}$ e média de $6 \mathrm{~m}$ no restante, sendo considerado assim um ambiente raso. A vazão afluente média é de $11,8 \mathrm{~m}^{3} \mathrm{~s}^{-1}$ e o volume de armazenamento útil é de $191610 \times 10^{3} \mathrm{~m}^{3}$ (Mozeto et al., 2001). Pode ser considerado polimítico, 
devido às correntes internas nos canais dos rios formadores e à ação dos ventos. Com uma área de drenagem de $639 \mathrm{Km}^{2}$, a bacia constitui atualmente o segundo maior manancial dos sistemas de abastecimento da RMSP. Produz em média 14 mil litros de água por segundo para atender cerca de 3,7 milhões de habitantes (20\% da população da RMSP) (Whately \& Cunha, 2006).

Para abastecer a população da região sudoeste de São Paulo são retirados cerca de 1,2 bilhões de litros de água por dia do sistema produtor Guarapiranga. Este sistema inclui o reservatório e duas transposições de água de outras bacias hidrográficas. A primeira e mais antiga é a reversão do rio Capivari para o rio Embu-Guaçu (cerca de mil litros por segundo). A segunda, em funcionamento desde 2000, é a reversão das águas do Braço Taquacetuba, do reservatório Billings, para o rio Parelheiros (entre dois e quatro mil litros por segundo). O reservatório tem uma vazão natural estimada em 9 mil litros de água por segundo (Whately \& Cunha, 2006). O reservatório operou por anos com $70 \%$ de sua capacidade até que no ano de 2010 , devido às grandes chuvas, passou a operar com $100 \%$ da capacidade, tendo sido interrompida a transposição de água da Billings pelo Parelheiros.

A leste e ao sul, o relevo à margem do reservatório é marcado por algumas planícies que estão assentadas sobre terrenos planos de micaxistos e gnaisses de funções cambrianas (Rocha, 1976). A morfologia dendrítica, estreita e alongada do reservatório, formada na base da bacia de drenagem e vale de rios, favorece os usos e ocupação do solo e, desta forma, a ação antrópica (Rocha, 1999). No entanto, algumas áreas do entorno apresentam severas restrições em relação à ocupação, como as planícies aluviais, nas quais predominam declividades inferiores a 5\%, pouca profundidade do lençol freático e solos com baixa capacidade de suporte, as quais facilitam o surgimento de sérios problemas de enchentes e criam dificuldades para implantação das obras de saneamento, edificações e sistema viário (Whately \& Cunha, 2006).

Quanto à vegetação natural, a área da Bacia do Guarapiranga abrange remanescentes de Mata Atlântica, incluindo áreas em estágio inicial, médio e avançado de regeneração, além de regiões de várzea e campo de altitude (Whately \& Cunha, 2006). Ao longo dos anos, a pressão antropogênica sobre o reservatório aumentou, em grande parte, devido ao crescimento da mancha urbana no seu entorno (Figura 2).

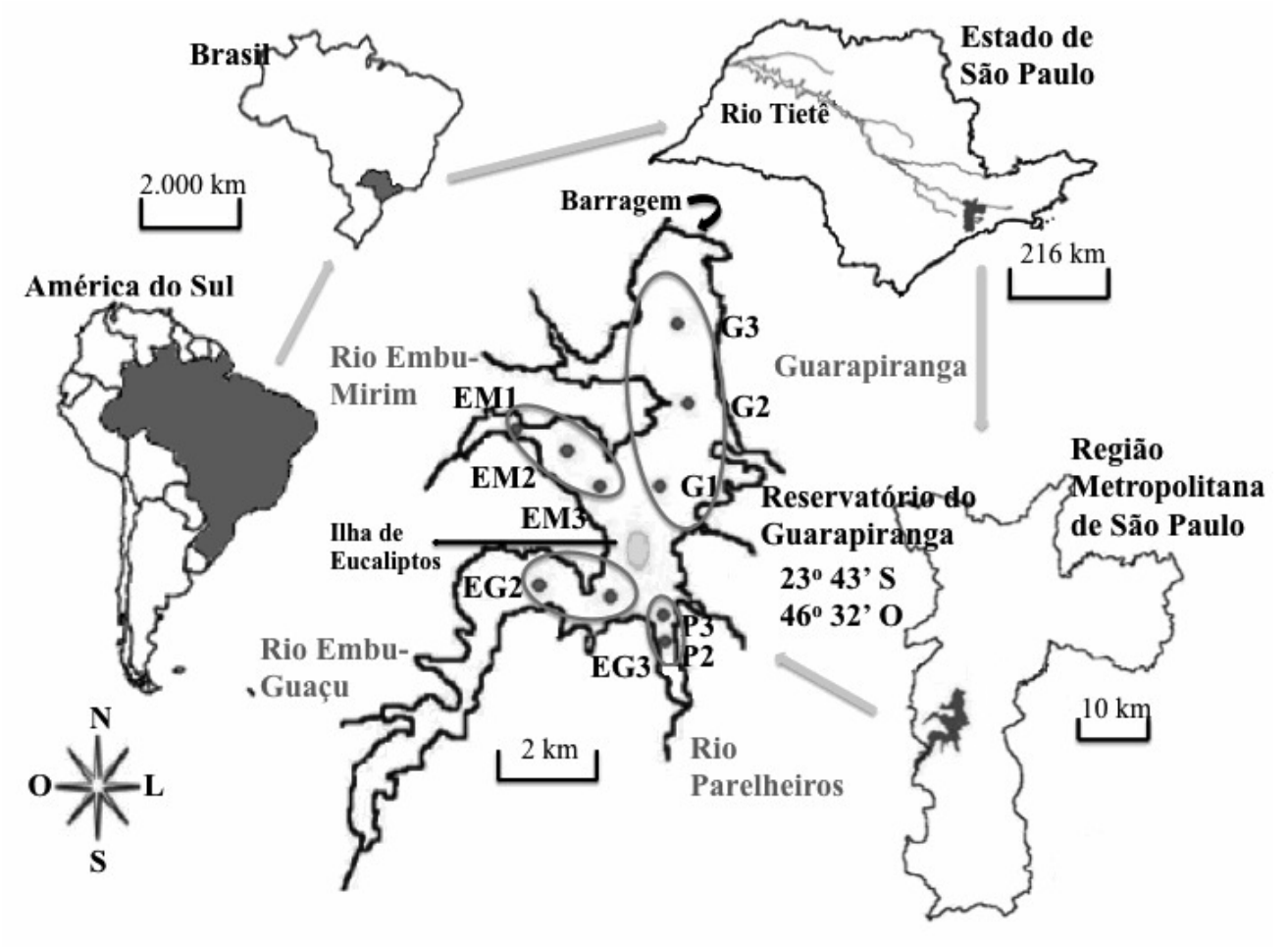

Figura 1. Localização do reservatório Guarapiranga (SP - Brasil). As elipses indicam as regiões analisadas: Guarapiranga (pontos amostrais G1, G2 e G3); Embu-Mirim (pontos amostrais EM1, EM2 e EM3); Embu-Guaçu (pontos amostrais EG1 e EG2); Parelheiros (pontos amostrais P1 e P2). 

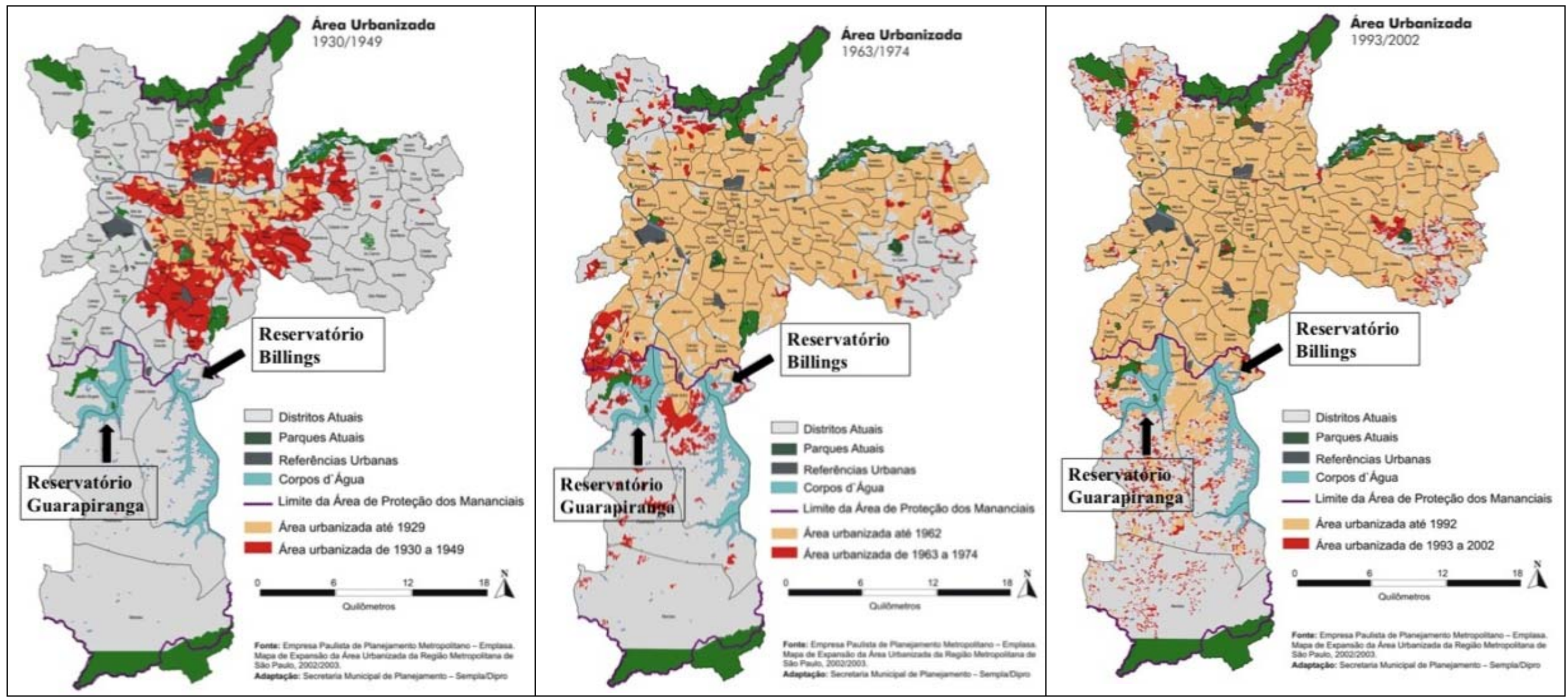

Figura 2. Mapas das áreas urbanizadas na região metropolitana de São Paulo nos anos de 1930/1949, 1963/1974 e 1993/2002 adaptados de EMPLASA (2002/2003). 


\subsubsection{Fonte de dados}

Foram analisados dados físicos e químicos do sedimento da região profundal do reservatório Guarapiranga, da água de fundo, das densidades e abundância relativa da comunidade de macroinvertebrados bentônicos presentes nas referências e no presente trabalho (Tabela 1). $O$ estudo de Kleerekoper (1939) se deu em 1936, enquanto os dados utilizados de Rocha (1976) são relativos ao ano de 1974. Rocha (1999) estudou o reservatório em 1996, e os dados de Mozeto e colaboradores (2003) são de 1996. Os dados da CETESB, constantes dos relatórios de 2003, 2004, 2005, 2006 e 2010, representam coletas de 1998 e 2002 a 2010. O presente trabalho apresenta dados coletados em 2010.

Para confrontar os dados de diferentes referências buscou-se utilizar trabalhos com metodologia de amostragem e as análises químicas o mais similar possível, de modo que nem todos os trabalhos puderam ser utilizados em cada uma das análises comparativas. Devido aos relatos de heterogeneidade espacial na água e no sedimento do reservatório (Padial, 2008; Cardoso-Silva 2008), o corpo d'água foi analisado por regiões: desembocadura do principais tributários (rios Embu-Mirim, Embu-Guaçu e Parelheiros) no reservatório e seu corpo principal denominado aqui de Guarapiranga.

Dez estações amostrais foram analisadas, todas elas com as mesmas coordenadas geográficas, na região médio-profundal (local incerto no trabalho de Kleerekoper) e todas as coletas realizadas no mesmo período, o de inverno. Nem todos os anos apresentam amostras dos dez pontos, assim se um trabalho apresentava um único ponto na região este foi considerado como representante do trecho para aquele ano.

Os trabalhos selecionados para comparar as concentrações de metais utilizaram análises de extração de metais potencialmente biodisponíveis no sedimento.

\subsubsection{Análise dos dados}

Para comparar a estrutura da comunidade de macroinvertebrados bentônicos em diferentes anos, foi aplicada a análise SIMPER, implementada pelo programa PAST. A análise determina o quanto cada táxon contribui (em densidade) para a dissimilaridade entre os anos estudados nos trabalhos referência, comparados dois a dois. As diferenças estruturais na comunidade são descritas pelo NMDS (Escalonamento Multimenssional Não Métrico) e testadas pela PERMANOVA.

A fim de verificar uma possível toxicidade do sedimento foi utilizada a relação entre a somatória das concentrações de metais-traço e a concentração de sulfeto volatizável por acidificação (SVA), estabelecida pela U.S.E.P.A. (2005), onde a toxicidade:

- $\quad$ é provável quando a relação $\Sigma\left[\right.$ metais]-[SVA] $>120 \mathrm{mmol} \mathrm{Kg}^{-1}$

- $\quad$ é incerta quando $1,7<\Sigma\left[\right.$ metais]-[SVA] $<120 \mathrm{mmol} \mathrm{Kg}^{-1}$

- $\quad$ é improvável quando $\Sigma\left[\right.$ metais]-[SVA] $<1,7 \mathrm{mmol} \mathrm{Kg}^{-1}$

Ainda para as concentrações de metais foram utilizados valores que servissem de guias para indicar limites de referência mínimos e máximos. Os valores guia abaixo citados referem-se à fração de metal fracamente ligada ou potencialmente biodisponível, mesma extração realizada por Mozeto e colaboradores (2003) e no presente trabalho:

- Valores de Referência Regional (VRR), referentes a sedimentos límnicos, descritos por Nascimento (2003) para a bacia do Tietê, dos quais utilizaremos os valores específicos para a bacia do Alto Tietê onde se localiza o reservatório de interesse (Tabela 2).

- Valores Guia de Qualidade do Sedimento (VGQS) estabelecidos pelo Conselho Canadense do Ministério do Meio Ambiente (CCME, 1999) foram desenvolvidos sobre um banco de dados de ocorrência que associa dados químicos e efeitos 
biológicos adversos. O valor mais baixo refere-se ao nível de efeito limiar ou "Threshold Effect Level"(TEL), abaixo do qual efeitos biológicos adversos raramente ocorrem enquanto o valor mais alto refere-se ao nível de efeitos prováveis "Probable Effect Level"(PEL), acima do qual efeitos adversos ocorrem com frequência (Tabela $3)$.

Tabela 1. Variáveis físicas e químicas do sedimento e da água de fundo avaliadas em regiões profundais do reservatório Guarapiranga da década de 1930 até o ano de 2010 e amostragem da fauna bentônica.

\begin{tabular}{|c|c|c|c|c|c|c|c|c|c|c|c|}
\hline \multirow[b]{2}{*}{ Autores } & \multirow[b]{2}{*}{$\begin{array}{c}\text { Ano } \\
\text { Coleta }\end{array}$} & \multicolumn{2}{|c|}{$\begin{array}{c}\begin{array}{c}\text { Macroinvertebrados } \\
\text { bentônicos }\end{array} \\
\end{array}$} & \multicolumn{8}{|c|}{ Variáveis físicas e químicas do sedimento e da água de fundo } \\
\hline & & Coletor & U.A. & MO & NT & PT & $\begin{array}{c}\text { Metais } \\
\text { (Cd, Cr, } \\
\text { Ni, Zn, } \\
\text { Pb e Cu) }\end{array}$ & SVA & Eh & OD & Gran. \\
\hline $\begin{array}{c}\text { Kleerekoper } \\
\text { (1939) }\end{array}$ & 1936 & Ekman-Birge & n.i. & + & & & & & & + & \\
\hline $\begin{array}{l}\text { Rocha } \\
\text { (1976) }\end{array}$ & 1974 & Ekman-Birge & 3 & + & & & & & & + & \\
\hline $\begin{array}{l}\text { Rocha } \\
\text { (1999) }\end{array}$ & 1996 & Ekman-Birge & 3 & & & & & & & + & \\
\hline $\begin{array}{l}\text { Mozeto } \\
\text { (2003) }\end{array}$ & 1998 & Ekman-Birge & - & & + & + & + & + & + & & \\
\hline $\begin{array}{l}\text { CETESB } \\
(2003 ; \\
2004 ; 2005 ; \\
2006 ; 2007 ; \\
2010)\end{array}$ & $\begin{array}{l}1998 \\
2002 \\
2003 \\
2004 \\
2005 \\
2010\end{array}$ & Ekman-Birge & 3 & & & & & & & + & + \\
\hline $\begin{array}{c}\text { Presente } \\
\text { Trabalho } \\
(2013)\end{array}$ & 2010 & Ekman-Birge & 3 & + & + & + & + & + & + & + & + \\
\hline
\end{tabular}

* foram coletadas 6 unidades amostrais, mas utilizadas somente as 3 primeiras para a comparação

n.i.= não informado; U.A. $=$ unidades amostrais; $+=$ dado utilizado na comparação entre os diferentes trabalhos

$\mathrm{MO}=$ teor de matéria orgânica; $\mathrm{NT}=$ nitrogênio total; $\mathrm{PT}=$ fósforo total; $\mathrm{Cd}=$ cádmio; $\mathrm{Cu}=$ cobre; $\mathrm{Cr}=\mathrm{cromo} ; \mathrm{Ni}=$ níquel; $\mathrm{Zn}=$ zinco; $\mathrm{Pb}=$ chumbo; $\mathrm{SVA}=$ sulfeto volatizável por acidificação; $\mathrm{Eh}=$ potencial de oxi-redução ; OD= oxigênio dissolvido; Gran.= granulometria

Tabela 2. Valores de Referência Regional (VRR) descritos por Nascimento (2003) para concentração de metais fracamente ligados em sedimento límnico. $\mathrm{Cd}=$ cádmio; $\mathrm{Cr}=$ cromo; $\mathrm{Ni}=$ níquel; $\mathrm{Zn}=$ zinco; $\mathrm{Pb}=$ chumbo; $\mathrm{Cu}=$ cobre.

\begin{tabular}{|c|c|}
\hline Metais & $\begin{array}{c}\text { VRR } \\
\left(\mathrm{mg} \mathrm{Kg}^{-1}\right)\end{array}$ \\
\hline $\mathrm{Cd}$ & 0,20 \\
\hline $\mathrm{Cr}$ & 40,00 \\
\hline $\mathrm{Ni}$ & 25,00 \\
\hline $\mathrm{Zn}$ & 85,00 \\
\hline $\mathrm{Pb}$ & 61,00 \\
\hline $\mathrm{Cu}$ & 25,00 \\
\hline
\end{tabular}


Tabela 3. Valores Guia de Qualidade do Sedimento (VGQS) (CCME, 1999) para concentrações de metais fracamente ligados em sedimento. TEL= Threshold Effect Level; PEL= Probable Effect Level; $\mathrm{Cd}=$ cádmio; $\mathrm{Cr}=$ cromo; $\mathrm{Ni}=$ níquel; $\mathrm{Zn}=$ zinco; $\mathrm{Pb}=$ chumbo; $\mathrm{Cu}=$ cobre.

\begin{tabular}{|c|c|c|}
\hline Metais & $\begin{array}{c}\text { TEL } \\
\left(\mathrm{mg} \mathrm{Kg}^{-1}\right)\end{array}$ & $\begin{array}{c}\text { PEL } \\
\left(\mathrm{mg} \mathrm{Kg}^{-1}\right)\end{array}$ \\
\hline $\mathrm{Cd}$ & 0,60 & 3,50 \\
\hline $\mathrm{Cr}$ & 37,30 & 90,00 \\
\hline $\mathrm{Ni}$ & 18,00 & 36,00 \\
\hline $\mathrm{Zn}$ & 123,00 & 315,00 \\
\hline $\mathrm{Pb}$ & 35,00 & 91,30 \\
\hline $\mathrm{Cu}$ & 36,00 & 197,00 \\
\hline
\end{tabular}

A fim de verificar se houve variação significativa nos dados físicos e químicos do sedimento e da água de fundo foram realizados testes de normalidade, os quais indicaram serem os dados nãoparamétricos. A partir daí foi aplicado o teste de Kruskal-Wallis, implementado pelo programa Statistica 6.0. Para os valores estatísticos da análise $(H)$ foi aceita significância $p<0,05$. Foram apresentadas em gráficos boxplot somente as variações significativas, assumindo $p<0,05$. No caso da concentração de oxigênio dissolvido e do teor de matéria orgânica, as variações nãosignificativas foram representadas por gráficos criados no programa Excel versão 14.0.

Para os dados biológicos foram calculadas as densidades (ind $\mathrm{m}^{-2}$ ), as abundâncias relativas, e o índice trófico $\mathrm{O} / \mathrm{O}+\mathrm{C}$ (Oligochaeta/ Oligochaeta + Chironomidae), o qual estima a trofia do reservatório (Wiederholm, 1980), e quanto mais próximo de 1 for o valor do índice, maior o grau de poluição orgânica. Para abundâncias relativas menores que $1 \%$, o táxon foi considerado raro; de $1 \%$ a $9 \%$, ocasional; de $10 \%$ a $29 \%$, comum; entre $30 \%$ e $49 \%$, abundante; igual ou superior a $50 \%$, dominante (McCullough \& Jackson, 1985).

Para ordenar as variáveis físicas e químicas e os pontos amostrais foi realizada uma Análise de Componentes Principais (ACP) e para ordenar pontos amostrais em relação às variáveis bióticas e abióticas foi realizada uma Análise de Correspondência Canônica (ACC), ambas implementadas pelo programa CANOCO (Legendre \& Legendre, 1998).

\subsection{Resultados}

$\mathrm{Na}$ região do rio Parelheiros a dissimilaridade da comunidade de macroinvertebrados bentônicos entre as 3 décadas analisadas foi acima de 45\% chegando a $83 \%$ entre os anos de 1996 e 2010. Oligochaeta, Chironomidae e Chaoboridae foram os principais grupos responsáveis pela dissimilaridade somando no mínimo 60\% de contribuição (Figura 3a).

A abundância relativa de Oligochaeta diminuiu ao longo dos anos (de $60 \%$ para $20 \%$ ) em contraponto à representatividade de Chaoboridae na estrutura da comunidade, a qual aumentou de menos de $10 \%$ para aproximadamente $80 \%$. Chironomidae, que representava pouco mais de $30 \%$ em 1976, praticamente desapareceu em 2013 para a região do Parelheiros (Figura 3b). Apesar da diminuição da abundância relativa de Oligochaeta ao longo dos anos, tanto Oligochaeta quanto Chaoboridae aumentaram em densidade, de $431 \mathrm{em} 1976$ para 2563 ind $\mathrm{m}^{-2}$ em 2010 para Oligochaeta e de 57 para 9956 ind $\mathrm{m}^{-2}$ para Chaoboridae (Tabela 4). 


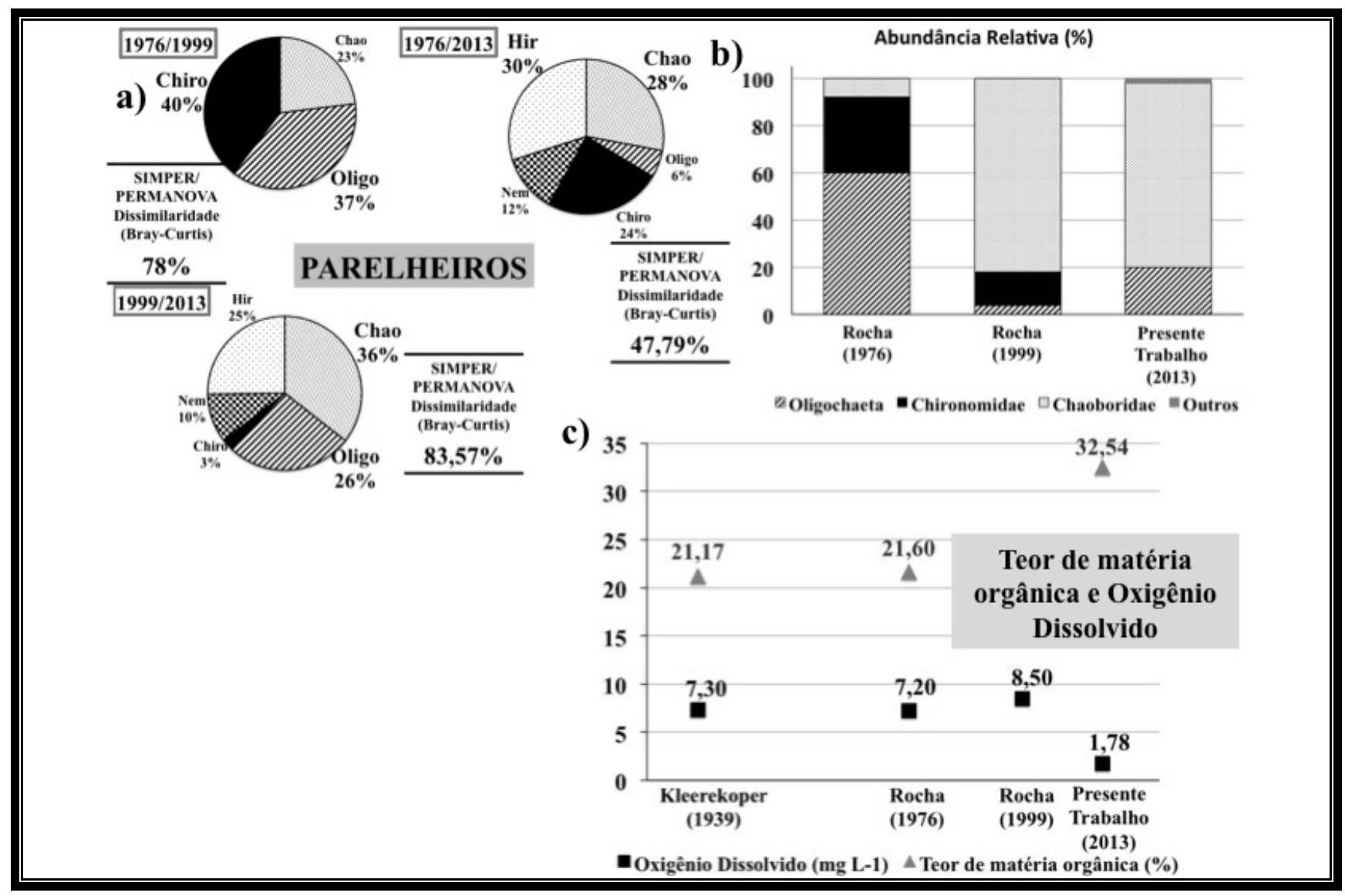

Figura 3. Análises de dados da região do rio Parelheiros, tributário do reservatório Guarapiranga, SP-Brasil. a) PERMANOVA das densidades (ind $\mathrm{m}^{-2}$ ) de macroinvertebrados bentônicos comparando os trabalhos de Rocha (1976), Rocha (1999) e o Presente Trabalho (2013). Nem= Nematoda; $\mathrm{Chao}=$ Chaoboridae; Chiro $=$ Chironomidae; Oligo $=$ Oligochaeta; Hir $=$ Hirudinea; $\mathrm{b}$ ) Abundâncias Relativas (\%) dos 3 taxa principais (Oligochaeta, Chironomidae e Chaoboridae) e dos raros $(<1 \%)$ ou ocasionais (de 1 a $9 \%$ ) representados por Outros, grupo constituído por: Bivalvia, Hirudinea, Ostracoda, Odonata, Ephemeroptera e Ceratopogonidae, observadas nos trabalhos de Rocha (1976), Rocha (1999) e no Presente Trabalho (2013); c) Scatter Plot das concentrações de oxigênio dissolvido $\left(\mathrm{mg} \mathrm{L}^{-1}\right)$ e teor de matéria orgânica (\%) observadas nos trabalhos de Kleerekoper (1939), Rocha (1976), Rocha (1999) e no presente trabalho (2013).

O teor de matéria orgânica aumentou de 1936 para 2010 em detrimento da concentração de oxigênio dissolvido na água de fundo, a qual diminui de $7,66 \mathrm{mg} \mathrm{L}^{-1}$ em média nos anos de 1936,

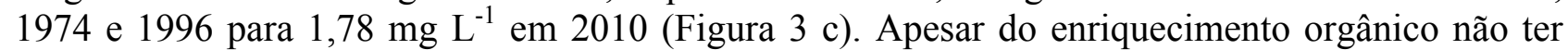
sido estatisticamente significante, o índice trófico apresentado pela relação de Oligochaeta e Chironomidae alcançou valor de 0,65 em 1974, indicou poluição orgânica, passou a 0,25 em 1996 e alcançou nível máximo de 1,00 em 2010 (Tabela 4).

Para a região do Embu-Guaçu a dissimilaridade da comunidade de macroinvertebrados bentônicos entre 1996 e 2010 foi de 57,43\%. Oligochaeta e Hirudinea foram os grupos com maior carga nessa dissimilaridade, somando $52 \%$ de contribuição. Três grupos de larvas de diptera (Chironomidae, Chaoboridae e Ceratopogonidae) apresentaram contribuições de 15\% a 17\% (Figura 4a). 
Tabela 4. Densidades (ind $\mathrm{m}^{-2}$ ) de taxa observadas para a região do rio Parelheiros, tributário do reservatório Guarapiranga, nos trabalhos de Rocha (1976), Rocha (1999) e no Presente Trabalho (2013) e índice trófico $\mathrm{O}(\mathrm{O}+\mathrm{C}) . \mathrm{O}=$ Oligochaeta e $\mathrm{C}=$ Chironomidae.

\begin{tabular}{lrrr}
\hline \multicolumn{1}{c}{ TAXA } & \multicolumn{3}{c}{ PARELHEIROS } \\
& $\begin{array}{l}\text { Rocha } \\
\text { (1976) }\end{array}$ & $\begin{array}{l}\text { Rocha } \\
\text { (1999) }\end{array}$ & $\begin{array}{l}\text { Presente } \\
\text { Trabalho } \\
(\mathbf{2 0 1 3 )}\end{array}$ \\
\hline Bivalvia & - & - & - \\
Oligochaeta & 431 & 22 & 2563 \\
\hline Hirudinea & - & - & 215 \\
Ostracoda & - & - & - \\
Odonata & - & - & - \\
Ephemeroptera & - & - & - \\
Chironomidae & 230 & 67 & 7 \\
Ceratopogonidae & - & - & - \\
Chaoboridae & 57 & 400 & 9956 \\
Índice Trófico & $\mathbf{0 , 6 5}$ & $\mathbf{0 , 2 5}$ & $\mathbf{1 , 0 0}$ \\
\hline
\end{tabular}

A abundância relativa de Oligochaeta aumentou de 1996 a 2010 (pouco mais de 20\% para próximo a 90\%) em contraponto a representatividade de Chaoboridae e Chironomidae na estrutura da comunidade, as quais diminuiram de $60 \%$ para menos de $10 \%$ e de pouco mais de $10 \%$ para representatividade mínima de $1 \%$, respectivamente (Figura 4b). Apesar da diminuição da abundância relativa de Chironomidae, sua densidade aumentou de 178 para 370 ind $\mathrm{m}^{-2}$ de 1996 para 2010. Oligochaeta apresentou aumento de 80 vezes em densidade, alcançando 24474 ind $\mathrm{m}^{-2}$ em 2010 (Tabela 5).

O teor de matéria orgânica demonstrou aumento significativo $(\mathrm{p}=0,049)$ de $25 \%$ para $37 \%$ em 1939 e 2010, respectivamente (Figura 4d). Por outro lado, a concentração de oxigênio dissolvido na água de fundo, era de $6,95 \mathrm{mg} \mathrm{L}^{-1} \mathrm{em} \mathrm{1939,} \mathrm{alcançou} 9 \mathrm{mg} \mathrm{L}^{-1} \mathrm{em} 1996$ e baixou para $2,40 \mathrm{mg} \mathrm{L}^{-1}$ em 2010 (Figura 4c). Corroborando com o enriquecimento orgânico indicado pelo aumento do teor de matéria orgânica, o índice trófico apresentado indicou aumento de poluição orgânica entre os anos de $1996(0,65)$ e $2010(0,99)$ (Tabela 5).

Tabela 5. Densidades (ind $\mathrm{m}^{-2}$ ) de taxa observadas para a região do rio Embu-Guaçu, tributário do reservatório Guarapiranga, nos trabalhos de Rocha (1999) e no Presente Trabalho (2013) e índice trófico $\mathrm{O}(\mathrm{O}+\mathrm{C})$, onde $\mathrm{O}=$ Oligochaeta e $\mathrm{C}=$ Chironomidae.

\begin{tabular}{lrr}
\hline \multicolumn{1}{c}{ TAXA } & \multicolumn{2}{c}{ EMBU-GUAÇU } \\
& $\begin{array}{c}\text { Rocha } \\
\text { (1999) }\end{array}$ & $\begin{array}{c}\text { Presente } \\
\text { Trabalho } \\
\text { (2013) }\end{array}$ \\
\hline Bivalvia & - & 15 \\
Oligochaeta & 326 & 24474 \\
\hline Hirudinea & 30 & 926 \\
\hline Ostracoda & - & 22 \\
Odonata & - & 7 \\
\hline Ephemeroptera & - & 15 \\
Chironomidae & 178 & 370 \\
Ceratopogonidae & - & 37 \\
\hline Chaoboridae & 859 & 1793 \\
\hline Índice Trófico & $\mathbf{0 , 6 5}$ & $\mathbf{0 , 9 9}$ \\
\hline
\end{tabular}




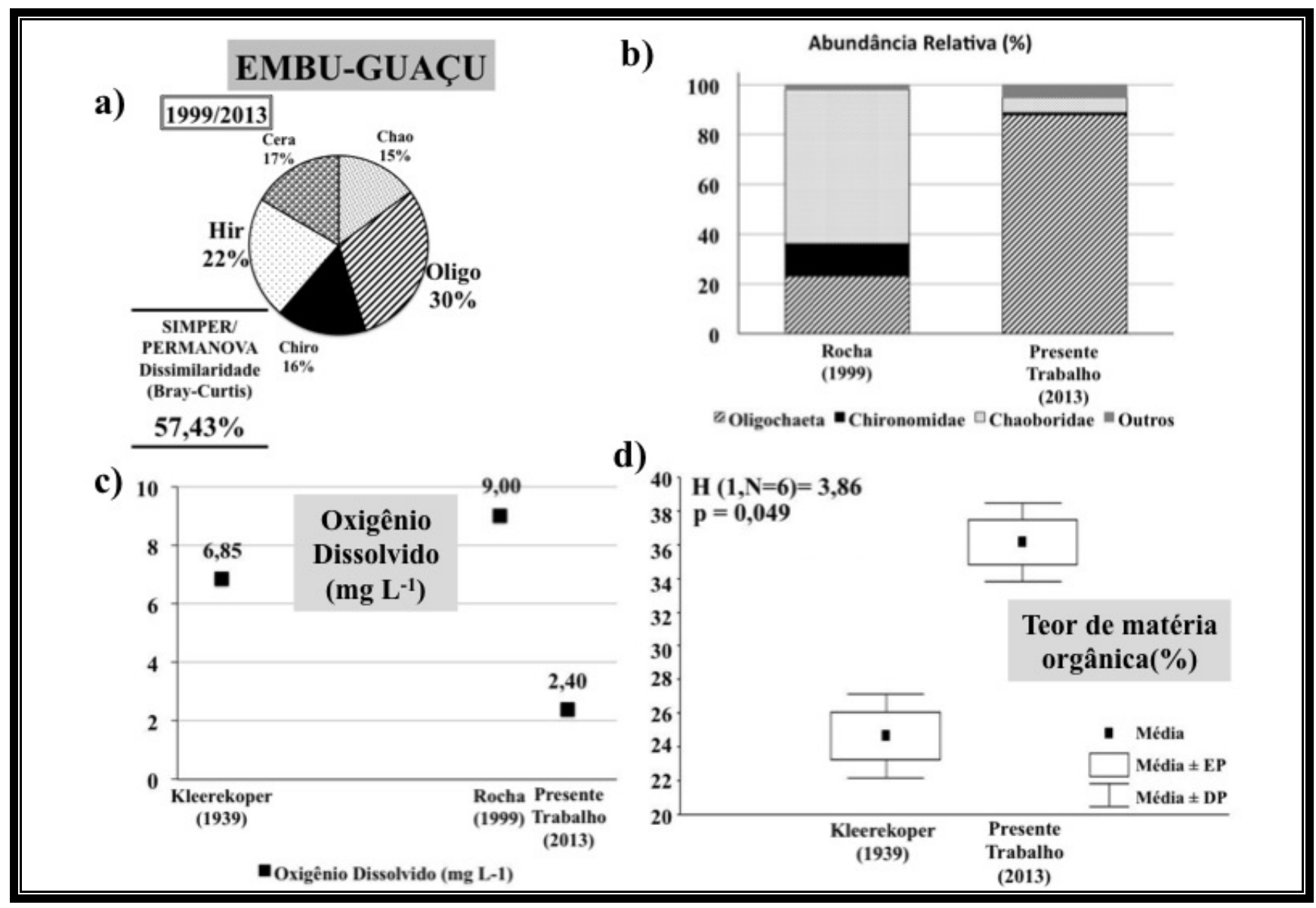

Figura 4. Análises de dados da região do rio Embu-Guaçu, tributário do reservatório Guarapiranga, SP-Brasil. a) PERMANOVA das densidades (ind $\mathrm{m}^{-2}$ ) de macroinvertebrados bentônicos comparando os trabalhos de Rocha (1999) e o Presente Trabalho (2013). Oligo= Oligochaeta; Hir= Hirudinea; $\mathrm{Cera}=$ Ceratopogonidae; $\mathrm{Chao}=$ Chaoboridae; Chiro= Chironomidae; b) Abundâncias Relativas (\%) dos 3 taxa principais (Oligochaeta, Chironomidae e Chaoboridae) e dos raros $(<1 \%)$ ou ocasionais (de 1 a 9\%) representados por Outros, grupo constituído por: Bivalvia, Hirudinea, Ostracoda, Odonata, Ephemeroptera e Ceratopogonidae, observadas nos trabalhos de Rocha (1999) e no Presente Trabalho (2013); c) Scatter Plot das concentrações de oxigênio dissolvido (mg L ${ }^{-1}$ ) observadas nos trabalhos de Kleerekoper (1939), Rocha (1999) e no presente trabalho (2013); d) Box Plot da análise não-paramétrica Kruskal-Wallis das concentrações de oxigênio dissolvido (mg $\mathrm{L}^{-1}$ ) e teor de matéria orgânica (\%) médias, seus erros padrão (EP) e desvios padrão (DP) observadas nos trabalhos de Kleerekoper (1939) e no presente trabalho (2013). H= valor da estatística de Kruskal-Wallis; $\mathrm{N}=$ número total de elementos analisados; $\mathrm{p}=$ valor de significância do teste.

$\mathrm{Na}$ região do rio Embu-Mirim a dissimilaridade da comunidade de macroinvertebrados bentônicos entre as 3 décadas analisadas foi acima de 39\%. Oligochaeta, Chaoboridae e Hirudinea foram os principais grupos responsáveis por essa dissimilaridade. A família Chaoboridae contribuiu em 40\% para a dissimilaridade comparando-se os anos de 1974 e 1996 e em 33\% comparando-se os anos de 1996 e 2010. Enquanto a classe Hirudinea contribuiu em 29\% entre 1974 e 1996, e 23\% comparando-se os anos de 1976 e 2010 (Figura 5a). 


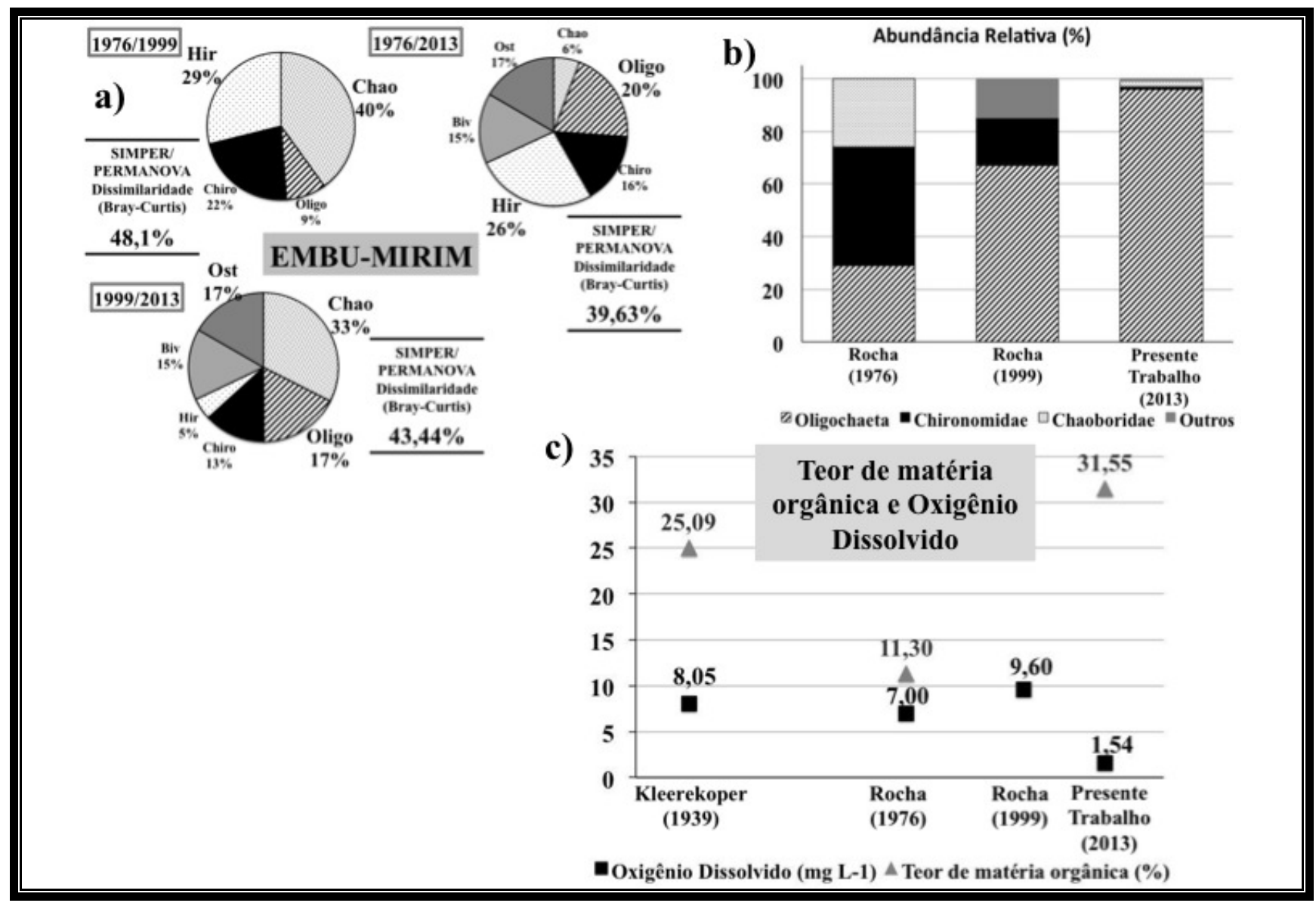

Figura 5. Análises de dados da região do rio Embu-Mirim, tributário do reservatório Guarapiranga, SP-Brasil. a) PERMANOVA das densidades (ind $\mathrm{m}^{-2}$ ) de macroinvertebrados bentônicos comparando os trabalhos de Rocha (1976), Rocha (1999) e o Presente Trabalho (2013). Biv= Bivalvia; Oligo $=$ Oligochaeta; Hir $=$ Hirudinea; Ost $=$ Ostracoda; Chao $=$ Chaoboridae; Chiro $=$ Chironomidae; b) Abundâncias Relativas (\%) dos 3 taxa principais (Oligochaeta, Chironomidae e Chaoboridae) e dos raros $(<1 \%$ ) ou ocasionais (de 1 a $9 \%$ ) representados por Outros, grupo constituído por: Bivalvia, Hirudinea, Ostracoda, Odonata, Ephemeroptera e Ceratopogonidae, observadas nos trabalhos de Rocha (1976), Rocha (1999) e no Presente Trabalho (2013); c) Scatter Plot das concentrações de oxigênio dissolvido $\left(\mathrm{mg} \mathrm{L}^{-1}\right)$ e teor de matéria orgânica (\%) observadas nos trabalhos de Kleerekoper (1939), Rocha (1976), Rocha (1999) e no presente trabalho (2013).

A classe Oligochaeta apresentou aumento ao longo dos anos na região do rio Embu-Mirim tal qual ocorreu na região do rio Embu-Guaçu, com abundâncias relativas de 29\%, 67\% e 96\% nos anos de 1974, 1996 e 2010, respectivamente. Já as famílias Chaoboridae e Chironomidae apresentaram diminuição da representatividade na comunidade passando de $26 \%$ e $45 \%$, respectivamente, em 1974 para 2\% e 1\%, respectivamente, em 2010 (Figura 5b). A densidade de Oligochaeta aumentou em 7 vezes de 1974 a 2010, enquanto as densidades de Chaoboridae e Chironomidae diminuíram em 5 e 31 vezes, respectivamente, apresentando densidades de 60 ind $\mathrm{m}^{-}$ 2 e 17 ind $\mathrm{m}^{-2}$ em 2010, respectivamente (Tabela 6).

$\mathrm{O}$ teor de matéria orgânica e a concentração de oxigênio dissolvido mostraram-se inversamente relacionados, sendo que o teor de matéria orgânica passou de 25,09\% em 1936 para $31,55 \%$ em 2010, enquanto a concentração de oxigênio dissolvido na água de fundo passou da

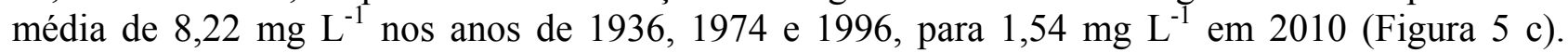
Apesar do aumento no teor de matéria orgânica não ter sido estatisticamente significativo, a relação entre Oligochaeta e Chironomidae indicou aumento na poluição orgânica na região do Embu-Mirim (0,39 em 1974; 0,79 em 1996 e 0,99 em 2010) (Tabela 6). 
Tabela 6. Densidades (ind $\mathrm{m}^{-2}$ ) de taxa observadas para a região do rio Embu-Mirim, tributário do reservatório Guarapiranga, SP-Brasil, nos trabalhos de Rocha (1976), Rocha (1999) e no Presente Trabalho (2013) e índice trófico $\mathrm{O}(\mathrm{O}+\mathrm{C})$, onde $\mathrm{O}=$ Oligochaeta e $\mathrm{C}=$ Chironomidae.

\begin{tabular}{lrrr}
\hline \multicolumn{1}{c}{ TAXA } & \multicolumn{3}{c}{ EMBU-MIRIM } \\
& $\begin{array}{l}\text { Rocha } \\
(\mathbf{1 9 7 6 )}\end{array}$ & $\begin{array}{r}\text { Rocha } \\
(\mathbf{1 9 9 9 )})\end{array}$ & $\begin{array}{c}\text { Presente } \\
\text { Trabalho } \\
(\mathbf{2 0 1 3 )}\end{array}$ \\
\hline Bivalvia & - & - & 5 \\
\hline Oligochaeta & 345 & 326 & 2493 \\
\hline Hirudinea & - & 74 & 16 \\
Ostracoda & - & - & 8 \\
\hline Odonata & - & - & 2 \\
\hline Ephemeroptera & - & - & - \\
Chironomidae & 546 & 89 & 17 \\
\hline Ceratopogonidae & - & - & 3 \\
\hline Chaoboridae & 316 & - & 60 \\
\hline Índice Trófico & $\mathbf{0 , 3 9}$ & $\mathbf{0 , 7 9}$ & $\mathbf{0 , 9 9}$ \\
\hline
\end{tabular}

Para a região Guarapiranga, que representa o corpo principal e região de maior profundidade do reservatório, chegando a 11 metros quando a 2 quilômetros de distância da barragem, a dissimilaridade da comunidade de macroinvertebrados bentônicos foi acima de $34 \%$ mas não passou de 54\% (53,38\% comparando os anos de 1974 e 2010). Chaoboridae e Oligochaeta foram os grupos que mais contribuíram para essa dissimilaridade, somando $55 \%$ e $61 \%$ de contribuição comparando-se os anos de 1974 e 2010 e 1976 e 1996, respectivamente. Para a dissimilaridade entre os anos de 1996 e 2010 os taxa que mais colaboraram foram Chironomidae (40\%) e Nematoda (22\%) (Figura 6a).

A classe Oligochaeta apresentou aumento na representatividade dentro da comunidade de 1974 (31\%) a 2006 (100\%) e uma queda nos anos seguintes alcançando 49\% em 2010. Já Chaoboridae aumentou de 23\% (1974) para 53\% (1996), desapareceu da comunidade nos anos seguintes e representou com 50\% dos indivíduos em 2010. Chironomidae diminui de 46\% (1976) para 6\% (1996), voltando com 14\% de representatividade em 2007 e não aparecendo novamente em 2010 (Figura 6c). A densidade de Chaoboridae aumentou ao longo dos anos em mais de 30 vezes (3010 ind $\mathrm{m}^{-2}$ no ano de 2010), enquanto Chironomidae diminuiu mais de 30 vezes $\left(5 \mathrm{ind} \mathrm{m}^{-2}\right.$ no ano de 2010). Oligochaeta apresentou-se 20 vezes mais abundante em 2010 (2928 ind $\mathrm{m}^{-2}$ ) comparado a 1974 (120 ind $\mathrm{m}^{-2}$ ) (Tabela 7$)$.

O teor de matéria orgânica demonstra aumento significativo $(p=0,027)$ de $20 \%$ para $40 \%$ em 1939 e 2010, respectivamente (Figura 6b). Enquanto, a concentração de oxigênio dissolvido na água de fundo, apresentou o contrário, uma diminuição significativa $(\mathrm{p}=0,016)$ de $7,16 \mathrm{mg} \mathrm{L}^{-1} \mathrm{em}$ 1939, alcançando 8,03 mg L-1 em 1996 e baixando para 3,38 mg L $\mathrm{mg}^{-1}$ em 2010 (Figura 6d). Corroborando com aumento significativo no teor de matéria orgânica no sedimento ao longo dos anos, o índice trófico apresentado pela relação de Oligochaeta e Chironomidae indica aumento de poluição orgânica com 0,40 em 1974, 0,87 em 1996 e com nível máximo de 1,00 em 2010, assim como observado na região do Parelheiros (Tabela 7). 


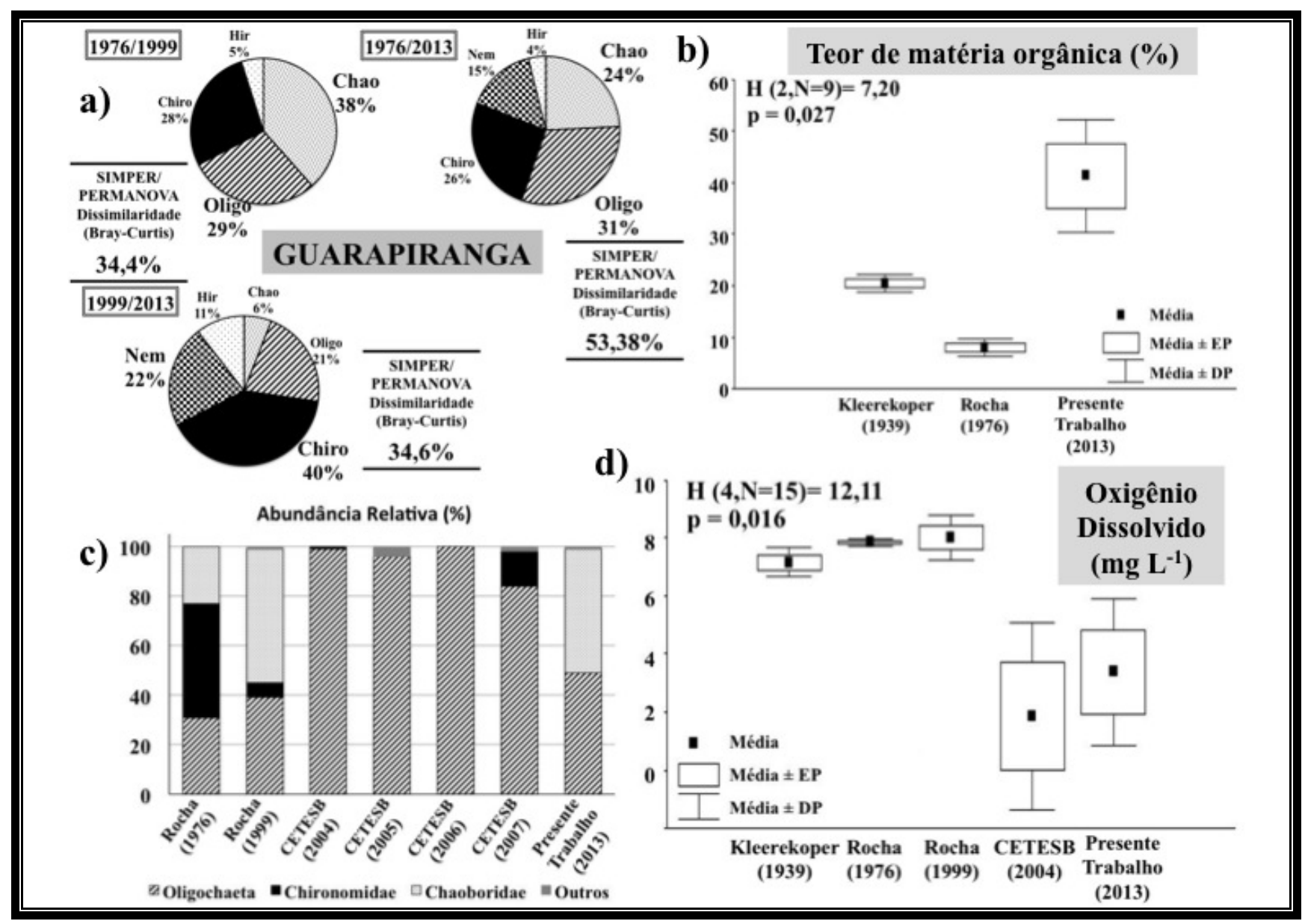

Figura 6. Análises de dados da região Guarapiranga, corpo principal do reservatório Guarapiranga, SP-Brasil. a) PERMANOVA das densidades (ind $\mathrm{m}^{-2}$ ) de macroinvertebrados bentônicos comparando os trabalhos de Rocha (1976), Rocha (1999) e o Presente Trabalho (2013). Nem= Nematoda; Oligo $=$ Oligochaeta; Hir $=$ Hirudinea; $\mathrm{Chao}=$ Chaoboridae; Chiro $=$ Chironomidae; $\mathrm{b}$ ) Box Plot da análise não-paramétrica Kruskal-Wallis para o teor de matéria orgânica (\%), apresentando suas médias, erros padrão (EP) e desvios padrão (DP) observadas nos trabalhos de Kleerekoper (1939), Rocha (1976) e no presente trabalho (2013). H= valor da estatística de Kruskal-Wallis; $\mathrm{N}=$ número total de elementos analisados; $\mathrm{p}=$ valor de significância do teste; c) Abundâncias Relativas (\%) dos 3 taxa principais (Oligochaeta, Chironomidae e Chaoboridae) e dos raros $(<1 \%$ ) ou ocasionais (de 1 a $9 \%$ ) representados por Outros, grupo constituído por: Bivalvia, Hirudinea, Ostracoda, Odonata, Ephemeroptera e Ceratopogonidae, observadas nos trabalhos de Rocha (1976), Rocha (1999), relatórios CETESB (2004, 2005, 2006 e 2007) e no Presente Trabalho (2013); d) Box Plot da análise não-paramétrica Kruskal-Wallis para as concentrações de oxigênio dissolvido ( $\mathrm{mg} \mathrm{L}^{-1}$ ), apresentando suas médias, erros padrão (EP) e desvios padrão (DP) observadas nos trabalhos de Kleerekoper (1939), Rocha (1976), Rocha (1999), CETESB (2004) e no presente trabalho (2013). $\mathrm{H}=$ valor da estatística de Kruskal-Wallis; $\mathrm{N}=$ número total de elementos analisados; $\mathrm{p}=$ valor de significância do teste.

$\mathrm{Na}$ figura 7 são apresentadas as concentrações de metais potencialmente biodisponíveis no sedimento de 1996 e 2010, e a abundância relativa de taxa de macroinvertebrados bentônicos analisados entre 1998 e 2010 para a região Guarapiranga, além das concentrações de metais potencialmente biodisponíveis no sedimento de 1996 e 2010 para a região do rio Embu-Guaçu. Na região Guarapiranga as concentrações de Cd, Cr, Zn e Ni em 2010 foram superiores as de 1996, sendo que $\mathrm{Cr}$ e $\mathrm{Zn}$ estavam acima de VRR e TEL em 2010. As concentrações de $\mathrm{Pb}$ e $\mathrm{Cu}$ foram mais altas em 1996 comparadas a 2010 e tais resultados podem ser devidos ao aparelho utilizado para leitura desses dois metais no presente trabalho (espectrofotômetro de emissão óptica por plasma acoplado indutivamente) não ser o mais apropriado, no caso teria sido melhor utilizar um 
espectrômetro de absorção atômica, segundo Nascimento (2003). Nesse caso pode ter ocorrido interferência de alto teor de ferro. De qualquer forma, as concentrações de chumbo estão acima de VRR e TEL nos dois anos analisados, enquanto as concentrações de cobre apresentadas tanto em 1996 quanto em 2010 estão acima de VRR, TEL e, inclusive, acima de PEL (Figura 7a).

Tabela 7. Densidades (ind $\mathrm{m}^{-2}$ ) de taxa observadas para a região Guarapiranga, corpo principal do reservatório Guarapiranga, SP-Brasil, nos trabalhos de Rocha (1976), Rocha (1999) e no Presente Trabalho (2013) e índice trófico $\mathrm{O}(\mathrm{O}+\mathrm{C})$, onde $\mathrm{O}=$ Oligochaeta e $\mathrm{C}=$ Chironomidae.

\begin{tabular}{lrrr}
\hline \multicolumn{1}{c}{ TAXA } & \multicolumn{3}{c}{ GUARAPIRANGA } \\
& $\begin{array}{l}\text { Rocha } \\
\mathbf{( 1 9 7 6 )}\end{array}$ & $\begin{array}{r}\text { Rocha } \\
\mathbf{( 1 9 9 9 )}\end{array}$ & $\begin{array}{c}\text { Presente } \\
\text { Trabalho } \\
(\mathbf{2 0 1 3 )}\end{array}$ \\
\hline Bivalvia & - & 5 & - \\
Oligochaeta & 120 & 617 & 2928 \\
\hline Hirudinea & - & 10 & 72 \\
Ostracoda & - & - & 2 \\
\hline Odonata & - & - & - \\
Ephemeroptera & - & - & - \\
Chironomidae & 177 & 94 & 5 \\
Ceratopogonidae & - & - & - \\
\hline Chaoboridae & 86 & 844 & 3010 \\
Índice Trófico & $\mathbf{0 , 4 0}$ & $\mathbf{0 , 8 7}$ & $\mathbf{1 , 0 0}$ \\
\hline
\end{tabular}

A abundância relativa da fauna de macroinvertebrados bentônicos na região Guarapiranga (Figura 7b) mostra uma dominância acima de $80 \%$ da espécie de Tubificinae Limnodrilus hoffmeisteri de 1998 a 2005, com 80\% e 100\%, respectivamente. Já em 2006 essa espécie caiu para $26 \%$, dividindo a dominância de $77 \%$ da classe Oligochaeta com os gêneros Dero (28\%) e Haemonais (23\%), enquanto em 2010 L. hoffmeisteri subiu para 54\%. Ainda em 2010 o gênero de diptera Chaoborus teve pela primeira vez representatividade significativa, mostrando-se abundante em $39,85 \%$.

As concentrações de metais potencialmente biodisponíveis na região do Embu-Guaçu, observadas na figura 7c, foram abaixo dos 3 limites em 1996 para $\mathrm{Cr}, \mathrm{Ni}, \mathrm{Zn}, \mathrm{Pb}$ e $\mathrm{Cu}$, mas em 2010 somente $\mathrm{Pb}$ e Ni estavam abaixo desses limites. Interessante notar que Ni permaneceu abaixo dos limites comparando-se os anos de 1996 e 2010, porém sua concentração potencialmente biodisponível no sedimento aumentou em 14 vezes. Cádmio esteve acima de VRR e TEL tanto em 1996 quanto em 2010. Cromo e Zinco também apresentaram concentrações acima de VRR e TEL em 2010. Já o metal cobre, cujas concentrações foram 11 vezes maior do que o valor de PEL para a região Guarapiranga, comparando-se 1996 e 2010, foi um pouco maior (28 $\mathrm{mg} \mathrm{Kg}^{-1}$ ) do que o VRR ( $25 \mathrm{mg} \mathrm{Kg}^{-1}$ ) para a região do rio Embu-Guaçu em 2010. Contudo, em relação a presença de metais no sedimento, de acordo com a relação $\Sigma$ [metais]-[SVA], os metais não estão biodisponíveis na região do Embu-Guaçu nem na região Guarapiranga (Tabela 8). 


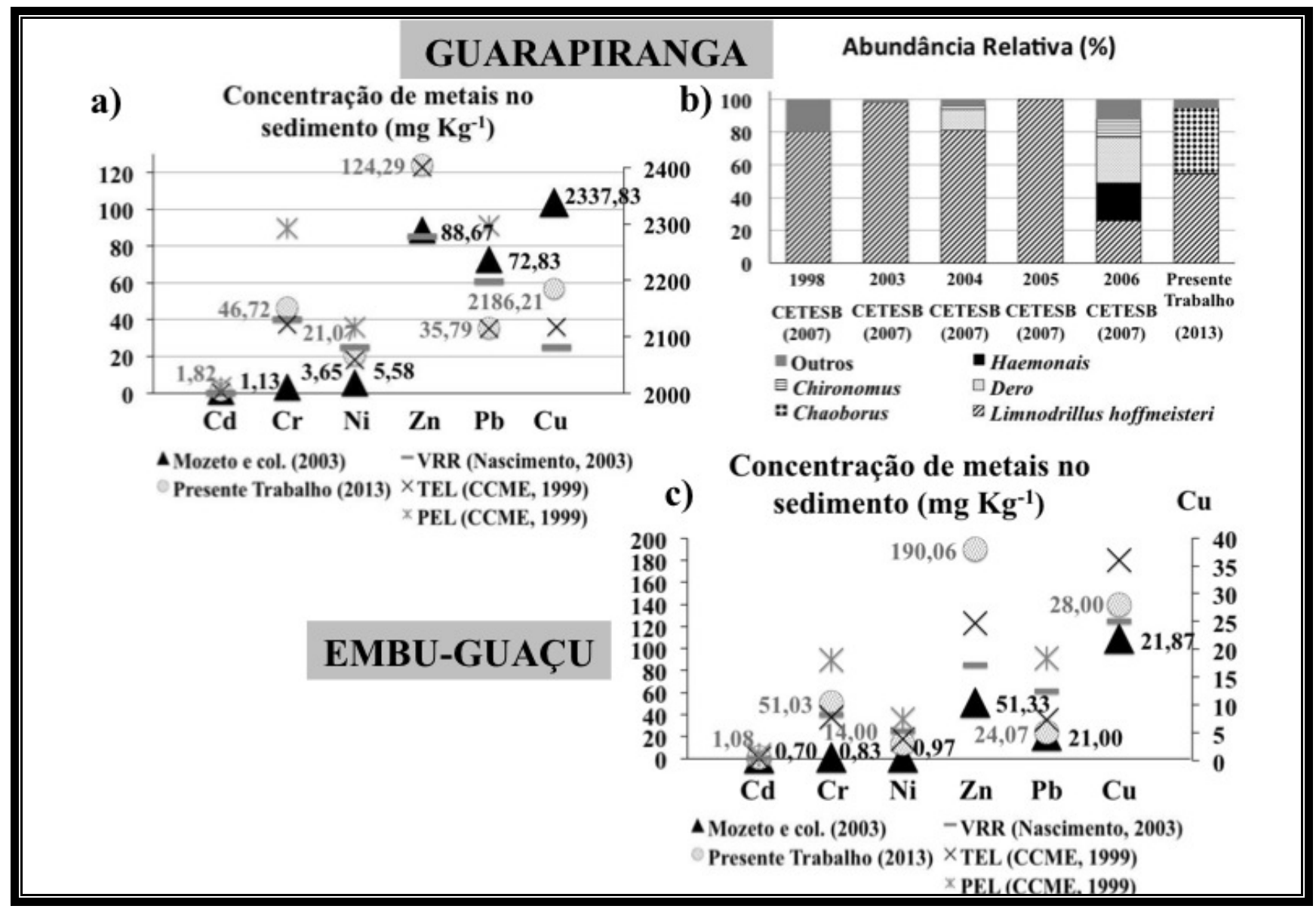

Figura 7. a) Scatter Plot das concentrações de metais no sedimento ( $\mathrm{mg} \mathrm{Kg}^{-1}$ ) observadas nos trabalhos de Mozeto e colaboradores (2003) e no presente trabalho (2013) na região Guarapiranga, corpo principal do reservatório Guarapiranga, SP-Brasil, e das concentrações de metais naturais do solo regional representadas pelos valores de referência regional (VRR) descritos por Nascimento (2003), além dos Valores-Guia de Qualidade de Sedimento (VGQS) estabelecidos pelo Conselho Canadense do Ministério do Meio Ambiente (CCME, 1999): TEL (Threshold Effect Level) e PEL (Probable Effect Level); $\mathrm{Cd}=$ cádmio; $\mathrm{Cr}=$ cromo; $\mathrm{Ni}=$ níquel; $\mathrm{Zn}=$ zinco; $\mathrm{Pb}=$ chumbo; $\mathrm{Cu}=$ cobre; b) Abundância Relativa (\%) dos gêneros de diptera (Chironomus e Chaoborus), de Oligochaeta (Haemonais e Dero), da família de Oligochaeta L. hoffmeisteri e de Outros (Nematoda, Branchiura sowerbyii, Pristinella, Pristina, Phreodrilidae, Polymitarcyidae, Pottselidae, Tanypus stelatus, Ablabesmyia, Cladopelma, Labrundinea); c) Scatter Plot das concentrações de metais no sedimento (mg Kg ${ }^{-1}$ ) observadas nos trabalhos de Mozeto e colaboradores (2003) e no presente trabalho (2013) na região do Embu-Guaçu, no reservatório Guarapiranga, SP-Brasil, e das concentrações de metais naturais do solo regional representadas pelos valores de referência regional (VRR) descritos por Nascimento (2003), além dos Valores-Guia de Qualidade de Sedimento (VGQS) estabelecidos pelo Conselho Canadense do Ministério do Meio Ambiente (CCME, 1999): TEL (Threshold Effect Level) e PEL (Probable Effect Level); O segundo eixo y representa as concentrações do metal cobre $(\mathrm{Cu})$. 
Tabela 8. Relação entre a somatória $(\Sigma)$ das concentrações de metais e as concentrações de sulfeto volatizável por acidificação (SVA) desenvolvida pela U.S.E.P.A. (2005) a fim de indicar a possibilidade de toxicidade para um determinado sedimento. Relações estabelecidas de acordo com os dados dos trabalhos de Mozeto e colaboradores (2003) e o presente trabalho (2003). Onde, G3 e G1 são pontos da região Guarapiranga e EG1 localiza-se no rio Embu-Guaçu, ambas regiões do reservatório Guarapiranga, SP-Brasil.

\begin{tabular}{lrcrc}
\hline & \multicolumn{2}{c}{ Mozeto e colaboradores } & \multicolumn{2}{c}{ Presente Trabalho } \\
\multicolumn{2}{c}{$(\mathbf{2 0 0 3 )}$} & \multicolumn{2}{c}{$(\mathbf{2 0 1 3 )}$} & \\
\hline Pontos & $\boldsymbol{\Sigma}$ [metais]-[SVA] & Toxicidade & $\boldsymbol{\Sigma}$ [metais]-[SVA] & Toxicidade \\
G3 & 47,97 & Incerta & 26,01 & Incerta \\
G1 & 28,03 & & 10,73 & \\
EG1 & 0,90 & Improvável & $-1,22$ & Improvável \\
\hline
\end{tabular}

A análise de componentes principais (ACP) explicou quase $60 \%$ da variabilidade dos dados ambientais e suas correlações nos anos de 1936, 1974, 1996 e 2010 no eixo 1 (CP1), o qual, segundo os altos coeficientes de correlação (Tabela 9), é representado por todos os metais, sulfetos, potencial de oxi-redução e profundidade (Figura 8a,b). Enquanto o eixo 2 (CP2) explica quase 21\% da variabilidade e é representado pelo teor de matéria orgânica, nitrogênio amoniacal, concentração de oxigênio dissolvido na água de fundo e $\mathrm{pH}$.

a)

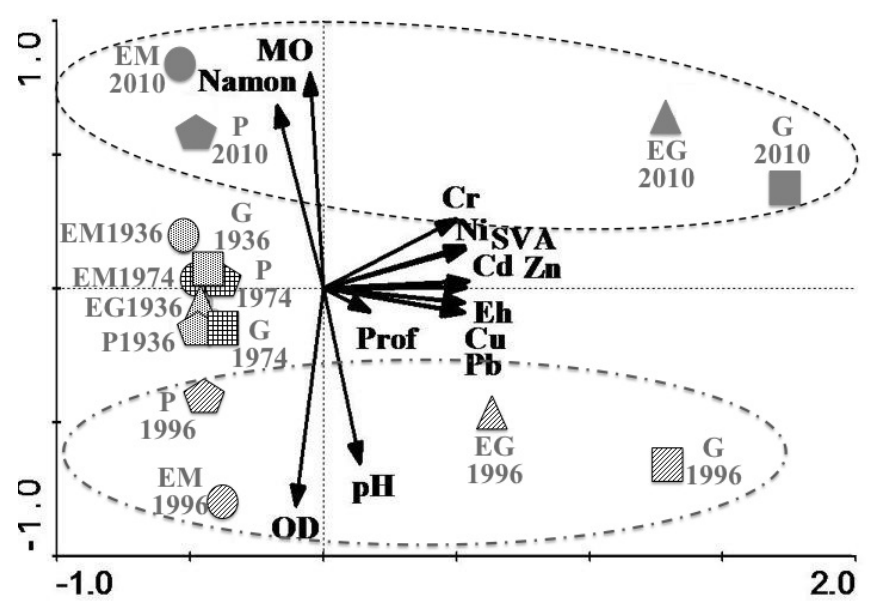

b)

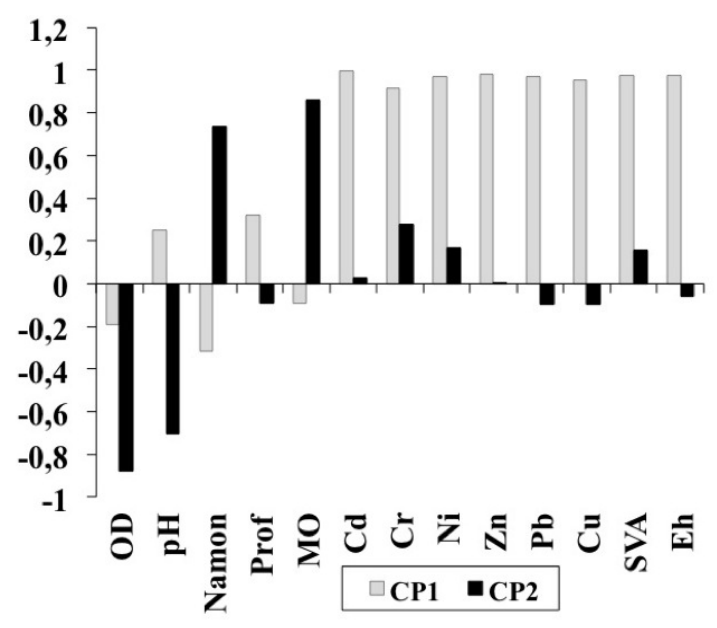

Figura 8. a) Análise de Componentes Principais (ACP) para ordenar os pontos amostrais e as variáveis físicas e químicas do sedimento. Triângulo= região EG (Embu-Guaçu); quadrado= região $\mathrm{G}$ (Guarapiranga); círculo= região EM (Embu-Mirim); pentágono= região $\mathrm{P}$ (Parelheiros); cores: 1936 (bolinhas); 1974 (xadrez); 1996 (listras); 2010 (cinza); MO= teor de matéria orgânica; Namon= nitrogênio amoniacal; $\mathrm{Cr}=$ cromo; $\mathrm{Ni}=$ níquel; $\mathrm{SVA}=$ sulfeto volatizável por acidificação; $\mathrm{Cd}=$ cádmio; $\mathrm{Zn}=$ zinco; $\mathrm{Eh}=$ potecial de oxi-redução; $\mathrm{Cu}=$ cobre; $\mathrm{Pb}=$ chumbo; Prof= profundidade; $\mathrm{OD}=$ oxigênio dissolvido; $\mathrm{pH}=$ potencial hidrogeniônico; b) Autovetores das correlações das variáveis utilizadas na ACP. Onde: $\mathrm{CP} 1=$ componente principal 1 ; $\mathrm{CP} 2=$ componente principal 2.

As quatro regiões do reservatório apresentaram os maiores teores de matéria orgânica e as menores concentrações de oxigênio dissolvido em 2010, comparado aos anos anteriores. Já em 1996, 14 anos antes de 2010, as quatro regiões do reservatório apresentavam condições inversas, ainda que seus teores de matéria orgânica não tenham sido analisados naquele trabalho, as concentrações de oxigênio dissolvido foram as mais altas comparadas aos demais anos analisados. Por termos somente dados de metais, sulfetos e potencial de oxi-redução para a região Guarapiranga 
e do rio Embu-Guaçu nos anos de 1996 e 2010, esses anos mostraram relação positiva com a componente principal 1 (PC1). Dessa forma os anos de 1974 e 1936 relacionaram-se negativamente a PC1. Ainda assim, observa-se que as regiões de Embu-Guaçu e Guarapiranga em 2010 estão mais associadas as altas concentrações dos metais cromo, níquel, cádmio e zinco, e de sulfeto, todos relacionados aos altos teores de matéria orgânica no sedimento $(>35 \%$ de matéria orgânica para estas duas regiões). Por outro lado, a região Guarapiranga, apresentou maiores concentrações de cobre e chumbo em 1996 que em 2010, associadas aos valores de potencial-redox somente analisados para estas duas regiões nesses dois anos. Tanto a região de Embu-Guaçu quanto a Guarapiranga em 1996 apresentaram os maiores valores de oxigênio dissolvido e pH, comparadas aos demais anos.

Tabela 9. Matriz de correlação da Análise de Componentes Principais (ACP). OD = oxigênio dissolvido; $\mathrm{pH}=$ potencial hidrogeniônico; Namon= nitrogênio amoniacal; Prof $=$ profundidade; $\mathrm{MO}=$ matéria orgânica; $\mathrm{Cd}=$ cádmio; $\mathrm{Cr}=$ cromo; $\mathrm{Ni}=$ níquel; $\mathrm{Zn}=$ zinco; $\mathrm{Pb}=$ chumbo; $\mathrm{Cu}=$ cobre; SVA = sulfeto volatizável por acidificação; $\mathrm{Eh}$ = potencial de oxi-redução;

\begin{tabular}{lcc}
\hline \multicolumn{3}{c}{ Matriz de correlação ACP } \\
\hline & CP1 & CP2 \\
OD & $-0,1911$ & $-0,8758$ \\
pH & 0,2503 & $-0,7066$ \\
Namon & $-0,318$ & 0,7328 \\
Prof & 0,3213 & $-0,0953$ \\
MO & $-0,0944$ & 0,8616 \\
Cd & 0,9965 & 0,0271 \\
\hline Cr & 0,9142 & 0,2761 \\
Ni & 0,9693 & 0,1696 \\
Zn & 0,9795 & 0,0046 \\
Pb & 0,9708 & $-0,0988$ \\
\hline Cu & 0,9512 & $-0,0987$ \\
SVA & 0,9749 & 0,1566 \\
\hline Eh & 0,9732 & $-0,0582$ \\
\hline
\end{tabular}

As regiões dos rios Embu-Mirim e Parelheiros em 2010, apresentaram os menores teores de oxigênio dissolvido e as maiores concentrações de nitrogênio amoniacal comparadas aos demais anos analisados. Porém em 1996 as mesmas regiões apresentaram as maiores concentrações de oxigênio dissolvido e de $\mathrm{pH}$ comparadas aos demais anos analisados.

Já em 1936 o reservatório parecia mais homogêneo quanto à química do sedimento e água de fundo ao apresentar pequena variação de $\mathrm{pH}$, concentração de oxigênio dissolvido e teor de matéria orgânica entre as quatro regiões do reservatório. A homogeneidade química do sedimento e água de fundo também foi observada no reservatório em 1974.

A Análise de Correspondência Canônica (ACC) (Figura 9) foi realizada para verificar se há relação entre a comunidade de macroinvertebrados bentônicos e as variáveis físicas e químicas do sedimento e da água de fundo do reservatório Guarapiranga entre os anos de 1974, 1996 e 2010. A significância da relação entre os taxa e as variáveis ambientais não colineares foi de $p=0,014$ e o teor de matéria orgânica, a somatória de metais, o pH e o nitrogênio amoniacal explicam $83,47 \%$ da variação dos dados, sendo $75,1 \%$ são explicados no eixo 1 . Já, se não considerarmos as variáveis ambientais, os organismos bentônicos explicam $62,6 \%$ da variabilidade dos dados no eixo 1 . 


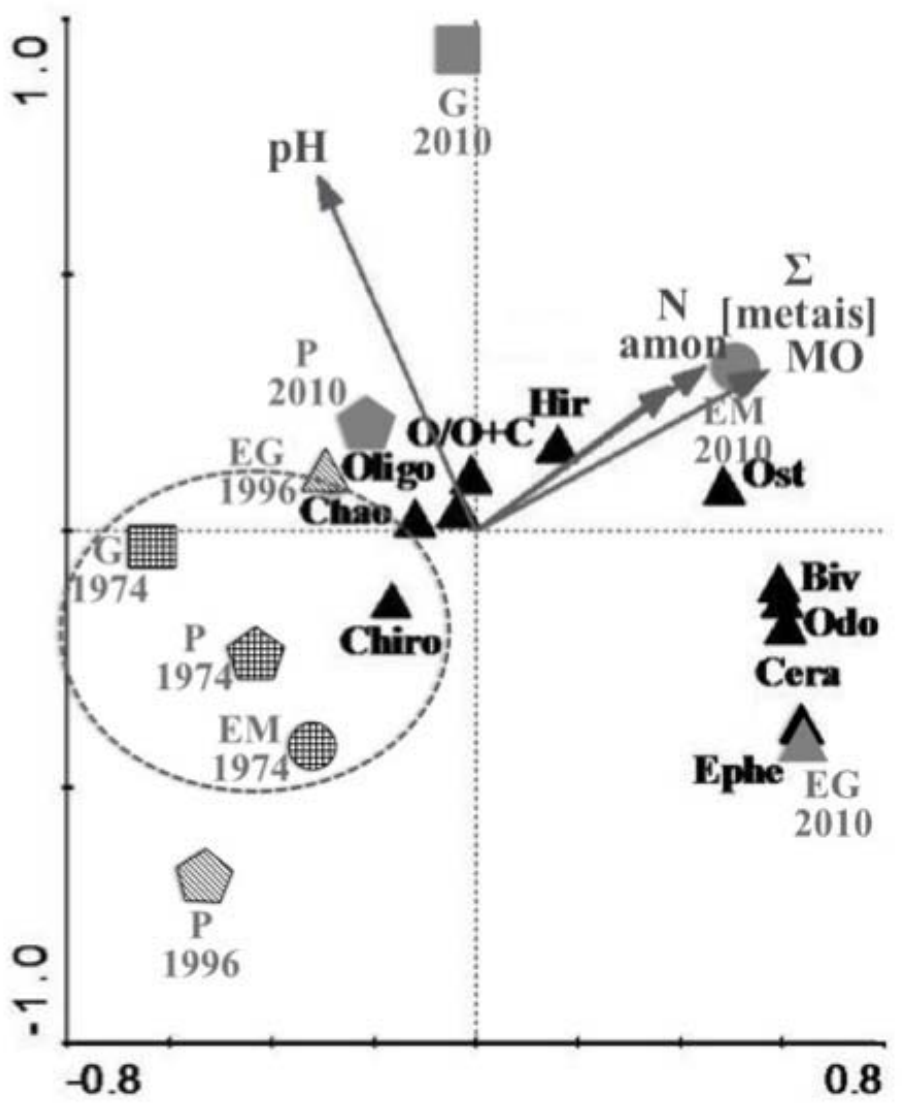

Figura 9. Análise de Correspondência Canônica (ACC) para ordenar os pontos amostrais e as variáveis físicas e químicas do sedimento. Onde: triângulo preto= taxa e índice trófico; triângulo= região EG (Embu-Guaçu); quadrado= região G (Guarapiranga); círculo= região EM (Embu-Mirim); pentágono= região $\mathrm{P}$ (Parelheiros); cores: 1974 (xadrez); 1996 (listras); 2010 (cinza); MO= teor de matéria orgânica; Namon= nitrogênio amoniacal; $\Sigma[$ metais] $=$ somatória das concentrações de metais; $\mathrm{pH}=$ potencial hidrogeniônico.

Ostracoda, Bivalvia, Odonata, Ceratopogonidae e Ephemeroptera foram mais abundantes ou estavam presentes somente na região do Embu-Mirim e do Embu-Guaçu em 2010. Com exceção de Bivalvia, os taxa supra citados se mostraram fortemente relacionados $(r=0,97)$ de acordo com a correlação de Pearson (Tabela 10). A maior concentração de nitrogênio amoniacal das quatro regiões nos 3 anos analisados ocorreu na região do Embu-Mirim em 2010. Quanto às regiões analisadas em 1974, Guarapiranga, Parelheiros e Embu-Mirim apresentaram baixos teores de nitrogênio amoniacal e de matéria orgânica $(8 \%, 11,3 \%$ e 21,6\%, respectivamente) e, Chironomidae foi o táxom mais expressivo da comunidade para 2 regiões e o segundo mais expressivo para a região Parelheiros nesse ano.

Tanto a região Embu-Guaçu em 1996 quanto a Parelheiros em 2010 apresentaram estrutura de comunidade semelhante, constituída pelos taxa Oligochaeta, Hirudinea, Chironomidae e Chaoboridae, sendo que Chaoboridae seguido por Oligochaeta foram os mais abundantes. A região Guarapiranga em 2010 a presentou índice trófico máximo, indicando alto grau de poluição orgânica além das mais altas concentrações de metais comparado aos demais anos para a região Guarapiranga. A correlação de Pearson mostrou com significância de $p<0,05$, uma fraca relação indireta entre o índice trófico $(\mathrm{O} / \mathrm{O}+\mathrm{C})$ e oxigênio dissolvido, $(\mathrm{r}=-0,71)$, e direta entre o índice trófico e o teor de matéria orgânica $(\mathrm{r}=0,66)$. Uma forte relação indireta entre o teor de matéria orgânica e a concentração de oxigênio dissolvido foi estabelecida $(r=-0,92)$.

As regiões Guarapiranga e Embu-Mirim 1996 foram excluídas da Análise de Correspondência Canônica por serem "outliers". 
Tabela 10. Matriz de correlação da Análise de Correspondência Canônica (ACC). OD = oxigênio dissolvido; $\mathrm{pH}=$ potencial hidrogeniônico; Namon= nitrogênio amoniacal; Prof $=$ profundidade; $\mathrm{MO}=$ matéria orgânica; $\mathrm{Cd}=$ cádmio; $\mathrm{Cr}=$ cromo; $\mathrm{Ni}=$ níquel; $\mathrm{Zn}=$ zinco; $\mathrm{Pb}=$ chumbo; $\mathrm{Cu}=$ cobre; SVA = sulfeto volatizável por acidificação; Eh = potencial de oxi-redução;

\begin{tabular}{lcc}
\hline \multicolumn{3}{l}{ Matriz de correlação ACP } \\
\hline & Eixo 1 & Eixo 2 \\
pH & $-0,3302$ & 0,6661 \\
Namon & 0,347 & 0,3638 \\
MO & 0,5594 & 0,314 \\
\hline$\sum$ metais] & 0,4603 & 0,2655 \\
\hline
\end{tabular}




\subsection{Discussão}

No reservatório Guarapiranga é interessante notar que as variáveis ambientais sofreram poucas alterações entre 1936 e 1974, ou seja, neste período as características físicas e químicas da água e do sedimento foram mais homogêneas. Observando os mapas de crescimento urbano vemos que em 1936 o reservatório se encontrava afastado da área urbana e que em 1974 a área urbana já se encontrava nas proximidades do rio Embu-Mirim e do corpo principal Guarapiranga. A partir de então, o reservatório passa a apresentar características de reservatórios urbanos. Nestas condições, estes ambientes são submetidos a grandes pressões pelas populações existentes no seu entorno, o que torna a qualidade se suas águas intimamente ligada às condições higiênicas e às econômicas das pessoas ali presentes (Straskraba \& Tundisi, 2000). A partir da década de 1980, ações de manejo passaram a ser necessárias no Guarapiranga, como: 1) aplicação de algicidas à base de sulfato de cobre, a partir de 1985, para controlar a qualidade da água desse reservatório de abastecimento público, principalmente na região Guarapiranga, área de captação da água, sendo que florações de fitoplâncton já eram notadas ao final da década de 1970 (Beyruth, 1992); 2) para manter o nível de de fornecimento de água, construiu-se a transposição Taquacetuba-Parelheiros em 2000, com águas vindas do reservatório Billings, que apresenta águas de qualidade questionável (Matsuzaki, 2007).

$\mathrm{O}$ aumento nos teores de matéria orgânica no sedimento de fundo e sua decomposição no reservatório Guarapiranga observados desde a década de 1970 são indicativos do que deve ser a primeira consequência do crescimento populacional e da industrialização, de acordo com Straskraba e Tundisi (2000). Da mesma forma, o oxigênio dissolvido no fundo passou a ser mais consumido na decomposição dessa matéria orgânica e, portanto, apresentou queda em suas concentrações, principalmente a partir da década de 1990, como indicado pela forte e inversa correlação entre ambas as variáveis. Como resultado desse enriquecimento orgânico, a grande disponibilidade de nitrogênio e fósforo seria a responsável pelo crescimento algal exagerado no reservatório, levando à necessidade de controle.

A importância dos sedimentos na dinâmica do corpo d'água é grande em reservatórios, assim como em outros ambientes, já que estes tendem a ser transportados e a formarem depósitos. Além disso, nos sedimentos pode haver formação de substâncias como carbonatos, sulfetos, material orgânico e outros, em diferentes estágios de cristalização, estequiometria ou hidratação (Fagnani et al. 2011). No caso dos metais, estes podem estar solúveis ou insolúveis e neste último estado formam óxidos adsorvidos à matéria orgânica e, portanto, presos ao sedimento. Dentre as principais fases ligantes de metais nos sedimentos destacam-se, no presente trabalho, a matéria orgânica e os sulfetos. Essa ligação depende também da granulometria do sedimento, sendo que a capacidade de adsorção é maior quanto mais fino o grão (U.S.E.P.A., 2005), o que é o caso da granulometria do Guarapiranga, com sedimento silte-argiloso. Segundo Hakanson e Jansson (1983) há uma relação direta entre o sedimento fino e o teor de matéria orgânica aí presente. Desta forma, o sedimento fino do reservatório é propício à adsorção de metais e matéria orgânica, ali presentes em grandes quantidades.

Mortimer (1941, 1942) e Hargrave (1972), estudando respectivamente um lago inglês e um dinamarquês, observaram que o potencial redox diminui com a profundidade, enquanto a captação de oxigênio dissolvido pelo sedimento aumenta, ou seja, que o potencial redox está inversamente relacionado a concentração de oxigênio dissolvido na água de fundo. O fundo anaeróbio é propício a formação de sulfetos pela ação de bactérias redutoras de sulfato, quando em presença de substâncias orgânicas de origem natural ou antropogênica (Fagnani et al., 2011). Potenciais de oxiredução apresentaram-se negativos em todo o reservatório Guarapiranga em 2010, abaixo de -130 $\mathrm{mV}$ na região Guarapiranga, assim como nas regiões analisadas em 1996 por Mozeto e colaboradores (2003), o que indica um ambiente de fundo anaeróbico. Segundo Marcussen (2008), sulfatos em condições de anoxia ou redutoras, com potenciais de oxi-redução abaixo de $-120 \mathrm{mV}$, são transformados em sulfetos. 
Os metais encontrados no sedimento do reservatório Guarapiranga desde 1996 possivelmente têm origem antropogênica e, com exceção do cobre, podem ter entrado no corpo d'água por meio de efluentes industrias, lixo urbano e por toda a lavagem e escoamento da área de entorno. Consideráveis concentrações de sulfeto também foram encontradas no sedimento do reservatório, mais baixas em 1996 do que em 2010, porém suficientes para não biodisponibilizar os metais em ambos os anos. Contudo, em 1996, o fundo apresentava-se mais oxigenado, sua água menos ácida e com menores teores de matéria orgânica no sedimento.

Em 1996, o reservatório já apresentava concentrações de chumbo acima dos valores naturais da região e dos limiares de efeito tóxico. O chumbo é um metal utilizado na produção de baterias, pigmentos e químicos muito comercializado principalmente a partir da década de 1990 (Paoliello \& Chasin, 2001).

Dos metais analisados, o cobre foi o que apresentou as maiores concentrações no sedimento no reservatório, chegando a 11 vezes o valor do limite de toxicidade provável, algo preocupante já que ele ficará retido no sedimento, juntamente com matéria orgânica e sulfeto, apenas enquanto o $\mathrm{pH}$ da água permanecer pouco alterado, entorno de neutro. Provavelmente sua origem venha da aplicação do algicida sulfato de cobre em todo o reservatório, a qual ainda era muito frequente em 2010.

Em 2010 os metais cromo, níquel, cádmio e zinco, além do sulfeto, mostraram concentrações superiores a 1996 no reservatório. O cádmio, por estar acima do valor natural para a região e do nível limiar de efeito tóxico, deve ser proveniente de produção, consumo e disposição de produtos contendo tal metal. A partir de 1987, principalmente, houve aumento de sua utilização para a fabricação de baterias de celular de níquel-cádmio; pigmentos amarelo, laranja e vermelho; estabilizador de PVC; recobrimento de produtos de aço e ferro (Cardoso \& Chasin, 2001).

O cromo também passou a ser muito explorado ao final da década de 1980. Suas concentrações no Guarapiranga, acima dos valores naturais para a região e do limiar de efeito tóxico, podem ter origem principalmente nos resíduos de água residencial (tingimento de couro e manufatura de tecidos) e na produção industrial (metais, produtos químicos e papel). Concentrações de 0,05 a $5 \mathrm{mg} \mathrm{Kg}^{-1}$ já são tóxicas para fitoplâncton e zooplâncton de acordo com Silva e Pedroso (2001), e na Guarapiranga foram encontradas concentrações de até $51 \mathrm{mg} \mathrm{Kg}^{-1}$.

Já o níquel apresentou concentrações um pouco acima do limiar de efeito tóxico, porém menor do que o valor regional. Como sua concentração foi 4 vezes maior em 2010 comparado a 1996, acredita-se que esta não seja natural, e que sua fonte antropogênica tenha tido início ao final da década de 1990, proveniente de produtos de aço inoxidável e de suas produções industriais, segundo Nascimento (2003).

O único metal que apresentou aumento considerável (3 vezes) de 1996 para 2010 na região do Embu-Guaçu foi o zinco. Este é aplicado no revestimento de proteção de ferro e aço e na fabricação de ligas de latão (Nascimento, 2003). Descartes irregulares desses materiais somados a lavagem da bacia de drenagem podem ser as portas de entrada de zinco no reservatório.

O aumento na entrada de nutrientes no corpo d'água e consequente crescimento de produtores primários são os efeitos diretos da eutrofização, enquanto seu efeito indireto é a alteração nas comunidades de organismos (Harper, 1992). Diferenças na composição da comunidade bentônica foram apontadas pelas análises exploratórias para todo o reservatório Guarapiranga nos anos comparados. Assim, a primeira hipótese nula, a qual nega a existência de variação na comunidade bentônica no reservatório ao longo dos anos foi rejeitada. A análise SIMPER apontou diferenças na composição da comunidade bentônica para todo o reservatório, além de variações significativas em concentrações de oxigênio dissolvido na água de fundo e de teores de matéria orgânica. A diferença entre os anos ficou clara a partir da análise de componentes principais principalmente para 1996 e 2010.

A análise de correspondência canônica aponta que a diferença observada de 1974 para os demais anos se dá pela presença de Chironomidae em densidade considerável naquele ano em todo o reservatório e isto está associado a teores de matéria orgânica e nitrogênio amoniacal mais baixos e concentrações de oxigênio dissolvido em torno de $7 \mathrm{mg} \mathrm{L}^{-1}$. Corroborando com os resultados 
deste trabalho, Dornfeld e colaboradores (2006), em ensaios ecotoxicológicos com Chironomus xanthus no sedimento do rio Monjolinho (médio Tietê), observaram tendência a aumento na mortalidade desses organismos conforme aumento na fração silte-argilosa e nos teores de matéria orgânica no sedimento do rio, e afirmam que as altas concentrações de cromo e cobre no sedimento aliadas à baixa concentração de oxigênio dissolvido seriam as causas da mortalidade da espécie de Chironomidae. Testes com Chironomus também mostraram que o acúmulo de metais nesses organismos se correlacionou com a quantidade de metais no sedimento, independente da presença de sulfeto, biodisponibilizando ou não os metais (De Jonge et al., 2010).

O índice trófico utilizado no trabalho indicou um aumento da poluição orgânica ao longo dos anos no Guarapiranga, uma vez que as densidades de Oligochaeta se tornaram maiores que as de Chironomidae, fato observado também pelo aumento no teor de matéria orgânica do sedimento e pela correlação direta porém sutil entre o índice e o teor de matéria orgânica. Além disso, foi observada relação considerável e inversa entre o índice trófico e a concentração de oxigênio dissolvido. Dessa forma, rejeitamos a segunda hipótese nula de que a comunidade bentônica não refletiria as condições físicas e químicas do reservatório. Em 1996, a comunidade bentônica do reservatório já mostrava sinais da forte poluição orgânica pela dominância de Oligochaeta, em especial dos gêneros Limnodrilus, Dero e Haemonais, todos tolerantes a poluição orgânica forte e significativa e portanto típicos de ambientes eutrofizados, segundo Mandaville (2002). Fica ainda mais clara a relação comunidade/sedimento e água de fundo quando consideramos a abundância de L. hoffmeisteri, que chegou a $80 \%$ de 1998 a 2005 e voltou a dominar com 54\% em 2010 na região Guarapiranga, região de sedimentação do reservatório, onde há altas concentrações de metais, sulfeto, além de sedimento predominantemente silte-argiloso. Segundo Mandaville (2002), a espécie L. hoffmeisteri é tolerante à poluição orgânica severa e portanto à anoxia de fundo dada pela decomposição dessa matéria orgânica. Chapman e Brinkhurst (1984) testaram as tolerâncias de $L$. hoffmeisteri e Tubifex tubifex a metais. No estudo, esses organismos aparentemente apresentaram maior tolerância à presença de cádmio se este estivesse ligado a um sal. Por outro lado, bioensaios realizados por Klerks e Weis (1987) indicaram que L. hoffmeisteri é tolerante a níveis extremamente altos de cádmio e níquel no sedimento, independente dos indivíduos teste serem originários de ambientes contaminados ou não. Esses organismos foram capazes de se reproduzir e crescer por mais de duas gerações sob tais condições, assim os autores inferiram que se trata de um caso de adaptação da espécie a metais-pesados. O gênero Chironomus também é apontado por ter uma certa resistência a poluição por metais (Klerks \& Weis, 1987).

De acordo com De Jonge e colaboradores (2010), os metais presentes nos organismos aquáticos têm origem na cadeia trófica, a partir do sedimento e água contaminados, passando por detritívoros até predadores. Ainda em condições anóxicas, quando há grande produção de sulfeto, o qual indisponibiliza os metais para a biota, houve acúmulo dos metais $\mathrm{Cr}, \mathrm{Ni}, \mathrm{Zn}$ e $\mathrm{Cd}$ nos organismos de acordo com os autores. Assim supõe-se que o mesmo pode ocorrer aos Oligochaeta já tolerantes a eutrofização (Limnodrilus, Dero e Haemonais) que dominam a comunidade bentônica no Guarapiranga. Segundo Hare e colaboradores (2001), alguns organismos constroem túneis e os oxigenam, impedindo o contato com o sulfeto e uma possível intoxicação, como alguns Chironomidae e Oligochaeta, mas no caso de L. hoffmeisteri os metais acumulados provém da alimentação nos sedimentos contaminados.

Em 2010 o quadro era similar ao de 1996 em relação à presença de organismos tolerantaes à poluição orgânica, mas com dominância de Limnodrilus e abundância significativa do Diptera Chaoborus. O aumento na densidade de Chaoboridae em todo o reservatório ao longo dos anos também é um indício da eutrofização desse corpo d'água (Mandaville, 2002). Hare e colaboradores (2001) observaram em testes laboratoriais que Chaoborus permaneceu pouco tempo próximo ao sedimento e não apresentou relação com concentrações de metais. Segundo os autores, Chaoborus se alimenta de zooplâncton na coluna d'água e portanto sua aquisição de metais seria por meio do zooplâncton. Por outro lado, Chaoborus é importante para o zoobentos pois durante o dia, principalmente no $4^{\circ}$ instar larval, entra e sai do sedimento, participando da bioturbação (Gosselin \& Hare, 2003). Bezerra-Neto e colaboradores (2012) em estudo no reservatório do Nado, 
considerado mesotrófico, observaram a liberação de bolhas na bioturbação por Chaoborus, sugerindo sua participação na emissão de metano. De qualquer forma, esses pesquisadores concordam que Chaoborus é tolerante a anoxia e ao entrar no sedimento não têm necessidade de construir tubos oxigenados, além disso é tolerante ao sulfeto e seu exoesqueleto é pouco permeável a elementos tóxicos presentes na coluna d'água ou na água intersticial.

Ambas as formas de manejo realizadas no reservatório citadas acima podem ter reforçado o processo de deterioração desse ambiente iniciado com o crescimento urbano desordenado avançando sobre a área de entorno do reservatório. Como dito por Straskraba e Tundisi (2000) sobre o manejo de reservatórios, na tentativa de resolver um problema, como o crescimento de algas tóxicas no Guarapiranga, pode-se optar por uma opção que leva a outro problema, no caso do Guarapiranga a alta e crescente concentração de cobre no sedimento de fundo, ao longo dos anos.

Dessa forma, conclui-se que o crescimento urbano desordenado, com consequente poluição difusa no reservatório Guarapiranga, proporcionou o enriquecimento orgânico de suas águas e sedimento. $\mathrm{O}$ enriquecimento orgânico, suas consequências e a entrada de metais-traço no corpo d'água influenciaram na alteração da estrutura da comunidade de macroinvertebrados bentônicos, além de favorecer a ocorrência de uma fauna tolerante à hipoxia, à poluição orgânica e à presença de elementos tóxicos como metais-traço e sulfetos. 


\subsection{Referências}

ADAMS, W.J.; ROWLAND, C.D. Aquatic Toxicology Test Methods. In: HOFFMAN, D.J. et al.(Eds.). Handbook of ecotoxicology. United States of America: Lewis Publishers, 2003. p. 19-44.

ALDEN, RW. Uncertainty and sediment quality assessments: I. confidence limits for the triad. Environmental Toxicology and Chemistry, v. 11, p. 637-644. 1992.

BEYRUTH, Z. Macrófitas aquáticas de um lago marginal ao rio Embu-Mirim, São Paulo, Brasil. Revista de Saúde Pública, São Paulo, v. 26, n. 4, p. 272-282, 1992.

BEZERRA-NETO, J.F. et al. Hydroacoustic assessment of fish and Chaoborus (DipteraCahoboridae) distribution in three Neotropical lakes. Acta Limnologica Brasiliensia, v. 24, n. 1, p. 18-28, 2012.

CALEFFI, S. Represa de Guarapiranga: Estudo da comunidade zooplanctônica e aspectos da eutrofização. 1994. 115 f. Tese (Mestrado em Saúde Ambiental) - Faculdade de Saúde Pública, Universidade de São Paulo, São Paulo. 1994.

CARDOSO, L.M.N.; CHASIN, A.A.M. Ecotoxicologia do cádmio e seus compostos. In: Série de cadernos de referencia Ambiental, v. 6. Salvador. 2001. 122p.

CARDOSO-SILVA, S. Heterogeneidade espacial e a qualidade das águas superficiais do reservatório Guarapiranga (São Paulo - SP - Brasil). 2008. 99f. Tese (Mestrado em Ecologia de ecossistemas terrestres e aquáticos) - Instituto de Biociências, Universidade de São Paulo. São Paulo. 2008.

CANADIAN COUNCIL OF MINISTERS OF THE ENVIRONMENT. Canadian Sediment Quality Guidelines for the Protection of Aquatic Life - Protocol for the derivation of Canadian Sediment Quality Guidelines for the Protection of Aquatic Life (CCME EPC-98E). 1999.

CHAPMAN, P.M.; BRINKHURST, R.O. Lethal and sublethal tolerances of aquatic oligochaetes with reference to their use as a biotic index of pollution. Hydrobiologia, v. 115, p. 139-144, 1984.

COMPANHIA AMBIENTAL DO ESTADO DE SÃO PAULO. Relatório de qualidade das águas interiores do estado de São Paulo 2002. São Paulo, 2003.

COMPANHIA AMBIENTAL DO ESTADO DE SÃO PAULO. Relatório de qualidade das águas interiores do estado de São Paulo 2003. São Paulo, 2004.

COMPANHIA AMBIENTAL DO ESTADO DE SÃO PAULO. Relatório de qualidade das águas interiores do estado de São Paulo 2004. São Paulo, 2005.

COMPANHIA AMBIENTAL DO ESTADO DE SÃO PAULO. Relatório de qualidade das águas interiores do estado de São Paulo 2005. São Paulo, 2006.

COMPANHIA AMBIENTAL DO ESTADO DE SÃO PAULO. Relatório de qualidade das águas interiores do estado de São Paulo 2005. São Paulo, 2007.

COMPANHIA AMBIENTAL DO ESTADO DE SÃO PAULO. Relatório de qualidade das águas interiores do estado de São Paulo 2010. São Paulo, 2010. 
DE JONGE, M.; BLUST, R.; BERVOETS, L. The relation between Acid Volatile Sulfides (AVS) and metal accumulation in aquatic invertebrates: Implications of feeding behavior and ecology. Environmental Pollution, v. 158, p. 1381-1391, 2010.

DORNFELD, C.B. et al. Comparação de bioensaios laboratoriais e "in situ" utilizando Chironomus xanthus na avaliação da toxicidade de sedimentos do rio Monjolinho (São Carlos, SP). Journal of the Brazilian Society of Ecotoxicology, v. 1, n. 2, p. 161-165, 2006.

EMPRESA PAULISTA DE PLANEJAMENTO METROPOLITANO. Mapa de Expansão da área urbanizada da região metropolitana de São Paulo. 2002/2003.

FAGNANI, E. et al. Sulfetos volatizáveis por acidificação e metais extraídos simultaneamente na avaliação de sedimentos de água doce. Quimica Nova, v. 34, n. 9, p. 1618-1628, 2011.

GOSSELIN, A.; HARE, L. Burrowing behavior of Chaoborus flavicans larvae and its ecological significance. Journal of the North American Benthological Society, v. 22, n. 4, p. 575-581, 2003.

HÅKANSON, L.; JANSSON, N. Principles of lake sedimentology. Berlim: Springer-Verlag. 1983. $316 \mathrm{p}$.

HARE, L.; TESSIER, A.; WARREN, L. Cadmium accumulation by invertebrates living at the sediment-water interface. Environmental Toxicology and Chemistry, v. 20, n. 4, p. 880-889, 2001.

HARGRAVE, B.T. Oxidation-reduction potencials, oxygen concentration and oxygen uptake of profundal sediments in a eutrophic lake. OIKOS, v. 23, n. 2, p. 167-177, 1972.

HARPER, D. Eutrophication of freshwaters: Principles, problems and restoration. London, UK: Chapman \& Hall. 1992. 327 p.

HELOU, L.C.; SILVA, L.G. Estudo da operação do reservatório de Guarapiranga. DAE, SABESP, São Paulo, v. 48, n. 151, p. 29-47, 1987.

KLEEREKOPER, H. Estudo limnológico da represa de Santo Amaro em São Paulo. Boletim da Faculdade de Filosofia e Ciências da Universidade de São Paulo, v. 7, n. 2, p. 9-151. 1939.

KLERKS, P.L.; WEIS, J.S. Genetic adaptation to heavy metals in aquatic organisms: A review. Environmental Pollution, v. 45, p. 173-205, 1987.

LEGENDRE, P.; LEGENDRE, L. Numerical Ecology. 2a Ed. Elsevier Science B.V. 1998. 853 p.

MANDAVILLE, S.M. Benthic macroinvertebrates in freshwaters: Taxa tollerance values, metrics and protocols. New York: Soil \& Water Conservation Society of Mero Halifax. 2002. 128 p..

MARCUSSEN, H.; DALSGAARD, A.; HOLM, P.E. Content, distribution and fate of 33 elements in sediments of rivers receiving wastewater in Hanoi, Vietnam. Environmental Pollution, v. 155, p. 41-51, 2008.

MARGALEF, R. Limnología. Barcelona, Espanha: Ediciones Omega, S.A. 1983. 1010 p.

MATSUZAKI, M. Transposição das águas do braço Taquacetuba da represa Billings para a represa Guarapiranga: aspectos relacionados à qualidade de água para abastecimento. 2007. $183 \mathrm{f}$. 
Tese (Doutorado em Saúde Pública) - Faculdade de Saúde Pública, Universidade de São Paulo, São Paulo. 2007.

MCCULLOUGH, J. D.; JACKSON, D. W. Composition and productivity of the benthic macroinvertebrate community of a subtropical reservoir. Revue der gesamten Hydrobiologie, v. 70, n. 2, p. 221-235, 1985.

MENEZES, L.C.B.; BEYRUTH, Z. Impactos da aquicultura em tanques-rede sobre a comunidade bentônica da represa de Guarapiranga - São Paulo- SP. Boletim do Instituto de Pesca, São Paulo, v. 29, n. 1, p. 77-86, 2003.

MORTIMER, C.H. The Exchange of dissolved substances between mud and water in lakes. Journal of Ecology, v.29, n.2, p. 280-329, 1941.

MORTIMER, C.H. The Exchange of dissolved substances between mud and water in lakes. Journal of Ecology, v.30, n.1, p. 147-201, 1942.

MOZETO, A.A.; SILVÉRIO, P.F.; SOARES, A. Estimates of benthic fluxes of nutrientes across the sediment-water interface (Guarapiranga reservoir, São Paulo, Brazil). The Science of the Total Environment, v. 266, p. 135-142, 2001.

MOZETO, A.A. et al. Weakly-bound metals and total nutriente concentrations of bulk sediments from some water reservoirs in São Paulo state, SE Brazil. Sediment Qality Assessment and Manegement: Insight and Progress. Burlington, Canadá: M. Munawar, p. 221-339, 2003.

NASCIMENTO, M.R.L. do. Proposição de valores de referência para concentração de metais e taloides em sedimentos límnicos e fluviais da bacia hidrográfica do Rio Tietê, SP. 2003. 111f. Tese Doutorado em Ciências) - Instituto de Química, Universidade Federal de São Carlos, São Carlos. 2003.

PADIAL, P. R. Qualidade, heterogeneidade espacial e biodisponibilidade de metais no sedimento de um reservatório tropical urbano eutrofizado (Reservatório Guarapiranga, SP). 2008. 109f. Dissertação (Mestrado em Ecologia) - Instituto de Biociências, Universidade de São Paulo, São Paulo. 2008.

PALMER, CM. Algas e suprimento de água na área de São Paulo. Revista DAE, vol. 21, p. 11-15, 1960.

PAOLIELLO, M.M.B.; CHASIN,A.A.M. Ecotoxicologia do chumbo e seus compostos. In: Série de cadernos de referencia Ambiental, v.3. Salvador. 2001. 144 p.

PATELLA, E. Caracterização biogeoquímica dos estoques de metais pesados contaminantes $e$ nutrientes de testemunhos de sediment e particulados do reservatório do Guarapiranga, São Paulo. 31/07/1998. 89f. Dissertação (Mestrado em Ciência da Engenharia Ambiental) - Escola de Engenharia de São Carlos, Universidade de São Paulo, São Carlos. 1998.

ROCHA, AA. A limnologia, os aspectos ecológicos-sanitários e a macrofauna bentônica da represa do Guarapiranga na Região Metropolitana de São Paulo. 1976. 194 f. Tese (Doutorado em Zoologia) - Instituto de Biociências, Universidade de São Paulo, São Paulo. 1976. 
ROCHA, S.M. Macroinvertebrados bentônicos como indicadores de poluição na Represa do Guarapiranga - SP. 1999. 200 f. Dissertação (Mestrado em Saúde Pública) - Faculdade de Saúde Pública, Universidade de São Paulo, São Paulo. 1999.

ROSENBERG, D. M.; RESH, V.H. Freshwater biomonitoring and benthic macroinvertebrates. New York: Chapmann \& Hall, 1993, 488 p.

SILVA, C.S.da; PEDROZO, M.F.M. Ecotoxicologia do cromo e seus compostos. In: Série de cadernos de referencia Ambiental, v.5. Salvador. 2001. 100p.

STRAŠKRABA, M.; TUNDISI, J.G. Gerenciamento da qualidade da água de reservatórios específicos. In: STRAŠKRABA, M.; TUNDISI, J.G. (Eds.). Diretrizes para o gerenciamento de lagos: Gerenciamento da qualidade da água de represas. São Carlos: ILEC/IIE. 2000. p. 183-193.

STRAŠKKRABA, M.; TUNDISI, J.G. Poluição de reservatórios e deterioração da qualidade da água. In: STRAŠKRABA, M.; TUNDISI, J.G. (Eds.). Diretrizes para o gerenciamento de lagos: Gerenciamento da qualidade da água de represas. São Carlos: ILEC/IIE. 2000. p. 85-96.

UNITED STATES ENVIRONMENTAL PROTECTION AGENCY. Procedures for the derivation of equilibrium partitioning sediment benchmarks (ESBs) for the protection of benthic organisms: Metal mixtures (cad- mium copper, lead nickel, silver, and zinc), EPA-600-R-02-011. Office of Research and Development: Washington DC, 2005.

WHATELY, M.; CUNHA, PM. Guarapiranga 2005: como e porque São Paulo está perdendo este manancial: resultados do diagnóstico socioambiental participativo da bacia hidrográfica da Guarapiranga. São Paulo: Instituto Socioambiental, 2006, 51 p.

WIEDERHOLM, T. Use of benthos on the lake monitoring. Journal of the Water Pollution Control Federation, v. 52, p. 537-547, 1980.

WRIGHT, S. Limnologia das águas de São Paulo. Relatório sobre uma investigação preliminar apresentado a Secretaria da Agricultura do estado de São Paulo. Archivos do Instituto Biológico, v. 7, art. 7, p. 65-67, 1936. 
Capítulo 2: Aplicação da Tríade da Qualidade do Sedimento em análise espacial no reservatório Guarapiranga (SP, Brasil) 


\title{
Aplicação da Tríade da Qualidade do Sedimento em análise espacial no reservatório Guarapiranga (SP, Brasil)
}

\begin{abstract}
With the main purpose to assess the sediment and the benthic fauna, by metal content and sediment toxicity and its effects on the fauna, the Sediment Quality Triad (SQT) was applied in Guarapiranga reservoir. This is one of the main urban water sources in the metropolitan region of São Paulo (Brazil), and 50 years eutrophication problem. Currently, it has sewage and diffuse pollution, including metals, as the main sources of pollution in the reservoir. A total of 35 taxa was found in 12 sampling stations distributed in the profundal region of the reservoir main body and in the regions where the three main tributaries (Embu-Mirim, Embu-Guaçu and Parelheiros) enter in the reservoir. Bottom hypoxia caused by the decomposition of large amounts of organic matter (average content of organic matter 20\%), limited the benthic community to organic enrichment and hypoxia tolerant organisms in practically all taxa. Limnodrilus hoffmeisteri, Chaoborus and Dero showed higher density and representation in the entire reservoir. Concentrations of $\mathrm{Cd}$ and $\mathrm{Cr}$ were above TEL in the entire reservoir and $\mathrm{Cu}$ above PEL also in the entire reservoir. The relationship $(\Sigma$ [metals] - [AVS]) / TOC indicated uncertain and improbable toxicity by metals, but tests showed acute toxic effect on most all the stations. Two calculations were applied for SQT, where on version 2 coarse sand and fine were excluded from chemical index. The SQT version 1 indicated that the stations located on the Embu-Guaçu region, except for the most upstream stations, chosen as reference station, are influenced by potential chemicals for degradation that may not be bioavailable while the most upstream station at Embu-Mirim region presents strong evidence of pollutioninduced degradation. In the other stations, SQT showed that toxic chemicals are causing stress on biota. The ICB $\mathrm{RES}_{\text {R }}$ enabled to select the SQT reference station, single point rated as having good quality. While SQT version 2 has divided the reservoir into two compartments: Embu-Mirim and main body with sediment more deteriorated, except for the Embu-Mirim upstream station, and Embu-Guaçu, Parelheiros and Embu-Mirim upstream station with lower deterioration. Concentrations of total phosphorus and nitrogen were above the limit permitted by federal law for dredged sediments in three stations of the reservoir except for Embu-Guaçu. The first null hypothesis about non transport of the six metals analyzed from tributaries upstream to the dam direction was accepted, since just $\mathrm{Cu}$ and $\mathrm{Cd}$ showed this trend more consistently. Copper comes from the application of algaecide copper sulfate in the waters of Guarapiranga. The second null hypothesis about not accordance of the bioassays' response with the normalized metals ratio by sulfide and total organic carbon was also accepted. The third null hypothesis, that the benthic fauna would not reflect these spatial differences, was refuted because the analysis showed that there was greater diversity in stations with lower concentrations of metals and nutrients. We conclude that organic enrichment, its consequences and incoming of trace metals in the water body influenced changes in benthic macroinvertebrate community promoting a tolerant fauna to hypoxia, organic pollution and presence of toxic substances such as trace metals and sulfides. According to the physical and chemical variables, the Guarapiranga sediment is spatially heterogeneous, allowing recognize four regions in the reservoir: the main body, and Embu-Mirim, Embu-Guaçu and Parelheiros regions. Since they have influence on the main body, it is suggested to include on the reservoir monitoring at least two or three sampling stations, one at each region.
\end{abstract}




\section{Resumo}

Com o objetivo principal de caracterizar o sedimento e a fauna bentônica, por meio das concentrações de metais, a toxicidade do sedimento e seus efeitos sobre esta fauna, a Tríade de Qualidade do Sedimento (TQS) foi aplicada no reservatório Guarapiranga. Este é um dos principais mananciais urbanos da região metropolitana de São Paulo (Brasil) e há 50 anos vem apresentando problemas de eutrofização. Atualmente, tem o esgoto e a poluição difusa, inclusive por metais, como as principais fontes de poluição. Um total de 35 taxa foi encontrado em 12 pontos amostrais distribuídos na região profundal do corpo principal e na desembocadura dos principais tributários(Embu-Mirim, Embu-Guaçu e Parelheiros) no reservatório. A hipoxia do fundo, causada pela decomposição de grande quantidade de matéria orgânica (teor médio de matéria orgânica de $20 \%$ ), limitou a comunidade a representantes tolerantes a tal situação em praticamente todos os taxa. Limnodrilus hoffmeisteri, Chaoborus e Dero apresentaram maior densidade e representatividade em todo o reservatório. As concentrações dos metais $\mathrm{Cd}$ e $\mathrm{Cr}$ estiveram acima de TEL em todo o reservatório e as de $\mathrm{Cu}$ acima de PEL também em todo o reservatório.A relação $(\Sigma$ [metais]-[SVA])/COT indicou toxicidade incerta e improvável por metais, contudo os testes agudos indicaram efeito tóxico para quase todos os pontos. Dois cálculos de TQS foram aplicados, excluindo-se na versão 2 a areia grossa e a fina do índice químico. A versão 1 da TQS indicou que os pontos localizados na região Embu-Guaçu, com exceção do ponto mais a montante eleito como ponto referência, sofrem influência de químicos com potencial para degradação mas que podem não estar biodisponíveis, e o ponto mais a montante da região Embu-Mirim apresenta forte evidência de degradação induzida por poluição. Nas demais regiões indicou que químicos tóxicos estão causando

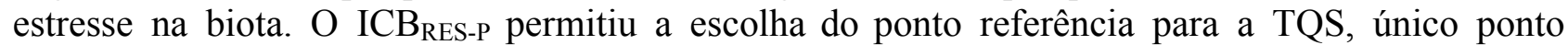
classificado com boa qualidade. Enquanto a TQS versão 2 dividiu o reservatório em 2 compartimentos: Embu-Mirim e corpo principal, com exceção do ponto mais a montante do EmbuMirim, com sedimento mais deteriorado; e Embu-Guaçu, Parelheiros e montante do Embu-Mirim com menor deterioração. Concentrações de nitrogênio e fósforo totais foram observadas acima do limite permitido por legislação federal para sedimentos dragados, em 3 regiões do reservatório, exceto na região Embu-Guaçu. A primeira hipótese nula sobre o não carreamento dos seis metais analisados da desembocadura dos tributários em direção à barragem foi aceita, já que somente $\mathrm{Cu} \mathrm{e}$ $\mathrm{Cd}$ demonstraram essa tendência de maneira mais consistente. $\mathrm{O}$ cobre provém da aplicação do algicida sulfato de cobre nas águas do Guarapiranga. A segunda hipótese-nula sobre a não consonância da resposta dos testes com a relação de metais normalizados pelo sulfeto e pelo carbono orgânico, também foi aceita. Já a terceira hipótese-nula de que a fauna bentônica não refletiria essas diferenças espaciais, foi refutada, pois as análises mostraram que houve maior diversidade em regiões com menores concentrações de metais e nutrientes. Conclui-se que o enriquecimento orgânico, suas consequências e a entrada de metais-traço no corpo d'água influenciaram na alteração da comunidade de macroinvertebrados bentônicos favorecendo uma fauna tolerante à hipoxia, à poluição orgânica e à presença de contaminantes tóxicos como metaistraço e sulfetos. De acordo com as variáveis físicas e químicas, o sedimento é heterogêneo, de forma podem ser reconhecidas quatro regiões no reservatório: corpo principal, Embu-Mirim, EmbuGuaçu e Parelheiros. Por este motivo, sugere-se a inclusão de ao menos 2 ou 3 pontos amostrais em cada uma das regiões para o monitoramento do reservatório, já que estas têm influência no corpo principal.

\subsection{Introdução}

\subsubsection{Influência antropogênica sobre o reservatório Guarapiranga}


As águas da Região Metropolitana de São Paulo (RMSP), no estado de São Paulo, Brasil, podem ser consideradas como um dos elementos propulsores do seu desenvolvimento. Criado em 1909 para gerar energia e, desde 1923, transformado em fonte de abastecimento de água para a população, o reservatório Guarapiranga teve o seu entorno inicialmente ocupado para lazer. Em 1950, no entanto, já recebia esgotos não tratados o que piorou muito a qualidade de suas águas sendo até observada mortandade de peixes no final dos anos 80. Em 2000 foi construída uma transposição de águas do reservatório Billings para o rio Parelheiros, tributário do Guarapiranga, a fim de auxiliar no abastecimento nos períodos de estiagem. Já em 2003, observava-se que mais da metade da área de sua bacia estava alterada por atividades humanas, com apenas $37 \%$ da área ocupada por remanescentes de Mata Atlântica, além da ocorrência de regiões de mineração adjacentes aos principais tributários do reservatório Guarapiranga: Embu-Mirim, Embu-Guaçu e Parelheiros.

Atualmente, o esgoto e a poluição difusa, inclusive por metais, constituem as principais fontes de poluição do reservatório e têm íntima ligação com a deficiência dos serviços de saneamento, em especial de rede de coleta, afastamento e tratamento do esgoto produzido pela população da bacia (Whately \& Cunha, 2006). Como se depreende do parágrafo anterior, estes problemas não são recentes e o reservatório tem sido considerado eutrófico desde 1960. Matsuzaki (2007) o classifica, de acordo com os valores de fósforo total, como supereutrófico a hipereutrófico. Além disso, a presença de metais-traço e a concentração de nutrientes no sedimento também indicam forte contaminação antropogênica (Rocha, 1976; Patella, 1998; Beyruth, 2000; Mozeto et al., 2001; Mozeto et al., 2003; Menezes \& Beyruth, 2003). Richter e colaboradores (2007) também observaram metais nas águas do reservatório, porém, alguns em concentrações aceitáveis, mas com certa variação sazonal. Observaram ainda no sedimento, assim como Patella (1998) e Mozeto et al. (2003), concentrações de metais e nutrientes que indicam forte contaminação antropogênica nas proximidades do tributário Embu-Guaçu comparado a pontos próximos à barragem. Corroborando esses resultados, Padial (2008) encontrou no sedimento de grande parte do reservatório Guarapiranga, valores de concentração de metais muito acima do sugerido para proteção da vida aquática e acima do que seria de ocorrência natural.

\subsubsection{Tríade da Qualidade do Sedimento}

A concentração de elementos poluentes no sedimento ocorre tanto para material autóctone como alóctone, formando bancos de lodo, nos quais, além da matéria orgânica, podem ser acumulados sais minerais nutrientes e metais-traço aderidos àquele material (Alden, 1992; Dodds, 2002). Os metais-traço são os mais preocupantes, porque em pequenas concentrações são capazes de provocar efeitos tóxicos graves em organismos. Mas esses metais podem estar biodisponíveis ou não, e isso dependerá do tamanho dos grãos do sedimento, já que quanto menor a partícula, maior a capacidade de adsorção de metais, além da presença de outras substâncias complexadoras de metais como matéria orgânica, sulfeto, ferro e manganês (Alden, 1992). O destino desses metais-traço passa a ser dependente do destino da fase com a qual estão complexados: a formação de complexos insolúveis precipita tais elementos; por outro lado, elementos-traço incorporados ou adsorvidos são liberados na coluna d'água quando sua fase complexadora é destruída ou solubilizada ou ainda quando há mudanças no pH (Santischi et al., 1990). No entanto, uma questão difícil é determinar se a presença de contaminantes está surtindo efeito adverso na biota, uma vez que outros fatores podem influenciar a comunidade bentônica de forma negativa (Araújo, 2005; Mariani, 2006).

A fauna bentônica também é um importante agente transformador do sedimento, pois, através de sua atividade mecânica (biorrevolvimento), altera características físicas e químicas do sedimento, além de promover a liberação de nutrientes para a coluna d'água. Além disso, estes organismos têm um papel fundamental no fluxo de energia e na ciclagem de nutrientes dos ecossistemas aquáticos, decorrente do fato de participarem indiretamente no processo de decomposição da matéria orgânica, ao reduzirem o tamanho das partículas detritais aumentando a área de atuação dos microrganimos decompositores, e por fazerem parte da dieta de vários organismos aquáticos (Margalef, 1983; Esteves, 2011). 
Como se vê, o sedimento apresenta importância no metabolismo de sistemas aquáticos pois é um local de intensa deposição de materiais particulados e de decomposição de matéria orgânica. Assim, integra e reflete todos os processos que ocorrem neste ambiente. Portanto, sua composição também deve dar indicação do seu estado trófico e da presença de contaminantes, e deve ser estudada com maior detalhe (Carmouze, 1994). Desta forma, estudos das características físicas e químicas do sedimento, aliados a bioensaios toxicológicos e à estrutura da fauna bentônica, conhecidos como Tríade de Qualidade do Sedimento (TQS), e podem determinar a concentração de contaminantes e seus efeitos sobre a comunidade zoobentônica, além de descrever relações ecológicas entre propriedades do sedimento e esta, identificando riscos à sua integridade (Chapman, 1992). O conceito da TQS foi introduzido por Long e Chapman (1985) e se desenvolveu como resultado da realização das 3 medidas complementares e da necessidade de fornecer forte evidência sobre a degradação induzida por poluição (Chapman et al., 1987). Essa abordagem de integração de dados tem sido empregada mundialmente devido a sua eficiência na caracterização, avaliação e monitoramento da qualidade de sedimentos e dos ecossistemas aquáticos auxiliando inclusive no gerenciamento ambiental (CETESB, 2007).

Alguns pesquisadores ainda hoje têm aplicado a tríade de acordo com a ideia original de Long e Chapman (1985) (Liu et al., 1999; Hollert et al., 2002b; CETESB, 2007; Da Silva, 2008). Contudo, conforme a aplicação da TQS, pesquisadores vêm sugerindo algumas modificações, adições e até novas avaliações como o desenvolvimento de um peso de evidência ("weight of evidence' - WOE) para a qualidade do sedimento (Burton et al., 2002; Chapman et al., 2002); propondo um quadro de 'environmental risk assessment' (ERA) o qual contribui para a estimativa final do 'environmental risk index' (EnvRI) (Dagnino et al., 2008); recomendações para reduzir a incerteza na integração dos dados e na interpretação da TQS (Bay et al., 2007); abordagem estatística diferente para a TQS (Hollert et al., 2002a), aplicada também pela CETESB (2007).

No presente trabalho optou-se por aplicar a tríade na sua forma original a fim de verificar quais seriam os pontos fracos e qual a melhor opção a ser adotada das sugestões acima citadas para um futuro trabalho. O objetivo do trabalho foi caracterizar o sedimento e a fauna bentônica dos tributários e do corpo principal do reservatório a fim de avaliar por meio das concentrações de metais, a toxicidade do sedimento e seus efeitos sobre a fauna bentônica. Baseia-se nas seguintes hipóteses-nulas: 1) não há carreamento com tendência a aumento na concentração de metais da montante dos tributários sentido barragem; 2) os bioensaios não responderão em consonância com os resultados da relação ( $\Sigma$ [metais] - [SVA])/ COT; 3$)$ a fauna bentônica não refletirá as diferenças espaciais do sedimento quanto à presença e concentração de metais.

\subsection{Materiais e Métodos}

\subsection{1. Área de estudo}

O reservatório Guarapiranga, localizada a $23^{0} 43^{\prime}$ Sul e $46^{0} 32^{\prime}$ 'Oeste a uma altitude de 742 $\mathrm{m}$, é uma sub-bacia da Bacia do Alto Tietê (Figura 1). Considerada um reservatório urbano, sua bacia abrange cinco municípios da Grande São Paulo: São Paulo $\left(211 \mathrm{~km}^{2}\right)$, Itapecerica da Serra $\left(183 \mathrm{~km}^{2}\right)$, Embu-Guaçu $\left(162 \mathrm{~km}^{2}\right)$, Embu $\left(41 \mathrm{~km}^{2}\right)$ e Cotia $\left(33 \mathrm{~km}^{2}\right)$. O município de São Paulo contorna toda a margem direita do reservatório e parte da margem esquerda, abrangendo $70 \%$ do perímetro do reservatório, sendo o restante pertencente aos municípios de Embu-Guaçu (27\%) e Itapecerica da Serra (3\%) (Whately \& Cunha, 2006). Tem como principais tributários os rios EmbuMirim, Embu-Guaçu e Parelheiros.

Apresenta um nível operacional mínimo de 726,37 m e máximo de 736,62 m (Helou \& Silva, 1987), profundidade máxima, próximo à barragem, de $13 \mathrm{~m}$ e média de $6 \mathrm{~m}$ no restante, sendo considerado assim um ambiente raso. A vazão afluente média é de $11,8 \mathrm{~m}^{3} \mathrm{~s}^{-1}$ e o volume de armazenamento útil é de $191610 \times 10^{3} \mathrm{~m}^{3}$ (Mozeto et al., 2001). Pode ser considerada polimítica, devido às correntes internas nos canais dos rios formadores e à ação dos ventos. Com uma área de drenagem de $639 \mathrm{Km}^{2}$, a bacia constitui atualmente o segundo maior manancial dos sistemas de 
abastecimento da RMSP. Produz em média 14 mil litros de água por segundo para atender cerca de 3,7 milhões de habitantes (20\% da população da RMSP) (Whately \& Cunha, 2006).

Para abastecer a população da região sudoeste de São Paulo são retirados cerca de 1,2 bilhões de litros de água por dia do sistema produtor Guarapiranga. Este inclui o reservatório e duas transposições de água de outras bacias hidrográficas. A primeira e mais antiga é a reversão do rio Capivari para o rio Embu-Guaçu (cerca de mil litros por segundo). A segunda, em funcionamento desde 2000, é a reversão das águas do Braço Taquacetuba, do reservatório Billings, para o rio Parelheiros (entre dois e quatro mil litros por segundo). O reservatório tem uma vazão natural estimada em 9 mil litros de água por segundo (Whately \& Cunha, 2006).

Ao leste e ao sul o relevo à margem do reservatório é marcado por algumas planícies que estão assentadas sobre terrenos planos de micaxistos e gnaisses de funções cambrianas (Rocha, 1976). O modelo do reservatório, de morfologia dendrítica, estreita e alongada, formada na base da bacia de drenagem e vale de rios, favorece os usos e ocupação do solo e, desta forma, a ação antrópica (Rocha, 1999). No entanto, algumas áreas do entorno apresentam severas restrições em relação à ocupação, como as planícies aluviais, nas quais predominam declividades inferiores a 5\%, pouca profundidade do lençol freático e solos com baixa capacidade de suporte, as quais facilitam o surgimento de sérios problemas de enchentes e criam dificuldades para implantação das obras de saneamento, edificações e sistema viário (Whately \& Cunha, 2006).

Quanto à vegetação natural, a área da Bacia do Guarapiranga abrange remanescentes de Mata Atlântica, incluindo áreas em estágio inicial, médio e avançado de regeneração, além de regiões de várzea e campo de altitude (Whately \& Cunha, 2006).

Devido aos relatos de heterogeneidade espacial na água e no sedimento do reservatório (Padial, 2008; Cardoso-Silva, 2008), o reservatório foi analisado em função da desembocadura de seus principais tributários (rios Embu-Mirim, Embu-Guaçu e Parelheiros) e de seu corpo principal denominado aqui de Guarapiranga. Deu-se preferência à região médio-profundal para amostragem devido ao histórico de metais apresentados na coluna d'água e no sedimento e segundo recomendação de Mandaville (2002). 


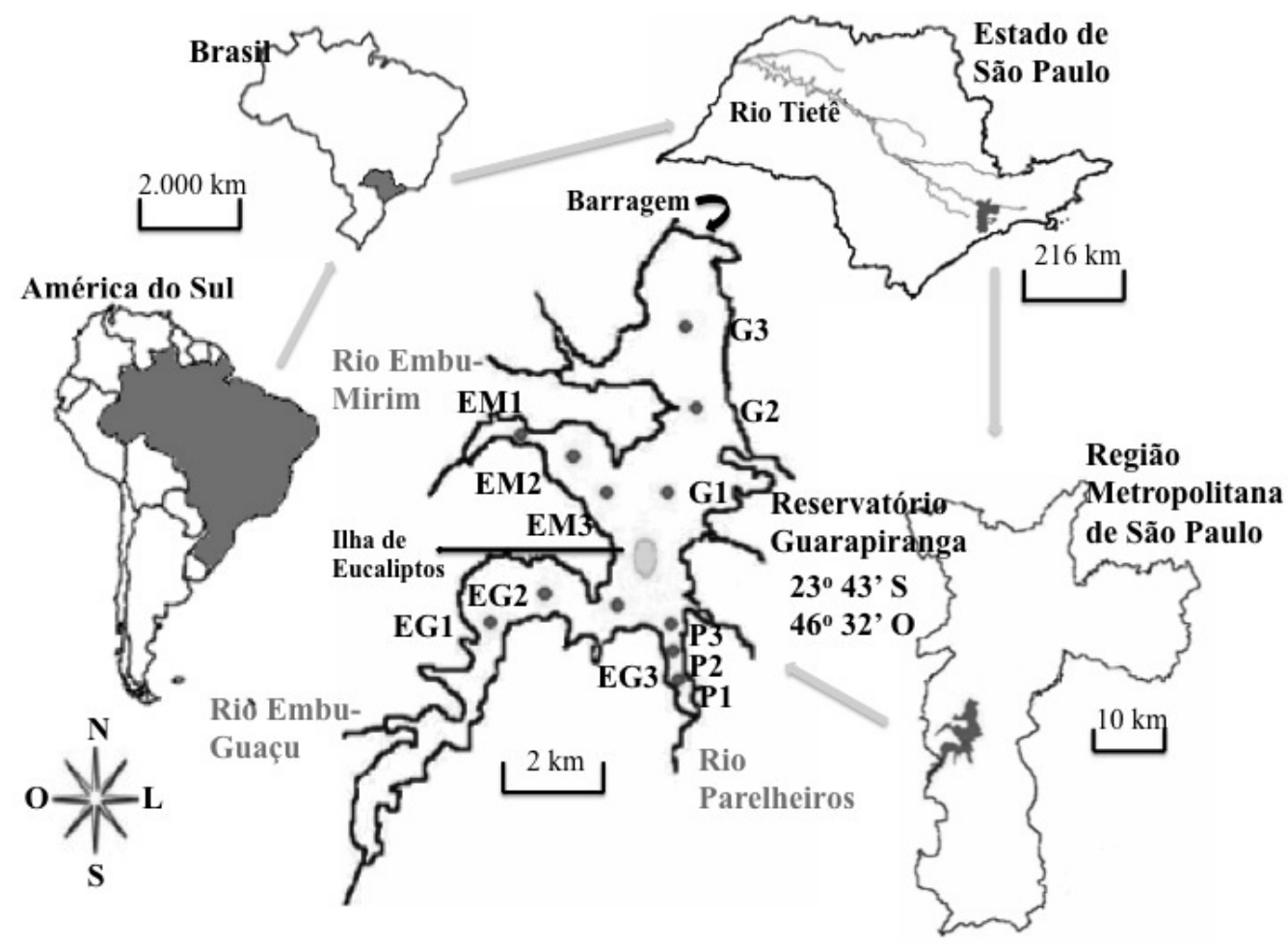

Figura 1. Localização do reservatório Guarapiranga, São Paulo - Brasil. Pontos escuros = pontos de amostragem. $\mathrm{G}=$ Guarapiranga; EM = Embu-Mirim; EG = Embu-Guaçu; $\mathrm{P}=$ Parelheiros.

\subsubsection{Amostragem do sedimento e análise dos dados}

A amostragem do sedimento foi realizada em 26 e 28 de julho de 2010 , pois se sabia de antemão que entre junho e agosto ocorre circulação de toda massa d'água, permitindo concentrações de oxigênio na região de fundo suficientes para a sobrevivência da fauna bentônica. No total foram amostrados 12 pontos, dos quais 3 longitudinalmente distribuídos no reservatório, entre a ilha de Eucaliptos e a barragem. Outros 9 pontos foram distribuídos longitudinalmente, em número de 3, na região de desembocadura de seus principais tributários (Embu-Guaçu, EmbuMirim e Parelhereiros), todos localizados na região médio-profundal.

\subsubsection{Macroinvertebrados bentônicos}

Seguindo recomendações de Kuhlmann e colaboradores (2005), a amostragem foi feita utilizando-se um pegador Eckman-Birge $\left(225 \mathrm{~cm}^{2}\right)$. Em cada ponto foram coletadas seis unidades amostrais seguindo recomendações de Canton e Chadwick (1988) e Voshell e colaboradores (1989) apud Rosenberg e Resh (1993), totalizando 72 unidades amostrais. As amostras foram guardadas em sacos plásticos e fixadas imediatamente com formalina neutralizada 4\%. Posteriormente, em laboratório, o material foi lavado em peneira de abertura de malha de $500 \mu \mathrm{m}$, corado com Rosa de Bengala e preservado em álcool 70\%.

Os organismos foram triados sob estereomicroscópio e identificados até o menor nível possível com base nas chaves encontradas em Merritt e Cummins (1996), Trivinho-Strixino (2011), 
Brinkhurst e Marchese (1991), Pennak (1989), Pérez (1988), Costa e col. (2004), Costa e col. (2006), Würdig e Pinto (1999) e Marchese (2009). Indivíduos de Oligochaeta foram identificados chegando-se em nível de espécie com ajuda da pesquisadora Mercedes Marchese do INALI, Santa Fé-Argentina.

Para avaliar a qualidade ambiental a partir da comunidade de macroinvertebrados bentônicos calculamos o Índice de Comunidade Bentônica para reservatórios (ICB RES-P) (Anexo 2.1) desenvolvido pela CETESB (2012). Trata-se de um índice multimétrico que combina as seguintes métricas:

1. Riqueza (S);

2. Índice de Diversidade (H');

3. Razão Tanytarsini/Chironomidae (Tt/Chi) (U.S.E.P.A., 1989): utilizando as abundâncias absolutas;

4. Dominância de grupos tolerantes (T/DT): T (densidade de tolerantes) e DT (densidade total de organismos da amostra). Os tolerantes considerados são Limnodrilus hoffmeisteri, Bothrioneurum, Tubifex, Dero, Pristina, Pristinella e Chironomus.

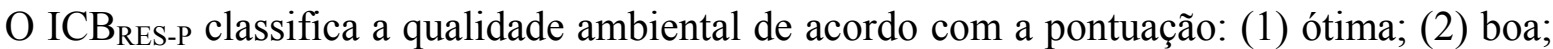
(3) regular; (4) ruim; (5) péssima.

Devido ao alto teor de matéria orgânica no sedimento, foi calculada também a Densidade de Oligochaeta $/ \mathrm{m}^{2}$ (Wright \& Tidd, 1933 apud. Fusari \& Fonseca-Gessner, 2006) a fim de avaliar o nível de enriquecimento orgânico, o qual considera densidade inferior a 1000 ind $\mathrm{m}^{-2}$ como indicativa de ambiente em equilíbrio natural, de 1000 a 5000 ind $\mathrm{m}^{-2}$ como moderadamente enriquecido e acima de 5000 ind $\mathrm{m}^{-2}$ como fortemente enriquecido.

\subsubsection{Bioensaios}

Os testes de toxicidade foram realizados no laboratório do professor Evaldo Gaeta Espíndola no CRHEA, na USP-São Carlos, com os seguintes organismos teste: Cladocera - Daphnia similis e Ceriodaphnia silvestri e Chironomidae - Chironomus xanthus. Em cada ponto de amostragem, foram coletadas três amostras de sedimento, uma para cada organismo-teste, com o auxílio do pegador do tipo Ekman-Birge $\left(325 \mathrm{~cm}^{2}\right)$. As amostras foram homogeneizadas e divididas em três potes de plástico previamente lavados com $\mathrm{HCl} 10 \%$, buscando-se o menor contato possível das amostras com o ar. Os potes foram postos em imersão em gelo e, em seguida, levados à refrigeração a $4^{\circ} \mathrm{C}$ (Allen et al., 1993; Mozeto, 2004; Mozeto, 2006).

A amostra de sedimento tomada para extração de água intersticial foi submetida à centrifugação, dez dias após a coleta, a cerca de $4^{\circ} \mathrm{C}$ e a $3500 \mathrm{rpm}$ por 15 minutos. Em seguida a água intersticial foi pipetada do tubo da centrífuga e colocada em frascos de PVC reforçados, previamente lavados com $\mathrm{HCl} 10 \%$, e levados à refrigeração a $4^{\circ} \mathrm{C}$ até o momento da realização dos bioensaios (CETESB, 1991; Mozeto, 2006).

Testes agudos foram realizados com Daphnia similis e Chironomus xanthus e testes crônicos com Ceriodaphnia silvestri, organismos já padronizados para as análises, de acordo com Rodgher e col. (2005), seguindo metodologia descrita pela CETESB (1991) utilizada no laboratório do CRHEA.

\section{concentração de nutrientes}

2.2.2.3. Análise granulométrica, teor de matéria orgânica no sedimento e

Uma amostra de sedimento foi coletada em cada ponto, com ajuda do coletor tipo Ambühl e Bührer (Ambühl \& Bührer, 1975), com tubo de acrílico de 7,2 cm de diâmetro. Foram retirados 
somente os 10 primeiros centímetros da coluna de sedimento para estudo da porção superficial, como sugerido por Mozeto (2006). A água superficial do tubo coletor foi sifonada com mangueira de silicone e descartada. A amostra de sedimento foi estocada em sacos plásticos tipo zip lock (previamente lavados com $\mathrm{HCl} 10 \%$ ) que, após a retirada do ar, foram selados e postos em imersão em gelo. Em seguida este material foi congelado em freezer a $-18^{\circ} \mathrm{C}$. (Allen et al., 1993; Mozeto, 2004; Mozeto, 2006).

Para determinação da granulometria foi seguido método úmido adaptado por Meguro (2000), teores de matéria orgânica (perda por ignição) e de água do sedimento seguindo o método descrito em Håkason e Jansson (1983), e cálculo de carbono orgânico total (COT). As análises de nitrogênio total seguiram o método analítico de Kjedahl e as de fósforo total, a metodologia descrita por Andersen (1976).

\subsubsection{Metais e caracterização física e química da água intersticial}

Uma amostra de sedimento foi recolhida em cada ponto, seguindo o mesmo procedimento adotado para as amostras destinadas à análise granulométrica. Ainda com sedimento e água superficial no tubo foram feitas medições de $\mathrm{pH}$, temperatura da água, oxigênio dissolvido e condutividade da água superficial, com ajuda de uma sonda multiparâmetros marca YSI, modelo 63/100 FT, e para Potencial Redox (Eh) um eletrodo Digimed, modelo DMP-CP1. Logo após a água foi sifonada e descartada e a amostra de sedimento foi estocada da mesma forma que a amostra para análises granulométrica.

Foram realizadas análises de Sulfeto Volatizável por Acidificação (SVA) (Allen e col., 1993) e de Metais (U.S.E.P.A. 3050b, 1996), estas últimas realizadas pelo laboratório do professor Rubens Cesar Lopes Figueira no IO-USP, para determinar a biodisponibilidade de íons metálicos nos sedimentos, analisando os metais $\mathrm{Cd}, \mathrm{Pb}, \mathrm{Cu}, \mathrm{Cr}$, $\mathrm{Ni}$ e $\mathrm{Zn}$, pelo método ICP-OES (Espectrometria de Emissão Óptica por Plasma Acoplado Indutivamente). O método de SVA consiste em extrair os metais divalentes fracamente ligados ao sedimento, na forma de sulfeto metálico, utilizando ácido clorídrico diluído e a frio, o qual em contato com o sulfeto metálico gera o sulfeto volátil que, por fim, reage com hidróxido de sódio e pode ser quantificado pelo método de colorimetria do azul de metileno (Mozeto, 2006).

De acordo com o cálculo desenvolvido pela U.S.E.P.A. (2005) levando-se em consideração a somatória da concentração de metais, a concentração de sulfeto volatizável e o teor de carbono orgânico total podemos determinar a biodisponibilidade de metal e o risco de toxicidade para os organismos:

1) toxicidade provável quando: $(\Sigma$ [metais] $-[\mathrm{SVA}]) / \mathrm{COT}>3000 \mathrm{mmol} / \mathrm{Kg}$

2) toxicidade incerta quando: $130<(\Sigma$ [metais] $-[\mathrm{SVA}]) / \mathrm{COT}<3000 \mathrm{mmol} / \mathrm{Kg}$

$3)$ toxicidade improvável quando: $(\Sigma$ [metais] $-[\mathrm{SVA}]) / \mathrm{COT}<130 \mathrm{mmol} / \mathrm{Kg}$

Para analisar os resultados das concentrações de metais utilizamos as referências dos Valores-Guia de Qualidade de Sedimento (VGQS) estabelecidos pelo Conselho Canadense do Ministério do Meio Ambiente (CCME, 1999): TEL (Threshold Effect Level) e PEL (Probable Effect Level). Além desses, buscou-se utilizar Valores de Referência Regionais (VRR), encontrados em concentrações naturais sem interferência antrópica e baseados na geologia regional, calculados para a Bacia do Tietê (Nascimento, 2003) (Anexo 2.3).

\subsubsection{Métricas e análises exploratórias}


Testes de normalidade e homogeneidade foram aplicados aos resultados dos bioensaios para analisar as variâncias (teste de Fisher) das ANOVAs através do programa TOXSTAT. A correção necessária aos testes ecotoxicológicos devido a alterações no bioensaio controle, foi feita por meio do corretor online http://www.ehabsoft.com/ldpline/onlinecontrol.htm\#Abbott (acesso em: 09/12/2012) segundo indicação do pesquisador Peter Chapman. A fórmula também pode ser encontrada em Fleming e Retnakaran (1985).

Quanto à TQS, foi selecionado, segundo recomendações de Chapman (1992) e Mandaville (2002), um ponto de referência no reservatório para comparação com os demais pontos amostrais, já que há heterogeneidade espacial, como citado anteriormente. O ponto EG1 foi o escolhido por ter apresentado maior número de variáveis com valores indicativos de boa qualidade ambiental e menor coeficiente de variação de comunidade, o que o tornou um dos mais dissimilares em relação aos demais pontos. Além disso, está distante da zona de sedimentação (pontos G).

Para cada ponto de amostragem foram determinados, de acordo com indicação de Chapman (1992), para a TQS:

A) Índice Biológico (Ib) ou de Comunidade

Para o cálculo do índice foram utilizadas as seguintes métricas:

1. Riqueza de taxa (S) (Rosenberg \& Resh, 1993): soma de todos os taxa encontrados em cada ponto, no menor nível taxonômico alcançado;

2. Abundância total (McCullough \& Jackson, 1985): somatória do número de indivíduos encontrados por ponto amostral (para cada taxa)/ área total amostrada;

3. Índice de Dominância de McNaughton's $\left(\mathrm{D}_{2}\right)$ (Odum, 1988; Margalef, 1983; Fusari \& Fonseca-Gessner, 2006): somam-se as duas proporções dos taxa mais abundantes do ponto;

4. Índice de Diversidade de Shannon (H') (Dajoz 2005);

5. Abundância absoluta dos maiores taxa (no caso, Oligocaheta e Chaoboridae);

6. Análise de agrupamento (Cluster) pela medida de distância do Índice de Morisita-Horn (Da Silva, 2008): determina a similaridade entre as comunidades de macroinvertebrados nos 12 pontos amostrais; sendo um índice quantitativo, considera tanto a presença/ausência das espécies quanto suas densidades.

Todos esses dados foram convertidos em RTR (razão para referência) na qual as concentrações médias de cada métrica utilizada, de cada ponto amostral, foram divididas pelas médias dos mesmas métricas para o ponto de referência EG1. As RTRs para o Ib foram somadas e divididas pelo número de métricas analisados, assim obtivemos um valor de $\mathrm{Ib}$ para cada ponto amostral.

B) Índice Químico (Iq)

Para cada ponto amostral, o índice químico foi determinado de duas maneiras diferentes quanto ao cálculo das RTRs : 1) utilizando os seis metais avaliados, nitrogênio e fósforo totais, carbono orgânico total, sulfeto volatizável por acidificação, areia grossa, areia fina, silte e argila (versão 1); 2) as variáveis citadas em (1), excluindo areia grossa e areia fina (versão 2). A opção pela segunda versão deveu-se ao efeitoda maior concentração de areia grossa ou fina nos pontos EG2, EG3 e P1, situação muito diferente da encontrada no ponto referência que resultou em um peso muito grande das variáveis químicas na TQS para estes três pontos, simplesmente pela presença de areia.

C) Índice Toxicológico (It)

As porcentagens de efeito tóxico dos testes agudos foram transformadas em RTRs e assim em Índices toxicológicos. O teste crônico não entrou no índice, pois resultou em toxicidade aguda para praticamente todos os pontos amostrais. 
A partir de IB, Iq e It foi produzido um gráfico de 3 eixos no qual cada ponto amostral formou um triângulo com área específica, sabendo que quanto maior a área do ponto comparado ao do ponto referência, maior a deterioração do local. Os gráficos também foram interpretados de acordo com as possíveis situações descritas por Chapman (1992) (Anexo 2.7).

Ainda para a TQS, foi realizada uma Análise de Componentes Principais (ACP) para ordenar as variáveis físicas e químicas e os pontos amostrais e uma Análise de Correspondência Canônica (ACC) para ordenar pontos amostrais em relação às variáveis bióticas e abióticas. $\mathrm{O}$ teste de Monte-Carlo foi aplicado para avaliar a significância da ACC e análises de correlacão de Pearson foram realizadas a fim de correlacionar as variáveis utilizadas na ACP e na ACC. Ambas as análises foram implementadas pelo programa CANOCO (Legendre \& Legendre, 1998).

\subsection{Resultados}

O reservatório do Guarapiranga apresentou 35 taxa e suas respectivas densidades médias e desvios padrão, além de se sua presença ou ausência em cada ponto de amostragem, estão apresentadas no Anexo 2.2. A maior parte deles foi identificada até o nível de gênero, e em alguns casos até o nível de espécie. A maioria dos 28 gêneros identificados é representada por imaturos de insetos como Chironomidae (12 gêneros, com maior densidade para Chironomus), Odonata, Ephemeroptera, Ceratopogonidae e Chaoboridae. O filo Annelida apresentou as maiores densidades, representadas por hirudíneos (Placobdella), indivíduos da Subfamília Tubificinae (espécies L. hoffmeisteri (Cnf.) e Aulodrilus pigueti), e pela Subfamília Naidinae (Dero e Haemonais).

De acordo com a análise de agrupamento da fauna (Figura 2) observa-se que o ponto P1 é o mais dissimilar do reservatório $(0,2)$ seguido por EM1 $(\approx 0,6)$ e EG1 $(\approx 0,67)$. Três grupos com alta similaridade $(\approx 0,9)$, de acordo com a composição e densidade da fauna: 1) pontos G1, G2 e G3; 2) pontos EM3 e EG3; 3) pontos EM2, P2 e P3.

O Índice de Comunidade Bentônica para reservatórios-zona profundal, que utiliza riqueza e diversidade de taxa e as relaçõesTanytarsini/Chironomidae e densidade de tolerantes/densidade total (Tabela 1), indica que a região do corpo principal/barragem do reservatório apresentou qualidade regular. Os pontos amostrais P3 e EM3 apresentaram qualidade próxima à regular, enquanto a maioria dos pontos apresentou qualidade próxima à boa. O ponto EG1, justamente o ponto escolhido como referência na TQS, é o único que apresentou qualidade boa. Já o índice de enriquecimento orgânico escolhido neste trabalho baseia-se na densidade do grupo Oligochaeta, conhecido pela tolerância e dominância ao enriquecimento orgânico, assim os pontos com menor densidade de Oligochaeta foram o P2 e o EM2, classificados como em equilíbrio natural. Os pontos considerados com forte enriquecimento orgânico são os mais dissimilares de acordo com o Cluster, o P1, EM1 e EG1, além dos demais pontos no Embu-Guaçu, EG2 e EG3. Os pontos restantes tiveram enriquecimento moderado. 

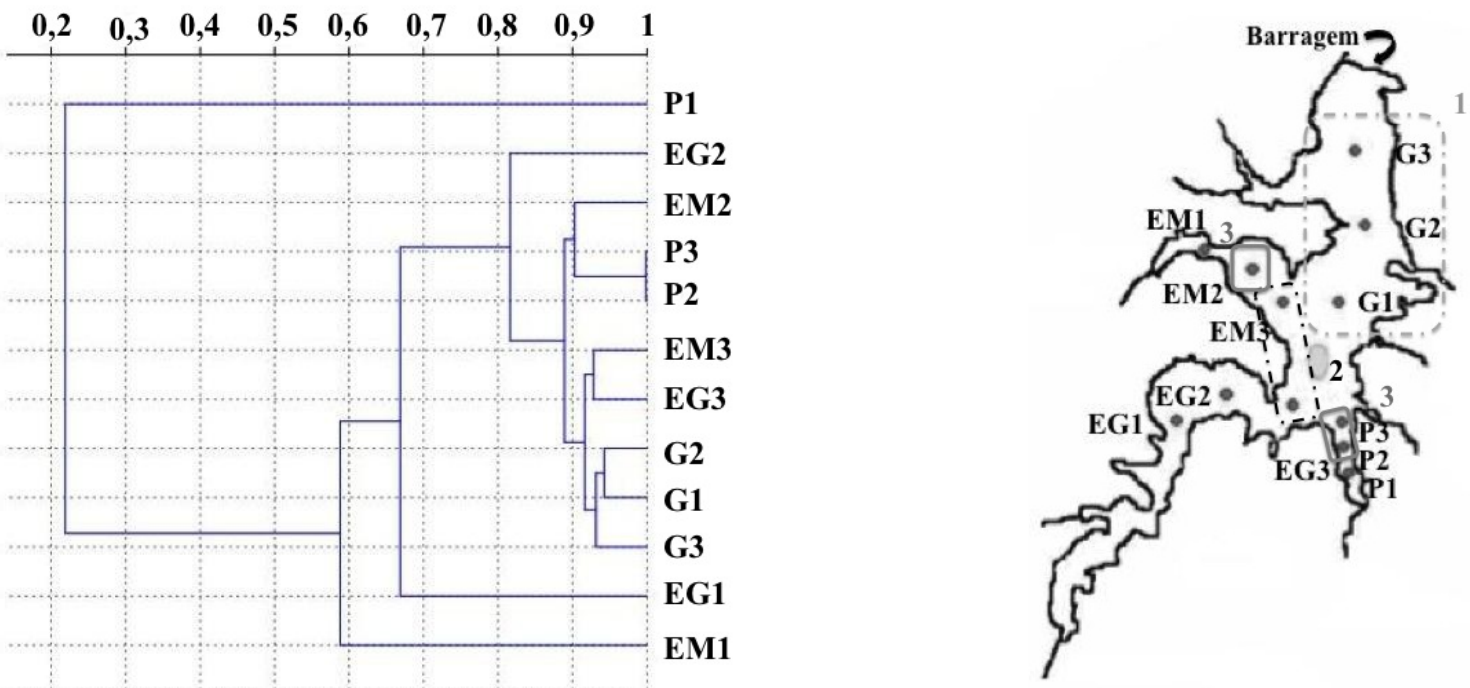

Figura 2. Dendrograma de análise de agrupamento (Cluster) para macroinvertebrados bentônicos utilizando o índice de similaridade de Morisita no reservatório Guarapiranga com grupos 1, 2 e 3 delineados no mapa.

Tabela 1. Índices calculados para a comunidade de macroinvertebrados bentônicos do reservatório Guarapiranga. (pont.) = pontuação do Índice de comunidade bentônica; (class.) = classificação; $\mathrm{S}=$ Riqueza; $\mathrm{D}_{2}=$ Dominância; $\mathrm{H}^{\prime}=$ diversidade; Tt/Chi = Tanytarsini/Chironomidae; T/DT = densidade de tolerantes/ densidade total dos taxa; $\mathrm{O} \mathrm{m}^{-2}=$ densidade de Oligochaeta; $\mathrm{ICB}_{\mathrm{RES}-\mathrm{P}}=$ índice de comunidade bentônica para região profundal de reservatórios.

\begin{tabular}{|c|c|c|c|c|c|c|c|c|c|c|c|c|c|}
\hline Pontos & $\mathbf{S}$ & $\begin{array}{c}\mathrm{S} \\
\text { (pont.) }\end{array}$ & $\mathbf{H}^{\prime}$ & $\begin{array}{c}\text { H'}^{\prime} \\
\text { (pont.) }\end{array}$ & Tt/Chi & $\begin{array}{l}\text { Tt/Chi } \\
\text { (pont.) }\end{array}$ & T/DT & $\begin{array}{c}\text { T/DT } \\
\text { (pont.) }\end{array}$ & $\begin{array}{c}\text { ICB }_{\text {RES- }} \\
\mathrm{P}\end{array}$ & $\begin{array}{c}\text { Diagnóstico da } \\
\text { qualidade ambiental }\end{array}$ & $\mathbf{D}_{2}$ & $\mathrm{O} \mathrm{m}^{-2}$ & $\begin{array}{c}\text { Enriquecimento } \\
\text { Orgânico }\end{array}$ \\
\hline P1 & 9 & 2 & 1,24 & 3 & 0 & 4 & 0,16 & 1 & 2,5 & Boa-Regular & 80,62 & 17740,74 & Forte \\
\hline $\mathbf{P 2}$ & 7 & 2 & 0,53 & 3 & 0 & 4 & 0,04 & 1 & 2,5 & Boa-Regular & 92,52 & 888,89 & $\begin{array}{l}\text { Equilíbrio } \\
\text { natural }\end{array}$ \\
\hline P3 & 9 & 2 & 0,45 & 4 & 0 & 4 & 0,01 & 1 & 2,75 & Próxima à Regular & 95,63 & 2696,30 & Moderado \\
\hline EG1 & 17 & 1 & 1,67 & 2 & 0,05 & 3 & 0,35 & 2 & 2 & Boa & 71,54 & 9325,93 & Forte \\
\hline EG2 & 17 & 1 & 1,19 & 3 & 0,04 & 3 & 0,67 & 3 & 2,5 & Boa-Regular & 83,27 & 17792,59 & Forte \\
\hline EG3 & 11 & 1 & 1,07 & 3 & 0 & 4 & 0,06 & 1 & 2,25 & Próxima à Boa & 91,26 & 6496,30 & Forte \\
\hline EM1 & 16 & 1 & 2,31 & 1 & 0 & 4 & 0,55 & 3 & 2,25 & Próxima à Boa & 38,53 & 6429,63 & Forte \\
\hline EM2 & 9 & 2 & 1,46 & 3 & 0 & 4 & 0,12 & 1 & 2,5 & Boa-Regular & 76,52 & 133,33 & $\begin{array}{l}\text { Equilíbrio } \\
\text { natural }\end{array}$ \\
\hline EM3 & 8 & 2 & 1,31 & 3 & 0 & 4 & 0,25 & 2 & 2,75 & Próxima à Regular & 71,79 & 3133,33 & Moderado \\
\hline G1 & 4 & 3 & 0,91 & 3 & 0 & 4 & 0,29 & 2 & 3 & Regular & 90,09 & 4681,48 & Moderado \\
\hline G2 & 4 & 3 & 1,38 & 3 & 0 & 4 & 0,40 & 2 & 3 & Regular & 78,01 & 1007,41 & Moderado \\
\hline G3 & 6 & 3 & 1,42 & 3 & 0 & 4 & 0,09 & 1 & 2,75 & Próxima à Regular & 78,41 & 1162,96 & Moderado \\
\hline
\end{tabular}

Nos bioensaios de toxicidade aguda variâncias significativas comparadas ao controle foram observadas no teste com C. xanthus para todos os pontos exceto EM2 e EG3, enquanto que para o teste com $D$. similis apenas nos pontos da região Embu-Guaçu não houve variação significativa (Tabela 2). O teste crônico com $C$. silvestri indicou toxicidade aguda para grande parte do reservatório, permitindo a reprodução dos organismos somente nos pontos EM1, EG1 e EG3.

Os resultados relativos aos parâmetros físicos e químicos do sedimento e da água de fundo são apresentados na Tabela 3. Maiores valores de metais e nutrientes foram observados na região do corpo principal/barragem, exatamente os pontos de maior profundidade, região denominada como zona de sedimentação. Já o teor de matéria orgânica, aqui representado como carbono orgânico total, mostrou-se alto em todos os 12 pontos de amostragem, com valores no mínimo 2 vezes acima de $10 \%$ de teor orgânico. As maiores concentrações de sulfeto no sedimento foram nos pontos EM2, P2 e EM1. A relação entre metais, sulfeto e carbono orgânico total indica toxicidade incerta para P3 e G3 e improvável para os pontos EG1, EG3, EM3, G1 e G2. Nos pontos P1, P2, EG2, EM1 e EM2 as concentrações de sulfeto ultrapassam as de metais indicando que não há biodisponibilidade de metais. O sedimento indicou o enriquecimento do reservatório por nutrientes, sendo que os níveis de nitrogênio $\left(4800 \mu \mathrm{gN} \mathrm{g}{ }^{-1}\right.$ sed) e fósforo total (2000 $\mathrm{MgP} \mathrm{g}^{-1}$ sed) naquele compartimento estão acima do nível permitido pelo CONAMA 344/2004 para a maior parte dos 
pontos analisados. Exceções s salvo P3 e todo o Embu-Guaçu para nitrogênio total e P1 e todo o Embu-Guaçu para fósforo total. Enquanto o potencial de oxi-redução dos sedimentos, o qual apresenta relação direta com o oxigênio, quanto mais anóxico o ambiente, mais reduzido se torna o sedimento, ou seja mais negativo e assim maior sua capacidade de ganhar elétrons. No reservatório do Guarapiranga o oxigênio dissolvido de fundo apresentou-se baixo na maioria dos pontos $(<3,5$ $\mathrm{mg} \mathrm{L}^{-1}$ ), mas não houve relação entre os níveis de oxigênio e o potencial de oxi-redução. Pontos na região Parelheiros apresentaram os menores valores de Eh, seguido dos pontos na região EmbuGuaçu. Os pontos da região do corpo principal/barragem, de maior profundidade e maiores concentrações de metais, nutrientes e teor de matéria orgânica, apresentaram-se os mais reduzidos do reservatório.

Tabela 2. Análises das variâncias entre as 12 amostras de sedimento do reservatório Guarapiranga comparadas ao tratamento controle dos testes agudos com larva de inseto e Cladocera. No. de ind. expostos $=$ número de indivíduos expostos; No. mortos $=$ número de indivíduos mortos no teste.

\begin{tabular}{|c|c|c|c|c|c|c|c|}
\hline \multicolumn{4}{|c|}{ Chironomus xanthus } & \multicolumn{4}{|c|}{ Daphnia similis } \\
\hline Amostras & $\begin{array}{l}\text { No. de } \\
\text { ind. } \\
\text { expostos }\end{array}$ & $\begin{array}{c}\text { No. } \\
\text { mortos }\end{array}$ & $\begin{array}{c}\text { Significância } \\
\text { p }<0,05\end{array}$ & Amostras & $\begin{array}{l}\text { No. de } \\
\text { ind. } \\
\text { expostos }\end{array}$ & $\begin{array}{c}\text { No. } \\
\text { mortos }\end{array}$ & $\begin{array}{c}\text { Significância } \\
\mathbf{p}<\mathbf{0 , 0 5}\end{array}$ \\
\hline Controle & 24 & 3 & & Controle & 20 & 3 & \\
\hline P1 & 24 & 12 & $*$ & P1 & 20 & 18 & $*$ \\
\hline Controle & 24 & 0 & & & & & \\
\hline P2 & 24 & 15 & $*$ & $\mathbf{P 2}$ & 20 & 20 & $*$ \\
\hline $\mathbf{P 3}$ & 24 & 13 & $*$ & $\mathbf{P 3}$ & 20 & 19 & $*$ \\
\hline EG1 & 24 & 11 & $*$ & EG1 & 20 & 2 & \\
\hline EG2 & 24 & 12 & $*$ & EG2 & 20 & 7 & \\
\hline Controle & 24 & 3 & & & & & \\
\hline EG3 & 24 & 8 & & EG3 & 20 & 7 & \\
\hline EM1 & 24 & 15 & $*$ & EM1 & 20 & 20 & $*$ \\
\hline EM2 & 24 & 7 & & EM2 & 20 & 20 & $*$ \\
\hline Controle & 24 & 0 & & & & & \\
\hline EM3 & 24 & 11 & $*$ & EM3 & 20 & 18 & $*$ \\
\hline G1 & 24 & 15 & $*$ & G1 & 20 & 20 & $*$ \\
\hline Controle & 24 & 3 & & & & & \\
\hline G2 & 24 & 19 & $*$ & G2 & 20 & 20 & $*$ \\
\hline G3 & 24 & 23 & $*$ & G3 & 20 & 20 & $*$ \\
\hline
\end{tabular}

Entre os metais o cobre foi o único que apresentou valores acima de PEL (Figura 3) para as regiões do corpo principal/barragem e Embu-Mirim e P3. A linha de tendência linear para cobre, com $\mathrm{R}^{2}$ de 0,78 e $\mathrm{p}<0,05$, indicou aumento de cobre sentido barragem (Figura $3 \mathrm{c}$ ). Para os demais metais, a maioria dos pontos apresentou concentrações acima do nível limiar (TEL) e dos valores de referência regionais (VRR). Foi observada uma linha de tendência de aumento de cádmio sentido barragem $\left(\mathrm{R}^{2}=0,73\right)$ (Figura $3 \mathrm{a}$ ). Tanto para níquel quanto para chumbo, a linha de tendência foi de $\mathrm{R}^{2}$ de 0,53 e 0,55 respectivamente, mas suas maiores concentrações no reservatório estão abaixo do valor de referência regional (Figuras 3d,f). Já para zinco não há tendência de aumento sentido barragem, mas suas maiores concentrações no reservatório, acima de TEL e VRR, estão nos pontos EG1 e EG2 (Figura 3e). 
Tabela 3. Médias, valores únicos dos parâmetros físicos e químicos utilizados, (desvios padrão) entre parênteses e Índice químico (Iq). Cd = cádmio

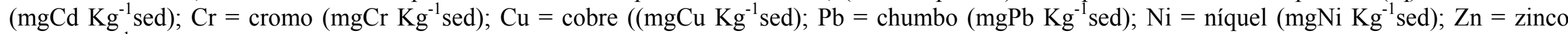
$\left(\mathrm{mgZn} \mathrm{Kg}{ }^{-1} \mathrm{sed}\right) ; \mathrm{COT}=$ carbono orgânico total $(\mathrm{mmol}) ; \mathrm{AG}=$ areia grossa $(\%)$; AF = areia fina (\%); Sil = silte (\%); Arg = argila (\%); SVA= sulfeto volatizável por acidificação ( $\left.\mathrm{mgSulfeto} \mathrm{Kg}^{-1} \mathrm{sed}\right) ;\left(\sum\right.$ metais]-[SVA])/COT = concentrações de metais normalizados pelo SVA e pelo COT (mmol $\left.\mathrm{Kg}^{-1}\right)$; $\mathrm{NKT}=$ nitrogênio Kjedahl total $\left(\mu \mathrm{gN} \mathrm{g}{ }^{-1}\right.$ sed $) ; \mathrm{PT}=$ fósforo total $\left(\mu \mathrm{gP} \mathrm{g}^{-1}\right.$ sed $) ; \mathrm{Z}=$ profundidade $(\mathrm{m}) ; \mathrm{pH}=$ potencial hidrogeniônico (log); $\mathrm{K}=$ condutividade $\left(\mu \mathrm{S} \mathrm{cm}^{-1}\right) ; \mathrm{T}=$ temperatura $\left({ }^{\circ} \mathrm{C}\right) ; \mathrm{Eh}=$ potencial de oxi-redução $(\mathrm{mV}) ; \mathrm{OD}=$ oxigênio dissolvido $\left(\mathrm{mg} \mathrm{L}^{-1}\right)$.

\begin{tabular}{|c|c|c|c|c|c|c|c|c|c|c|c|c|}
\hline $\begin{array}{l}\text { Pontos/Parâmetros } \\
\text { Físicos e Químicos }\end{array}$ & P1 & P2 & P3 & EG1 & EG2 & EG3 & EM1 & EM2 & EM3 & G1 & G2 & G3 \\
\hline Cd & $\begin{array}{l}0,63 \\
(0,02)\end{array}$ & $\begin{array}{c}1,14 \\
(0,01)\end{array}$ & $\begin{array}{c}1,43 \\
(0,02)\end{array}$ & $\begin{array}{c}0,81 \\
(0,04)\end{array}$ & $\begin{array}{c}1,08 \\
(0,01)\end{array}$ & $\begin{array}{c}1,43 \\
(0,00)\end{array}$ & $\begin{array}{c}1,08 \\
(0,01)\end{array}$ & $\begin{array}{c}1,42 \\
(0,01)\end{array}$ & $\begin{array}{c}1,71 \\
(0,07)\end{array}$ & $\begin{array}{c}1,62 \\
(0,03)\end{array}$ & $\begin{array}{c}2,02 \\
(0,02)\end{array}$ & $\begin{array}{c}2,03 \\
(0,08)\end{array}$ \\
\hline $\mathrm{Cr}$ & $\begin{array}{l}44,60 \\
(0,73)\end{array}$ & $\begin{array}{l}52,07 \\
(2,70)\end{array}$ & $\begin{array}{l}58,19 \\
(0,98)\end{array}$ & $\begin{array}{l}54,81 \\
(0,83)\end{array}$ & $\begin{array}{l}51,03 \\
(1,87)\end{array}$ & $\begin{array}{l}52,30 \\
(2,63)\end{array}$ & $\begin{array}{l}32,20 \\
(1,09)\end{array}$ & $\begin{array}{l}37,06 \\
(0,17)\end{array}$ & $\begin{array}{l}42,37 \\
(3,83)\end{array}$ & $\begin{array}{l}44,08 \\
(4,84)\end{array}$ & $\begin{array}{l}57,80 \\
(0,94)\end{array}$ & $\begin{array}{l}49,36 \\
(0,94)\end{array}$ \\
\hline $\mathrm{Cu}$ & $\begin{array}{l}55,84 \\
(1,25)\end{array}$ & $\begin{array}{l}230,64 \\
(0,33)\end{array}$ & $\begin{array}{l}445,14 \\
(11,29)\end{array}$ & $\begin{array}{l}22,86 \\
(0,71)\end{array}$ & $\begin{array}{l}28,21 \\
(0,02)\end{array}$ & $\begin{array}{r}200,57 \\
(1,15)\end{array}$ & $\begin{array}{l}137,88 \\
(0,47)\end{array}$ & $\begin{array}{l}904,73 \\
(50,62)\end{array}$ & $\begin{array}{l}1243,25 \\
(42,02)\end{array}$ & $\begin{array}{l}1586,94 \\
(53,54)\end{array}$ & $\begin{array}{l}1674,58 \\
(22,97)\end{array}$ & $\begin{array}{r}2785,49 \\
(41,97)\end{array}$ \\
\hline $\mathbf{N i}$ & $\begin{array}{l}12,70 \\
(0,49)\end{array}$ & $\begin{array}{l}19,86 \\
(2,92)\end{array}$ & $\begin{array}{l}21,53 \\
(0,86)\end{array}$ & $\begin{array}{l}15,56 \\
(0,52)\end{array}$ & $\begin{array}{l}13,81 \\
(1,82)\end{array}$ & $\begin{array}{l}16,76 \\
(1,15)\end{array}$ & $\begin{array}{l}11,78 \\
(1,20)\end{array}$ & $\begin{array}{l}16,97 \\
(0,13)\end{array}$ & $\begin{array}{l}18,85 \\
(1,55)\end{array}$ & $\begin{array}{l}17,37 \\
(2,48)\end{array}$ & $\begin{array}{l}23,69 \\
(1,00)\end{array}$ & $\begin{array}{l}24,78 \\
(0,11)\end{array}$ \\
\hline $\mathbf{P b}$ & $\begin{array}{l}28,02 \\
(0,74)\end{array}$ & $\begin{array}{l}30,00 \\
(1,75)\end{array}$ & $\begin{array}{l}35,73 \\
(0,32)\end{array}$ & $\begin{array}{l}25,73 \\
(0,02)\end{array}$ & $\begin{array}{l}24,07 \\
(0,67)\end{array}$ & $\begin{array}{l}28,47 \\
(0,64)\end{array}$ & $\begin{array}{l}38,45 \\
(1,81)\end{array}$ & $\begin{array}{l}37,00 \\
(0,83)\end{array}$ & $\begin{array}{l}38,65 \\
(1,33)\end{array}$ & $\begin{array}{l}29,99 \\
(1,71)\end{array}$ & $\begin{array}{l}43,24 \\
(1,23)\end{array}$ & $\begin{array}{l}41,59 \\
(1,10)\end{array}$ \\
\hline Zn & $\begin{array}{l}58,24 \\
(0,33)\end{array}$ & $\begin{array}{l}121,76 \\
(4,38)\end{array}$ & $\begin{array}{l}116,05 \\
(3,90)\end{array}$ & $\begin{array}{r}200,89 \\
(1,30)\end{array}$ & $\begin{array}{l}190,06 \\
(0,08)\end{array}$ & $\begin{array}{l}123,44 \\
(0,94)\end{array}$ & $\begin{array}{l}117,13 \\
(0,21)\end{array}$ & $\begin{array}{l}110,82 \\
(3,44)\end{array}$ & $\begin{array}{l}102,94 \\
(1,48)\end{array}$ & $\begin{array}{l}99,11 \\
(6,05)\end{array}$ & $\begin{array}{l}153,41 \\
(2,18)\end{array}$ & $\begin{array}{l}149,47 \\
(4,49)\end{array}$ \\
\hline COT & 0,05 & 0,12 & 0,07 & 0,09 & 0,08 & 0,10 & 0,07 & 0,09 & 0,07 & 0,13 & 0,09 & 0,09 \\
\hline $\mathbf{A G}$ & 0,52 & 0,96 & 9,29 & 0,07 & 3,90 & 50,21 & 0,13 & 1,98 & 0,63 & 5,05 & 0,98 & 0,72 \\
\hline $\mathbf{A F}$ & 19,36 & 4,55 & 1,83 & 0,07 & 1,37 & 6,98 & 0,96 & 4,73 & 1,53 & 1,03 & 0,28 & 0,78 \\
\hline Arg & 3,86 & 9,17 & 4,52 & 5,78 & 17,41 & 9,13 & 3,50 & 2,26 & 0,63 & 29,69 & 13,81 & 4,17 \\
\hline Sil & 76,26 & 85,33 & 84,36 & 94,08 & 77,31 & 33,68 & 95,41 & 91,04 & 97,21 & 64,23 & 84,93 & 94,34 \\
\hline SVA & $\begin{array}{c}497,29 \\
(2,30)\end{array}$ & $\begin{array}{l}1380,25 \\
(293,58)\end{array}$ & $\begin{array}{c}32,37 \\
(13,45)\end{array}$ & $\begin{array}{c}32,27 \\
(13,02)\end{array}$ & $\begin{array}{c}226,21 \\
(13,57)\end{array}$ & $\begin{array}{l}142,58 \\
(20,96)\end{array}$ & $\begin{array}{c}1096,88 \\
(374,22)\end{array}$ & $\begin{array}{l}2362,44 \\
(537,35)\end{array}$ & $\begin{array}{l}688,53 \\
(20,62)\end{array}$ & $\begin{array}{c}578,73 \\
(141,87)\end{array}$ & $\begin{array}{c}853,80 \\
(161,38)\end{array}$ & $\begin{array}{c}731,48 \\
(49,26)\end{array}$ \\
\hline 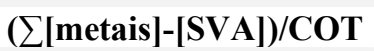 & $-233,11$ & $-298,62$ & 147,54 & 59,58 & $-14,34$ & 33,79 & $-412,46$ & $-628,49$ & 26,40 & 81,27 & 58,97 & 305,76 \\
\hline NKT & 5009,06 & $\begin{array}{l}6282,20 \\
(408,44)\end{array}$ & $\begin{array}{l}4637,86 \\
(131,15)\end{array}$ & 3000,83 & $\begin{array}{l}3031,57 \\
(438,93)\end{array}$ & $\begin{array}{l}4019,13 \\
(494,34)\end{array}$ & $\begin{array}{l}4883,17 \\
(197,79)\end{array}$ & $\begin{array}{c}6465,85 \\
(202,61)\end{array}$ & $\begin{array}{c}6914,21 \\
(116,83)\end{array}$ & $\begin{array}{c}5331,33 \\
(80,82)\end{array}$ & $\begin{array}{c}6299,39 \\
(87,69)\end{array}$ & 7660,56 \\
\hline PT & $\begin{array}{c}1541,99 \\
(5,74)\end{array}$ & $\begin{array}{c}2649,93 \\
(23,10)\end{array}$ & $\begin{array}{c}2627,45 \\
(74,57)\end{array}$ & $\begin{array}{l}928,57 \\
(51,88)\end{array}$ & $\begin{array}{l}773,12 \\
(34,38)\end{array}$ & $\begin{array}{c}1376,17 \\
(5,73)\end{array}$ & $\begin{array}{c}2171,09 \\
(28,44)\end{array}$ & $\begin{array}{c}3820,94 \\
(28,57)\end{array}$ & $\begin{array}{r}3083,17 \\
(11,43)\end{array}$ & $\begin{array}{c}3289,98 \\
(11,36)\end{array}$ & $\begin{array}{c}3226,43 \\
(73,98)\end{array}$ & $\begin{array}{r}3423,99 \\
(22,82)\end{array}$ \\
\hline $\mathbf{Z}$ & 2,17 & 3,85 & 5,06 & 4,14 & 5,34 & 7,24 & 3,35 & 5,25 & 6,32 & 8,83 & 10,90 & 11,00 \\
\hline pH & 6,59 & 6,44 & 6,67 & 6,56 & 6,49 & 6,49 & 6,61 & 6,50 & 6,63 & 6,78 & 6,68 & 6,89 \\
\hline $\mathbf{K}$ & 153,00 & 138,00 & 106,00 & 49,00 & 119,00 & 96,00 & 228,00 & 183,00 & 139,00 & 139,00 & 175,00 & 178,00 \\
\hline Temp & 19,26 & 18,53 & 18,51 & 17,08 & 18,05 & 18,02 & 19,34 & 18,27 & 18,50 & 18,63 & 19,13 & 19,66 \\
\hline Eh & -18 & -49 & -99 & -63 & -99 & -99 & -130 & -146 & -140 & -198 & -123 & -134 \\
\hline OD & 1,78 & 1,42 & 2,14 & 3,20 & 3,38 & 1,42 & 1,42 & 0,89 & 2,31 & 6,24 & 2,49 & 1,42 \\
\hline
\end{tabular}

* os metais aqui estão representados em $\mathrm{mgMetal} \mathrm{Kg}^{-1} \mathrm{sed}$, mas para o cálculo do SVA normalizado, assim chamado aqui, deve-se converter suas concentrações para mmol Kg ${ }^{-1}$ 
a)

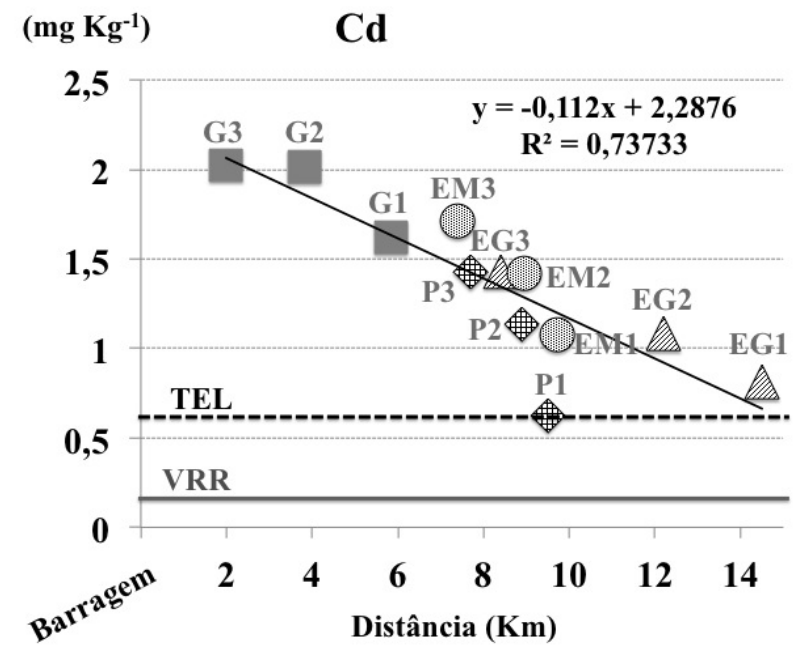

c)

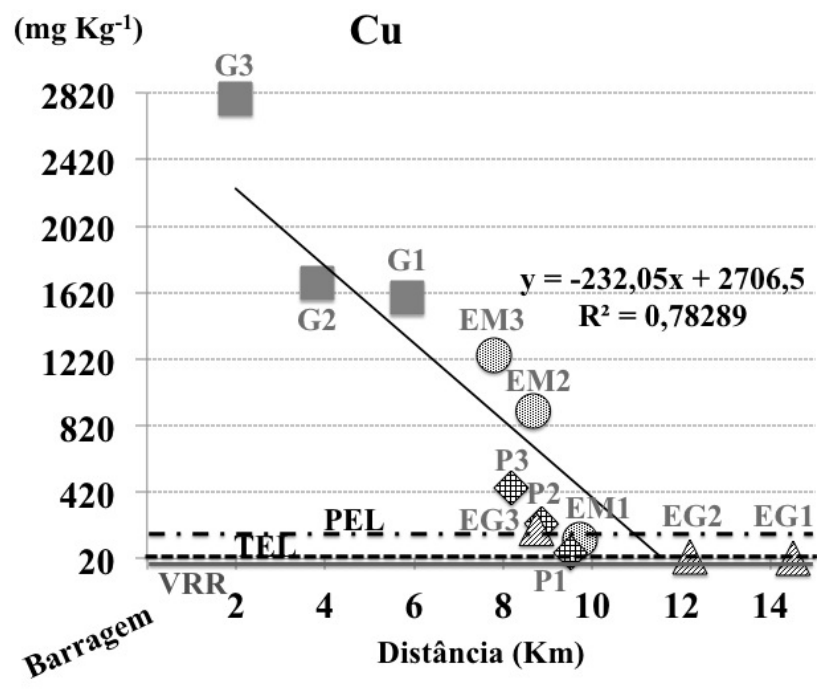

e)

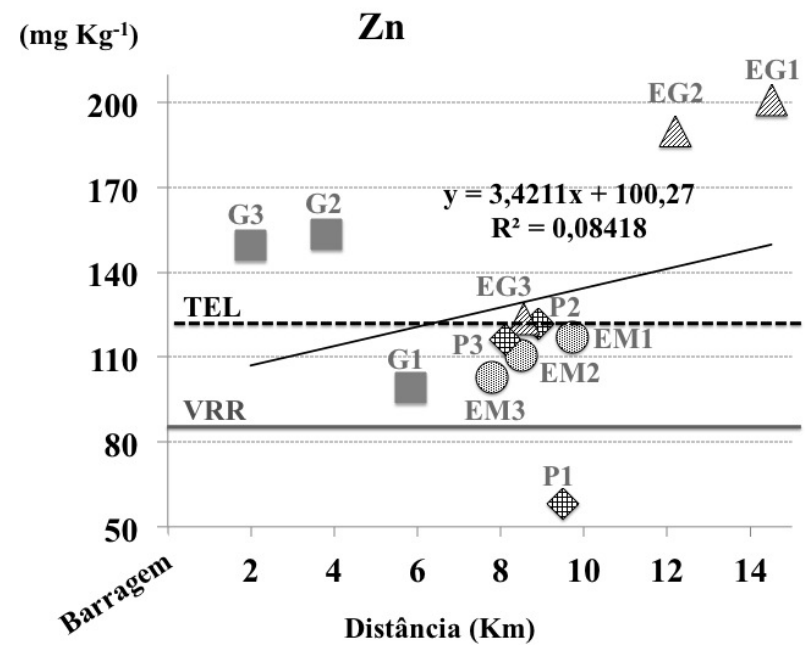

b)

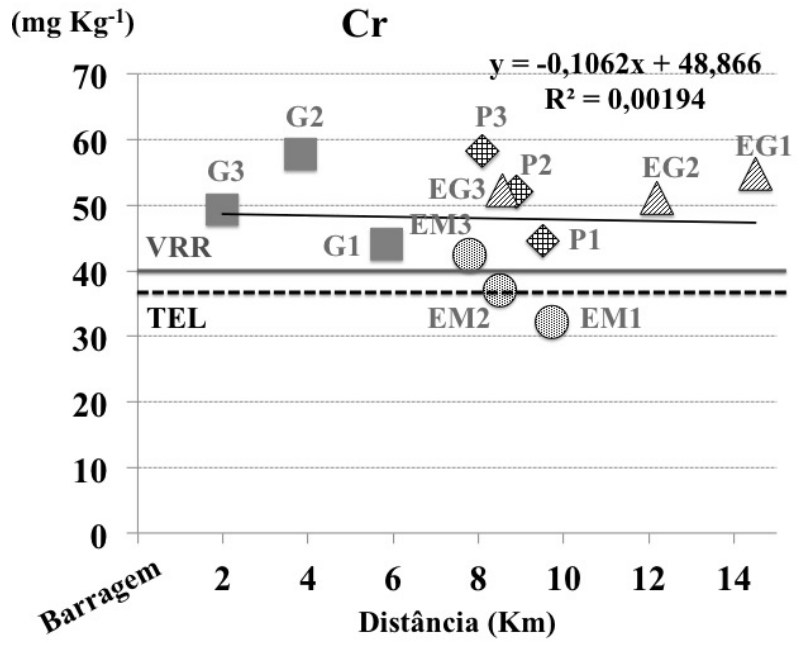

d)

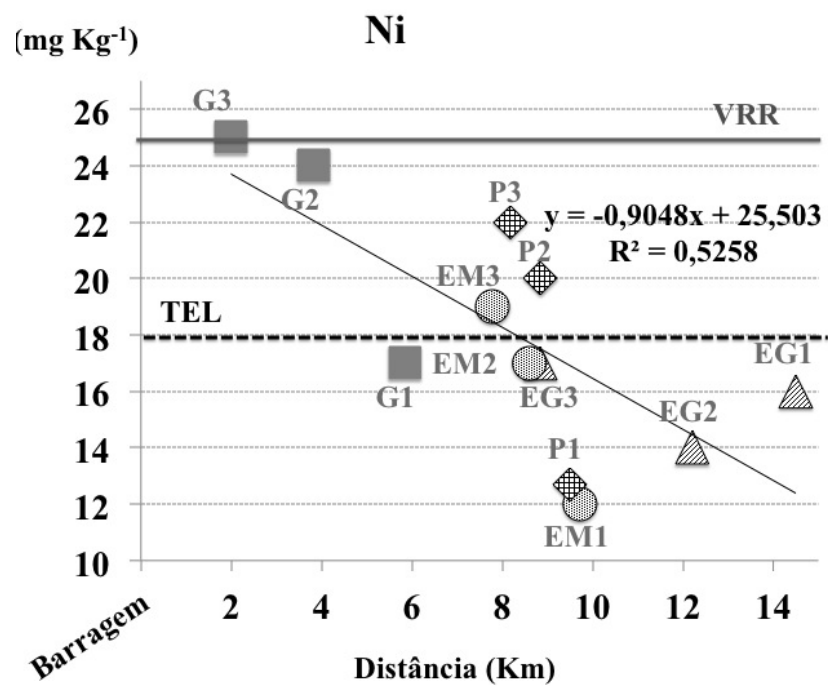

f)

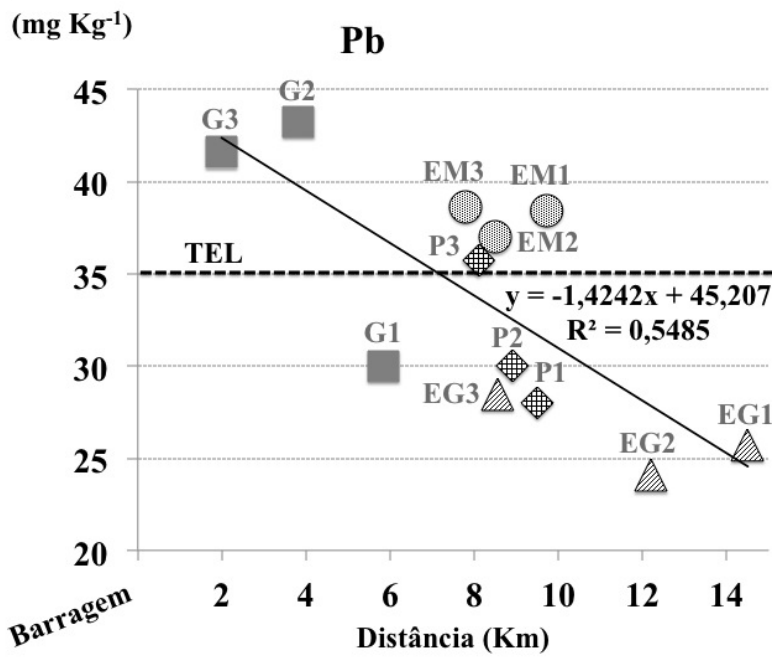

Figura 3. Gráficos das concentrações em $\mathrm{mg} \mathrm{Kg}^{-1}$ dos 6 metais analisados nos sedimentos e as equações lineares de cada metal ao longo do reservatório do Guarapiranga. a) $\mathrm{Cd}=$ cádmio; b) $\mathrm{Cr}=$ cromo; c) $\mathrm{Cu}=$ cobre; d) $\mathrm{Ni}=$ níquel; e) $\mathrm{Zn}=$ zinco; f) $\mathrm{Pb}=$ chumbo; Onde: $\mathrm{PEL}=$ nível de efeito provável; TEL = nível de efeito limiar; VRR = valor de referencia regional. 
De acordo com a ACP (Figura 4a), o primeiro eixo explica 35,9\% da variação das variáveis físicas e químicas e representa os metais cádmio, cobre e chumbo, além de nitrogênio e fósforo totais e condutividade elétrica (Figura 4c). O segundo eixo explica 21,9\% da variação e é representado pela profundidade (Figura 4c). Correlações positivas com o eixo 2 foram observadas para $\mathrm{pH}$, potencial de oxi-redução, carbono orgânico total, oxigênio dissolvido, argila e areia grossa, além dos metais níquel, cromo e zinco (Tabela 4).

a)

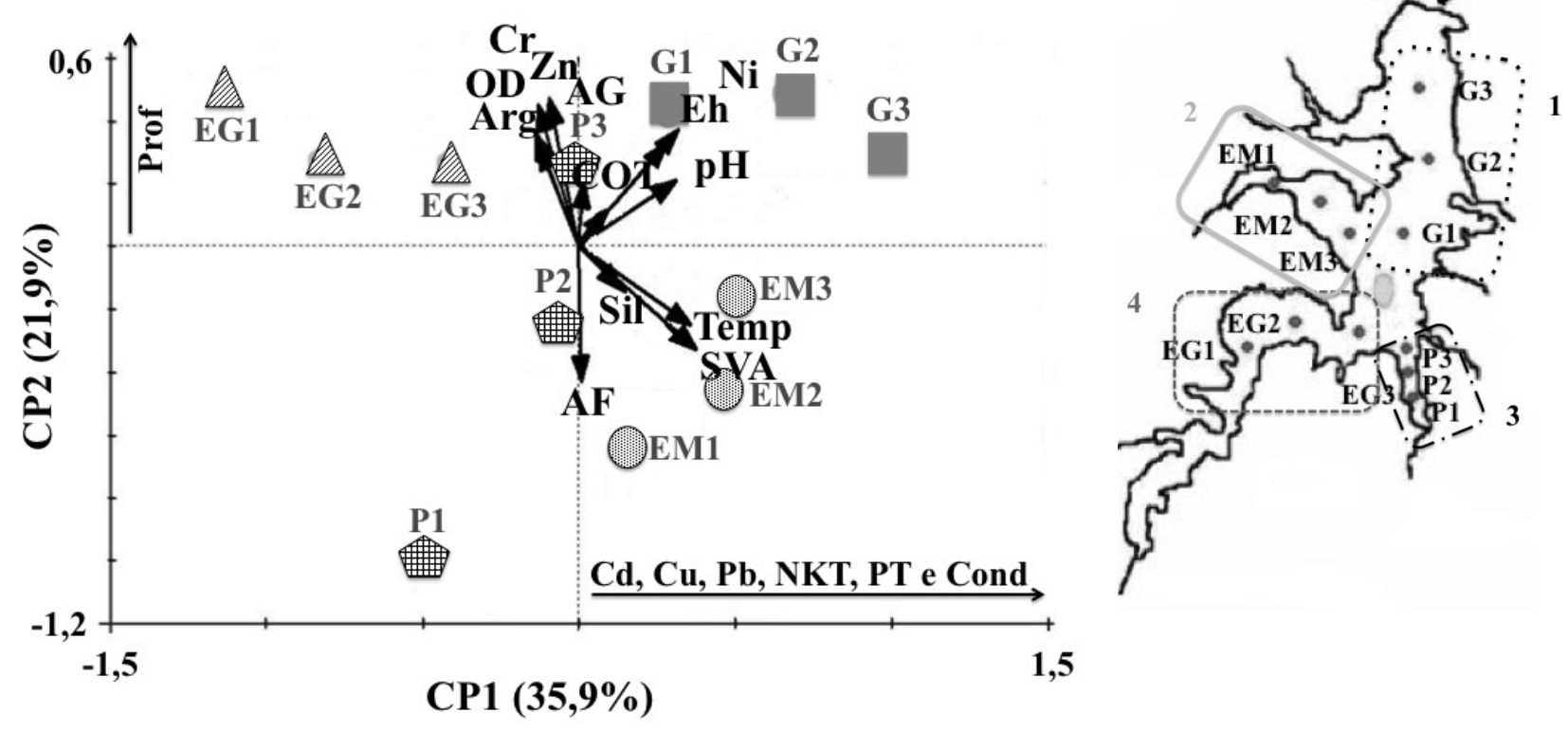

b)

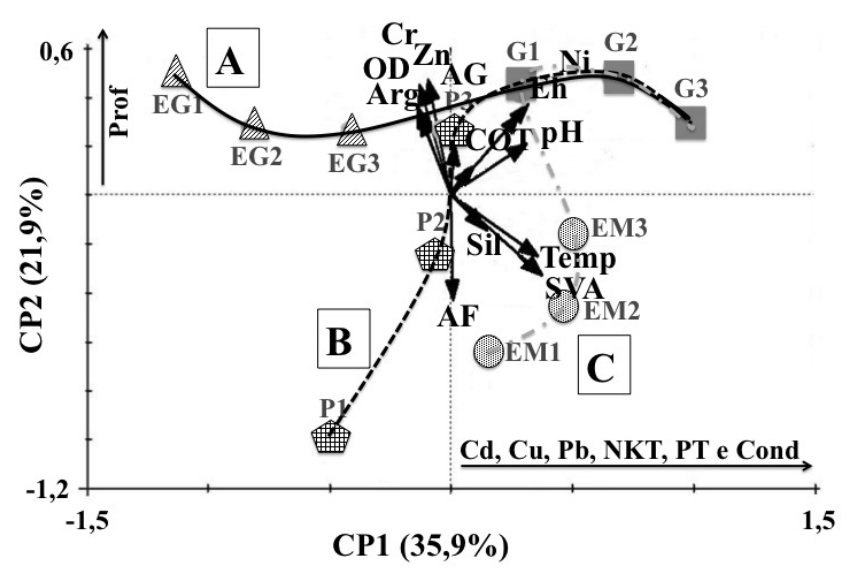

c)

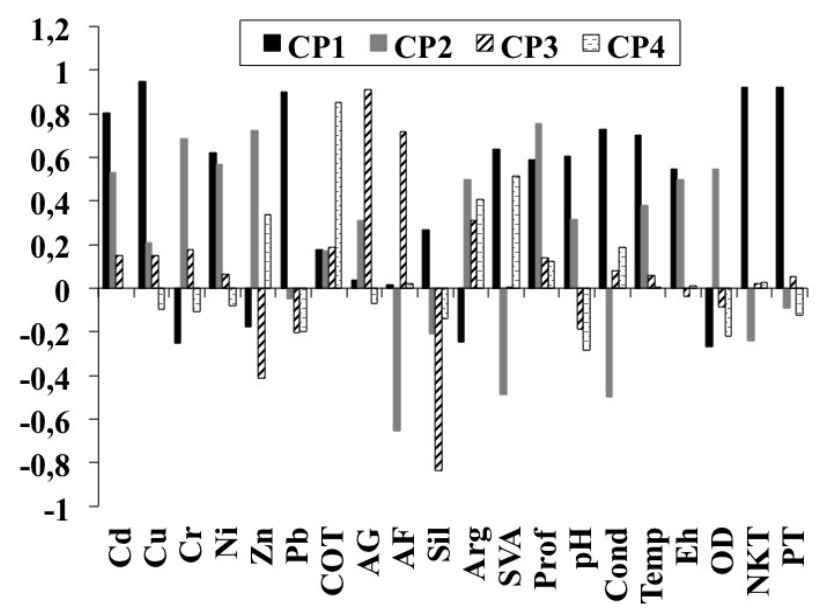

Figura 4. a) Análise de Componentes Principais (ACP) para ordenar os pontos amostrais e as variáveis físicas e químicas do sedimento e figura do reservatório Guarapiranga com as regiões 1, 2, 3 e 4 delineadas. b) Representação dos fluxos de água e sedimento a partir da desembocadura dos três principais tributários do Guarapiranga, onde $[\mathrm{A}]=$ sentido Embu-Guaçu - barragem; [B]= sentido Parelheiros - barragem; $[\mathrm{C}]=$ sentido Embu-Mirim - barragem; c) Autovetores das correlações das variáveis utilizadas na $\mathrm{ACP}$; Onde: $\mathrm{CP} 1=$ componente principal 1 ; $\mathrm{CP} 2=$ componente principal 2; $\mathrm{CP} 3=$ componente principal 3; $\mathrm{CP} 4=$ componente principal 4; Círculo $=$ EM; Quadrado = G; Triângulo = EG e Pentágono = Parelheiros. Eh = potencial de oxi-redução; Cond $=$ condutividade elétrica; Temp $=$ temperatura; NKT $=$ nitrogênio Kjedhal total; PT = fósforo total; Prof = profundidade; $\mathrm{SVA}=$ sulfeto volatizável por acidificação; $\mathrm{COT}=$ carbono orgânico total; $\mathrm{OD}=$ oxigênio dissolvido; $\mathrm{AG}=$ areia grossa; $\mathrm{AF}=$ areia fina; Sil = silte; $\mathrm{Arg}=$ argila; $\mathrm{Pb}=$ chumbo; $\mathrm{Cu}=$ cobre; $\mathrm{Cd}=$ cádmio; $\mathrm{Ni}=$ níquel; $\mathrm{Cr}=$ cromo; $\mathrm{Zn}=$ zinco. 
As regiões do corpo principal-barragem e Embu-Guaçu mostraram-se as mais profundas, sendo que o corpo principal está mais relacionado ao teor de carbono orgânico total, potencial de oxi-redução, pH e níquel, enquanto a região Embu-Guaçu está mais relacionada a areia grossa e argila, ao oxigênio dissolvido e aos metais cromo e zinco. Já as regiões Parelheiros e Embu-Mirim se relacionaram negativamente à $\mathrm{CP} 2$, sendo que o Embu-Mirim mostrou relação com sulfeto, temperatura e silte. Os pontos $\mathrm{P} 1$ e $\mathrm{P} 2$ relacionaram-se à porcentagem de areia fina no sedimento, enquanto P3 está mais relacionado à areia grossa. Observa-se ainda a formação de 4 grupos de sedimento de acordo com as variáveis físicas e químicas: (1) o corpo principal do reservatório (pontos G1, G2 e G3); (2) pontos EM1, EM2 e EM3; (3) pontos P1, P2 e P3 e (4) pontos EG1, EG2 e EG3. Três fluxos ainda podem ser observados na figura $4 \mathrm{~b}$, cada um com início na desembocadura de um tributário, sentido barragem, chamados aqui de fluxos A (Embu-GuaçuBarragem), B (Parelheiros-Barragem) e C (Embu-Mirim-Barragem).

Tabela 4. Matriz de correlação da Análise de Componentes Principais (ACP). Onde: Eh = potencial de oxi-redução; Cond= condutividade elétrica; Temp = temperatura; NKT $=$ nitrogênio Kjedhal total; $\mathrm{PT}=$ fósforo total; Prof = profundidade; $\mathrm{SVA}=$ sulfeto volatizável por acidificação; COT = carbono orgânico total; $\mathrm{OD}=$ oxigênio dissolvido; $\mathrm{AG}=$ areia grossa; $\mathrm{AF}=$ areia fina; Sil = silte; $\mathrm{Arg}=$ argila $; \mathrm{Pb}=$ chumbo $\mathrm{Cu}=$ cobre $\mathrm{Cd}=$ cádmio; $\mathrm{Ni}=$ níquel $; \mathrm{Cr}=$ cromo; $\mathrm{Zn}=$ zinco.

\begin{tabular}{lrrrr}
\hline \multicolumn{5}{c}{ Matriz de correlação ACP } \\
\hline Cd & \multicolumn{1}{c}{ CP1 } & \multicolumn{1}{c}{ CP 2 } & \multicolumn{1}{c}{ CP3 } & \multicolumn{1}{c}{ CP4 } \\
Cu & 0,9454 & 0,5271 & 0,1511 & 0 \\
Cr & $-0,2519$ & 0,6832 & 0,1501 & $-0,0968$ \\
Ni & 0,619 & 0,5681 & 0,06427 & $-0,08207$ \\
Zn & $-0,17778$ & 0,7198 & $-0,411$ & 0,3361 \\
Pb & 0,8973 & $-0,04744$ & $-0,2032$ & $-0,1982$ \\
COT & 0,176 & 0,1721 & 0,1853 & 0,8516 \\
AG & 0,03491 & 0,3118 & 0,9122 & $-0,06814$ \\
AF & 0,01558 & $-0,6525$ & 0,7173 & 0,02362 \\
Sil & 0,2661 & $-0,2069$ & $-0,8328$ & $-0,1374$ \\
Arg & $-0,2485$ & 0,4962 & 0,311 & 0,404 \\
SVA & 0,635 & $-0,4887$ & 0,001518 & 0,5135 \\
Prof & 0,5861 & 0,7556 & 0,1401 & 0,1238 \\
pH & 0,607 & 0,3156 & $-0,185$ & $-0,2848$ \\
K & 0,7302 & $-0,4974$ & 0,0802 & 0,189 \\
Temp & 0,6984 & 0,3811 & 0,05734 & 0,002173 \\
Eh & 0,5477 & 0,5001 & $-0,039$ & 0,0114 \\
OD & $-0,2658$ & 0,5458 & $-0,08742$ & $-0,2188$ \\
NKT & 0,9181 & $-0,2414$ & 0,02155 & 0,02821 \\
PT & 0,9229 & $-0,09167$ & 0,05075 & $-0,1236$ \\
\hline
\end{tabular}

Com relação à estrutura da comunidade, observa-se uma diminuição de Oligochaeta desde Embu-Guaçu até o G1, seguida por aumento na representatividade em G2 e G3 (Figura 5a). L. hoffmeisteri domina no corpo principal-barragem $(>70 \%)$ e divide a dominância com Aulodrilus pigueti em Embu-Guaçu (Figura 5b). No sentido Parelheiros-Barragem observou-se diminuição de Oligochaeta, de mais de $80 \%$ no ponto $\mathrm{P} 1$ para $5 \%$ no $\mathrm{P} 3$, com aumento sentido barragem chegando a $60 \%$ no G3 (Figura 5c). Haemonais waldvogeli e Aulodrilus pigueti apresentaram em torno de $80 \%$ no P1 e P3 respectivamente (Figura 5d). Na região Embu-Mirim ocorreu variação na representatividade dos grupos sentido barragem (Figura 5e). O ponto EM1 apresentou quase 90\% de Oligochaeta, o EM2 menos de 20\% e o EM3 pouco mais de 50\%. Com relação aos Oligochaeta, não houve gêneros dominantes em EM1 e EM2, havendo distribuição mais equilibrada de Dero, Haemonais, Opistocysta, Limnodrilus e Aulodrilus (Figura 5f). 
a)

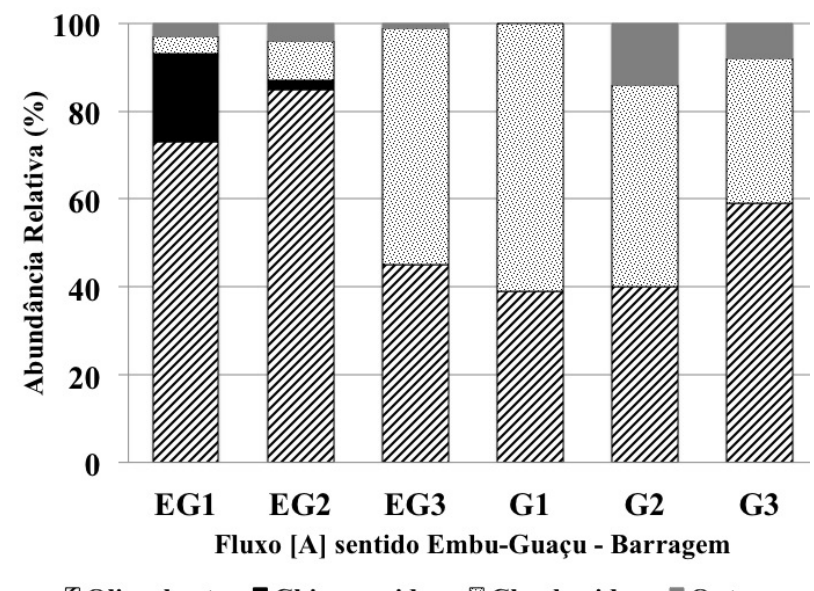

c)

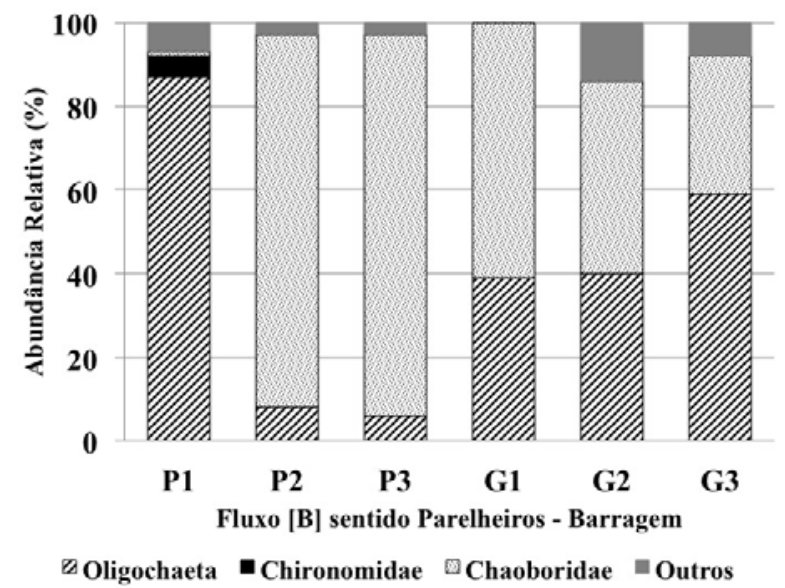

e)

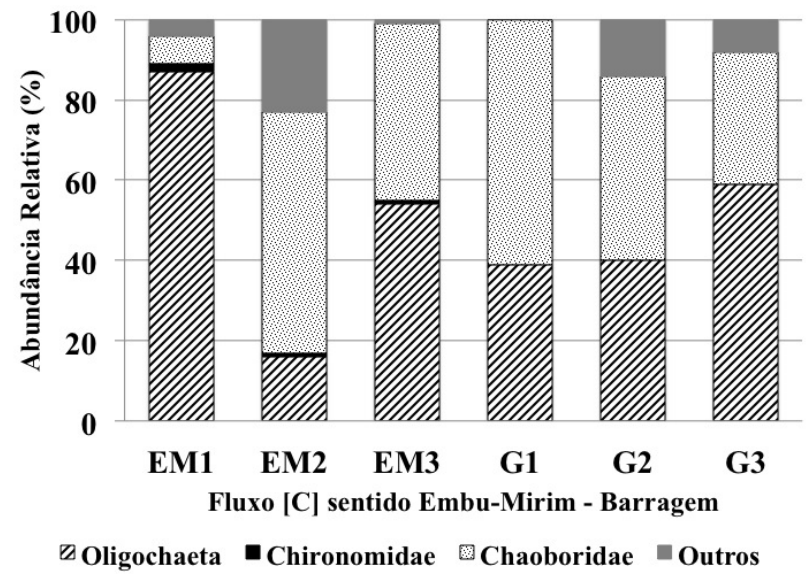

b)

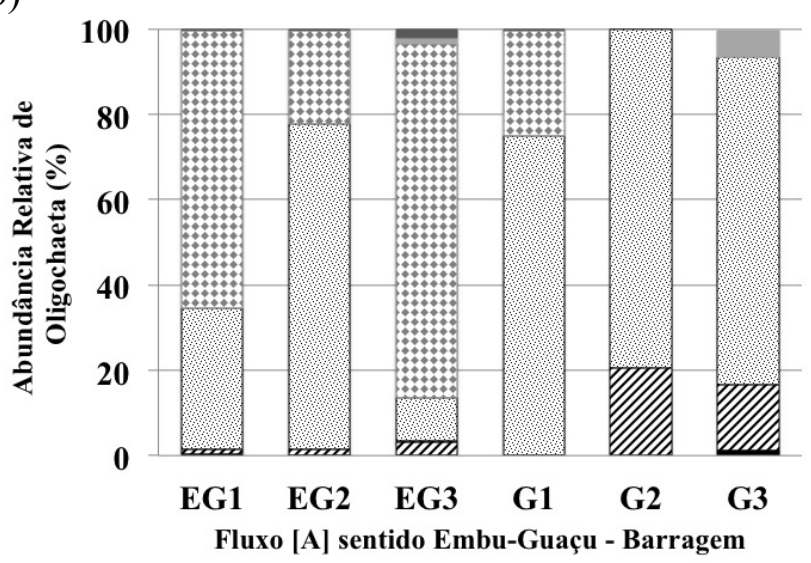

Opistocysta Dero Haemonais Limnodrlus

Aulodrilus Branchiura $\square$ Outros

d)

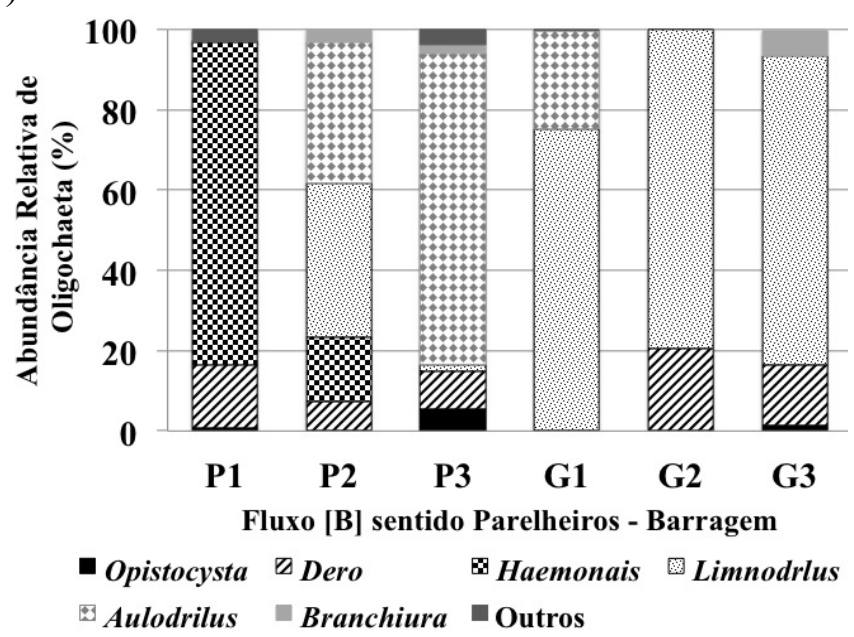

f)

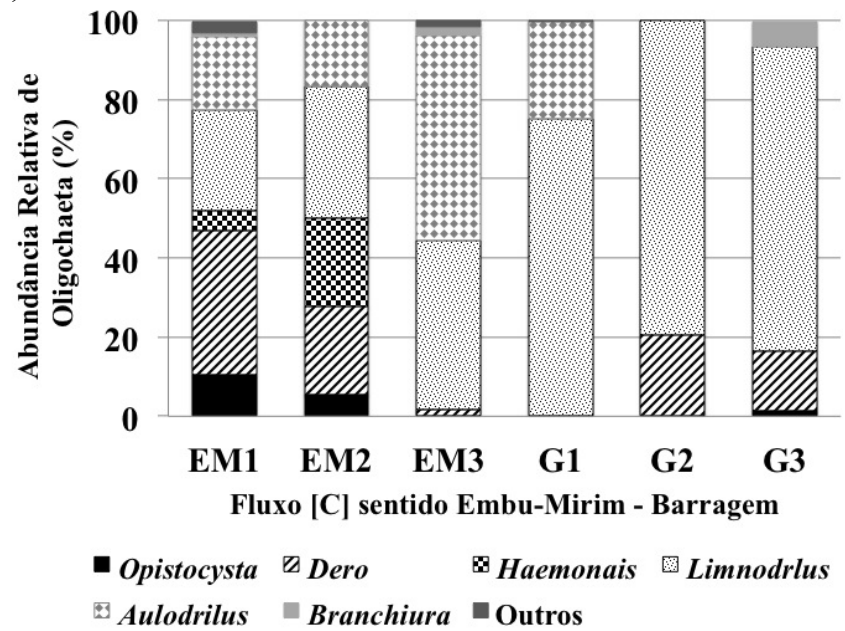

Figura 5. Abundâncias relativas (\%) dos principais taxa de macroinvertebrados bentônicos nos 12 pontos amostrais do reservatório Guarapiranga. a) Taxa de Embu-Guaçu e Guarapiranga representando o fluxo [A] observado na ACP; b) Gêneros de Oligochaeta de Embu-Guaçu e Guarapiranga representando o fluxo [A] observado na ACP; c) Taxa de Parelheiros e Guarapiranga representando o fluxo [B] observado na ACP; d) Gêneros de Oligochaeta de Parelheiros e Guarapiranga representando o fluxo [B] observado na ACP; e) Taxa de Embu-Mirim e Guarapiranga representando o fluxo [C] observado na ACP; f) Gêneros de Oligochaeta de EmbuMirim e Guarapiranga representando o fluxo [C] observado na ACP. 
O teste de Monte-Carlo mostrou significância de $0,01 \quad(\mathrm{~F}=1,87)$ para a Análise de Correspondência Canônica. Nesta análise de ordenação, as variáveis ambientais explicam 76,4\% da variabilidade dos dados, $50,3 \%$ é explicada pelo eixo 1 e $24,8 \%$ pelo eixo 2 (Figura 6). A região corpo principal-barragem se relacionou mais à concentração de cobre, carbono orgânico total, $\mathrm{pH}$ e presença do gênero Chaoborus (Figura $6 \mathrm{~b}$ e Tabela 5). Já a região do Embu-Mirim se relacionou mais à quantidade de sulfeto e silte no sedimento e à presença de Nematoda e do Oligochaeta Branchiura sowerbyi. Enquanto a região Embu-Guaçu relaciona-se com a concentração de zinco no sedimento, além da presença do Odonata Hexagenia e dos Oligochaeta Dero, Aulodrilus pigueti, Opistocysta e L. hoffmeisteri. A região do Parelheiros relacionou-se com Chaoborus, Chironomidae e Nematoda. A correlação de Pearson mostrou correlação direta entre Dero e Opistocysta $(r=0,73)$, e inversa entre Chironomus e as variáveis nitrogênio total $(r=-0,60)$, fósforo total $(r=-0,65)$ e cádmio $(r=-0,63)$ (Anexo 2.9). Como foi observada toxicidade para praticamente todo o reservatório, os bioensaios encontram-se no centro da análise.

a)

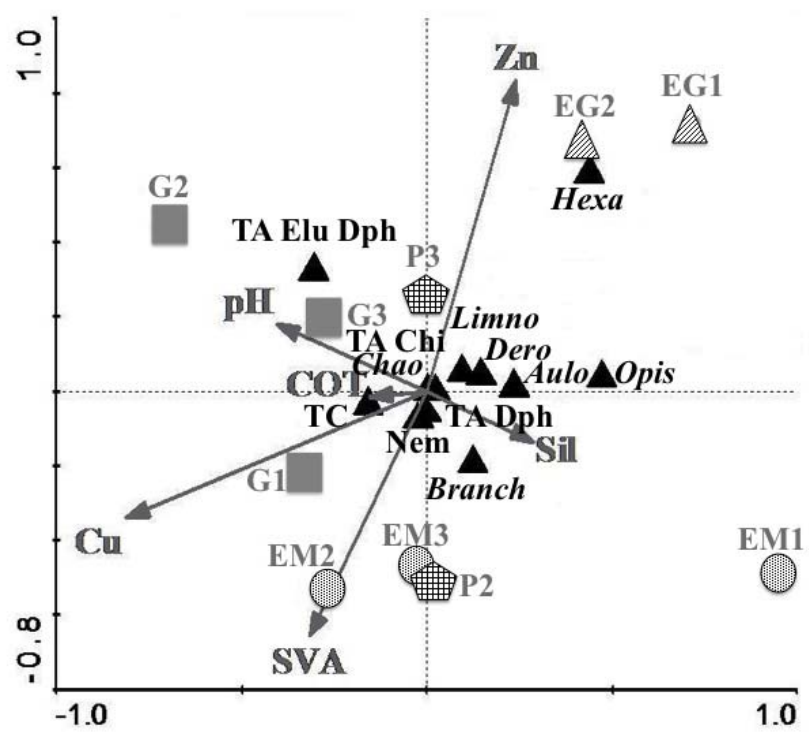

b)

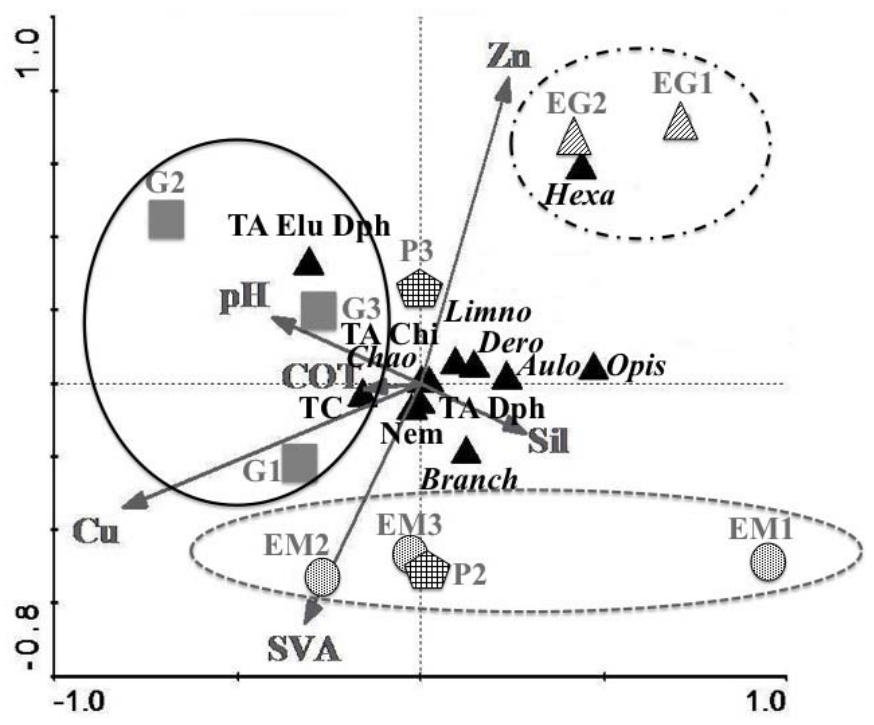

Figura 6. Ordenação dos pontos amostrais do reservatório Guarapiranga com variáveis bióticas e abióticas, por meio de Análise de Correlação Canônica (ACC). Onde: Dero = Dero; Aulo = Aulodrilus; Branch = Branchiura; Chao = Chaoborus; Limno = Limnodrilus; Nem = Nematoda; Opisto $=$ Opistocysta; Círculo $=$ EM; Quadrado $=\mathrm{G}$; Triângulo Listrado $=$ EG; Pentágono $=$ Parelheiros e Triângulo Preto $=$ organismos bentônicos; $\mathrm{pH}=$ potencial hidrogeniônico; SVA = sulfeto volatizável por acidificação; COT = carbono orgânico total; Sil = silte; $\mathrm{Cu}=$ cobre; $\mathrm{Zn}=$ zinco; TA Elu Dph= teste agudo em água intersticial com $D$. similis; TA $C h i=$ teste agudo em sedimento com Chironomus xanthus; $\mathrm{TA} \mathrm{Dph}=$ teste agudo em sedimento com $D$. similis; $\mathrm{TC}=$ teste crônico com $C$. silvestri.

Tabela 5. Matriz de correlação da Análise de Correspondência Canônica (ACC). Onde: SVA= sulfeto volatizável por acidificação; $\mathrm{COT}=$ carbono orgânico total; Sil = silte; $\mathrm{Cu}=$ cobre; $\mathrm{Zn}=$ zinco; $\mathrm{pH}=$ potencial hidrogeniônico.

\begin{tabular}{lrr}
\hline \multicolumn{3}{c}{ Matriz de correlação ACC } \\
& \multicolumn{1}{c}{ Eixo 1 } & \multicolumn{1}{c}{ Eixo 2 } \\
\hline Cu & $-0,8118$ & $-0,341$ \\
Zn & 0,2386 & 0,8339 \\
COT & $-0,1558$ & $-0,0142$ \\
Sil & 0,2868 & $-0,1359$ \\
SVA & $-0,3177$ & $-0,6591$ \\
pH & $-0,4057$ & 0,1785 \\
\hline
\end{tabular}


A Tríade de Qualidade do Sedimento versão 1, representada por áreas na figura 7, e cujos índices estão apresentados na tabela 6 e anexos 2.4, 2.5 e 2.7, mostrou as diferenças entre os pontos amostrais. Ao observar as áreas dos triângulos, sabendo que quanto maior a área, maior a deterioração do ambiente em relação ao ponto referencial, no caso o EG1, a análise indica como pontos mais deteriorados o P1 $(A=293,39)$ seguido por EM2 $(A=208,97)$ e $G 1(A=184,82)$. Já o ponto cuja qualidade do sedimento esteve mais próxima ao referencial $E G 1(A=0,87)$ foi o EM1 $(\mathrm{A}=4,05)$.

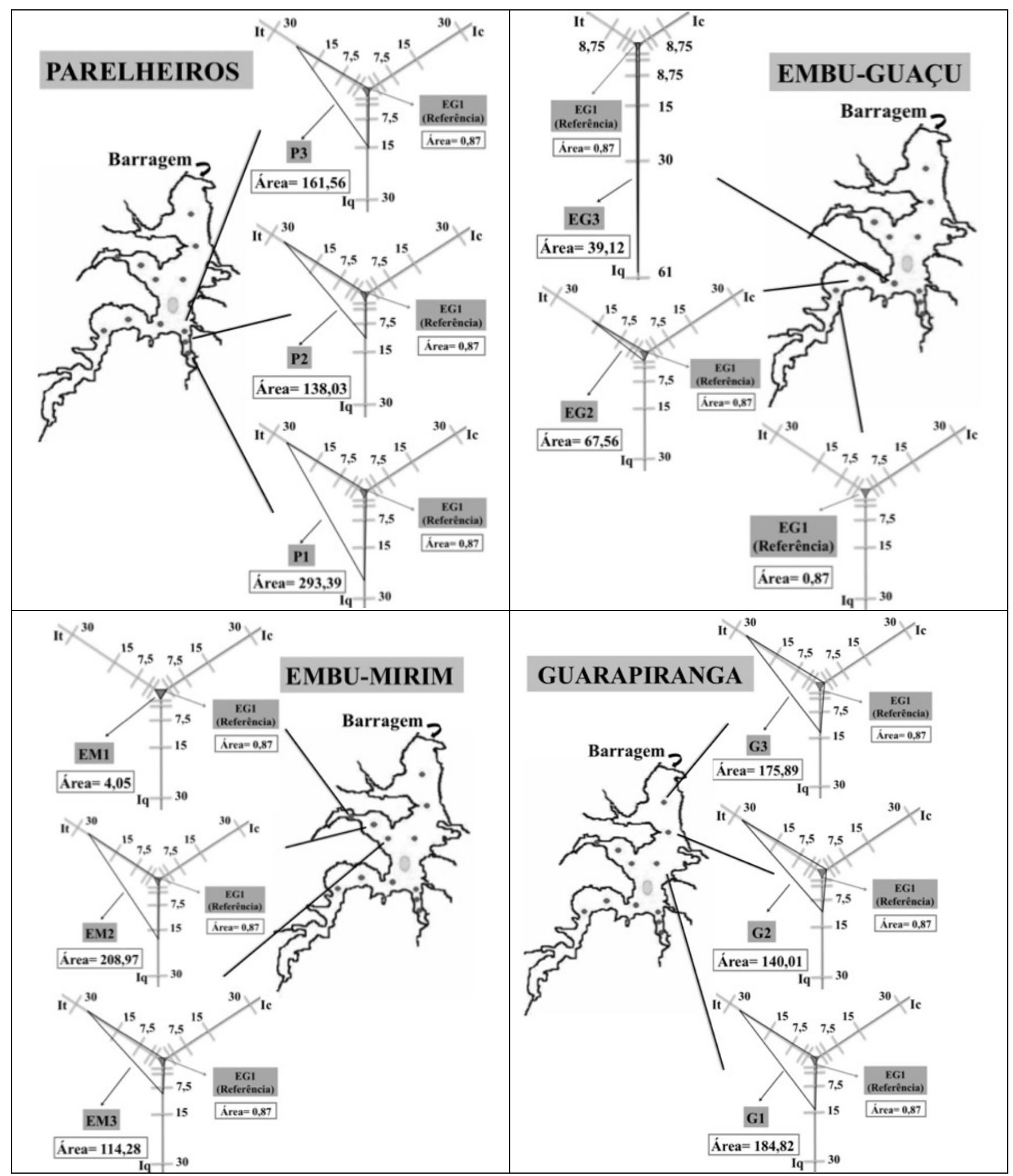

Figura 7. Áreas triangulares originadas para os 12 pontos amostrais do reservatório Guarapiranga, calculadas a partir dos índices de comunidade (Ic), químico versão 1 (Iq) e toxicológico (It), constituintes da Tríade de Qualidade do Sedimento versão 1. 


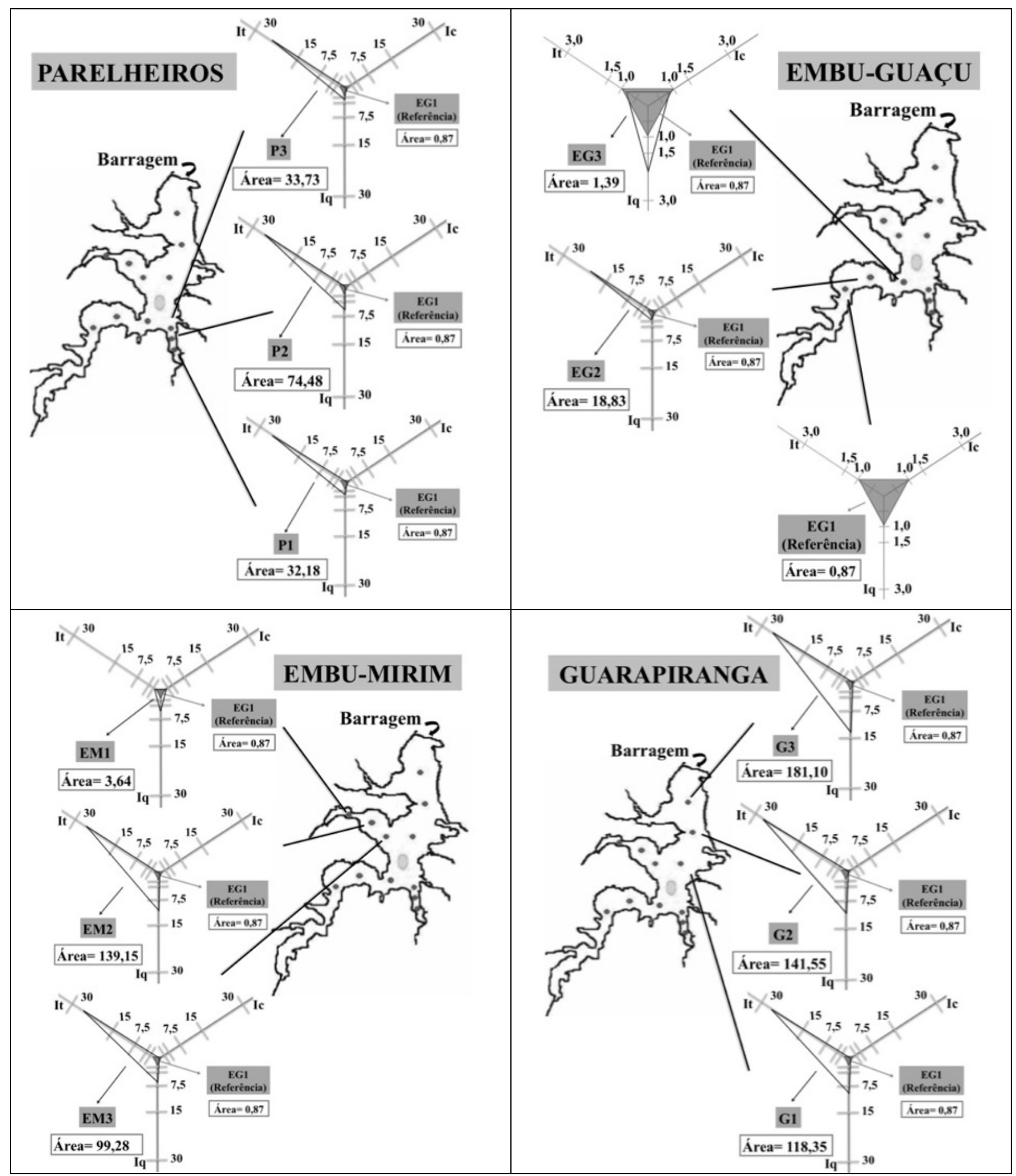

Figura 8. Áreas triangulares originadas para os 12 pontos amostrais do reservatório Guarapiranga, calculadas a partir dos índices de comunidade (Ic), químico versão 2 (Iq) e toxicológico (It), constituintes da Tríade de Qualidade do Sedimento versão 2.

Com exceção dos pontos localizados na região Embu-Guaçu e o ponto EM1, os demais podem ser interpretados como regiões onde químicos tóxicos estão estressando o ambiente (Anexo 2.8). No ponto EG2, variáveis químicas não medidas ou condições locais específicas têm o potencial de causar degradação, enquanto no ponto EG3 entende-se que os contaminantes não estão biodisponíveis. Já no ponto EM1 há forte evidência de poluição induzindo à degradação, mas como a área do triângulo é a mais próxima da referencial, essa degradação possivelmente é pequena. 
Porém a grande diferença no índice químico do P1 foi causada pela presença de areia fina no sedimento e em EG2 e EG3 pela presença de areia grossa. Como a granulometria do sedimento é uma característica física da região e não um aspecto químico, as frações de areia foram excluídas do índice químico, numa TQS versão 2 (Figura 8; Tabela 6; Anexo 2.6). As variáveis silte e argila foram mantidas para cumprir indicação de utilização do dado granulométrico no índice químico em Chapman (1992) e porque frações mais finas, sobretudo a argila, podem interferir no ambiente químico devido à sua capacidade de adsorver matéria orgânica e metais. A TQS versão 2 indicou como ponto mais deteriorado o $\mathrm{G} 3(\mathrm{~A}=181,10)$, seguido pelos demais pontos na região do corpo principal e EM2 $(\mathrm{A}=139,15)$ e EM3 $(\mathrm{A}=99,28)$. Já o ponto menos deteriorado foi o $\mathrm{EG} 3(\mathrm{~A}=$ $1,39)$ seguido por $\operatorname{EM} 1(\mathrm{~A}=3,64)$.

A versão 2 da TQS indica que para Parelheiros, químicos não medidos ou outros fatores não avaliados neste trabalho têm o potencial de causar degradação (Anexo 2.8). Na região Embu-Guaçu o ponto EG2 indica o mesmo que Parelheiros, enquanto o EG3 indica a existência de contaminantes mas estes não estão biodisponíveis. Já em Embu-Mirim, para o ponto mais a montante, o EM1, a TQS indicou a mesma condição que para EG3. Enquanto para os demais pontos do Embu-Mirim e corpo principal do reservatório, a possível conclusão é de que químicos tóxicos estão estressando a biota.

Tabela 6. Índices biológico (Ib), químico 1 e 2 (Iq) e toxicológico (It) calculados a partir das RTRs para os 12 pontos amostrais no reservatório Guarapiranga para cálculo da Tríade de Qualidade do Sedimento (TQS).

\begin{tabular}{ccccccccc}
\hline & \multicolumn{3}{c}{ TQS versão 1 } & & \multicolumn{3}{c}{ TQS versão 2 } \\
\cline { 2 - 4 } \cline { 7 - 8 } Pontos & Ib & Iq & It & & Ib & Iq & It \\
\hline P1 & 1,03 & 22,23 & 26,36 & & 1,03 & 2,27 & 26,36 \\
P2 & 0,83 & 10,40 & 26,46 & & 0,83 & 5,58 & 26,46 \\
P3 & 1,35 & 13,72 & 23,50 & & 1,35 & 2,77 & 23,50 \\
EG1 & 1,00 & 1,00 & 1,00 & & 1,00 & 1,00 & 1,00 \\
EG2 & 1,15 & 6,80 & 19,66 & & 1,15 & 1,65 & 19,66 \\
EG3 & 1,00 & 60,10 & 0,92 & & 1,00 & 2,03 & 0,92 \\
EM1 & 0,93 & 4,77 & 1,26 & & 0,93 & 4,26 & 1,26 \\
EM2 & 0,71 & 15,91 & 26,21 & & 0,71 & 10,57 & 26,21 \\
EM3 & 0,80 & 8,58 & 26,46 & & 0,80 & 7,44 & 26,46 \\
G1 & 0,85 & 13,70 & 26,91 & & 0,85 & 8,75 & 26,91 \\
G2 & 0,70 & 9,64 & 28,87 & & 0,70 & 9,75 & 28,87 \\
G3 & 0,73 & 13,05 & 26,87 & & 0,73 & 13,44 & 26,87 \\
\hline
\end{tabular}




\subsection{Discussão}

A Tríade da Qualidade do Sedimento é um instrumento de fácil visualização e compreensão para profissionais não especializados, mostrando-se uma ferramenta potencialmente útil ao monitoramento da qualidade de sedimentos (Shimizu et al., 2002). No caso do Guarapiranga, as possíveis conclusões baseadas na disposição dos triângulos nos eixos, e a visualização da possível degradação da região comparada ao ponto referência, auxiliaram na visualização das diferenças granulométricas e de outras características físicas e químicas do sedimento em trechos distintos dentro de um mesmo corpo d' água. Almeida \& Rocha (2006) observaram que o cálculo das áreas dos triângulos permitiu classificar os sedimentos dos reservatórios da bacia do baixo Tietê quanto ao impacto sofrido e a distribuição espacial dos sedimentos potencialmente tóxicos acompanhou o grau de trofia do rio Tietê. Shimizu e colaboradores (2002) afirmam que em ambientes com alto ou baixo grau de degradação há coerência entre dados de toxicidade e a contaminação química e a estrutura da comunidade; já quando se trata de grau intermediário, os resultados não concordam, como ocorre no caso do reservatório Guarapiranga.

A TQS versão 1 separou o reservatório em relação às características químicas, toxicológicas e biológicas do sedimento seguindo-se em ordem crescente de 'deterioração' (ou diferença em relação à qualidade do ponto referencial): $\mathrm{EG} 1<\mathrm{EM} 1<\mathrm{EG} 3<\mathrm{EG} 2<\mathrm{EM} 3<\mathrm{P} 2<\mathrm{G} 2<\mathrm{P} 3<\mathrm{G} 3<$ G1 $<$ EM2 < P1. Seguindo a sequência acima, os pontos localizados na região Embu-Guaçu, com exceção do ponto referência, sofrem influência de químicos com potencial para degradação mas que podem não estar biodisponíveis, enquanto o ponto mais a montante da região Embu-Mirim apresenta forte evidência de poluição induzindo a degradação. Nas demais regiões do Guarapiranga como Parelheiros, corpo principal e médio-jusante do Embu-Mirim, químicos tóxicos estão causando estresse à biota. Porém, foi a diferente característica granulométrica de P1 (areia fina) e EG2 e EG3 (areia grossa) comparadas ao ponto referência que os fizeram apresentar altos índices químicos. A região do Embu-Guaçu apresenta consideráveis quantidades de areia, tanto que seu tributário tem concessão para exploração de areia. Já a versão 2 da TQS apresentou a seguinte ordem crescente de deterioração: $\mathrm{EG} 1<\mathrm{EG} 3<\mathrm{EM} 1<\mathrm{EG} 2<\mathrm{P} 1<\mathrm{P} 3<\mathrm{P} 2<\mathrm{EM} 3<\mathrm{G} 1<\mathrm{EM} 2<\mathrm{G} 2<$ G3. A ordem de deterioração segue as distâncias de cada ponto até a barragem, mesmas distâncias utilizadas nos gráficos de concentrações de metais, sendo que pontos mais distantes da barragem estão menos deteriorados, enquanto pontos com áreas acima de 99,28 (EM3) estão mais deteriorados. Dessa forma, com exceção do ponto mais a montante de Embu-Mirim, a região do Embu-Mirim e a do corpo principal (Guarapiranga) são as mais deterioradas, enquanto EmbuGuaçu, Parelheiros e EM1 são as menos deterioradas. Padial (2008), somente com variáveis físicas e químicas do sedimento, separou Embu-Mirim e Guarapiranga como regiões de sedimento mais deteriorado e Embu-Guaçu e Parelheiros como menos deteriorados. A tríade permitiu refinar essa compartimentalização do sedimento, trabalhando também dados biológicos e ecotoxicológicos e assim foi possível excluir o ponto mais a montante do Embu-Mirim do compartimento mais deteriorado. Como visto, apenas a aplicação da TQS não é suficiente para a avaliação da qualidade do sedimento, o que pode resultar na necessidade de análise individual de cada componente da tríade de forma mais aprofundada, como apresentado a seguir.

Com relação aos metais, a primeira hipótese sobre o não carreamento dos seis metais analisados a partir da desembocadura dos tributários sentido barragem foi aceita, já que nem todos os metais mostraram tendência de aumento sentido barragem. Apenas apresentaram essa tendência de maneira mais expressiva os metais cobre e cádmio. Como a origem do cobre provavelmente se deve, sobretudo, à aplicação do sulfato de cobre em todo o reservatório para controle de algas (Richter et al., 2007) esse metal é transportado no sentido barragem e se acumula no sedimento silte-argiloso da zona de sedimentação do reservatório (corpo principal). A maior preocupação com o cobre é o fato de suas concentrações estarem acima do nível de efeito tóxico provável, apesar da sua não-biodisponibilidade sugerida pelos teores de sulfeto e carbono orgânico nesses sedimentos. Testes com o Tubificinae T. tubifex mostraram que em sedimento com mais sulfeto do que metais, 
no Guarapiranga é o caso dos pontos P1, P2, EG2, EM1 e EM2, um acúmulo de $60 \%$ de cobre se deu em suas organelas, já quando há maiores concentrações de metais do que sulfeto, como nos demais pontos do reservatório, este acúmulo de cobre pode subir para 80\% (De Jonge et al., 2011).

O cádmio apresenta valores acima dos naturais para a região e do efeito tóxico limiar. Pode ter sua origem na produção, consumo ou disposição de produtos com cádmio, como baterias de celular, pigmento amarelo-vermelho, estabilizador de PVC, recobrimento de produtos de aço e ferro (Cardoso \& Chasin, 2001). Possivelmente entra no corpo d'água pela lavagem da bacia de drenagem pelas chuvas, por efluentes não-tratados e disposição incorreta de resíduos contendo o metal. Para cádmio, ocorre efeito contrário ao de cobre quanto ao acúmulo em T. tubifex, pois quando em sedimento com mais sulfeto que metais (P1, P2, EG2, EM1 e EM2), o acúmulo de cádmio é de aproximadamente 100\% no resíduo-fezes e apenas 10\% em organelas (De Jonge et al., 2011). Atenção deve ser dada à entrada deste metal no reservatório e principalmente para sua acumulação nos pontos onde a concentração de metais são as mais altas do reservatório, sendo maiores que as de sulfeto (pontos EG3 $=\mathrm{P} 3<\mathrm{G} 1<\mathrm{EM} 3<\mathrm{G} 2<\mathrm{G} 3$ ). Em seu estudo De Jonge e colaboradores (2011) observaram que T. tubifex acumulou $60 \%$ de cádmio em suas organelas quando as concentrações de metais foram mais altas do que as de sulfeto. Um resultado similar poderia ocorrer com os Oligochaeta presentes no Guarapiranga.

As maiores concentrações de zinco no reservatório ocorrem na região Embu-Guaçu, mas a concentração desse metal não apresenta tendência de aumento sentido barragem. O zinco é aplicado no revestimento de proteção de ferro e aço e na fabricação de ligas de latão (Nascimento, 2003). Descartes irregulares desses materiais somados à lavagem da bacia de drenagem podem ser as portas de entrada de zinco no reservatório. O acúmulo de zinco em $T$. tubifex foi de praticamente $50 \%$ em organelas e $50 \%$ em resíduo-fezes com maiores ou menores concentrações de sulfeto em relação a de metais (De Jonge et al., 2011), de modo que também teria potencial de ser bioacumulado em Oligochaeta do Guarapiranga.

Os bioensaios indicaram toxicidade aguda para quase todo o reservatório, contudo a relação ( $\Sigma$ [metais] - [SVA])/ COT indicou não biodisponibilidade de metais, o que nos leva a aceitar a segunda hipótese nula sobre a não consonância da resposta dos testes com a relação de metais normalizados pelo sulfeto e pelo carbono orgânico. Por outro lado testes ecotoxicológicos desenvolvidos por De Jonge et al. (2011) mostraram acúmulo de metais em organismos que se alimentam no sedimento, com diferenças na acumulação entre os metais, ainda que a relação metais/ sulfetos/ carbono orgânico indique não-biodisponibilidade. Portanto, deve-se tomar muito cuidado ao afirmar a que os metais não estão biodisponíveis no reservatório Guarapiranga apenas com base naquela relação.

Deve-se levar em consideração uma das principais características do reservatório Guarapiranga que é a presença de diversos e densos bancos de macrófitas, de modo que com exceção do corpo principal, as demais regiões apresentam sedimento formado por restos de macrófitas com considerável número de organismos vivendo dentro de restos de caules de Polygonum, como o caso do Naidinae Haemonais waldvogeli, ou nas folhas de Salvinia ocupadas por gêneros de outros Naidinae como Dero e Opistocysta. Segundo Learner e colaboradores. (1978), 'Naididae' são observados em densidades consideráveis em sistemas de água para abastecimento e, ainda, associados a substratos com gravetos e folhas. Os gêneros Dero e Opistocysta tiveram correlação significativa positiva entre si, possivelmente devido ao mesmo substrato explorado por ambos. Outros autores observaram diminuição na riqueza e densidade de Naididae de acordo com a diminuição no tamanho do grão de sedimento. Essa relação Naididaetamanho de sedimento foi observada na substituição da dominância de Tubificidae por Naididae sob tais condições granulométricas (Learner et al., 1978). No processo de decomposição dessas plantas há liberação de nitrogênio, e uma de suas fases é a amônia, tóxica a muitos organismos aquáticos em concentrações de $5 \mathrm{mg} \mathrm{L}^{-1}$ (Silva et al., 2010). Em estudo realizado por Araújo e colaboradores (2006), entre os anos 2000 e 2001, nos reservatórios do rio Tietê, foi observada amônia como o maior componente suspeito de causar toxicidade nos organismos testes de acordo com o 'toxicity identification evaluation' (TIE). Apesar das concentrações relativamente altas dos metais cobre, 
chumbo e zinco na água intersticial encontradas pelos autores, os testes de EDTA mostraram que os metais não são responsáveis pela toxicidade. Ankley e Schubauer-Berigan (1995) também observaram a amônia como principal componente causador de toxicidade em 6 de 16 sedimentos analisados no TIE. No presente estudo não foi realizado o TIE, mas pelo observado na coluna d'água por Araújo e colaboradores (2006) no reservatório Billings e por Richter e colaboradores (2007) no Guarapiranga, pode-se supor que a toxicidade no Guarapiranga também seria causada pela amônia.

As altas concentrações de nitrogênio e fósforo totais no sedimento das diferentes regiões do Guarapiranga estão relacionadas com o estado trófico do reservatório. De acordo com estudos realizados por Richter e colaboradores (2007), a propagação de algas, e possivelmente a de macrófitas, está diretamente ligada aos nutrientes, principalmente ao fósforo, que são despejados nas águas do reservatório via esgotos não tratados da população que habita o entorno da bacia. Os níveis de nitrogênio acima do limite permitido para água de abastecimento (CONAMA 357/2005) estariam relacionados às altas concentrações de amônia, uma das fases na decomposição do nitrogênio, uma substância tóxica restritiva à vida de muitos organismos. Assim, a precipitação e a liberação desse nutriente a partir da decomposição de matéria orgânica no sedimento de fundo do Guarapiranga pode restringir a comunidade bentônica a indivíduos tolerantes a tal toxicidade.

Todos os macroinvertebrados bentônicos encontrados no reservatório Guarapiranga, independente do nível de identificação, são resistentes a poluição orgânica razoável, segundo Mandaville (2002). Dentro daqueles que toleram poluição orgânica severa foram encontrados Naididae (L. hoffmeisteri, Dero sp) e Chironomidae (Tanypus Stellatus, Chironomus sp.). L. hoffmeisteri foi o gênero dominante ou mais abundante em todo o reservatório, enquanto Dero sp. foi sempre abundante. Já a família Chironomidae não foi tão abundante e Chironomus sp apresentou correlação significativa e inversa com nitrogênio e fósforo totais e cádmio. Dornfeld e col. (2006) em ensaios ecotoxicológicos com Chironomus xanthus no sedimento do rio Monjolinho (médio Tietê), observaram tendência a aumento na mortalidade desses organismos com o aumento da fração silte-argilosa e dos teores de matéria orgânica no sedimento do rio, e afirmam que as altas concentrações de cromo e cobre no sedimento aliadas à baixa concentração de oxigênio dissolvido seriam as causas da mortalidade desta espécie. Testes com Chironomus também mostraram que o acúmulo de metais nesses organismos se correlacionou com a quantidade de metais no sedimento normalizados pela fração silte-argiloso e pela quantidade de matéria orgânica, indicando que para o gênero a presença de sulfeto no sedimento não interfere na biodisponibilidade dos metais (De Jonge et al., 2010). Contudo o gênero Chironomus também é apontado por ter uma certa resistência a poluição por metais (Klerks \& Weis, 1987).

Em testes de tolerância desenvolvidos por Chapman e Brinkhurst (1984), espécimes de Oligochaeta sobreviveram à introdução de cádmio no teste devido à introdução simultânea de um sal, o qual se complexa ao metal e não o disponibiliza para os organismos. Porém no estudo de Klerks \& Weis (1987), em corpos d'água poluídos, foi observada tolerância de L. hoffmeisteri a níveis extremamente altos de cádmio e níquel no sedimento. Esses organismos foram capazes de se reproduzir e crescer por mais de duas gerações sob tais condições, inferindo-se que seria um caso de adaptação da espécie a metais-traço.

A dominância de indivíduos na comunidade de invertebrados bentônicos foi compartilhada por L. hoffmeisteri e Chaoborus sp. Hare e colaboradores (2001) observaram em testes laboratoriais que Chaoborus permaneceu pouco tempo próximo ao sedimento e não apresentou relação com concentrações de metais. Estes autores salientam que Chaoborus se alimenta de zooplâncton na coluna d'água e, portanto, sua aquisição de metais seria por meio do zooplâncton. Por outro lado, Chaoborus é importante para o zoobentos pois durante o dia, principalmente no $4^{\circ}$ instar larval, os indivíduos entram e saem do sedimento, participando da bioturbação (Gosselin \& Hare, 2003). De qualquer forma, há concordância que Chaoborus é tolerante a anoxia e ao entrar no sedimento não tem necessidade de construir tubos e promover sua oxigenação, além disso é tolerante ao sulfeto e seu exoesqueleto é pouco permeável a elementos tóxicos presentes na coluna d'água ou na água 
intersticial. Além disso, a grande densidade de Chaoborus é um indício da eutrofização dos corpos d'água segundo Mandaville (2002).

Acredita-se ainda que os metais no geral possam se acumular nos tecidos dos macroinvertebrados bentônicos, sendo passado a outros organismos através da cadeia alimentar, mas que a contaminação química apontada pela tríade de qualidade do sedimento seja realmente causada pelo enriquecimento orgânico, especificadamente pela amônia liberada da decomposição da matéria orgânica.

De acordo com a ACC e a correlação de Pearson, os macroinvertebrados do Guarapiranga refletem as diferenças espaciais no sedimento e na água de fundo do reservatório, observadas na $\mathrm{ACP}$, refutando a terceira hipótese-nula de que a fauna bentônica não refletiria essas diferenças espaciais. Dessa forma, infere-se que o ambiente no Guarapiranga seleciona organismos tolerantes a, poluição orgânica, eutrofização, anoxia, metais e sulfetos. Assim, visando a boa qualidade ecológica do reservatório, seria importante estabelecer mais algumas estações de amostragem no monitoramento realizado pelo órgão responsável pelo controle ambiental. Isso ajudaria nas tomadas de decisão quanto ao manejo do reservatório.

Somente uma ACP e uma ACC não conseguiriam caracterizar o sedimento do reservatório. A ACP mostrou-se imprescindível no estudo de qualidade do sedimento já que as características físicas e químicas do fundo são responsáveis pela maior variabilidade dos dados em uma ACC, influenciando assim a fauna bentônica. A aplicação somente da TQS também deixaria lacunas na interpretação da qualidade do sedimento, embora os triângulos chamem a atenção para alguma contaminação pontual, permitindo assim realizar o manejo mais adequado. $O$ cuidado que se deve tomar com a utilização de triângulos é o de conferir quais variáveis dentro de cada índice estão influenciando de maneira mais substancial o valor do índice o que leva às áreas dos triângulos. A ACC, por sua vez, não é uma análise tão fácil de se trabalhar dados de qualidade de sedimento, pois a tríade exige a leitura de uma série de variáveis físicas e químicas que por fím serão colineares numa ACC, exigindo do pesquisador selecionar as originalmente influentes para a fauna.

Outra alternativa à complementação da TQS é a aplicação de índices que classifiquem o sedimento de acordo com uma ou outra componente. No caso elegemos a métrica descrita por Wiederholm (1980) que leva em consideração a densidade de Oligochaeta como informação sobre o grau de trofia do ambiente. $\mathrm{O}$ autor testou a métrica para locais de clima temperado e lagos de diferentes estados tróficos de acordo com a clorofila $a$ e a concentração de fósforo total e encontrou alta correlação direta daquela densidade com valores de clorofila $a$. Fusari e Fonseca-Gessner (2006) testaram essa métrica em pequenos reservatórios do estado de São Paulo, um oligotrófico e outro eutrófico, e confirmaram a relação entre a densidade de Oligochaeta e a trofia dos ambientes. Para o reservatório Guarapiranga, esta métrica indicou enriquecimento orgânico forte nos pontos menos degradados segundo a TQS, incluindo o ponto referência e os com os maiores índices de diversidade. A densidade de Oligochaeta indicou um ponto de extrema proliferação de macrófitas aquáticas e outro de baixa diversidade como pertencentes à classe denominada equilíbrio natural. Tais resultados nos levam a crer que essa métrica talvez não seja a mais indicada para comparar regiões de um mesmo corpo d'água, mesmo que este apresente heterogeneidade espacial, mas parece funcionar bem na comparação entre corpos d'água de diferentes estados tróficos. $O$ índice de comunidade bentônica específico para a região profundal de reservatórios possibilitou eleger o ponto referência para a tríade, já que o EG1 foi o único apontado pelo índice como apresentando boa qualidade ambiental. Dessa forma, conclui-se que o enriquecimento orgânico, suas consequências e a entrada de metais-traço no corpo d'água influenciaram a estrutura da comunidade de macroinvertebrados bentônicos favorecendo uma fauna tolerante à hipoxia, à poluição orgânica e à presença de substâncias tóxicas como metais-traço e sulfetos. No entanto, a nãobiodisponibilidade desses metais nos leva a crer que, a provável presença de amônia na água intersticial, decorrente da decomposição da matéria orgânica, poderia ser a causa da toxicidade desse sedimento em testes ecotoxicológicos. Sugere-se aos órgãos responsáveis pelo monitoramento e gerenciamento do reservatório que pontos amostrais localizados na desembocadura dos principais 
tributários do reservatório sejam adicionados ao monitoramento a fim de controlar a degradação atual e evitar futuras perdas na qualidade da água e sedimento do reservatório. 


\subsection{Referências}

ALDEN, RW. Uncertainty and sediment quality assessments: I. confidence limits for the triad. Environmental Toxicology and Chemistry, v. 11, p. 637-644,1992.

ALLEN, H.E.; FU, G.; DENG, B. Analysis of acid-volatile sulfide (AVS) and simultaneously extracted metals (SEM) for the estimation of potential toxicity in aquatic sediments. Environmental Toxicology and Chemistry, v. 12, p. 1441-1453, 1993.

ALMEIDA, C.A.; ROCHA, O. Estudo comparative da qualidade dos sedimentos dos reservatórios do rio Tietê (SP). Journal of Brazilian Society of Ecotoxicology, v. 1, n. 2, p. 141-145, 2006.

AMBHÜL, H.; BÜHRER, H. Zur Technik der Entnahme ungestörter grossproben Von Seesedimenten: ein verbessertes Bohlot Schweiz. Z. Hydrol., v. 37, p. 175-186, 1975.

ANDERSEN, J.M. An ignition method for determination of total phosphorus in lake sediments. Waters Research, v. 10, n. 4, p. 329-331, 1976.

ANKLEY, G.T.; SCHUBAUER-BERIGAN, M.K. Background and overview of current sediment toxicity identification evaluation procedures. Journal of Aquatic Ecosystem Health, v. 4, p. 133$149,1995$.

ARAÚJO, R.P.A. Teste de toxicidade como instrumento na avaliação dos sedimentos de água doce do Estado de São Paulo. 2005. 283f. Tese (Doutorado em Ecologia), Instituto de Biociências, Universidade de São Paulo, São Paulo. 2005.

ARAÚJO, R.P.A. et al. Application of toxicity identification evaluation to sediment in a highly contaminated water reservoir in southeastern Brazil. Environmental Toxicology and Chaemistry, v. 25, n. 2, p. 581-588, 2006.

BAY, S.; BERRY, W.; CHAPMAN, P.M.; FAIREY, R.; GRIES, T.; LONG, E.; MACDONALD, D.; WEISBERG, S.B. Evaluating consistency of best professional judgment in the application of a multiple lines of evidence sediment quality triad. Integrated Environmental Assessment and Management, v. 3, n. 4, p. 491-497, 2007.

BEYRUTH, Z. Periodic disturbance, trophic gradient and phytoplankton characteristics related to cyanobacterial growth in Guarapiranga Reservoir, São Paulo State, Brazil. Hydrobiologia, v. 424, p. 51-65, 2000.

BRINKHURST, R. O.; MARCHESE, M. R. Guia para la identificación de oligoquetos acuáticos continentals de sud y Centroamérica. Argentina: Asociación de Ciencias Naturales del Litoral, 1991. $207 \mathrm{p}$.

BURTON Jr, G.A.; CHAPMAN, P.M.; SMITH, E.P. Weight of evidence approaches for assessing ecosystem impairment. Journal of Human and Ecological Risk Assessment, v. 8, p. 1657-1673, 2002.

CARDOSO, L.M.N.; CHASIN, A.A.M. Ecotoxicologia do cádmio e seus compostos. In: Série de cadernos de referencia Ambiental, v. 6. Salvador. 2001. 122p.

CARDOSO-SILVA, S. Heterogeneidade espacial e a qualidade das águas superficiais do reservatório Guarapiranga (São Paulo - SP - Brasil). 2008. 99f. Tese (Mestrado em Ecologia de 
ecossistemas terrestres e aquáticos) - Instituto de Biociências, Universidade de São Paulo, São Paulo. 2008.

CARMOUZE, J. P. Metabolismo do meio bentônico e reciclagem dos nutrientes. In: O metabolismo dos ecossistemas aquáticos: fundamentos teóricos, métodos de estudos e análises químicas. São Paulo: Editora Edgard Blücher, FAPESP. 1994. p.103-128.

CANADIAN COUNCIL OF MINISTERS OF THE ENVIRONMENT. Canadian Sediment Quality Guidelines for the Protection of Aquatic Life - Protocol for the derivation of Canadian Sediment Quality Guidelines for the Protection of Aquatic Life (CCME EPC-98E). 1999. 35 p.

CANTON, S.P.; CHADWICK, J.W. Variability in benthic invertebrate density estimates from stream samples. Journal of Freshwater Ecology, v. 4. p. 291-297, 1988.

CHAPMAN, P.M.; BRINKHURST, R.O. Lethal and sublethal tolerances of aquatic oligochaetes with reference to their use as a biotic index of pollution. Hydrobiologia, v. 115, p. 139-144, 1984.

CHAPMAN, P.M.; DEXTER, R.N.; LONG, E.R. Synoptic measures of sediment contamination, toxicity and infaunal community composition (the Sediment Quality Triad) in San Francisco Bay. Marine Ecology - Progress Series, v. 37, p. 75-96, 1987.

CHAPMAN, P.M. Chapter 10: Sediment Quality Triad Approach. In: Sediment Classification Methods Compendium. EPA 823-R-92-006, 1992. p.10-1 - 10-18.

CHAPMAN, P.M. The sediment quality triad: then, now and tomorrow. International Journal of Environment and Polution, Geneva, v. 13, n. 1, p. 351-355, 2000.

CHAPMAN, P.M.; McDONALD, B.G.; LAWRENCE, G.S. Weight-of-evidence issues and frameworks for sediment quality (and other) assessments. Journal of Human and Ecological Risk Assessment, v. 8, p. 1489-1515, 2002.

COMPANHIA AMBIENTAL DO ESTADO DE SÃO PAULO. Água e teste de toxicidade aguda com Daphnia similis Claus, 1876 (Cladocera, Crustacea). Norma Técnica, L5.018, São Paulo, 1991, p.33.

COMPANHIA AMBIENTAL DO ESTADO DE SÃO PAULO. Aplicação da tríade na avaliação da qualidade de sedimentos em redes de monitoramento. KUHLMANN, M.L.; WATANABE, H.M.; ARAÚJO, R.P.A.; LAMPARELLI, M.C. (autores). São Paulo, 2007.

COMPANHIA AMBIENTAL DO ESTADO DE SÃO PAULO. Protocolo para o biomonitoramento com as comunidades bentônicas de rios e reservatórios do estado de São Paulo. KUHLMANN, M.L.; JOHNSCHER-FORNASARO, G.; OGURA, L.L.; IMBIMBO, H.R.V. (Eds.). São Paulo, 2012. p. 113.

CONSELHO NACIONAL DO MEIO AMBIENTE. Resolução No 344, de 25 de março de 2004. In: Resoluções do CONAMA: Resoluções vigentes publicadas entre setembro de 1974 e janeiro de 2012. Brasília: MMA. 2012. p. 840 - 848.

CONSELHO NACIONAL DO MEIO AMBIENTE. Resolução No 357, de 17 de março de 2005. In: Diário Oficial da União n. 053, de 18/03/2005. p. 58-63. 
COSTA, J.M.; SOUZA, L.O.I.; OLDRINI, B.B. Chave para identificação das famílias e gêneros das larvas conhecidas de Odonata do Brasil: comentários e registros bibliográficos (Insecta, Odonata). In: Publicações Avulsas do Museu Nacional, n. 99, p. 1-44, 2004.

COSTA, C.; IDE, S. SIMONKA, C.E. (Org.). Insetos imaturos: metamorfose e identificação. Ribeirão Preto: Holos. 2006. 249 p.

DA SILVA, A.M. Avaliação da qualidade do rio São Lourenço, SP, sob influência de estações de tratamento de água e estações de tratamento de esgoto. 08/2008. 176f. Tese de Doutorado em Ciências - Tecnologia Nuclear/Materias - Instituto de Pesquisas Energéticas e Nucleares, Universidade de São Paulo, São Paulo. 2008.

DAGNINO, A.; SFORZINI, S.; DONDERO, F.; FENOGLIO, S.; BONA, E.; JENSEN, J.; VIARENGO, A.; A "weight-of-evidence" approach for the integration of environmental "triad" data to assess ecological risk and biological vulnerability. Integrated Environmental Assessment and Management, v. 4, n. 3, p. 314-326, 2008.

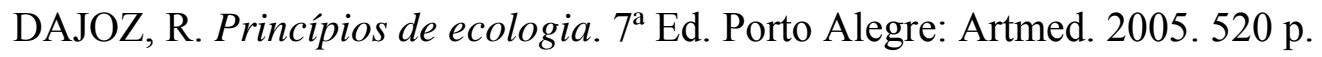

DE JONGE, M.; BLUST, R.; BERVOETS, L. The relation between Acid Volatile Sulfides (AVS) and metal accumulation in aquatic invertebrates: Implications of feeding behavior and ecology. Environmental Pollution, v. 158, p. 1381-1391, 2010.

DE JONGE, M. et al. Are accumulated sulfide-bound metals metabilically available in the benthic Oligochaete Tubifex tubifex? Environmental Science \& Technology, v.45, p. 3131-3137, 2011.

DODDS, W.K. Freshwater Ecology: Concepts and Environmental Applications. San Diego, California: Academic Press/ Elsevier. 2002. 569 p.

DORNFELD, C.B.; ALVES, R.G.; LEITE, M.A.; ESPÍNDOLA, E.L.G. Oligochaeta in eutrophic reservoir: the case of Salto Grande reservoir and their main affluent (Americana, São Paulo, Brazil). Acta Limnológica Brasileira, v. 18, n. 2, p. 189-197, 2006.

ESTEVES, FA. Fundamentos de limnologia, $3^{\mathrm{a}}$ ed. Rio de Janeiro: Interciência. 2011. 826 p.

FLEMING, R.; RETNAKARAN, A. Evaluating single treatment data using Abbott's formula with reference to insecticides. Journal of Economic Entomology, v. 78, n. 6, p. 1179-1181, 1985.

FUSARI, L.M.; FONSECA-GESSNER, A.A. Environmental assessment of two small reservoirs in southeastern Brazil, using macroinvertebrate community metrics. Acta Limnologica Brasileira, v. 18, n. 1, p. 89-99, 2006.

GOSSELIN, A.; HARE, L. Burrowing behavior of Chaoborus flavicans larvae and its ecological significance. Journal of the North American Benthological Society, v. 22, n. 4, p. 575-581, 2003.

HÅKANSON, L.; JANSSON, M. Principles of lakes sedimentology. Berlin: Springer-Verlag, 1983. $316 \mathrm{p}$.

HARE, L.; TESSIER, A.; WARREN, L. Cadmium accumulation by invertebrates living at the sediment-water interface. Environmental Toxicology and Chemistry, v. 20, n. 4, p. 880-889, 2001. 
HELOU, L.C.; SILVA, L.G. Estudo da operação do reservatório de Guarapiranga. DAE, SABESP. v. 48, n. 151 , p. 29-47, 1987.

HOLLERT, H; HEISE, S.; PUDENZ, S.; BRÜGGEMANN, W.A.; BRAUNBECK, T. Application of a sediment quality triad and diferente statistical approaches (Hasse Diagrams and Fuzzy Logic) for the comparative evaluation of small streams. Ecotoxicology, v. 11, p. 311-321, 2002a.

HOLLERT, H.; DÜRR, M.; OLSMAN, H.; HALLDIN, K.; VAN BAVEL, B.; BRACK, W; TYSKLIND, M.; ENGWALL, M.; BRAUNBECK, T. Biological and chemical determination of dioxina-like compounds in sediments by means of a sediment triad approach in the catchment área of the river Neckar. Ecotoxicology, v. 11, p. 323-336, 2002 b.

KLERKS, P.L.; WEIS, J.S. Genetic adaptation to heavy metals in aquatic organisms: A review. Environmental Pollution, v. 45, p. 173-205, 1987.

KUHLMANN, M.L.; WATANABE, H.M.; BRANDIMARTE, A.L.; ANAYA, M.; GUERESCHI, R.M. Developing a protocol for the use os benthic invertebrates in São Paulo State's reservoirs biomonitoring. I. Habitat, sampling period, mesh size and taxonomic level. Acta Limnologica Brasiliensia, v. 17, n. 2, p. 143-153, 2005.

LEARNER, M.A.; LOCHHEAD,G.; HUGHES,B.D. A review of the biology of British Naididae (Oligochaeta) with emphasis on the lotic environment. Freshwater Biology, v. 8, p. 357 - 375, 1978.

LEGENDRE, P.; LEGENDRE, L. Numerical Ecology. $2^{\mathrm{a}}$ Ed., Elsevier Science B.V. 1998. 853 p.

LIU, W.; LUAN, Z.; TANG, H. Use of the sediment quality triad to assess metal contamination in freshwater superficial sediments from the Le An river, China. Water, Air and Soil Pollution, v. 113, p. 227-239, 1999.

LONG, E.R.; CHAPMAN, P.M. A sediment quality triad: measures of sediment contamination, toxicity and infaunal community composition in Puget Sound. Marine Pollution Bulletin, v. 16, p. 405-415, 1985.

MANDAVILLE, S.M. Benthic macroinvertebrates in freshwaters: Taxa tollerance values, metrics and protocols. New York: Soil \& Water Conservation Society of Mero Halifax. 2002. 128 p.

MARCHESE, M. Cap 17. Annelida Oligochaeta. In: DOMINGUEZ, E. E FERNÁNDEZ, H.E. (Eds.). Macroinvertebrados bentônicos sudamericanos. Sistemática y biologia. Tucuman, Argentina: Fundación Miguel Lillo, 2009. p. 551-565.

MCCUllough, J. D.; JACKSON, D. W. Composition and productivity of the benthic macroinvertebrate community of a subtropical reservoir. Rev. Gesamten Hydrobiol, v. 70, n. 2, p. 221-235, 1985.

MENEZES, L.C.B.; BEYRUTH, Z. Impactos da aquicultura em tanques-rede sobre a comunidade bentônica da represa de Guarapiranga - São Paulo- SP. Boletim do Instituto de Pesca, São Paulo, v. 29, n. 1, p. 77-86, 2003.

MERRITT, R. W.; CUMMINS, K. W. An introduction to the aquatic insects of North America. Dubuque: Kendall/ Hunt. 1996. 862 p. 
MARIANI, C.F. Reservatório Rio Grande: caracterização limnológica da água e biodisponibilidade de metais-traço no sedimento. 2006. 123f. Dissertação (Mestrado em Ecologia) - Instituto de Biociências, Universidade de São Paulo, São Paulo. 2006.

MARGALEF, R. Limnología. Barcelona, Espanha: Ediciones Omega, S.A. 1983. 1010 p.

MATSUZAKI, M. Transposição das águas do braço Taquacetuba da represa Billings para a represa Guarapiranga: aspectos relacionados à qualidade de água para abastecimento. 2007. 183 f. Tese (Doutorado em Saúde Pública) - Faculdade de Saúde Pública, Universidade de São Paulo, São Paulo. 2007.

MEGURO, M. Métodos em ecologia vegetal. São Paulo: Universidade de São Paulo, Instituto de Biociências, Departamento de Ecologia Geral. 2000. 119 p.

MOZETO, A.A.; SILVÉRIO, P.F.; SOARES, A. Estimates of benthic fluxes of nutrientes across the sediment-water interface (Guarapiranga reservoir, São Paulo, Brazil). The Science of the Total Environment, v. 266, p. 135-142, 2001.

MOZETO, A.A. et al. Weakly-bound metals and total nutriente concentrations of bulk sediments from some water reservoirs in São Paulo state, SE Brazil. Sediment Qality Assessment and Manegement: Insight and Progress. Burlington, Canadá: M. Munawar, p. 221-339, 2003.

MOZETO, A.A. Sedimentos e Particulados Lacustres: amostragem e análises biogeoquímicas. In: BICUDO, C.E.M.; BICUDO, D.C. (Eds.). Amostragem em Limnologia. São Paulo: Ed. RiMa, 2004. p. 295-320.

MOZETO, A.A. Coleta de sedimentos de ambientes aquáticos continentais, extração de águas intersticiais e determinação granulométrica. In: MOZETO, A.A.; UMBUZEIRO, G.A.; JARDIM, W.F. (Eds.). Métodos de coleta, análises físico-químicas e ensaios biológicos e ecotoxicológicos de sedimentos de água doce. Projeto Qualised. Ed.: Cubo, 2006. 224 p.

NASCIMENTO, R.L.D. Proposicão de Valores de Refereñcia para concentracão de metais $e$ metalóides em sedimentos límnicos e fluviais da Bacia Hidrográfica do Rio Tietê, SP. $2003142 \mathrm{f}$. Tese (Doutorado em Química Analítica), Instituto de Química, Universidade Federal de São Carlos, São Carlos. 2003.

ODUM, E. P. Ecologia. Rio de Janeiro: Guanabara, 1988. 434 p.

PADIAL, P. R. Qualidade, heterogeneidade espacial e biodisponibilidade de metais no sedimento de um reservatório tropical urbano eutrofizado (Reservatório Guarapiranga, SP). 2008. 109f. Dissertação (Mestrado em Ecologia) - Instituto de Biociências, Universidade de São Paulo, São Paulo. 2008.

PATELLA, E. Caracterização biogeoquímica dos estoques de metais pesados contaminantes $e$ nutrientes de testemunhos de sedimentos e particulados do reservatório do Guarapiranga, São Paulo. 31/07/1998. 89f. Dissertação (Mestrado em Ciência da Engenharia Ambiental) - Escola de Engenharia de São Carlos, Universidade de São Paulo, São Carlos. 1998.

PENNAK, R. W. Fresh-water invertebrates of the United States. Protozoa to Mollusca. John Wiley \& Sons, INC., 1989. p. 628. 
PÉREZ, G.R. Guía para el estudio de los macroinvertebrados acuáticos del Departamento de Antioquia. Colombia. 1988. 217 p.

RICHTER, E.M.; FORNARO, A.; LAGO, C.L. DO; ANNES, L. Avaliação da composição química de águas do sistema Guarapiranga: estudo de caso nos anos de 2002 e 2003. Quimica Nova, v. 30, n. 5, p. 1147-1152, 2007.

ROCHA, AA. A limnologia, os aspectos ecológicos-sanitários e a macrofauna bentônica da represa do Guarapiranga na Região Metropolitana de São Paulo. 1976. 194 f. Tese (Doutorado em Zoologia) - Instituto de Biociências, Universidade de São Paulo, São Paulo. 1976.

ROCHA, S.M. Macroinvertebrados bentônicos como indicadores de poluição na Represa do Guarapiranga - SP. 1999. 200 f. Dissertação (Mestrado em Saúde Pública) - Faculdade de Saúde Pública, Universidade de São Paulo, São Paulo. 1999.

RODGHER, S.; ESPÍNDOLA, E.L.G.; ROCHA, O.;FRACÁCIO, R.; PEREIRA, R.H.G.; RODRIGUES, M.H.S. Limnological and ecotoxicological studies in the cascade of reservoirs in the Tietê River (São Paulo, Brazil). Brazilian Journal of Biology, v. 65, n. 4, p. 697-710, 2005.

ROSENBERG, D. M.; RESH, V.H. Freshwater biomonitoring and benthic macroinvertebrates. New York: Chapmann \& Hall, 1993, 488 p.

SANTISCHI,P.H.; HÖHENER,P.;BERNOIT,G.;BRINK,M.B. Chemical processes at the sedimentwater interface. Marine Chemistry, v. 30, p. 269-315, 1990.

SHIMIZU, G.Y. et al. Estudos preliminares para o uso de índices biológicos no biomonitoramento de ambientes aquáticos continentais - riachos e corredeiras na bacia hidrográfica do rio Atibaia. Relatório Técnico: CETESB, agosto/2002. 85 p.

SILVA, M.R. et al. Distribuição de nutrientes em sedimentos fluviais do rio Itajaí-Açú, Blumenau, SC, Brasil. Ambiente e Água - Na Interdisciplinary Journal of Applied Science, v. 5, n. 1, p. 102$113,2010$.

TRIVINHO-STRIXINO, S. Larvas de Chironomidae (Diptera) do Estado de São Paulo: guia de identificação e diagnose dos gêneros. São Carlos, PPG-ERN/UFSCAR, 2011. 371 p.

UNITED STATES ENVIRONMENTAL PROTECTION AGENCY. Biological criteria for the protection of aquatic life: standardized biological field sampling and laboratory methods for assessing fish and macroinvertebrate communities. Collumbus, Ohio, v. 3, sec. 1, 1989. 19 p.

UNITED STATES ENVIRONMENTAL PROTECTION AGENCY. Method 3050B: Acid Digestion of Sediments, sludges and soils. Office of Research and Development. Washington, D. C.: December, 1996. 12 p.

UNITED STATES ENVIRONMENTAL PROTECTION AGENCY. Procedure for the derivation of Equilibrium Partitioning Sediment Benchmarks (ESBs) for the protection of benthic organisms: metal mixtures (cadmium, cooper, lead, nickel, silver and zinc. Office of Research and Development. Washington, D. C.: January, 2005 (EPA-600-R-02-011). 2005. 121 p.

WHATELY, M.; CUNHA, PM. Guarapiranga 2005: como e porque São Paulo está perdendo este manancial: resultados do diagnóstico socioambiental participativo da bacia hidrográfica da Guarapiranga. São Paulo: Instituto Socioambiental. 2006. 51 p. 
WIEDERHOLM, T. Use of benthos on the lake monitoring. Journal of the Water Pollution Control Federation, v. 52, p. 537-547, 1980.

WURDIG, N.; PINTO, I.D. Classe Ostracoda. In: BUCKUP, L.; BOND-BUCKUP, G. (Orgs.) Os Crustáceos do Rio Grande do Sul. Porto Alegre: Ed. Universidade/ UFRGS. 1999. p. 116-143. 
Capítulo 3: How do you deal with your organic sediment sample for benthic macroinvertebrate community analyses? 
IEAM - 1427

Integrated Environmental Assessment and Management - Volume 9999, Number 00 - pp. 1-2 - 2013 SETAC

HOW DO YOU DEAL WITH AN ORGANIC SEDIMENT SAMPLE FOR BENTHIC MACROINVERTEBRATE COMMUNITY ANALYSES?

Fernanda Lage* and Ana Lúcia Brandimarte Departamento de Ecologia, Instituto de Biociências, Universidade de Sáo Paulo, Sáo Paulo,

Sáo Paulo, Brazil

*fernandaparro@hotmail.com

DOI: 10.1002/ieam.1427

In 2010, we applied the Sediment Quality Triad to the Guarapiranga Reservoir in the State of São Paulo, Brazil. This reservoir has a history of abundant growth of aquatic plants and phytoplankton and is contaminated by metals in its water and sediment.

Abundant growth of primary producers is a common feature of large reservoir systems in tropical regions as a result of diffuse nutrient inputs from their drainage areas. To control this growth, copper sulfate is applied to reservoirs in Brazil to preserve the quality of water provided to the population.

Our study evaluated the influence of copper and other metals on the benthic macroinvertebrate community. The substrate of the reservoir and its tributaries was highly enriched with organic matter, an average of $35 \%$ organic matter.

The aquatic plant genus Polygonum (Figure 1B) dominated the water surface in Parelheiros tributary (Figure 1A). Samples for macroinvertebrate analyses were collected with an Eckman-Birge grab sampler, fixed with formaldehyde neutralized in the field, washed in the laboratory, preserved in $70 \%$ alcohol, and stained with rose Bengal to facilitate the sorting of organisms. While washing the preserved samples, we found many stems of Polygonum. As usual, we washed these stems under running water, taking care not to lose or damage any invertebrates and intended to then discard the stems. However, as we were doing this, we noticed pink structures coming out of the stems. We decided to keep the stems, put them in Petri dishes and open them under a stereo microscope.

We discovered that there were many oligochaetes (the pink structures) inside the monocotyledon stems (Figure 1C) We identified these oligochaetes as 1 species, Haemonais waldvogeli Bretscher 1900. It was the dominant oligochaete in our benthic samples where there was a predominance of Polygonum, but rare when this aquatic plant was absent.

This oligochaete species has been found previously in similar water bodies (Montanholi-Martins and Takeda 1999;

A

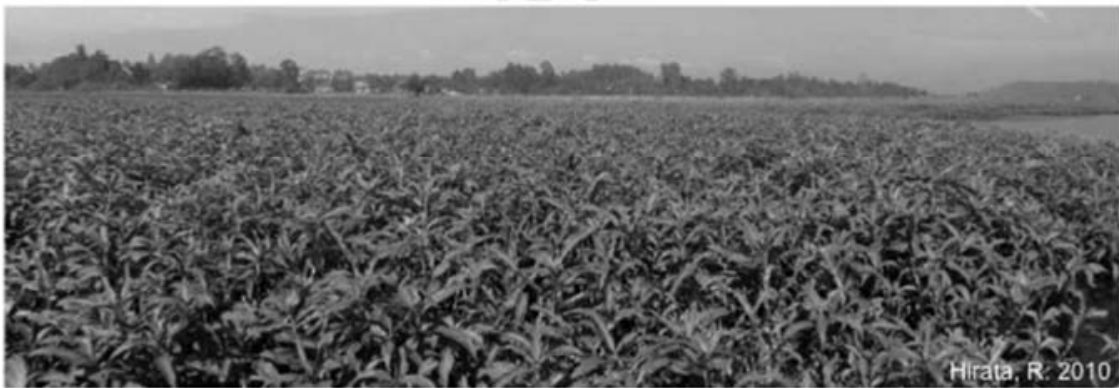

B

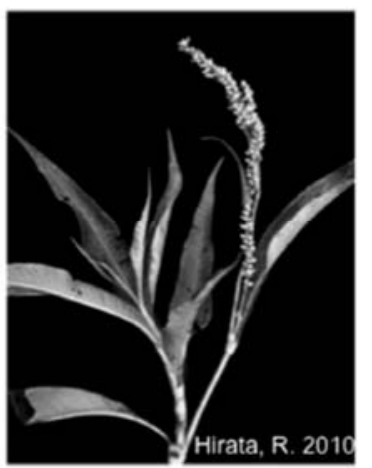

C

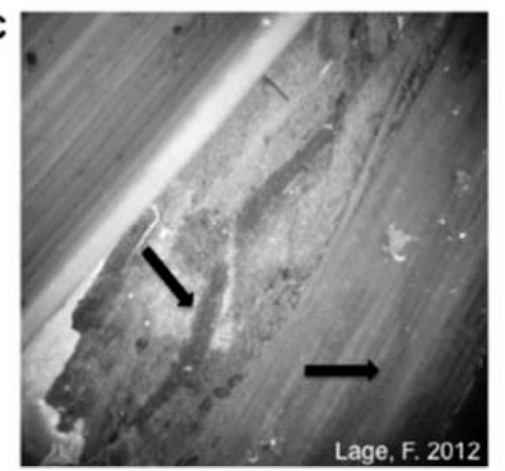

Figure 1. Presence in the reservoir of Hamonais waldvogeli inside the aquatic plant stem Polygonum. Polygonum in the reservoir (A). Polygonum (B). Oligochaeta found in the monocotyledon stem (C). 
Pamplin et al. 2005) and in association with the gastropod Pomacea (Gorni and Alves 2006). Pomacea was also observed in aquatic plants present in the Guarapiranga reservoir.

We now understand that $H$. waldvogeli living in the bottom substrate are more closely related to decomposing aquatic plants, especially Polygonum, than to the sediment. We also found high densities of oligochaetes from the genera Dero and Opistocysta in substrates containing leaves of Salvinia (a floating plant) in decomposition. Other organisms live in association with aquatic plants rooted in the sediments but not directly in or on the sediments (Strayer et al. 2003), including other oligochaetes (Paoletti and Sambugar 1984; Xie et al. 2008).

If we had not noticed and investigated the pink structures on the plant stems, our benthic invertebrate data would have been underestimated. As noted above, in some cases our data were dominated by this oligochaete species.

Based on our experience, we caution investigators conducting benthic studies in water bodies dominated by aquatic plants to take care to examine what may be living associated with aquatic plants but not directly associated with the sediments. We note that Haemonais waldvogeli has a worldwide distribution, and is thus a particular, but not the only, species to watch out for in such water bodies.

\section{REFERENCES}

Gorni GR, Alves RG. 2006. Naididae (Annelida, Oligochaeta) associated with Pomacea bridgesii (Reeve) (Gastropoda, Ampullaridae). Revista Brasileira de Zoologia 23:1059-1061.

Montanholi-Martins MC, Takeda AM. 1999. Communities of benthic oligochaetes in relation to sediment structure in the Upper Paraná River, Brazil. Studies on Neotropical Fauna and Environment 34:52-58.

Pamplin PAZ, Rocha O. Marchese M. 2005. Oligochaeta (Annelida, Clitellata) species richness in two reservoirs belonging to Tietê River System (Saao Paulo). Biota Neotropica 5:63-70.

Paoletti A, Sambugar B. 1984. Oligochaeta of the middle Po River (Italy): principal component analysis of the benthic data. Hydrobiologia 115:145-152.

Strayer DL, Lutz C, Malcom HM, Munger K, Shaw WH. 2003. Invertebrate communities associated with a native (Vallisneria americana) and an alien (Trapa natans) macrophyte in a larger river. Freshw Biol 48:1938-1949.

Xie Z, Shu S, Zhang J, Chen J, Cai Q. 2008. Oligochaete assemblages associated with macrophytes in the Liangzi Lake District, China. J Freshw Ecol 23:237-244. 
Capítulo 4: Composição da fauna bentônica em quatro regiões de um reservatório raso tropical em diferentes períodos do ano 


\title{
Composição da fauna bentônica em quatro regiões de um reservatório raso tropical em diferentes períodos do ano
}

\begin{abstract}
This study aimed to evaluate the variation of the environmental conditions imposed by the summer and winter on the composition of benthic fauna and sediment in the Guarapiranga reservoir in the Metropolitan Region of São Paulo (Brazil). In February and July 2010, in each one of four sampling sites of the reservoir (mouth of the three main tributaries and near the dam), six samples were collected with sediment grab Ekman-Birge for analysis of benthic fauna and two with corer Ambühl and Bührer for analysis of physical and chemical parameters of the sediment pore water and bottom. Fauna is represented in the four sites mainly by Nematoda, Hirudinea, Oligochaeta and Chaoboridae, and those latter two were more abundant. The Canonical Correspondence Analysis ordered samples collected in different months indicating significant influence of the temperature of the pore water, which average varied between sites $6^{\circ} \mathrm{C}$ from one month to another. Higher levels of organic matter were observed in July in the mouth of a tributary and the site near the dam, with 39\% and $35 \%$, respectively. The content of dissolved oxygen in the bottom water was less than $2.4 \mathrm{mg} \mathrm{L}^{-}$ ${ }^{1}$ in all the sites. The study observed high concentrations of nitrogen and total phosphorus in the sediment, with maximum values of $5998 \mathrm{mgN} \cdot \mathrm{g}^{-1}$ and $2627 \mathrm{mgP} . \mathrm{g}^{-1}$. Temperature and organic matter in the sediment seem to have limited benthic community, leading to a higher density of organisms in the winter, possibly due to its influence on the availability of dissolved oxygen.
\end{abstract}

\section{Resumo}

Este estudo visou avaliar a variação entre as condições ambientais impostas pelo verão e inverno sobre a composição da fauna bentônica e o sedimento no reservatório Guarapiranga, Região Metropolitana de São Paulo (Brasil). Em fevereiro e julho de 2010, e em quatro pontos do reservatório (foz dos três principais tributários e próximo à barragem), foram coletadas seis amostras de sedimento com pegador Ekman-Birge para análises da fauna bentônica e duas com corer Ambühl e Bührer para análises de variáveis físicas e químicas do sedimento, água intersticial e de fundo. A fauna foi representada nos quatro pontos principalmente por Nematoda, Hirudinea, Oligochaeta e Chaoboridae, sendo que os dois últimos foram mais abundantes. A Análise de Correspondência Canônica ordenou os pontos de coleta nos diferentes meses indicando influência significativa da temperatura da água intersticial, cuja média entre os pontos variou cerca de $6^{\circ} \mathrm{C}$ de um mês para outro. Maiores teores de matéria orgânica foram observados em julho na foz de um dos tributários e no ponto próximo à barragem, com $39 \%$ e $35 \%$, respectivamente. $\mathrm{O}$ teor de oxigênio dissolvido na água de fundo foi inferior a $2,4 \mathrm{mg} . \mathrm{L}^{-1}$ em todos os pontos. Foram observadas altas concentrações de nitrogênio e fósforo totais no sedimento, com valores máximos de $5998 \mu \mathrm{g} \mathrm{N} . \mathrm{g}^{-1}$ e $2627 \mu \mathrm{g} \mathrm{P.g}{ }^{-1}$. A temperatura e o teor de matéria orgânica no sedimento parecem ter limitado a comunidade bentônica, levando a uma maior densidade de organismos no inverno, possivelmente devido à sua influência sobre a disponibilidade de oxigênio dissolvido. 


\subsection{Introdução}

A Região Metropolitana de São Paulo (RMSP) é constituída por uma grande área urbana, com tendência à expansão para as zonas periféricas, ocupadas principalmente pela população de baixa renda. Tal expansão desordenada agrava a degradação ambiental, especialmente nas áreas de proteção de mananciais e de várzeas, associada à uma disposição inadequada de resíduos sólidos e impermeabilização do solo (SMA/CEA, 2008). Este é o caso do reservatório Guarapiranga, na qual o esgoto e a poluição difusa constituem as principais fontes de poluentes, tendo íntima ligação com a deficiência dos serviços de saneamento. Estudos realizados pela CETESB (2008), entre 1989 e 2004, e Caleffi e col. (1994), indicaram, um elevado aporte de esgotos domésticos pelo rio Parelheiros e, em menor intensidade, pelos rios Embu-Guaçu e Embu-Mirim. Também foi observada na região de captação de água da Sabesp - a $2 \mathrm{Km}$ da barragem -, alta concentração de fósforo total (CETESB, 2008).

Ao longo dos anos, uma série de trabalhos não publicados, representados por relatórios técnicos e teses, sobre a fauna bentônica do Guarapiranga evidencia a diferença sazonal desta comunidade, indicando maior abundância total e maior riqueza de grupos no inverno. Tal comunidade foi relacionada a aspectos limnológicos e sanitários e aqueles estudos advertiam sobre a necessidade do controle da eutrofização. Beyruth (2000) mostrou a dominância de grupos indicadores. Richter e col. (2007) observaram, assim como Mozeto e col. (2001), concentrações de metais e nutrientes que indicam forte contaminação antropogênica no Embu-Guaçu comparado a pontos próximos à barragem.

Apesar deste conjunto de informações relativamente extenso, faltam trabalhos que caracterizem melhor o sedimento e a fauna bentônica de forma a contribuir para o manejo deste corpo d'água, em função de sua importância para o abastecimento da RMSP e dos impactos antropogênicos que vem sofrendo. Neste sentido, este trabalho tem o objetivo de avaliar os fatores que influenciam a fauna bentônica em dois meses representantes de verão e inverno, através da análise de sua composição e das características do sedimento em quatro pontos do reservatório.

\subsection{Materiais e Métodos}

\subsection{1. Área de estudo}

O reservatório Guarapiranga localizado na Bacia do Alto Tietê (Figura 1) é considerada um reservatório urbano. O município de São Paulo contorna toda a margem direita e parte da margem esquerda, abrangendo $70 \%$ do perímetro da represa, sendo o restante limitado aos municípios de Embu-Guaçu (27\%) e Itapecerica da Serra (3\%) (Pedroso, 1960). 


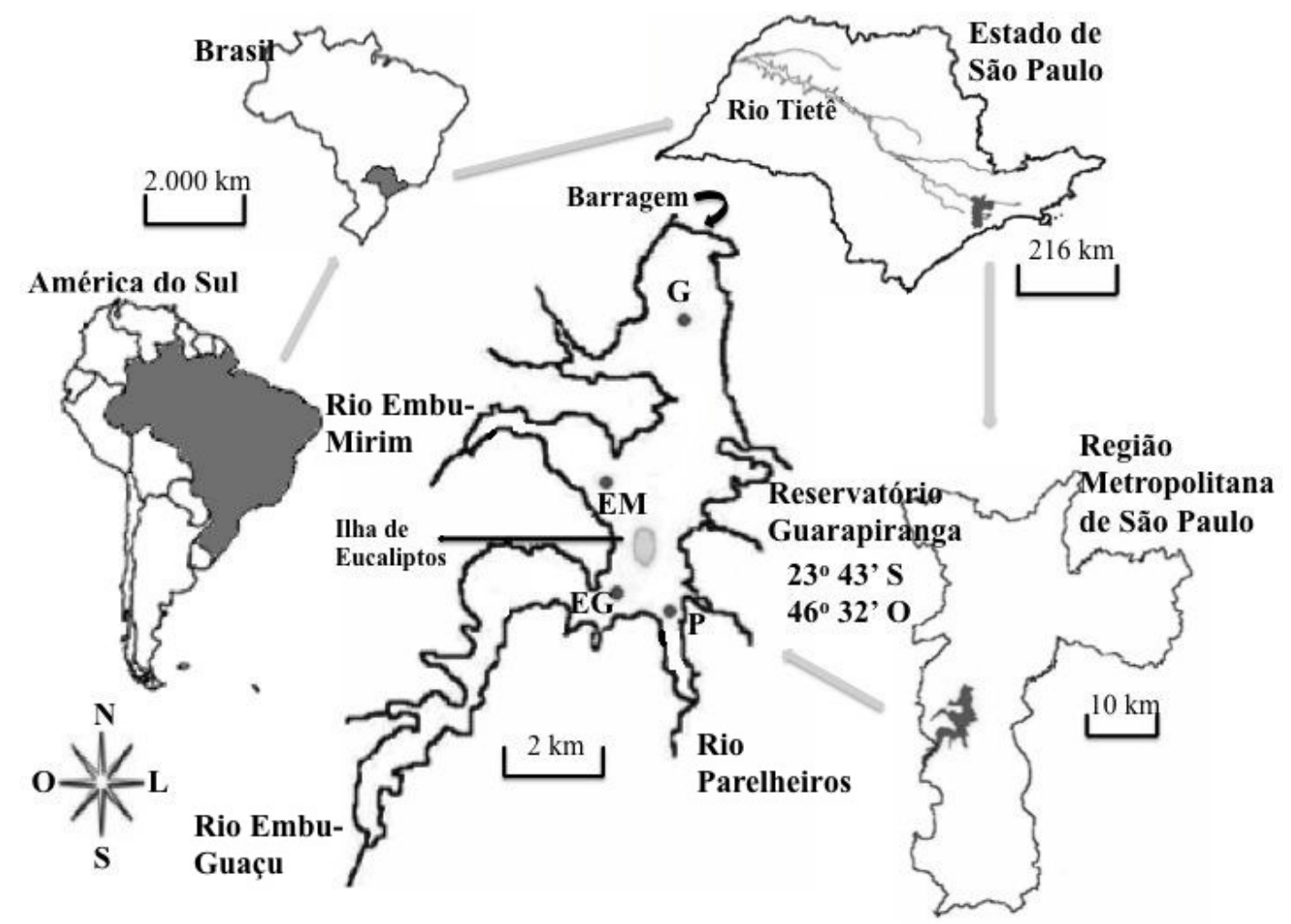

Figura 1. Localização do Reservatório Guarapiranga (SP - Brasil). Pontos de coleta: G: Guarapiranga; EM: Embu-Mirim; EG: Embu-Guaçu; P: Parelheiros.

Com uma área de drenagem de $639 \mathrm{Km}^{2}$, a bacia constitui atualmente o segundo maior manancial dos sistemas de abastecimento da Região Metropolitana de São Paulo. Produz em média 14 mil litros de água por segundo para atender cerca de 3,7 milhões de habitantes (20\% da população da RMSP) (Helou \& Silva, 1987; Whately \& Cunha, 2006).

A área da Bacia do Guarapiranga abrange remanescentes de Mata Atlântica e inclui Mata Atlântica em estágio inicial, médio e avançado de regeneração, Mata Atlântica primária, várzea e campo de altitude (Whately \& Cunha, 2006).

O modelo topográfico da represa, de morfologia dendrítica, estreita e alongada, formada na base da bacia de drenagem e vale de rios, favorece os usos e ocupação do solo e desta forma a ação antrópica (Pedroso, 1960).

Apresenta profundidade máxima, próximo à barragem, de $13 \mathrm{~m}$ e no restante a média de 6 $\mathrm{m}$, considerado assim um ambiente raso. Pode ser considerada polimítica, devido às correntes internas nos canais dos rios formadores e a ação dos ventos.

\subsubsection{Amostragem}




\subsubsection{Sedimento}

As amostragens do sedimento foram realizadas em fevereiro e julho de 2010, na região médio-profundal, no ponto Guarapiranga $(\mathrm{G})$ a $2 \mathrm{~km}$ da barragem e em 3 pontos

localizados na foz dos 3 principais tributários: Embu-Guaçu (EG), Embu-Mirim (EM), e Parelhereiros $(\mathrm{P})$, respectivamente com profundidades de: 11, 7,2, 6,3 e $5 \mathrm{~m}$.

Para análises de granulometria (método úmido adaptado por Meguro, 2000), concentração de matéria orgânica (perda por ignição, $550^{\circ} \mathrm{C} / 1 \mathrm{~h}$ ), nitrogênio total (método Kjedahl) e fósforo total (método colorimétrico), foram recolhidos os primeiros $10 \mathrm{~cm}$ de sedimento de duas amostras recolhidas com o amostrador tipo corer Ambül e Bührer. Estas foram guardadas em sacos plásticos do tipo zip lock, previamente lavados com $\mathrm{HCl} 10 \%$, e postas em imersão em gelo a $4^{\circ} \mathrm{C}$ (Mozeto, 2004). Variáveis físicas e químicas da água intersticial e a $5 \mathrm{~cm}$ do fundo foram medidas em todos os pontos no momento das coletas: $\mathrm{pH}$, temperatura da água, condutividade (sonda YSI modelo 63/100 FT) e potencial de oxi-redução (sonda Hanna); oxigênio dissolvido (método Winkler). Para nitrogênio e fósforo totais e granulometria, as análises foram feitas nas duas amostras. Já para as variáveis abióticas medidas pelas sondas, foram obtidos os valores absolutos de uma das amostras.

\subsubsection{Macroinvertebrados bentônicos}

Para o estudo da fauna bentônica, foram coletadas 6 unidades amostrais em cada ponto em fevereiro e julho, por meio de pegador do tipo Ekman-Birge $\left(225 \mathrm{~cm}^{2}\right)$. As amostras foram lavadas em rede de abertura de malha de $500 \mu \mathrm{m}$, guardadas em sacos plásticos tipo zip lock e fixadas imediatamente com formol neutralizado 4\%. Em laboratório foram novamente lavadas em peneira de mesma abertura de malha, coradas com Rosa de Bengala e armazenadas em álcool 70\%. Os organismos foram triados e identificados em lupa estereoscópica em grupos..

Foi determinada a abundância relativa (\%) de cada taxon e a riqueza de taxa.

\subsubsection{Análises exploratórias}

Foi realizada uma Análise de Correspondência Canônica (ACC), para ordenar as variáveis, por meio do programa R Cran Project (2005). Devido ao baixo número de correlações significativas utilizando um limite de 95\%, foram realizadas 1.000 permutações utilizando um nível de significância de $\mathrm{p}=0,03$ para variáveis abióticas e $\mathrm{p}=0,05$ para bióticas. Foram realizadas Análises de Variância (ANOVA), para verificar as diferenças entre variáveis bióticas, entre os dois meses e entre os quatro pontos analisados. A posteriori, o teste de Fisher LSD, foi usado para identificar a significância das diferenças entre variáveis bióticas em relação aos meses e pontos amostrados e o teste de Tukey para indicar a diferença entre as médias das densidades da Anova. As análises de variância e os testes de Fisher e de Tukey foram feitos utilizando o programa Statistica 6.0. 


\subsection{Resultados}

O conteúdo de matéria orgânica está correlacionado negativamente a ambos os eixos da ACC (Figura 2). A presença de silte está mais correlacionada ao eixo 1, o qual explica 35\% da ordenação. Já condutividade elétrica e temperatura (positivamente), oxigênio dissolvido, argila e areia grossa (negativamente) estão mais correlacionados ao eixo 2 , o qual explica $28 \%$ da ordenação. Nematoda e Hirudinea se relacionam negativamente com a temperatura e, em julho, se associam ao Parelheiros (P). Neste mesmo mês, Ceratopogonidae se associou ao EG e ao EmbuMirim (EM). Ephemeroptera se relacionou com a presença de areia grossa e negativamente com a temperatura. Oligochaeta e Chaoboridae se associaram principalmente com os quatro pontos em fevereiro e com G e EM em julho, se relacionando positivamente com a temperatura e negativamente com o teor de matéria orgânica. De acordo com a análise, os quatro pontos de amostragem mostram-se mais similares entre si em fevereiro que em julho.

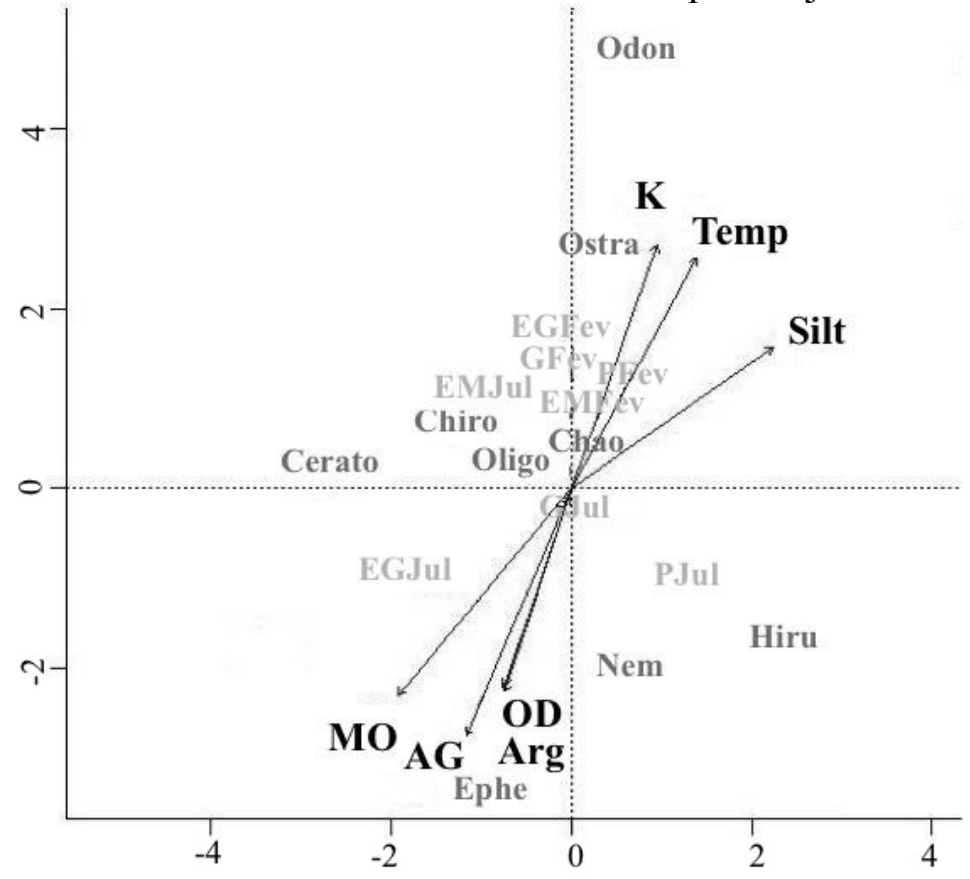

Figura 2. Diagrama de ordenação produzido pela Análise de Correspondência Canônica das variáveis abióticas e bióticas de quatro pontos do reservatório Guarapiranga (SP - Brasil), nos meses de fevereiro e julho de 2010. Taxa, pontos e meses estão abreviados assim como as variáveis abióticas, representadas por vetores, respectivamente por Nem: Nematoda; Chiro: Chironomidae; Ephe: Ephemeroptera; Hiru: Hirudinea; Ostra: Ostracoda; Oligo: Oligochaeta; Chao:Chaoboridae; Cera: Ceratopogonidae e Odon: Odonata; G: Guarapiranga; EM: Embu-Mirim; EG: Embu-Guaçu; P: Parelheiros; Jul: julho; Fev: fevereiro; MO: matéria orgânica; AG: areia grossa; Arg: argila; OD: oxigênio dissolvido; K: condutividade; Temp: temperatura; Silt: silte; 
Tabela 1. Coordenadas para variáveis bióticas e abióticas nos Eixos de Ordenação da Análise de Correspondência Canônica de quatro pontos do reservatório Guarapiranga (SP - Brasil), nos meses de fevereiro e julho de 2010. CA1: eixo de correspondência canônica 1; CA2: eixo de correspondência canônica $2 ; \mathrm{r}^{2}$ : coeficiente de correspondência canônica ajustado; $p$ : nível de significância; Oligo: Oligochaeta; Hiru: Hirudinea; Ephe: Ephemeroptera; Chiro: Chironomidae; Cera: Ceratopogonidae Chao: Chaoboridae; Nem: Nematoda; Ostra: Ostracoda; e Odon: Odonata; pH: potencial hidrogeniônico; K: condutividade; Temp: temperatura; Eh: potencial redox; OD: oxigênio dissolvido; MO: matéria orgânica; NKT: nitrogênio total; PT: fósforo total; AG: areia grossa; AF: areia fina.

\begin{tabular}{|c|c|c|c|c|c|}
\hline & CA1 & CA2 & $\mathrm{r}^{2}$ & $p$ & \\
\hline \multicolumn{6}{|c|}{ Variáveis Bióticas } \\
\hline Oligo & $-0,43229$ & $-0,90173$ & 0,7661 & 0,011988 & $*$ \\
\hline Hiru & 0,73839 & $-0,67438$ & 0,7563 & 0,082917 & \\
\hline Clad & $-0,88529$ & $-0,46504$ & 0,9369 & 0,000999 & $* * *$ \\
\hline Cop & $-0,51887$ & $-0,85846$ & 0,7870 & 0,048951 & $*$ \\
\hline Ephe & $-0,34920$ & $-0,93705$ & 0,7869 & 0,030969 & $*$ \\
\hline Chiro & $-0,94864$ & $-0,31635$ & 0,4406 & 0,240759 & \\
\hline Cera & $-0,97654$ & $-0,21535$ & 0,8891 & 0,006993 & $* *$ \\
\hline Chao & 0,17236 & $-0,98503$ & 0,6487 & 0,058941 & \\
\hline Nema & 0,21894 & $-0,97574$ & 0,9251 & 0,005994 & $* *$ \\
\hline Ostra & 0,23411 & 0,97221 & 0,0790 & 0,790210 & \\
\hline Zigo & 0,01927 & 0,99981 & 0,1805 & 0,379620 & \\
\hline \multicolumn{6}{|c|}{ Variáveis Abióticas } \\
\hline $\mathrm{pH}$ & 0,767602 & 0,640927 & 0,1146 & 0,75824 & \\
\hline Cond & 0,330705 & 0,943734 & 0,6718 & 0,05195 & \\
\hline Temp & 0,478431 & 0,878125 & 0,6979 & 0,02098 & $*$ \\
\hline $\mathrm{Eh}$ & 0,906332 & 0,422566 & 0,1912 & 0,59740 & \\
\hline OD & $-0,321539$ & $-0,946896$ & 0,4419 & 0,24076 & \\
\hline MO & $-0,642303$ & $-0,766451$ & 0,7378 & 0,03796 & $*$ \\
\hline NKT & 0,076765 & 0,997049 & 0,2299 & 0,57243 & \\
\hline PT & 0,987217 & 0,159382 & 0,0766 & 0,83916 & \\
\hline $\mathrm{AG}$ & $-0,389419$ & $-0,921061$ & 0,7289 & 0,09491 & \\
\hline $\mathrm{AF}$ & $-0,383480$ & 0,923549 & 0,1935 & 0,57742 & \\
\hline Arg & $-0,310864$ & $-0,950454$ & 0,4658 & 0,19980 & \\
\hline Silt & 0,818107 & 0,575066 & 0,6080 & 0,20879 & \\
\hline
\end{tabular}


As coordenadas da Análise de Correspondência Canônica e os respectivos valores de $p$ estão apresentados na Tabela 1. Dentre as variáveis bióticas, Cladocera, Ceratopogonidae e Nematoda mostraram-se mais significantes $(\mathrm{p}<0,001)$, seguidos por Oligochaeta, Ephemeroptera e Copepoda $(\mathrm{p}<0,05)$ e dentre as abióticas, a temperatura da água intersticial foi significante $(\mathrm{p}<0,03)$ e a matéria orgânica marginalmente significante $(\mathrm{p}=0,03796)$.

Em fevereiro menor valor de riqueza de táxons foi observado no ponto próximo à barragem $(S=2)$, enquanto os valores em $P, E G$ e EM foram 7, 6 e 5, respectivamente. Já em julho a riqueza foi igual para todos os pontos $(S=7)$, com exceção de $E G(S=9)$.

As ANOVAs mostraram diferenças entre as médias de densidades entre meses (Figura 3, Tabela 2). Os grupos que apresentaram variação significativa foram Nematoda, Oligochaeta, Cladocera, Chaoboridae, Hirudinea, Copepoda e Ceratopogonidae apresentando densidades de 6 a 23 vezes maiores em julho. 
Nematoda

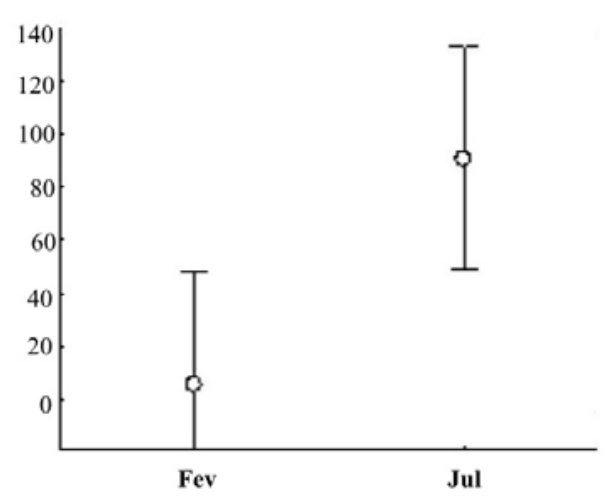

Hirudinea

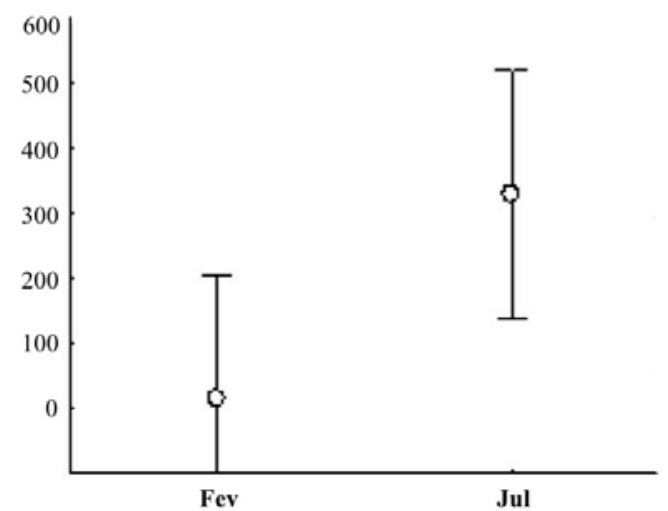

Chaoboridae

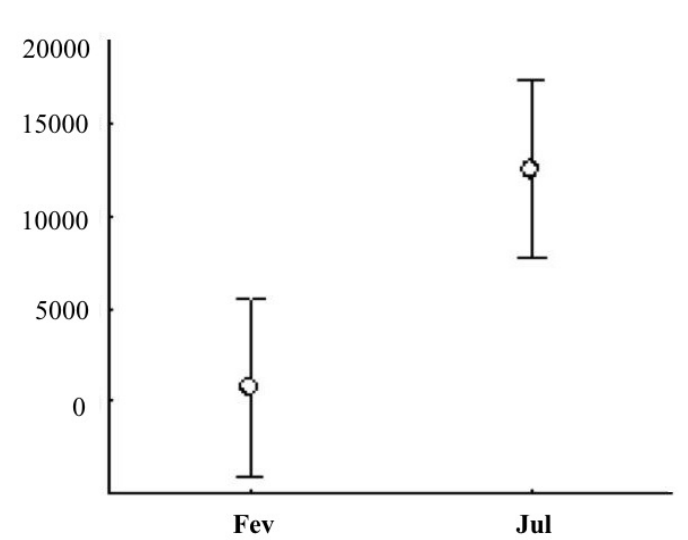

Oligochaeta

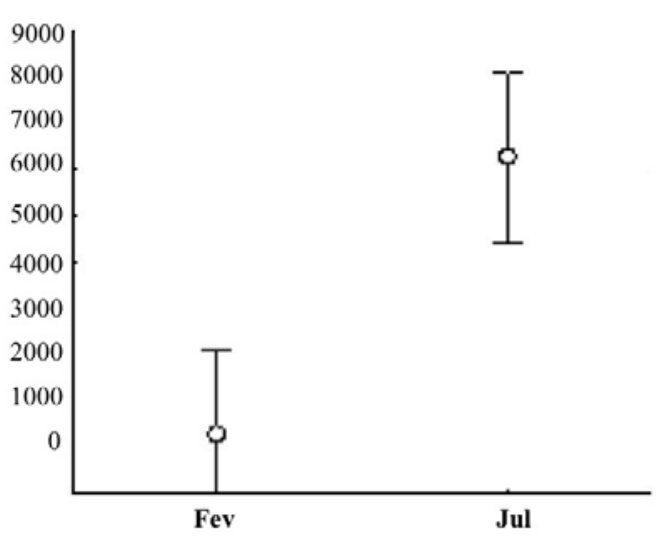

Ceratopogonidae

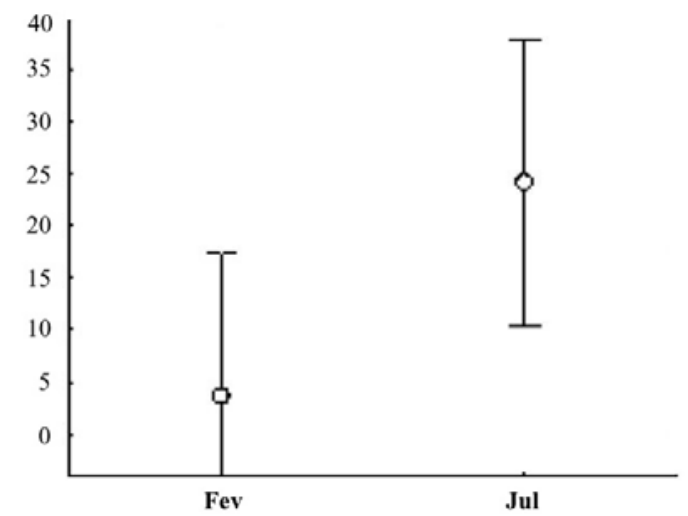

Abundância Média

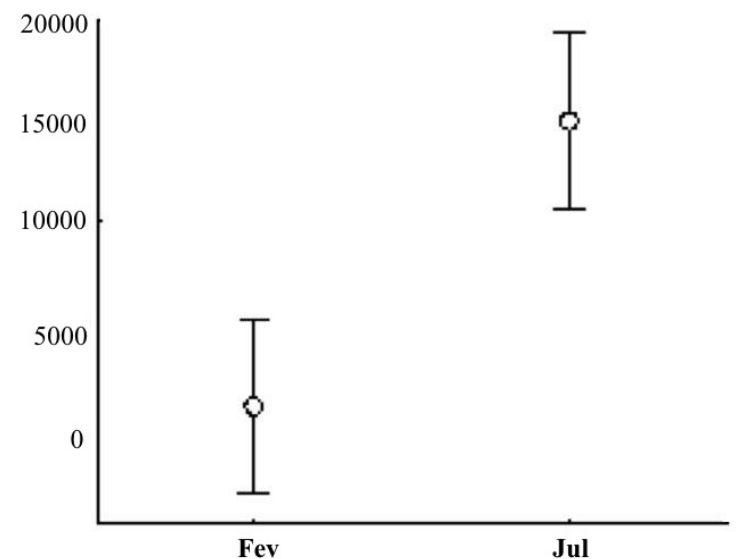

Figura 3. Gráficos das Análises de Variâncias (ANOVA) mostrando os valores de abundância média e erro padrão da fauna total e dos grupos taxonômicos (ind. $\mathrm{m}^{-2}$ ) para os quais foram detectadas diferenças significativas entre os meses de amostragem. Fev: fevereiro; Jul: julho; 
Tabela 2. Resultados do teste de Fisher com os valores de $\mathrm{F}$ e $p$ para as variáveis bióticas entre meses (fev-jul) e entre pontos (GUA, EM, EG, PAR). Valores significativos em negrito para $\mathrm{p}<0,05$.

\begin{tabular}{cllll}
\hline \multirow{2}{*}{ Taxa } & \multicolumn{2}{c}{$\begin{array}{c}\text { Anova } \\
\text { (Meses) }\end{array}$} & \multicolumn{2}{c}{$\begin{array}{c}\text { Anova } \\
\text { (Pontos) }\end{array}$} \\
\cline { 2 - 5 } & \multicolumn{1}{c}{$\mathrm{F}$} & $p$ & $\mathrm{~F}$ & $p$ \\
\cline { 2 - 5 } Turbellaria & 1,00 & 0,32 & 1,00 & 0,40 \\
Nematoda & 15,96 & $\mathbf{0 , 0 0}$ & 2,23 & 0,10 \\
Bivalve & 1,00 & 0,32 & 1,00 & 0,40 \\
Oligochaeta & 73,54 & $\mathbf{0 , 0 0}$ & 0,90 & 0,45 \\
Hirudinea & 4,85 & $\mathbf{0 , 0 3}$ & 13,50 & $\mathbf{0 , 0 0}$ \\
Ostracoda & 0,01 & 0,94 & 1,32 & 0,28 \\
Odonata & 1,00 & 0,32 & 1,00 & 0,40 \\
Ephemeroptera & 3,29 & 0,08 & 1,30 & 0,29 \\
Chironomidae & 1,82 & 0,18 & 2,24 & 0,10 \\
Ceratopogonidae & 4,04 & $\mathbf{0 , 0 5}$ & 4,47 & $\mathbf{0 , 0 1}$ \\
Chaoboridae & 9,44 & $\mathbf{0 , 0 0}$ & 8,91 & $\mathbf{0 , 0 0}$ \\
Densidade Total & 55,07 & $\mathbf{0 , 0 0}$ & 5,21 & $\mathbf{0 , 0 0}$ \\
\hline
\end{tabular}

Diferenças significativas entre os pontos de amostragem foram observadas para Hirudinea, Chaoboridae e Ceratopogonidae (Figura 4; Tabela 2). Chaoboridae foi dominante em todos os pontos em fevereiro, representando mais de $65 \%$ dos organismos e, em julho, foi dominante apenas em P com mais de 80\%, enquanto Oligochaeta foi dominante nos demais pontos (Figura 5). 


\section{Hirudinea}

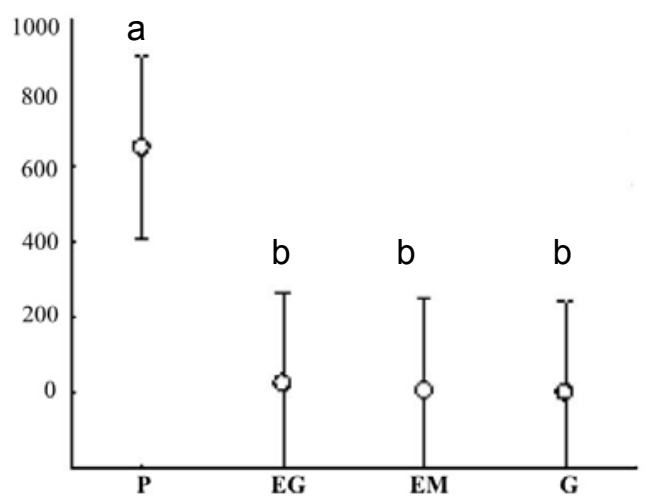

Chaoboridae

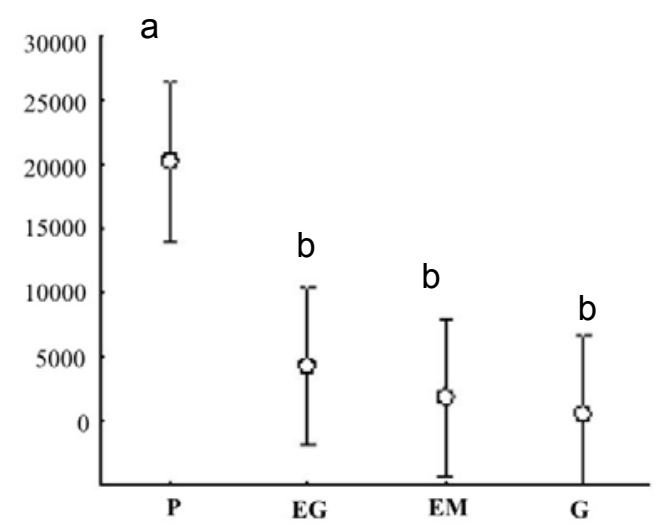

\section{Ceratopogonidae}

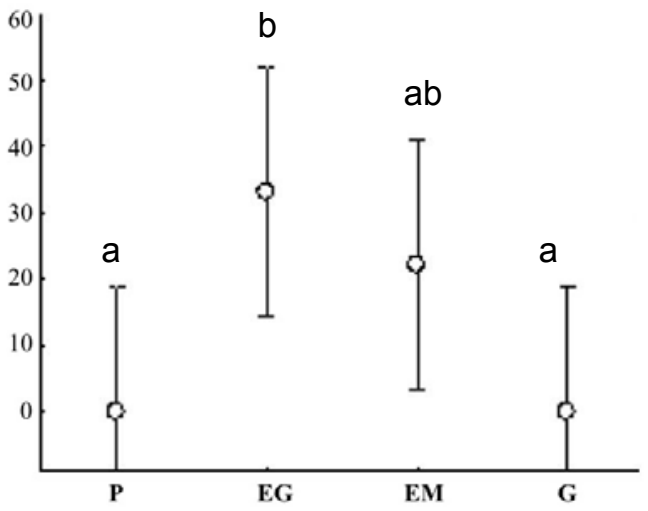

Abundância Média

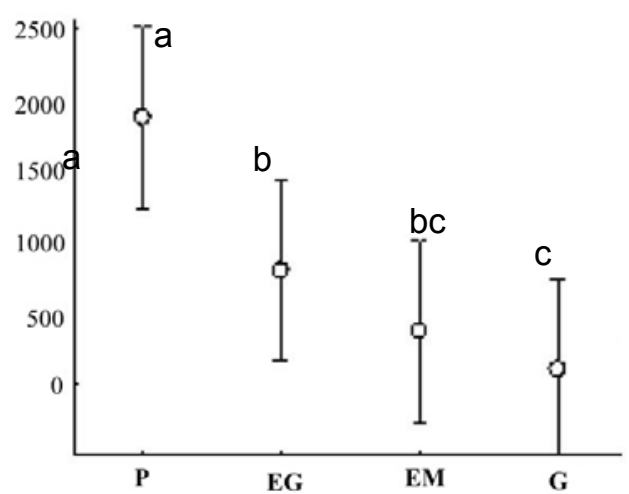

Figura 4. Gráficos das Análises de Variâncias (ANOVA) mostrando os valores de abundância média e erro padrão da fauna total e dos grupos taxonômicos (ind. $\mathrm{m}^{-2}$ ) para os quais foram detectadas diferenças significativas comparando-se os quatro pontos de amostragem. P: Parelheiros; EG: Embu-Guaçu; EM: Embu-Mirim; G: Guarapiranga; a, b, c, d indicam diferentes médias, segundo o teste de Tukey. 


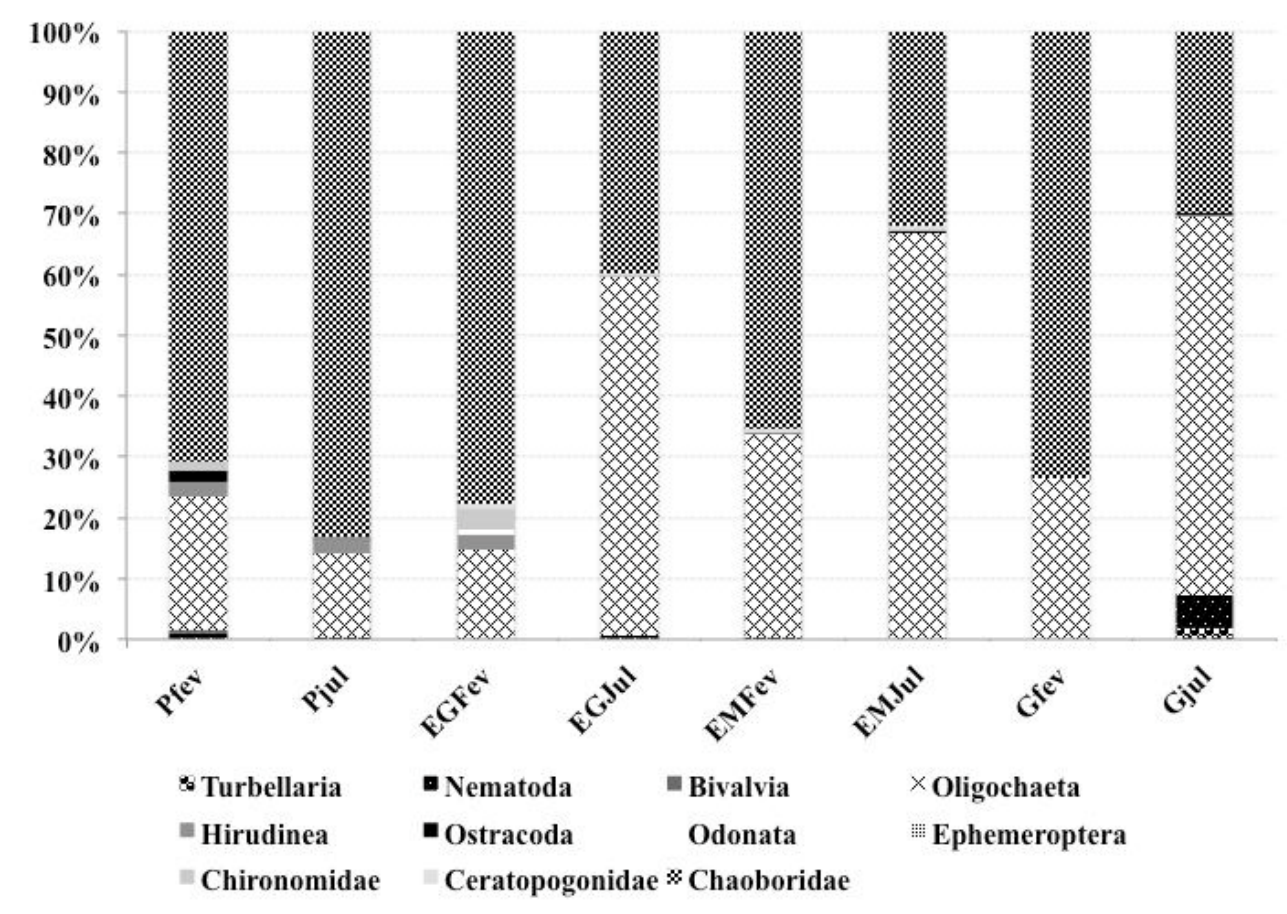

Figura 5. Abundância relativa dos grupos taxonômicos de quatro pontos do reservatório Guarapiranga (SP - Brasil), nos meses de fevereiro e julho de 2010. Onde: P: Parelheiros; EG: Embu-Guaçu; EM: Embu-Mirim; G: Guarapiranga; Fev: fevereiro; Jul: julho.

A temperatura apresentou variação de 18 a $26,2{ }^{\circ} \mathrm{C}$ (Tabela 3 ), com médias de $18,7^{\circ} \mathrm{C}$ em julho e $25^{\circ} \mathrm{C}$ em fevereiro. $\mathrm{O}$ teor de matéria orgânica aumentou de 40 a $60 \%$ entre fevereiro e julho em todos os pontos, exceto EM que continuou em torno de $30 \%$. Os maiores teores foram observados em EG (39\%) e G (35\%). A condutividade elétrica revelou-se elevada em todos os pontos amostrados e com maiores valores em fevereiro $\left(\mathrm{EM}=267 \mu \mathrm{S} \mathrm{cm}^{-1}\right)$. O EG apresentou $50 \%$ de areia grossa em julho, diferindo dos demais pontos/meses que tiveram predominância de sedimento siltoso, acima de $70 \%$ de silte.

$\mathrm{O} \mathrm{pH}$ apresentou-se levemente ácido em todo o reservatório, com média de 6,68. O potencial de oxi-redução do sedimento foi mais alto em fevereiro comparado a julho, com respectivas médias de $132 \mathrm{mV}$ e $87 \mathrm{mV}$. A solubilidade do oxigênio foi menor que $2,4 \mathrm{mg} \mathrm{L}^{-1} \mathrm{em}$ todos os pontos nos dois meses. O teor de nitrogênio total foi alto em todos os pontos, sendo que os maiores valores foram observados em EM e $\mathrm{G}$ em ambos os meses. As maiores concentrações de fósforo foram observadas no $\mathrm{G}\left(3191 \mu \mathrm{g} \mathrm{P} \mathrm{g}^{-1}\right)$ e as menores no $\mathrm{EG}$ (1505 $\left.\mu \mathrm{g} \mathrm{P} \mathrm{g}^{-1}\right)$, nos dois meses analisados. 
Tabela 3. Variáveis ambientais com valores medidos na água intersticial (pH, cond.,Temp. e Eh), água de fundo (OD) e sedimento (\%MO) e valores médios (mínimo-máximo) medidos no sedimento (NT, PT, AG, AF, Sil, Arg) no reservatório Guarapiranga (SP Brasil), fevereiro e julho de 2010. pH: potencial hidrogeniônico; Cond: condutividade; Temp:temperatura; Eh: potencial de oxi-redução; OD: oxigênio dissolvido; MO: matéria orgânica; NT: nitrogênio total; PT: fósforo total; AG: areia grossa; AF: areia fina; Arg: argila; Silt: silte.

\begin{tabular}{|c|c|c|c|c|c|c|c|c|}
\hline \multirow[t]{2}{*}{ Variáveis } & \multicolumn{2}{|c|}{$\mathbf{P}$} & \multicolumn{2}{|c|}{ EG } & \multicolumn{2}{|c|}{ EM } & \multicolumn{2}{|c|}{$\mathbf{G}$} \\
\hline & Fev & Jul & Fev & Jul & Fev & Jul & Fev & Jul \\
\hline \multicolumn{9}{|l|}{ Água Intersticial: } \\
\hline $\mathrm{pH}$ & 6,45 & 6,67 & 6,82 & 6,49 & 6,67 & 6,63 & 6,83 & 6,89 \\
\hline Cond $\left(\mu \mathrm{S} . \mathrm{cm}^{-1}\right)$ & 227 & 106 & 277 & 96 & 267 & 139 & 165 & 178 \\
\hline Temp $\left({ }^{\circ} \mathrm{C}\right)$ & 26,24 & 18,51 & 24,61 & 18,02 & 24,88 & 18,5 & 24,7 & 19,66 \\
\hline $\mathrm{Eh}(\mathrm{mV})$ & 160 & 106 & 106 & 106 & 106 & 65 & 158 & 71 \\
\hline \multicolumn{9}{|l|}{$\begin{array}{c}\text { Água de fundo (5 } \\
\text { cm): }\end{array}$} \\
\hline OD $\left(\mathrm{mg} \cdot \mathrm{L}^{-1}\right)$ & 0,2 & 2,14 & 0,28 & 1,42 & 0,1 & 2,31 & 0,4 & 1,42 \\
\hline \multicolumn{9}{|l|}{ Sedimento: } \\
\hline $\mathrm{MO}(\%)$ & 19,45 & 29,74 & 24,21 & 38,82 & 30,6 & 30,22 & 24,26 & 34,73 \\
\hline \multirow[t]{2}{*}{ NT $\left(\mu \mathrm{g} \mathrm{N} \cdot \mathrm{g}^{-1}\right)$} & 5017 & 4637,86 & 5244,5 & 4019,12 & 7219,5 & 6914,21 & 6513,5 & 7660,56 \\
\hline & $\begin{array}{l}(4607- \\
5427)\end{array}$ & $\begin{array}{l}(4545- \\
4730)\end{array}$ & $\begin{array}{l}(5229- \\
5260)\end{array}$ & $\begin{array}{c}(3669- \\
4368)\end{array}$ & $\begin{array}{l}(7053- \\
7386)\end{array}$ & $\begin{array}{c}(6831- \\
6996)\end{array}$ & $\begin{array}{c}(6331- \\
6696)\end{array}$ & $(7660,56)$ \\
\hline \multirow[t]{2}{*}{ PT $\left(\mu \mathrm{g} \mathrm{P} \cdot \mathrm{g}^{-1}\right)$} & 1733,67 & 2627,45 & 1633,75 & 1376,17 & 2251,65 & 3083,17 & 2957,59 & 3424,00 \\
\hline & $\begin{array}{l}(1717- \\
1750)\end{array}$ & $\begin{array}{l}(2575- \\
2680)\end{array}$ & $\begin{array}{l}(1593- \\
1674)\end{array}$ & $\begin{array}{l}(1372- \\
1380)\end{array}$ & $\begin{array}{l}(2235- \\
2268)\end{array}$ & $\begin{array}{l}(3075- \\
3091)\end{array}$ & $\begin{array}{l}(2933- \\
2982)\end{array}$ & $\begin{array}{l}(3408- \\
3440)\end{array}$ \\
\hline \multirow[t]{2}{*}{$\mathrm{AG}$} & 0,91 & 9,29 & 0,83 & 50,21 & 0,14 & 0,63 & 1,25 & 0,72 \\
\hline & $(0,55-1,37)$ & $\begin{array}{l}(4,62- \\
13,63)\end{array}$ & $(0,70-0,97)$ & $\begin{array}{l}(46,40- \\
53,72)\end{array}$ & $(0,13-0,16)$ & $(0,53-0,73)$ & $(0,67-1,57)$ & $(0,4-1,02)$ \\
\hline \multirow[t]{2}{*}{$\mathrm{AF}$} & 3,96 & 1,83 & 21,58 & 6,98 & 2,30 & 1,53 & 13,28 & 0,78 \\
\hline & $(0,17-7,02)$ & $(1,63-2,02)$ & $\begin{array}{l}(16,59- \\
25,88)\end{array}$ & $\begin{array}{l}(0,14- \\
13,30)\end{array}$ & $(1,01-3,91)$ & $(0,29-2,67)$ & $\begin{array}{l}(12,20- \\
13,77)\end{array}$ & $(0,4-1,14)$ \\
\hline Arg & $\begin{array}{c}0,15 \\
(0,14-0,17)\end{array}$ & $\begin{array}{c}4,52 \\
(1,26-8,01)\end{array}$ & $\begin{array}{c}5,56 \\
(0,81-9,70)\end{array}$ & $\begin{array}{c}9,13 \\
(8,64-9,65)\end{array}$ & $\begin{array}{c}0,42 \\
(0,13-0,78)\end{array}$ & $\begin{array}{c}0,63 \\
(0,00-1,31)\end{array}$ & 0,00 & $\begin{array}{c}4,17 \\
(1,02-7,49)\end{array}$ \\
\hline
\end{tabular}

... cont. Tabela 3 
(24,34-

97,14

$(95,15$ -

97,21

85,47

94,34

98,29)

$85,73)$

$81,64)$

$43,80)$

$98,74)$

$97,67)$

$(84,66$

$(91,71$ -

$96,83)$ 


\subsection{Discussão}

A fauna dos quatro pontos do reservatório Guarapiranga apresentou diferenças entre os períodos de verão (fevereiro) e inverno (julho). Os quatro pontos analisados parecem mais semelhantes em fevereiro, comparados a julho, provavelmente devido às chuvas que carregam materiais e solutos, comprovado pelos maiores valores de condutividade elétrica observados neste mês, e que têm potencial de provocar mistura das águas (Talling \& Lemoalle, 1998), tornando o ambiente mais homogêneo.

A temperatura da água intersticial e o teor de matéria orgânica no sedimento atuaram indiretamente como fatores limitantes para a distribuição e abundância dos organismos. Os menores teores de matéria orgânica em fevereiro podem ser resultantes da maior velocidade na decomposição por microorganismos em altas temperaturas, diminuindo assim o alimento disponível e resultando em menor abundância e riqueza de organismos bentônicos (Esteves, 1998). Como resultado da maior taxa de decomposição, há um déficit de oxigênio dissolvido que afeta negativamente a fauna. Esta situação é agravada pela menor solubilidade do gás em altas temperaturas. Assim, a fauna foi indiretamente limitada pela temperatura e pelo teor de matéria orgânica devido à ligação destes fatores com a disponibilidade de oxigênio dissolvido.

A composição granulométrica do sedimento e as diferenças de morfometria entre os pontos de amostragem parecem ter sido limitantes aos organismos bentônicos, tal como observado em outros reservatórios por Di Giovanni e col. (1996), Moretto e col. (2003) e Pamplin e col. (2006). EM e $\mathrm{G}$, pontos com maiores profundidades, mais próximos à barragem e com características mais lênticas, apresentaram menor riqueza e densidade de organismos. Enquanto $P$ e EG, com profundidades menores, sedimento mais heterogêneo e características lóticas, observadas em campo, apresentaram maiores abundâncias de organismos e riquezas. Efeitos semelhantes foram observados por Pamplin e col. (2006) no reservatório de Americana.

Comparando-se a comunidade bentônica encontrada nos dois meses estudados e nos quatro pontos de amostragem com dados da comunidade nas mesmas regiões do reservatório, em trabalhos anteriores não publicados, observa-se a total ausência ou baixa ocorrência de Chironomidae, Mollusca e Ostracoda. Esta aparente simplificação da comunidade pode estar relacionada à deterioração da qualidade da água do reservatório associada ao avanço da urbanização em sua bacia ao longo dos anos. Como resultado, se observa que as características físicas e químicas do sedimento do Guarapiranga permitem a ocorrência de Nematoda, Oligochaeta, Hirudinea e Chaoboridae como fauna comum aos quatro pontos analisados. Estes mesmos grupos foram os observados em reservatórios com enriquecimento orgânico (Di Giovanni et al. 1996; Moretto et al. 2003; Pamplin et al. 2006). Oligochaeta e Chaoboridae são conhecidos por sua alta tolerância a poluição orgânica (Mandaville, 2002). Portanto, o sedimento do reservatório Guarapiranga é seletivo para organismos mais tolerantes.

O aporte de matéria orgânica no reservatório deve ser o responsável pela presença constante de Oligochaeta, inclusive dominante, com abundância relativa acima de 50\%, em julho, quando os teores de matéria orgânica são maiores nos quatro pontos analisados. Condição semelhante foi observada no reservatório de Americana (Pamplin et al., 2006).

A grande abundância de Chaoboridae no reservatório Guarapiranga é um fato comum em reservatórios rasos tropicais, observada, por exemplo, nas Lagoas do Nado (Bezerra-Neto \& PintoCoelho, 2002) e Monte Alegre (Cleto-Filho \& Arcifa, 2006). Sua ocorrência é favorecida pela anoxia da região profunda, a presença de organismos bentônicos e a grande biomassa de zooplâncton (Bezerra-Neto \& Pinto-Coelho, 2002; Sendacz et al., 2006). 
A baixa riqueza de taxa também foi observada por Pamplin e col. (2006) no reservatório de Americana-SP, grandemente afetado por enriquecimento orgânico. Tal impacto também é evidente no reservatório Guarapiranga, na qual além do sedimento se apresentar orgânico, com teor acima de $10 \%$, apresentou concentrações elevadas de nitrogênio e fósforo totais, inclusive acima do valor alerta estabelecido pela resolução CONAMA 344/2004 para a disposição de sedimentos dragados. Por pelo menos duas décadas, trabalhos vem discorrendo sobre o intenso processo de eutrofização no reservatório (Caleffi et al., 1994; Beyruth, 2000; Sendacz et al., 2006; CETESB 2008; Gemelgo et al., 2009). Durante a triagem do sedimento do EM e P foram observados restos de macrófitas em quantidades consideráveis compondo o substrato. Uma característica do reservatório Guarapiranga é a presença, em certas épocas, de extensos bancos de macrófitas (Parente, 2008). Essa presença pode estar modificando as características do substrato habitado pelos macroinvertebrados, contribuindo para mudança na comunidade bentônica ao longo dos anos.

A composição da fauna bentônica observada no presente trabalho reflete o processo acelerado de degradação do reservatório. Um estudo, simultaneamente a este, utilizando a Tríade de Qualidade do Sedimento indicou a presença de alguns metais em níveis acima do limiar e em concentrações crescentes sentido tributário-barragem. Tal resultado pode contribuir grandemente para o controle da qualidade do sedimento, uma questão fundamental diante de alterações na bacia de drenagem de um manancial que, além dos usos múltiplos, serve de abastecimento para a população. 


\subsection{Referências}

BEYRUTH, Z. Periodic disturbance, trophic gradient and phytoplankton characteristics related to cyanobacterial growth in Guarapiranga Reservoir, São Paulo State, Brazil. Hydrobiologia, v. 424, p. 51-65. 2000.

BEZERRA-NETO, J.F.; PINTO-COELHO, R.M. Migração vertical das larvas de Chaoborus brasiliensis (Theobald, 1901) (Díptera, Chaoboridae) em um reservatório tropical: lagoa do Nado, Belo Horizonte, Estado de Minas Gerais. Acta Scientiarum, Maringá, v. 24, n. 2, p. 329-336, 2002.

CALEFFI, S.; ZANARDI, E.; BEYRUTH, Z. Trophic state of Guarapiranga Reservoir in 1991/92. Verhandlungen Internationale Vereinnigung für Theoretische and Angewandte Limnologie, v. 25, p. 1306-1310, 1994.

COMPANHIA AMBIENTAL DO ESTADO DE SÃO PAULO. Relatório da qualidade das águas interiores do Estado de São Paulo 2007, São Paulo: Secretaria do Estado do Meio Ambiente. 2008. $540 \mathrm{p}$.

CLETO-FILHO, S.E.N.; ARCIFA, M.S. Horizontal distribution and temporal variation of the zoobenthos of a tropical Brazilian lake. Acta Limnologica Brasiliensia, v. 18, n. 4, p. 407-421. 2006.

CONSELHO NACIONAL DO MEIO AMBIENTE. Resolução No 344, de 25 de março de 2004. In: Resoluções do CONAMA: Resoluções vigentes publicadas entre setembro de 1974 e janeiro de 2012. Brasília: MMA. 2012. p. 840 - 848.

DI GIOVANNI, M.V.; GORETTI, E.; TAMANTI,V. Macrobenthos in Montedoglio Reservoir, Central Italy. Hydrobiologia, v. 321, p. 17-28, 1996.

ESTEVES, FA. Fundamentos de limnologia. $3^{\mathrm{a}}$ ed. Rio de Janeiro: Interciência. 2011. 826 p.

GEMELGO, M.C.P.; MUCCI, J.L.N.; NAVAS-PEREIRA, D. Population dynamics: seasonal variation of phytoplankton functional groups in Brazilian reservoirs (Billings and Guarapiranga, São Paulo). Brazilian Journal of Biology, v. 69, n. 4, p. 1001-1013, 2009.

HELOU, L.C.; SILVA, L.G. Estudo da operação do reservatório de Guarapiranga. DAE, SABESP, v. 48, n. 151 , p. 29-47, 1987.

MANDAVILLE, S.M. Benthic macroinvertebrates in freshwaters: Taxa tollerance values, metrics and protocols. New York: Soil \& Water Conservation Society of Mero Halifax. 2002. 128 p.

MEGURO, M. Métodos em ecologia vegetal. São Paulo: Universidade de São Paulo, Instituto de Biociências, Departamento de Ecologia Geral. 2000. 119 p.

MORETTO, Y.; HIGUTI, J.; TAKEDA, A.M. Spatial variation of the benthic community in the Corumbá Reservoir, Goiás, Brazil. Acta Scientiarum Biological Sciences, v. 25, p. 23-30, 2003.

MOZETO, A.A.; SILVÉRIO, P.F.; SOARES, A. Estimates of benthic fluxes of nutrientes across the sediment-water interface (Guarapiranga reservoir, São Paulo, Brazil). The Science of the Total Environment, v. 266, p. 135-142, 2001. 
MOZETO, A.A. Sedimentos e Particulados Lacustres: amostragem e análises biogeoquímicas. In: BICUDO, C.E.M.; BICUDO, D.C. (Eds.). Amostragem em Limnologia. São Paulo: Ed. RiMa, 2004. p. 295-320.

PAMPLIN, P.A.Z.; ALMEIDA,T.C.M. AND ROCHA,O. Composition and distribution of benthic macroinvertebrates in Americana Reservoir (SP, Brazil). Acta Limnologica Brasiliensia, v. 18, n. 2 , p. 121-132, 2006.

PEDROSO, J.S.O. Medidas de Proteção das Águas do Reservatório do Guarapiranga. Revista DAE, v. 36, n. 21, p. 53-56, 1960.

PARENTE, P. Macrófitas: As plantas aquáticas da Guarapiranga e a qualidade da nossa água. Revista do Projeto Yporã: Proliferação de Plantas Aquáticas na Represa do Guarapiranga. Janfer Editora e Gráfica Ltda. p. 37. 2008.

RICHTER, E.M.; FORNARO, A.; LAGO, C.L. DO; ANNES, L. Avaliação da composição química de águas do sistema Guarapiranga: estudo de caso nos anos de 2002 e 2003. Quimica Nova, v. 30, n. 5, p. 1147-1152, 2007.

SENDACZ, S.; CALEFFI, S.; SANTOS-SOARES, J. Zooplankton biomass of reservoirs in different trophic conditions in the state of São Paulo, Brazil. Brazilian Journal of Biology, v. 66, n. 1B, p. 337-350, 2006.

SECRETARIA DO MEIO AMBIENTE DO ESTADO DE SÃO PAULO/ COORDENADORIA DE EDUCAÇÃO AMBIENTAL. Caderno Ambiental Guarapiranga, São Paulo: SMA/CEA, p. 84. 2008.

TALLING, J.F.; LEMOALLE, J. Ecological Dynamics of tropical inland waters. Cambridge: Cambridge University, 1998. 441 p.

WHATELY, M.; CUNHA, P.M. Guarapiranga 2005: como e porque São Paulo está perdendo este manancial: resultados do diagnóstico socioambiental participativo da bacia hidrográfica da Guarapiranga. São Paulo: Instituto Socioambiental. 2006. 51 p. 


\section{Conclusão Geral}

O crescimento urbano desordenado ocorrido na região metropolitana de São Paulo iniciado a 100 anos atrás, o qual levou a construção do reservatório Guarapiranga, teve como consequência a poluição difusa no reservatório, proporcionando o enriquecimento orgânico de suas águas e sedimento. Esse enriquecimento orgânico, suas consequências e a entrada de metais-traço no corpo d'água influenciaram na alteração da estrutura da comunidade de macroinvertebrados bentônicos, além de favorecer a ocorrência de uma fauna tolerante à hipoxia, à poluição orgânica e à presença de elementos tóxicos como metais-traço e sulfetos. Em 2010, a maioria dos metais estava acima dos valores naturais regionais e dos valores limiares de efeito tóxico. $\mathrm{O}$ metal mais preocupante seria o cobre, acima do nível de provável efeito tóxico. No entanto, a não-biodisponibilidade desses metais, a grande quantidade de bancos de macrófitas e dados de trabalhos anteriores no reservatório indicam que a provável presença de amônia na água intersticial, decorrente da decomposição da matéria orgânica, pode ser a causa da toxicidade desse sedimento em testes ecotoxicológicos. O enriquecimento das águas por nutrientes e o consequente crescimento de produtores primários, em parte representado por algas, levou à escolha, por órgãos gestores do reservatório, de um algicida à base de cobre, o qual é o grande responsável pelas altas concentrações de cobre no sedimento. A eutrofização da água e do sedimento também permitiu o desenvolvimento de bancos de macrófitas, os quais oferecem diversidade de habitat, proteção e alimento para a fauna local. Mesmo os restos dessas plantas servem de habitat no substrato para organismos como demonstrado pela ocorrência do de Naidinae Haemonais waldvogeli associada a Polygonum.

A tríade de qualidade do sedimento é uma boa ferramenta para avaliar a qualidade do sedimento de reservatórios em programas de monitoramento. Necessita apenas cuidado na interpretação. A avaliação do ambiente se torna mais segura quando é composta de vários instrumentos, como neste trabalho que utilizou simultaneamente a tríade, análises de componentes principais, análise de correspondência canônica, correlações de Pearson e multimétricos o índice multimétrico de comunidade bentônica para região profundal de reservatórios desenvolvido pela Cetesb. Com as ferramentas citadas conclui-se que o reservatório apresenta sedimento heterogêneo, dividindoo em 4 regiões: a desembocadura dos três principais tributários e o corpo principal. Em 2010 as regiões mais próximas à barragem apresentavam-se mais deterioradas do que as mais distantes, separando o reservatório em dois compartimentos de acordo com a deterioração do sedimento.

Enquanto num estudo pontual o sedimento do reservatório favorece a ocorrência de uma fauna tolerante à hipoxia, à poluição orgânica e à presença de elementos tóxicos como metais-traço e sulfetos, na comparação entre verão e inverno, mostrou que a temperatura da água intersticial e o teor de matéria orgânica no sedimento também podem, indiretamente, atuar como fatores limitantes na distribuição e abundância de macroinvertebrados bentônicos. 


\section{Resumo Geral}

Com o intuito de saber se a comunidade bentônica sofreu variação temporal ao longo de 100 anos de criação do reservatório Guarapiranga, hoje um reservatório urbano de abastecimento público eutrofizado, e ainda avaliar a variação entre as condições ambientais impostas pelo verão e inverno sobre esta comunidade e o sedimento no reservatório, além de caracterizar esse sedimento e a fauna bentônica, por meio das concentrações de metais, a toxicidade do sedimento e seus efeitos sobre esta fauna, por meio da aplicação da Triade de Qualidade do Sedimento, foram analisadas quatro regiões médio-profundal do reservatório (corpo principal/barragem - Guarapiranga, e desembocadura dos principais tributários - Embu-Mirim, Embu-Guaçu e Parelheiros). As densidades de Oligochaeta e Chaoboridae apresentaram aumento ao longo dos anos. $\mathrm{O}$ índice trófico dado pela relação Oligochaeta/Oligochaeta + Chironomidae indica enriquecimento orgânico máximo em 2010 para todo o reservatório, e ainda os gêneros de Oligochaeta mais abundantes são todos tolerantes a altos níveis de poluição orgânica e a hipoxia, como Limnodrilus, Dero e Haemonais. Os restos da macrófita aquática Polygonum serviram de habitat e alimento para um alta população de Haemonais waldvogeli em uma determinada área de Parelheiros. E ainda a hipoxia do fundo, causada pela decomposição de grande quantidade de matéria orgânica (teor médio de matéria orgânica de $20 \%$ ), limitou a comunidade a representantes tolerantes a tal situação em praticamente todos os taxa. Limnodrilus hoffmeisteri, Chaoborus e Dero apresentaram maior densidade e representatividade em todo o reservatório. Em 2010, as concentrações dos metais Cd e $\mathrm{Cr}$ estiveram acima de TEL e as de $\mathrm{Cu}$, acima de PEL, em todo o reservatório. A relação $(\Sigma$ [metais]-[SVA])/COT indicou toxicidade incerta e improvável por metais, contudo os testes agudos indicaram efeito tóxico para quase todos os pontos. $\mathrm{O}$ aumento nas concentrações de metais no sedimento foi relevante a partir da década de 1990 neste reservatório e demonstrou origem antrópica principalmente para $\mathrm{Cu}, \mathrm{Cr}, \mathrm{Ni}, \mathrm{Zn}$ e $\mathrm{Pb}$. Análises exploratórias e métricas indicaram influência significativa da temperatura da água intersticial, cuja média entre os pontos variou cerca de $6^{\circ} \mathrm{C}$ do mês de fevereiro para julho. Maiores teores de matéria orgânica foram observados em julho na foz de um dos tributários e no ponto próximo à barragem, com $39 \%$ e $35 \%$, respectivamente. $\mathrm{O}$ teor de oxigênio dissolvido na água de fundo foi inferior a $2,4 \mathrm{mg}$. $\mathrm{L}^{-1}$ nas quatro regiões analisadas para os meses de fevereiro e julho. O reservatório foi dividido em 4 compartimentos heterogêneos (corpo principal e desembocaduras dos 3 principais tributários EmbuMirim, Embu-Guaçu e Parelheiros) de acordo com as características físicas e químicas do sedimento e dividido em duas regiões (Embu-Mirim - exceto montante - e corpo principal; EmbuGuaçu, Parelheiros e montante de Embu-Mirim) quanto à deterioração dada pela TQS. Conclui-se que o crescimento urbano desordenado, e a consequente poluição difusa no reservatório, proporcionou o enriquecimento orgânico de suas águas e sedimento, o que juntamente com a entrada de metais-traço no corpo d'água resultou na alteração da estrutur da comunidade de macroinvertebrados bentônicos, favorecendo a ocorrência de uma fauna tolerante à hipoxia, poluição orgânica e presença de elementos tóxicos como metais-traço e sulfetos. A comparação entre o período seco e o de chuva para o mesmo ambiente, a temperatura e o teor de matéria orgânica no sedimento limitaram a comunidade bentônica, levando a uma maior densidade de organismos no inverno, possivelmente devido à sua influência sobre a disponibilidade de oxigênio dissolvido. 


\begin{abstract}
With the purpose to know if the benthic community suffered temporal variation over 100 years of Guarapiranga reservoir creation, today an eutrophic urban and public water supply reservoir, and also to evaluate the variation of the environmental conditions imposed by the summer and winter on this community and sediment, and characterize this benthic fauna and sediment, through metal concentrations, toxicity and effects of the sediment on benthic fauna by the application of sediment quality triad, four regions were analyzed in the mid-profundal reservoir (main body / dam Guarapiranga and the major tributaries entrance into reservoir- Embu-Mirim, Embu-Guaçu and Parelheiros). Densities of Oligochaeta and Chaoboridae showed an increase over the years. The trophic index presented in relation Oligochaeta / Chironomidae + Oligochaeta indicates maximum organic enrichment in 2010 for the entire reservoir, and also the most abundant genera of oligochaetes are all tolerant to high levels of organic pollution and hypoxia, as Limnodrilus, Dero and Haemonais. The remains of the aquatic macrophyte Polygonum serve as a habitat and food resource for the large density of Haemonais waldvogeli in a certain region of Parelheiros. Further the bottom hypoxia, caused by the decomposition of large amounts of organic matter (average content of $20 \%$ of organic matter), limited community to tolerant representatives to such a situation in practically all taxa. L. hoffmeisteri, Chaoborus and Dero showed higher density and representation in the entire reservoir. In 2010, the concentrations of the metals $\mathrm{Cd}$ and $\mathrm{Cr}$ were above TEL and $\mathrm{Cu}$ above PEL also in the entire reservoir. The relationship ( $\Sigma$ [metal] - [AVS]) / TOC indicated uncertain and improbable toxicity by metals, but tests have indicated acute toxic effect on nearly all points. The increase in the concentrations of metals in the sediment was relevant since 1990s in this reservoir and demonstrated anthropogenic origin mainly for $\mathrm{Cu}, \mathrm{Cr}, \mathrm{Ni}, \mathrm{Zn}$ and $\mathrm{Pb}$. Exploratory analysis and metrics showed significant influence of the temperature of the pore water, which average between stations ranged around 6c from February to July. Higher levels of organic matter were observed in July at the mouth of one of the tributaries and in the station near the dam, with $39 \%$ and $35 \%$, respectively. The content of dissolved oxygen in the bottom water was less than $2.4 \mathrm{mg} \mathrm{L}^{-1}$ in the four regions analyzed for the months of February and July. The reservoir was divided into four heterogeneous compartments (main body and mouths of three major tributaries Embu-Mirim, Embu-Guaçu and Parelheiros) according to the physical and chemical characteristics of the sediment and divided into two regions (Embu-Mirim - except upstream of it the main body; Embu-Guaçu, Embu-Mirim upstream and Parelheiros) according to the deterioration provided by SQT. We conclude that unplanned urban growth and the consequent diffuse pollution in the reservoir provided the the organic enrichment of its waters and sediment which, together with the input of trace metals in the water body, resulted in changes to the structure of the benthic macroinvertebrate community favoring the occurrence of a fauna tolerant to hypoxia, organic pollution and the presence of toxic elements such as trace metals and sulfides. Whereas the comparison of the same environment under different climatic influences showed that temperature and organic matter in the sediment limited the benthic community, leading to a higher density of organisms in the winter, possibly due to its influence on the availability of dissolved oxygen.
\end{abstract}


ANEXOS 
Anexo 2.1. Índice da Comunidade Bentônica para região profundal de reservatórios (ICB RES-P)

\begin{tabular}{lccccc}
\hline Classe & $\begin{array}{l}\text { Pontuação } \\
\text { qualitativa }\end{array}$ & S & H' & T/DT & Tt/Chi \\
\hline Péssima & 5 & & & Azóico & \\
Ruim & 4 & $1-3$ & $\leq 0,50$ & $\geq 0,80$ & $\leq 0,03$ \\
Regular & 3 & $4-6$ & $>0,50-\leq 1,50$ & $\geq 0,50-<0,80$ & $>0,03-\leq 0,06$ \\
Boa & 2 & $7-9$ & $>1,50-\leq 2,00$ & $\geq 0,20-<0,50$ & $>0,06-<0,10$ \\
Ótima & 1 & $\geq 10$ & $>2,00$ & $<0,20$ & $\geq 0,10$ \\
\hline
\end{tabular}

Anexo 2.2. Lista dos taxa encontrados para macroinvertebrados bentônicos, suas densidades médias (ind $\mathrm{m}^{-2}$ ) e desvio padrão (entre parênteses) para os 12 pontos amostrais no reservatório Guarapiranga. Seguindo classificação de Rupert et al. $(2005)$. (F) = Filo; $(C)=$ Classe; $(\mathrm{G})$ = Gênero; $(\mathrm{E})$ = Espécie; $(\mathrm{Gmt})$ = morfotipo do Gênero; $(\mathrm{SF})$ = Subfamília;

\begin{tabular}{|c|c|c|c|c|c|c|c|c|c|c|c|c|}
\hline Taxa/Pontos & P1 & $\mathbf{P 2}$ & P3 & EG1 & EG2 & EG3 & EM1 & EM2 & EM3 & G1 & G2 & G3 \\
\hline Turbellaria (C) & $\begin{array}{c}7,41 \\
(0,41)\end{array}$ & & & & $\begin{array}{l}22,22 \\
(1,22)\end{array}$ & & $\begin{array}{l}29,63 \\
(1,03)\end{array}$ & & & & $\begin{array}{l}51,85 \\
(2,86)\end{array}$ & $\begin{array}{l}37,04 \\
(2,04)\end{array}$ \\
\hline Nematoda (F) & $\begin{array}{l}29,63 \\
(1,63)\end{array}$ & $\begin{array}{l}74,07 \\
(1,63)\end{array}$ & $\begin{array}{l}22,22 \\
(1,22)\end{array}$ & $\begin{array}{c}7,41 \\
(0,41)\end{array}$ & & $\begin{array}{l}14,81 \\
(0,52)\end{array}$ & $\begin{array}{l}96,30 \\
(2,71)\end{array}$ & $\begin{array}{c}140,74 \\
(7,76)\end{array}$ & & $\begin{array}{c}7,41 \\
(0,41)\end{array}$ & $\begin{array}{l}96,30 \\
(2,04)\end{array}$ & $\begin{array}{l}111,11 \\
(1,76)\end{array}$ \\
\hline Bivalvia (C) & $\begin{array}{l}125,93 \\
(6,94)\end{array}$ & & & $\begin{array}{l}14,81 \\
(0,52)\end{array}$ & $\begin{array}{l}14,81 \\
(0,52)\end{array}$ & & $\begin{array}{l}29,63 \\
(0,82)\end{array}$ & $\begin{array}{l}14,81 \\
(0,82)\end{array}$ & & & & \\
\hline Gastropoda (C) & & & & & $\begin{array}{l}14,82 \\
(0,41)\end{array}$ & & $\begin{array}{c}7,41 \\
(0,41)\end{array}$ & & & & & \\
\hline Opistocysta (G) & $\begin{array}{l}125,93 \\
(3,43)\end{array}$ & & $\begin{array}{l}148,15 \\
(1,89)\end{array}$ & $\begin{array}{l}22,22 \\
(0,61)\end{array}$ & $\begin{array}{l}29,63 \\
(0,62)\end{array}$ & & $\begin{array}{l}666,67 \\
(8,79)\end{array}$ & $\begin{array}{c}7,41 \\
(0,41)\end{array}$ & & & & $\begin{array}{l}14,81 \\
(0,82)\end{array}$ \\
\hline $\begin{array}{l}\text { Prístina americana } \\
\text { (E) }\end{array}$ & & & & & & & $\begin{array}{l}22,22 \\
(0,84)\end{array}$ & & & & & \\
\hline Dero (G) & $\begin{array}{c}429,63 \\
(6,77)\end{array}$ & $\begin{array}{l}22,22 \\
(0,84)\end{array}$ & $\begin{array}{l}66,67 \\
(3,67)\end{array}$ & $\begin{array}{l}37,04 \\
(0,98)\end{array}$ & $\begin{array}{l}29,63 \\
(1,03)\end{array}$ & $\begin{array}{l}88,89 \\
(3,52)\end{array}$ & $\begin{array}{l}133,33 \\
(1,79)\end{array}$ & $\begin{array}{l}22,22 \\
(1,22)\end{array}$ & $\begin{array}{l}22,22 \\
(1,22)\end{array}$ & & & $\begin{array}{c}7,41 \\
(0,41)\end{array}$ \\
\hline $\begin{array}{c}\text { Dero (Aulophorus) } \\
\text { lodeni }(\mathrm{E})\end{array}$ & $\begin{array}{l}2266,67 \\
(39,13)\end{array}$ & $\begin{array}{l}22,22 \\
(0,55)\end{array}$ & & & $\begin{array}{l}14,81 \\
(0,82)\end{array}$ & $\begin{array}{c}7,41 \\
(0,41)\end{array}$ & $\begin{array}{l}1022,22 \\
(17,25)\end{array}$ & $\begin{array}{c}7,41 \\
(0,41)\end{array}$ & & & & \\
\hline
\end{tabular}


... cont. Anexo 2.2

\section{Dero (Aulophorus)} costatus (E)

Dero (Dero) botrytis

(E)

Dero (Dero) digitata

(E)

Dero (Dero) righii

(E)

Dero (Dero)

multibranchiata (E)

Dero (Dero)

sawayai $(\mathrm{E})$

Slavina evelinae (E)

\begin{tabular}{|c|c|c|c|c|c|c|c|c|c|c|c|c|}
\hline $\begin{array}{c}\text { Haemonais } \\
\text { waldvogeli (E) }\end{array}$ & $\begin{array}{c}14222,22 \\
(279,43)\end{array}$ & $\begin{array}{c}140,74 \\
(6,79)\end{array}$ & & & & $\begin{array}{l}22,22 \\
(1,22)\end{array}$ & $\begin{array}{c}318,52 \\
(9,75)\end{array}$ & $\begin{array}{l}29,63 \\
(1,63)\end{array}$ & & & & \\
\hline $\begin{array}{c}\text { Limnodrilus } \\
\text { hoffmeisteri (Cnf.) } \\
\text { (E) }\end{array}$ & $\begin{array}{c}7,41 \\
(0,41)\end{array}$ & $\begin{array}{l}340,74 \\
(3,61)\end{array}$ & $\begin{array}{l}44,44 \\
(0,89)\end{array}$ & $\begin{array}{c}3088,89 \\
(34,81)\end{array}$ & $\begin{array}{l}13592,59 \\
(167,61)\end{array}$ & $\begin{array}{l}659,26 \\
(6,74)\end{array}$ & $\begin{array}{l}1637,04 \\
(29,01)\end{array}$ & $\begin{array}{l}44,44 \\
(1,55)\end{array}$ & $\begin{array}{c}1340,74 \\
(24,63)\end{array}$ & $\begin{array}{l}14,81 \\
(0,82)\end{array}$ & $\begin{array}{c}800,00 \\
(7,13)\end{array}$ & $\begin{array}{l}888,89 \\
(12,73)\end{array}$ \\
\hline $\begin{array}{l}\text { Aulodrilus pigueti } \\
\text { (E) }\end{array}$ & & $\begin{array}{c}311,11 \\
(4,90)\end{array}$ & $\begin{array}{c}2088,89 \\
(59,16)\end{array}$ & $\begin{array}{l}6088,89 \\
(158,22)\end{array}$ & $\begin{array}{l}3881,48 \\
(144,02)\end{array}$ & $\begin{array}{l}5392,59 \\
(162,41)\end{array}$ & $\begin{array}{c}1192,59 \\
(35,77)\end{array}$ & $\begin{array}{l}22,22 \\
(1,22)\end{array}$ & $\begin{array}{r}1622,22 \\
(71,04)\end{array}$ & $\begin{array}{l}3511,11 \\
(61,85)\end{array}$ & & \\
\hline $\begin{array}{l}\text { Branchiura } \\
\text { sowerbyi (E) }\end{array}$ & & $\begin{array}{l}29,63 \\
(0,82)\end{array}$ & $\begin{array}{l}59,26 \\
(1,21)\end{array}$ & & & $\begin{array}{l}96,30 \\
(2,40)\end{array}$ & $\begin{array}{l}51,85 \\
(1,17)\end{array}$ & & $\begin{array}{l}66,67 \\
(1,05)\end{array}$ & & & $\begin{array}{l}74,07 \\
(0,82)\end{array}$ \\
\hline $\begin{array}{l}\text { Placobdella sp1 } \\
\text { (Gmt) }\end{array}$ & $\begin{array}{l}1192,59 \\
(16,58)\end{array}$ & $\begin{array}{l}170,37 \\
(2,40)\end{array}$ & $\begin{array}{l}651,85 \\
(10,19)\end{array}$ & $\begin{array}{l}155,56 \\
(1,22)\end{array}$ & $\begin{array}{l}585,19 \\
(12,69)\end{array}$ & $\begin{array}{c}7,41 \\
(0,41)\end{array}$ & $\begin{array}{l}118,52 \\
(2,07)\end{array}$ & $\begin{array}{c}7,41 \\
(0,41)\end{array}$ & $\begin{array}{c}7,41 \\
(0,41)\end{array}$ & $\begin{array}{l}1155,56 \\
(29,62)\end{array}$ & $\begin{array}{l}200,00 \\
(10,54)\end{array}$ & \\
\hline $\begin{array}{c}\text { Placobdella sp2 } \\
\text { (Gmt) }\end{array}$ & & $\begin{array}{l}37,04 \\
(2,04)\end{array}$ & $\begin{array}{c}585,19 \\
(9,45)\end{array}$ & $\begin{array}{l}140,74 \\
(5,85)\end{array}$ & $\begin{array}{l}318,52 \\
(2,32)\end{array}$ & $\begin{array}{l}22,22 \\
(0,84)\end{array}$ & & & & & & \\
\hline $\begin{array}{l}\text { Placobdella } \\
\text { montífera (E) }\end{array}$ & $\begin{array}{l}74,07 \\
(4,08)\end{array}$ & & & & & & & & & & & \\
\hline Alicenula (G) & & & & & $\begin{array}{c}7,41 \\
(0,41)\end{array}$ & & & $\begin{array}{c}7,41 \\
(0,41)\end{array}$ & & & & \\
\hline Cypricercinae (SF) & & & & $\begin{array}{c}7,41 \\
(0,41)\end{array}$ & $\begin{array}{l}14,81 \\
(0,82)\end{array}$ & & $\begin{array}{l}44,44 \\
(1,10)\end{array}$ & $\begin{array}{l}29,63 \\
(1,21)\end{array}$ & $\begin{array}{l}14,81 \\
(0,52)\end{array}$ & & & \\
\hline Campsurus (G) & & & $\begin{array}{c}7,41 \\
(0,41)\end{array}$ & $\begin{array}{l}44,44 \\
(1,10)\end{array}$ & $\begin{array}{l}14,81 \\
(0,52)\end{array}$ & $\begin{array}{l}14,81 \\
(0,52)\end{array}$ & & & & & & \\
\hline
\end{tabular}

7,41

$(0,41)$

74,07

$(1,86)$

7,41

$(0,41)$

37,04

$(2,04)$

$\begin{array}{lllll}66,67 & 1200,00 & 14,81 & 133,33 & 140,74\end{array}$

$(1,05) \quad(19,73) \quad(0,52)$

$(4,10) \quad(6,79)$

29,63

$(0,82)$

7,41

41) 
... cont. Anexo 2.2

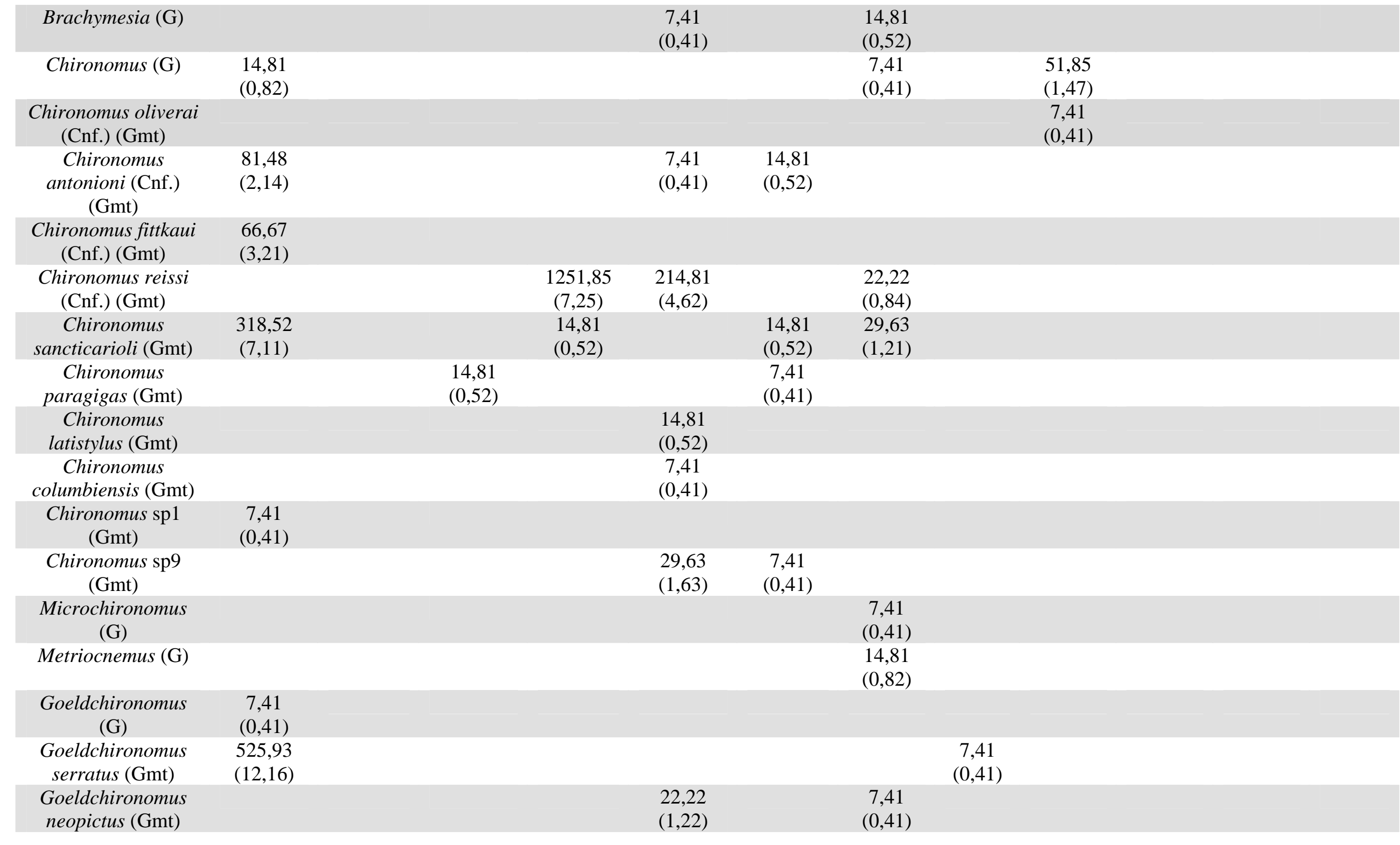


... cont. Anexo 2.2

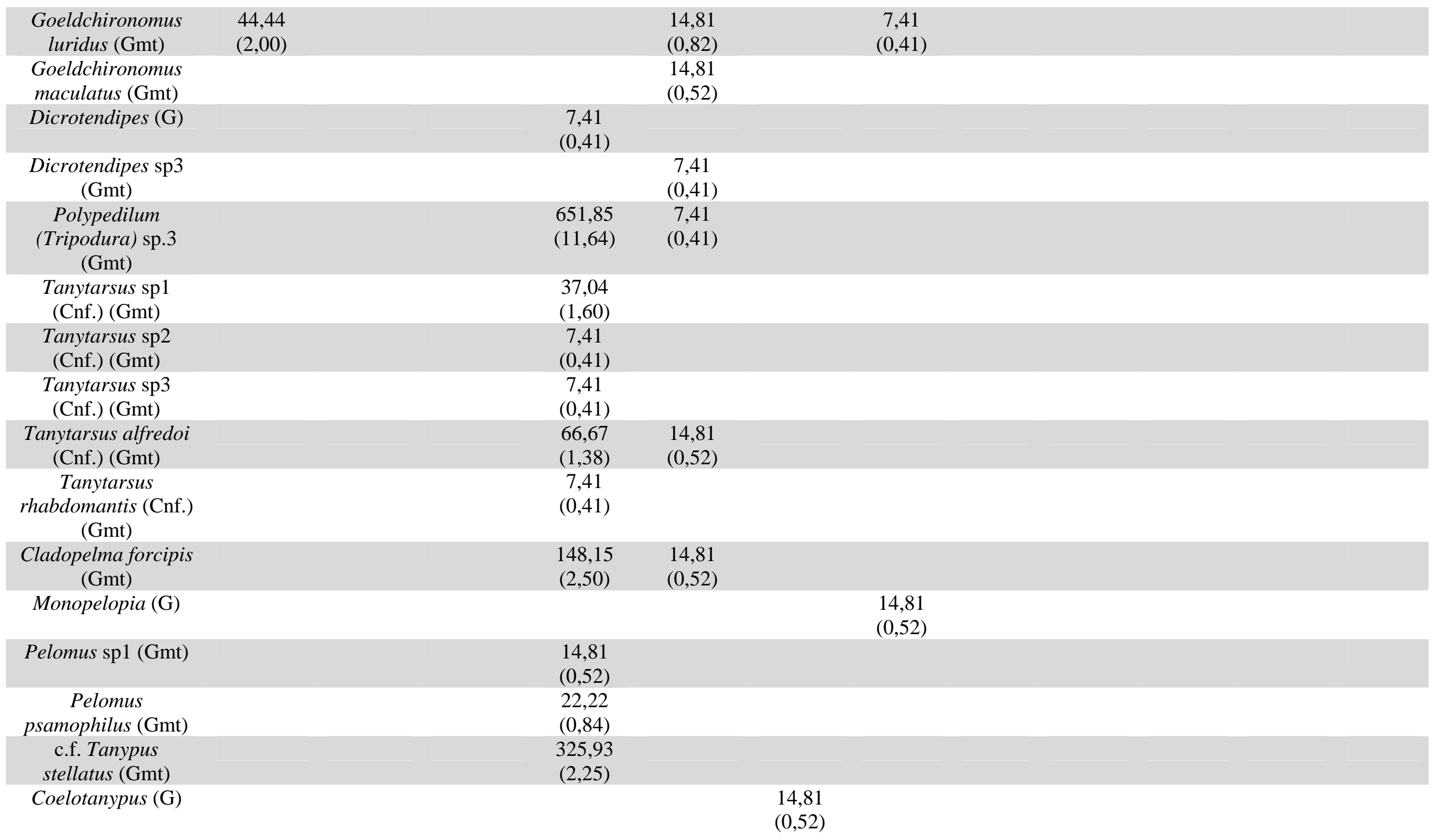


... cont. Anexo 2.2

\begin{tabular}{|c|c|c|c|c|c|c|c|c|c|c|c|c|}
\hline $\begin{array}{c}\text { Ablabesmyia } \\
\text { (Karelia) } 1(\mathrm{Gmt}) \\
\text { Larsia }(\mathrm{G})\end{array}$ & $\begin{array}{c}7,41 \\
(0,41)\end{array}$ & & & $\begin{array}{c}7,41 \\
(0,41)\end{array}$ & & & & & & & & \\
\hline $\begin{array}{l}\text { Alluaudomyia sp1 } \\
\text { (Gmt) }\end{array}$ & & & & $\begin{array}{l}37,04 \\
(0,98)\end{array}$ & $\begin{array}{l}37,04 \\
(0,75)\end{array}$ & $\begin{array}{l}51,85 \\
(1,60)\end{array}$ & $\begin{array}{l}14,81 \\
(0,52)\end{array}$ & & $\begin{array}{l}37,04 \\
(0,98)\end{array}$ & & & \\
\hline $\begin{array}{c}\text { Alluaudomyia sp2 } \\
\text { (Gmt) }\end{array}$ & & & & & & & $\begin{array}{c}7,41 \\
(0,41)\end{array}$ & & & & & \\
\hline ... cont. Tabela 2 & & & & & & & & & & & & \\
\hline Chaoborus sp (Gmt) & $\begin{array}{c}207,41 \\
(1,97)\end{array}$ & $\begin{array}{l}9918,52 \\
(196,71)\end{array}$ & $\begin{array}{c}39200,00 \\
(184,48)\end{array}$ & $\begin{array}{c}525,93 \\
(3,06)\end{array}$ & $\begin{array}{l}1785,19 \\
(32,62)\end{array}$ & $\begin{array}{l}7911,11 \\
(80,14)\end{array}$ & $\begin{array}{l}451,85 \\
(14,02)\end{array}$ & $\begin{array}{c}511,11 \\
(5,28)\end{array}$ & $\begin{array}{c}2525,93 \\
(37,18)\end{array}$ & $\begin{array}{c}7,41 \\
(0,41)\end{array}$ & $\begin{array}{l}1170,37 \\
(26,73)\end{array}$ & $\begin{array}{l}644,44 \\
(15,69)\end{array}$ \\
\hline
\end{tabular}

Anexo 2.3. Valores de TEL e PEL (CCME, 1999), e VRR (NASCIMENTO, 2003) para os metais cádmio, chumbo, cobre, cromo, níquel e zinco.

\begin{tabular}{|c|c|c|c|}
\hline Metal & TEL (mg Kg $\left.{ }^{-1}\right)$ & PEL (mg Kg $\left.{ }^{-1}\right)$ & VRR (mg Kg $\left.{ }^{-1}\right)$ \\
\hline Cádmio & 0,6 & 3,5 & 0,22 \\
\hline Cromo & 37,3 & 90 & 38 \\
\hline Cobre & 35,7 & 197 & 18 \\
\hline Níquel & 18 & 36 & 26 \\
\hline Chumbo & 35 & 91,3 & 61 \\
\hline Zinco & 123 & 315 & 82 \\
\hline
\end{tabular}


Anexo 2.4. Dados da TQS para Índice Biológico (Ib) transformados em RTR baseado no ponto de referência EG1. Dados transformados: densidades médias de macroinvertebrados bentônicos, índices de riqueza $(\mathrm{R})$, dominância $\left(\mathrm{D}_{2}\right)$ e diversidade $\mathrm{H}^{\prime}$;

\begin{tabular}{ccccccccc}
\hline RTR & S & D2 & H' & $\begin{array}{c}\text { Relação } \\
\text { Taxa mais abundantes/ } \\
\text { Abundância Total }\end{array}$ & $\begin{array}{c}\text { Abundância Total } \\
\text { (ind m } \mathbf{~}^{-2} \text { ) }\end{array}$ & SOMA & Ib \\
\hline P1 & 0,53 & 0,96 & 0,75 & 1,13 & 1,14 & 4,51 & $\mathbf{0 , 9 0}$ \\
P2 & 0,41 & 0,47 & 0,32 & 1,29 & 1,27 & 3,76 & $\mathbf{0 , 7 5}$ \\
P3 & 0,53 & 0,35 & 0,27 & 1,34 & 1,26 & 3,75 & $\mathbf{0 , 7 5}$ \\
EG1 & 1,00 & 1,00 & 1,00 & 1,00 & 1,00 & 5,00 & $\mathbf{1 , 0 0}$ \\
EG2 & 1,00 & 0,72 & 0,72 & 1,16 & 1,21 & 4,81 & $\mathbf{0 , 9 6}$ \\
EG3 & 0,65 & 0,76 & 0,65 & 1,28 & 1,29 & 4,62 & $\mathbf{0 , 9 2}$ \\
EM1 & 0,94 & 1,41 & 1,38 & 0,54 & 1,22 & 4,50 & $\mathbf{1 , 1 0}$ \\
EM2 & 0,53 & 1,13 & 0,88 & 1,07 & 0,99 & 4,59 & $\mathbf{0 , 9 2}$ \\
EM3 & 0,47 & 1,07 & 0,79 & 1,00 & 1,28 & 4,61 & $\mathbf{0 , 9 2}$ \\
G1 & 0,24 & 1,11 & 0,54 & 1,26 & 1,30 & 4,45 & $\mathbf{0 , 8 9}$ \\
G2 & 0,24 & 1,70 & 0,83 & 1,09 & 1,12 & 4,98 & $\mathbf{1 , 0 0}$ \\
G3 & 0,35 & 1,35 & 0,85 & 1,10 & 1,20 & 4,85 & $\mathbf{0 , 9 7}$ \\
\hline
\end{tabular}

Anexo 2.5. Dados da TQS versão 1 para Índice químico (Iq) transformados em RTR: Cd = cádmio (mgCd $\left.\mathrm{Kg}^{-1} \mathrm{sed}\right) ; \mathrm{Cr}=\mathrm{cromo}\left(\mathrm{mgCr} \mathrm{Kg}{ }^{-1} \mathrm{sed}\right)$; $\mathrm{Cu}=$ cobre ((mgCu Kg-1 sed); $\mathrm{Pb}=$ chumbo (mgPb Kg-1 sed); $\mathrm{Ni}=$ níquel (mgNi Kg-1 sed); $\mathrm{Zn}=$ zinco (mgZn Kg-1 sed); COT = carbono orgânico total (mmol); AG = areia grossa (\%); AF = areia fina (\%); Sil = silte (\%); Arg = argila (\%); SVA= sulfeto volatizável por acidificação; NKT = nitrogênio Kjedahl total ( $\mu g \mathrm{~N} \mathrm{~g}^{-1}$ sed) ; PT = fósforo total $\left(\mu \mathrm{gP} \mathrm{g}^{-1}\right.$ sed). 


\begin{tabular}{|c|c|c|c|c|c|c|c|c|c|c|c|c|c|c|c|c|}
\hline RTR & Cd & $\mathrm{Cr}$ & $\mathrm{Cu}$ & $\mathbf{N i}$ & $\mathrm{Zn}$ & $\mathbf{P b}$ & COT & AG & AF & Sil & Arg & SVA & NKT & PT & SOMA & Iq \\
\hline P1 & 0,78 & 0,81 & 2,44 & 0,82 & 0,29 & 1,09 & 0,76 & 7,43 & 276,57 & 0,81 & 0,67 & 15,41 & 1,67 & 1,66 & 311,21 & 22,23 \\
\hline P2 & 1,41 & 0,95 & 10,09 & 1,28 & 0,61 & 1,17 & 1, & 13,71 & 65,00 & 0,91 & 1,59 & 42,77 & 2,09 & 2,85 & & 10,40 \\
\hline P3 & 1,77 & 1,06 & 15 & 1,38 & 058 & 1,39 & 0 , & 1 & 14 & & 0,78 & & & & & 13 \\
\hline EG1 & 1,00 & 1, & 1,00 & 1 & 1 , & 1 , & & 1 & 0 & 0 & 0 & & 0 & 0 & & 00 \\
\hline EG2 & 1,33 & 93 & 1,23 & 0,89 & 5 & 0,94 & 0 & 55,7 & 57 & 0,82 & 3 & r & 1 & 0 , & & 6,80 \\
\hline EG3 & 1,77 & 95 & 8,77 & 1,08 & 0,61 & 1,11 & 0,90 & 17,29 & 99,71 & 0,36 & 1,58 & 4,42 & 4 & 1,48 & 37 & 60,10 \\
\hline EM1 & 1,33 & 0,59 & 6,03 & 0,76 & 0,58 & 1,49 & 0,78 & 1,86 & 13,71 & 1,01 & 0,61 & 33,99 & 1,63 & 2,34 & 71 & 4,77 \\
\hline EM2 & 1,75 & 0,68 & 39,58 & 1,09 & 0,55 & 1,44 & 0,93 & 28,29 & 67,57 & 0,97 & 0,39 & 73,21 & 2,15 & 4,11 & 71 & 15,91 \\
\hline EM3 & 2,11 & 0,77 & 54,39 & 1,21 & 0,51 & 1,50 & 0,73 & 9,00 & 21,86 & 1,03 & 0,11 & 21,34 & 2,30 & 3,32 & 120,18 & 8,58 \\
\hline G1 & 2,00 & 0,80 & 69,42 & 1,12 & 0,49 & 1,17 & 0,89 & 72,14 & 14,71 & 0,68 & 5,14 & 17,93 & 1,78 & 3,54 & 191,82 & 13,70 \\
\hline G2 & 2,49 & 1,05 & 73,25 & 1,52 & 0,76 & 1,68 & 0,91 & 14,00 & 4,00 & 0,90 & 2,39 & 26,46 & 2,10 & 3,47 & 135,00 & 9,64 \\
\hline G3 & 2,51 & 0,90 & 121,85 & 1,59 & 0,74 & 1,62 & 1,39 & 10,29 & 11,14 & 1,00 & 0,72 & 22,67 & 2,55 & 3,69 & 182,66 & 13,05 \\
\hline
\end{tabular}

Anexo 2.6. Dados da TQS versão 2 para Índice químico (Iq) transformados em RTR: Cd = cádmio (mgCd $\left.\mathrm{Kg}^{-1} \mathrm{sed}\right)$; $\mathrm{Cr}=\mathrm{cromo}\left(\mathrm{mgCr} \mathrm{Kg}{ }^{-1} \mathrm{sed}\right)$; $\mathrm{Cu}=$ cobre ((mgCu Kg-1 $\mathrm{sed}) ; \mathrm{Pb}=$ chumbo (mgPb Kg${ }^{-1}$ sed); $\mathrm{Ni}=$ níquel (mgNi Kg-1 sed); $\mathrm{Zn}=$ zinco (mgZn Kg-1 sed); COT = carbono orgânico total (mmol); Sil = silte (\%); Arg = argila (\%); SVA= sulfeto volatizável por acidificação; NKT = nitrogênio Kjedahl total $(\mu g N$ g-1 sed) ; PT = fósforo total $\left(\mu \mathrm{gP} \mathrm{g}{ }^{-1}\right.$ sed).

\begin{tabular}{|c|c|c|c|c|c|c|c|c|c|c|c|c|c|c|}
\hline RTR & Cd & $\mathrm{Cr}$ & Cu & $\mathrm{Ni}$ & Zn & $\mathbf{P b}$ & COT & Sil & Arg & SVA & NKT & PT & SOMA & Iq \\
\hline P1 & 0,78 & 0,81 & 2,44 & 0,82 & 0,29 & 1,09 & 0,76 & 0,81 & 0,67 & 15,41 & 1,67 & 1,66 & 27,21 & 2,27 \\
\hline P2 & 1,41 & 0,95 & 10,09 & 1,28 & 0,61 & 1,17 & 1,23 & 0,91 & 1,59 & 42,77 & 2,09 & 2,85 & 66,94 & 5,58 \\
\hline P3 & 1,77 & 1,06 & 19,47 & 1,38 & 0,58 & 1,39 & 0,52 & 0,90 & 0,78 & 1,00 & 1,55 & 2,83 & 33,22 & 2,77 \\
\hline EG1 & 1,00 & 1,00 & 1,00 & 1,00 & 1,00 & 1,00 & 1,00 & 1,00 & 1,00 & 1,00 & 1,00 & 1,00 & 12,00 & 1,00 \\
\hline EG2 & 1,33 & 0,93 & 1,23 & 0,89 & 0,95 & 0,94 & 0,89 & 0,82 & 3,01 & 7,01 & 1,01 & 0,83 & 19,85 & 1,65 \\
\hline EG3 & 1,77 & 0,95 & 8,77 & 1,08 & 0,61 & 1,11 & 0,90 & 0,36 & 1,58 & 4,42 & 1,34 & 1,48 & 24,37 & 2,03 \\
\hline EM1 & 1,33 & 0,59 & 6,03 & 0,76 & 0,58 & 1,49 & 0,78 & 1,01 & 0,61 & 33,99 & 1,63 & 2,34 & 51,14 & 4,26 \\
\hline EM2 & 1,75 & 0,68 & 39,58 & 1,09 & 0,55 & 1,44 & 0,93 & 0,97 & 0,39 & 73,21 & 2,15 & 4,11 & 126,85 & 10,57 \\
\hline EM3 & 2,11 & 0,77 & 54,39 & 1,21 & 0,51 & 1,50 & 0,73 & 1,03 & 0,11 & 21,34 & 2,30 & 3,32 & 89,33 & 7,44 \\
\hline G1 & 2,00 & 0,80 & 69,42 & 1,12 & 0,49 & 1,17 & 0,89 & 0,68 & 5,14 & 17,93 & 1,78 & 3,54 & 104,97 & 8,75 \\
\hline
\end{tabular}




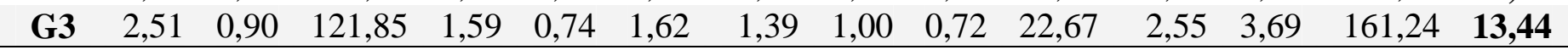

Anexo 2.7. Dados da TQS para Índice toxicológico (It) transformados em RTR: . silvestri= teste crônico (reprodução); $C$. xanthus = teste agudo (mortalidade) no sedimento dos 12 pontos com a larva de inseto Chironomus xanthus; $D$. similis = teste agudo (mortalidade) no sedimento dos 12 pontos com o Cladocera D. similis; D. similis (int.) = teste agudo (mortalidade) com o Cladocera D. similis na água intersticial dos 12 pontos.

\begin{tabular}{crrccrr}
\hline RTR & $\begin{array}{c}\text { C. } \\
\text { silvestri }\end{array}$ & $\begin{array}{c}\text { C. } \\
\text { xanthus }\end{array}$ & $\begin{array}{c}\text { D. } \\
\text { similis }\end{array}$ & $\begin{array}{c}\text { D. } \\
\text { similis } \\
\text { (int) }\end{array}$ & SOMA & It \\
\hline P1 & 101,00 & 1,85 & 2,81 & 1,83 & 107,49 & $\mathbf{2 6 , 8 7}$ \\
P2 & 101,00 & 2,34 & 2,81 & 9,33 & 115,47 & $\mathbf{2 8 , 8 7}$ \\
P3 & 101,00 & 2,82 & 2,81 & 1,00 & 107,63 & $\mathbf{2 6 , 9 1}$ \\
EG1 & 101,00 & 1,85 & 2,81 & 0,17 & 105,82 & $\mathbf{2 6 , 4 6}$ \\
EG2 & 101,00 & 0,88 & 2,81 & 0,17 & 104,85 & $\mathbf{2 6 , 2 1}$ \\
EG3 & 1,00 & 1,36 & 2,53 & 0,17 & 5,06 & $\mathbf{1 , 2 6}$ \\
EM1 & 1,00 & 1,36 & 0,31 & 1,00 & 3,67 & $\mathbf{0 , 9 2}$ \\
EM2 & 76,00 & 1,49 & 1,00 & 0,17 & 78,65 & $\mathbf{1 9 , 6 6}$ \\
EM3 & 1,00 & 1,00 & 1,00 & 1,00 & 4,00 & $\mathbf{1 , 0 0}$ \\
G1 & 89,00 & 1,49 & 2,53 & 1,00 & 94,01 & $\mathbf{2 3 , 5 0}$ \\
G2 & 101,00 & 1,85 & 2,81 & 0,17 & 105,82 & $\mathbf{2 6 , 4 6}$ \\
G3 & 101,00 & 1,61 & 2,67 & 0,17 & 105,44 & $\mathbf{2 6 , 3 6}$ \\
\hline
\end{tabular}


Anexo 2.8. Possíveis Conclusões apresentadas no gráfico ternário da Tríade de Qualidade do Sedimento (Chapman, 1992). Lembrando que deve-se imaginar cada ponto como centro do triângulo e suas posições demostrando para quais índices as amostras estão tendendo. + = ocorrência observada; = não observada ocorrência.

\begin{tabular}{|c|c|c|c|c|}
\hline Situação & Contaminação & Toxicidade & $\begin{array}{l}\text { Alteração na } \\
\text { comunidade }\end{array}$ & Conclusões Possíveis \\
\hline $\mathbf{1}$ & + & + & + & Forte evidência de degradação induzida por poluição \\
\hline 2 & - & - & - & Forte evidência pela ausência de degradação induzida por poluição \\
\hline 3 & + & - & - & Contaminates não estão biodisponíveis \\
\hline 4 & - & + & - & $\begin{array}{l}\text { Variáveis químicas não medidas ou as condições existem e tem potencial para } \\
\text { causar degradação }\end{array}$ \\
\hline 5 & - & - & + & $\begin{array}{l}\text { A alteração na comunidade não é provavelmente devida a contaminação química } \\
\text { tóxica }\end{array}$ \\
\hline 6 & + & + & - & Químicos tóxicos estão estressando o sistema \\
\hline 7 & - & + & + & Químicos tóxicos não medidos estão causando degradação \\
\hline 8 & + & - & + & $\begin{array}{l}\text { Químicos não estão biodisponíveis ou a alteração na comunidade se deve a } \\
\text { toxicidade química }\end{array}$ \\
\hline
\end{tabular}

Anexo 2.9. Matriz de Correlação de Pearson. $\mathrm{Cd}$ = cádmio; $\mathrm{Cr}=$ cromo; $\mathrm{Cu}=$ cobre; $\mathrm{Pb}$ = chumbo; $\mathrm{Ni}=$ níquel; $\mathrm{Zn}=$ zinco; $\mathrm{COT}$ = carbono orgânico total; $\mathrm{AG}$ = areia grossa; $\mathrm{AF}$ = areia fina; Sil = silte; $\mathrm{Arg}$ = argila; $\mathrm{SVA}=$ sulfeto volatizável por acidificação; $\mathrm{NKT}=$ nitrogênio Kjedahl total ; PT = fósforo total; $\mathrm{pH}=$ potencial hidrogênionico; $\mathrm{OD}=$ oxigênio dissolvido; Cond= condutividade; Prof= profundidade; Temp= temperatura; $\mathrm{Eh}=$ potencial de oxi-redução; 


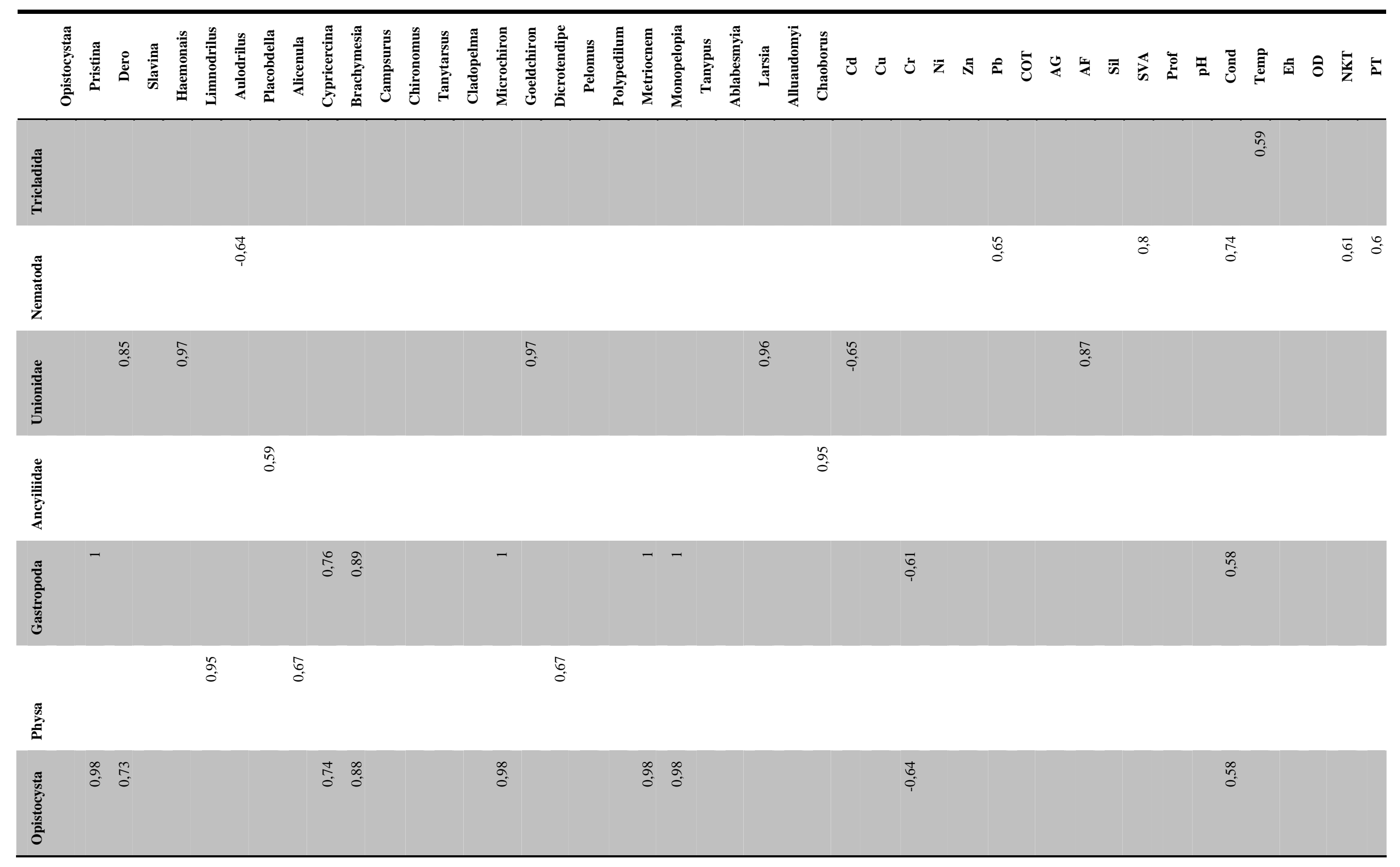




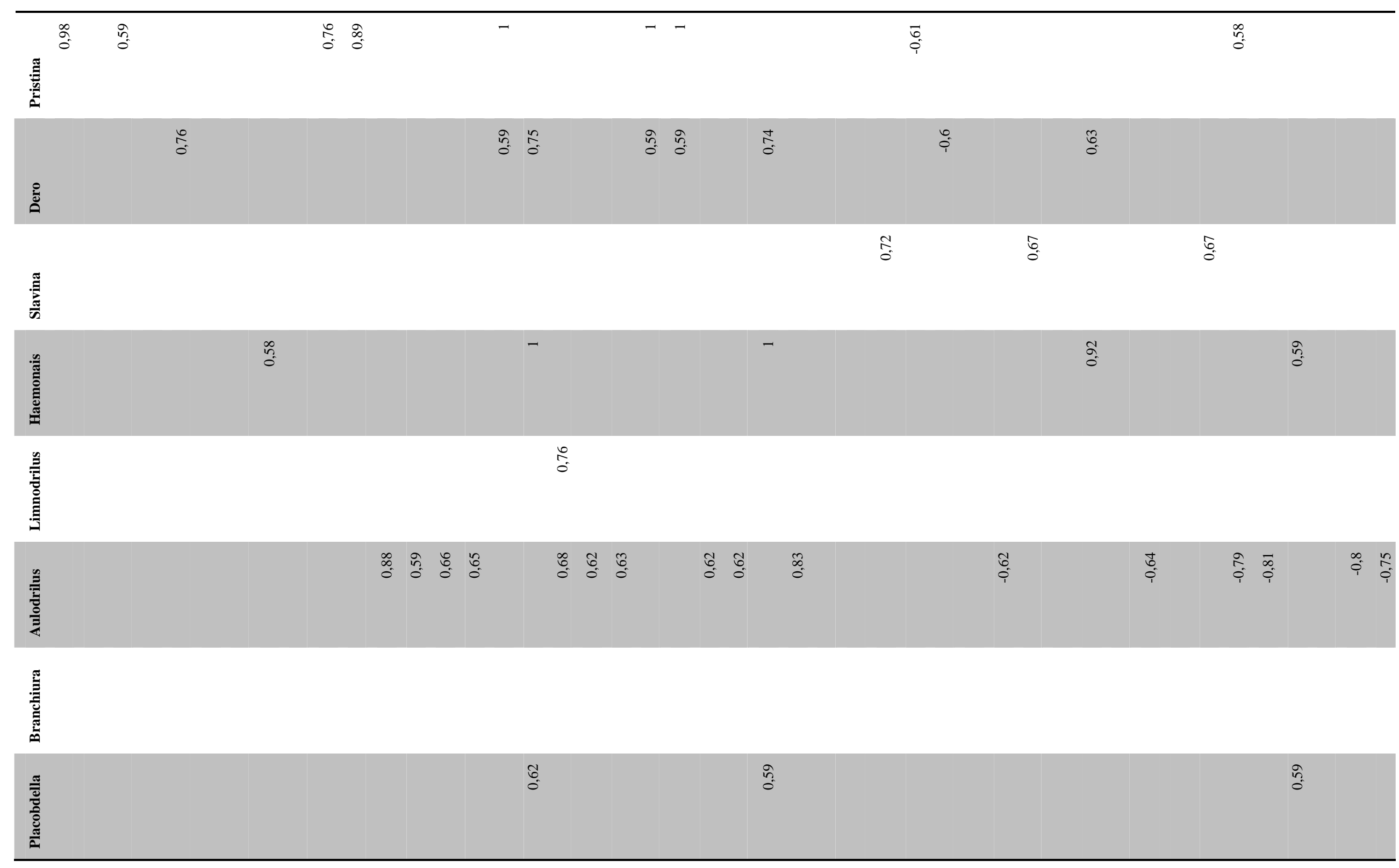




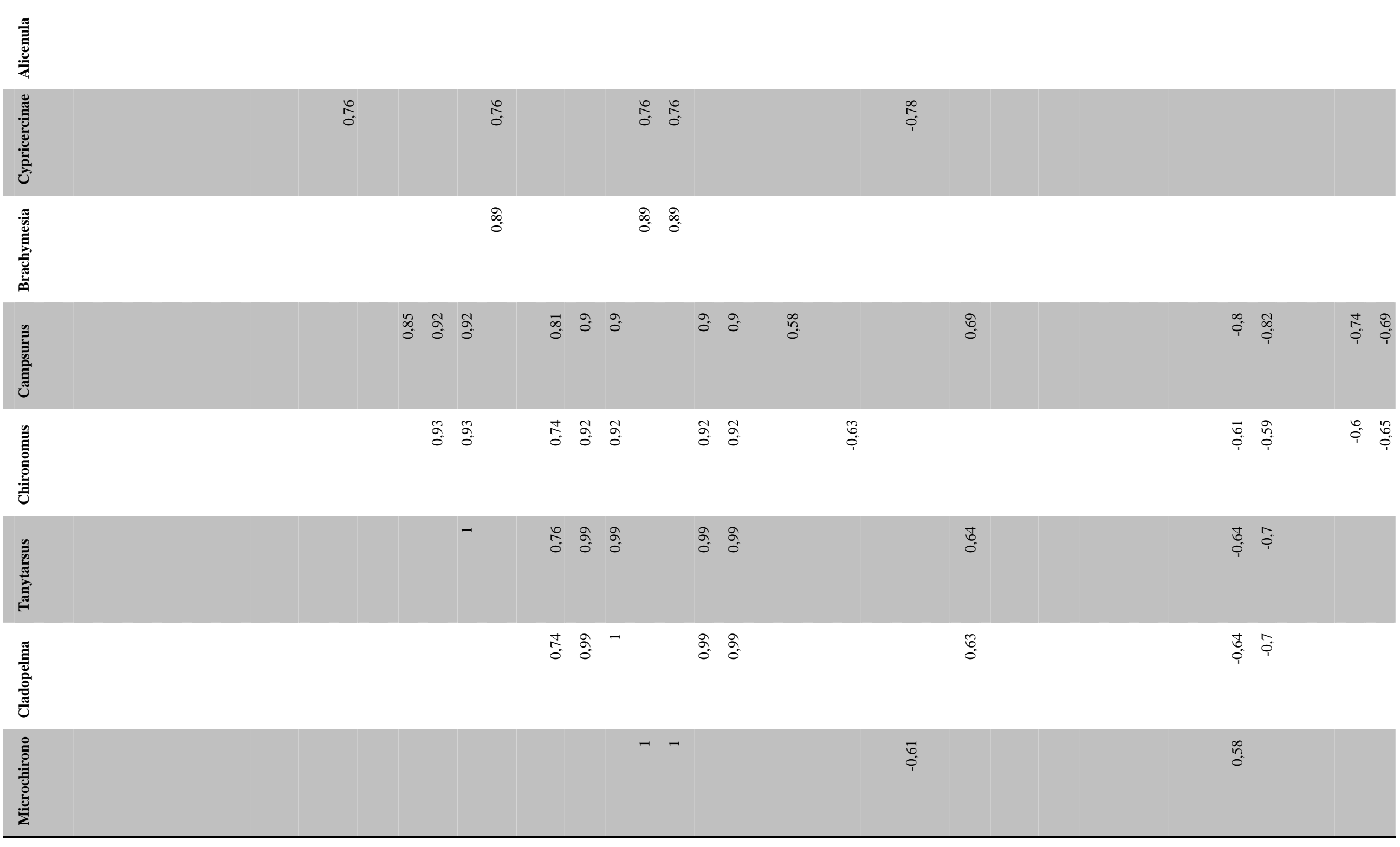




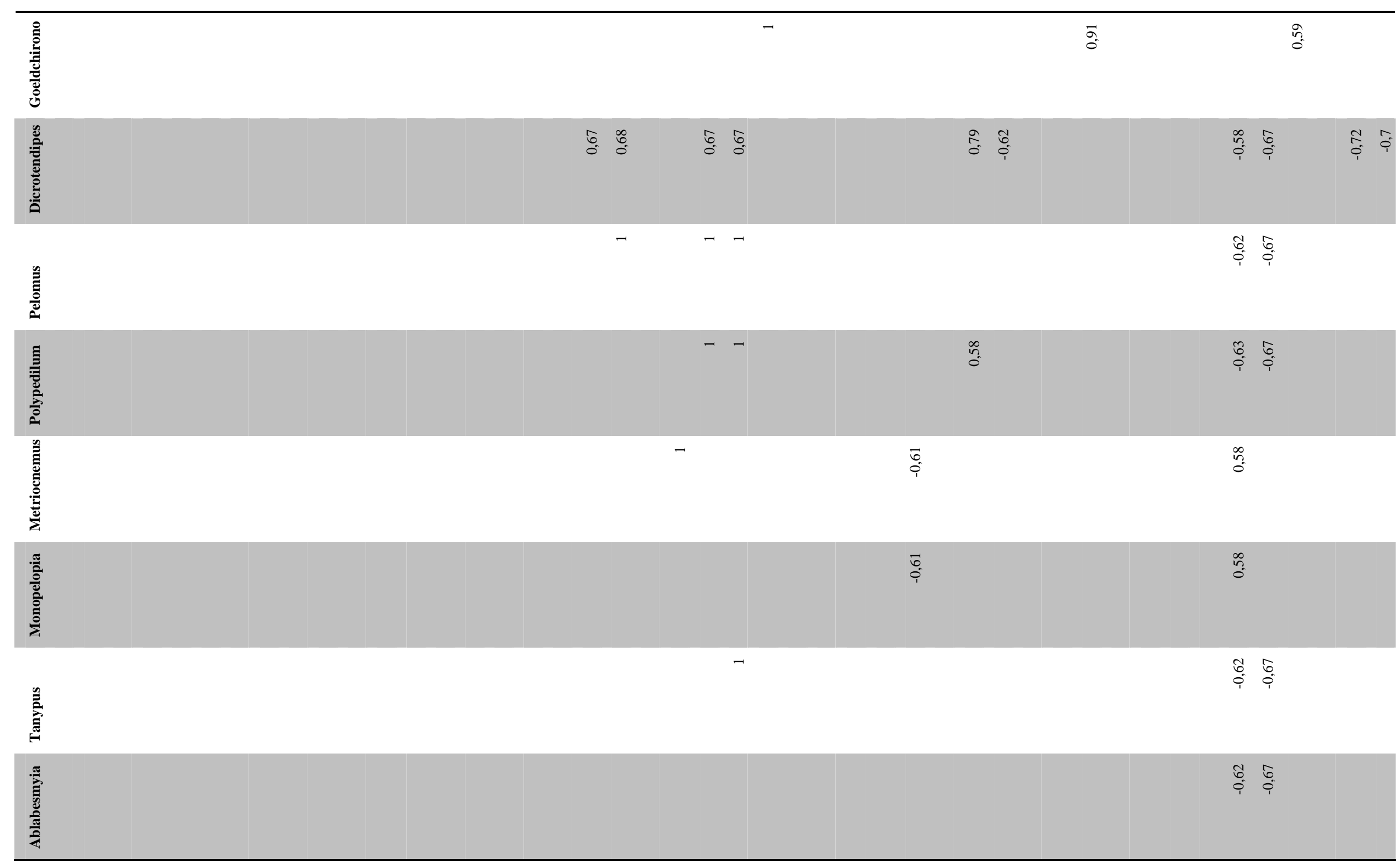




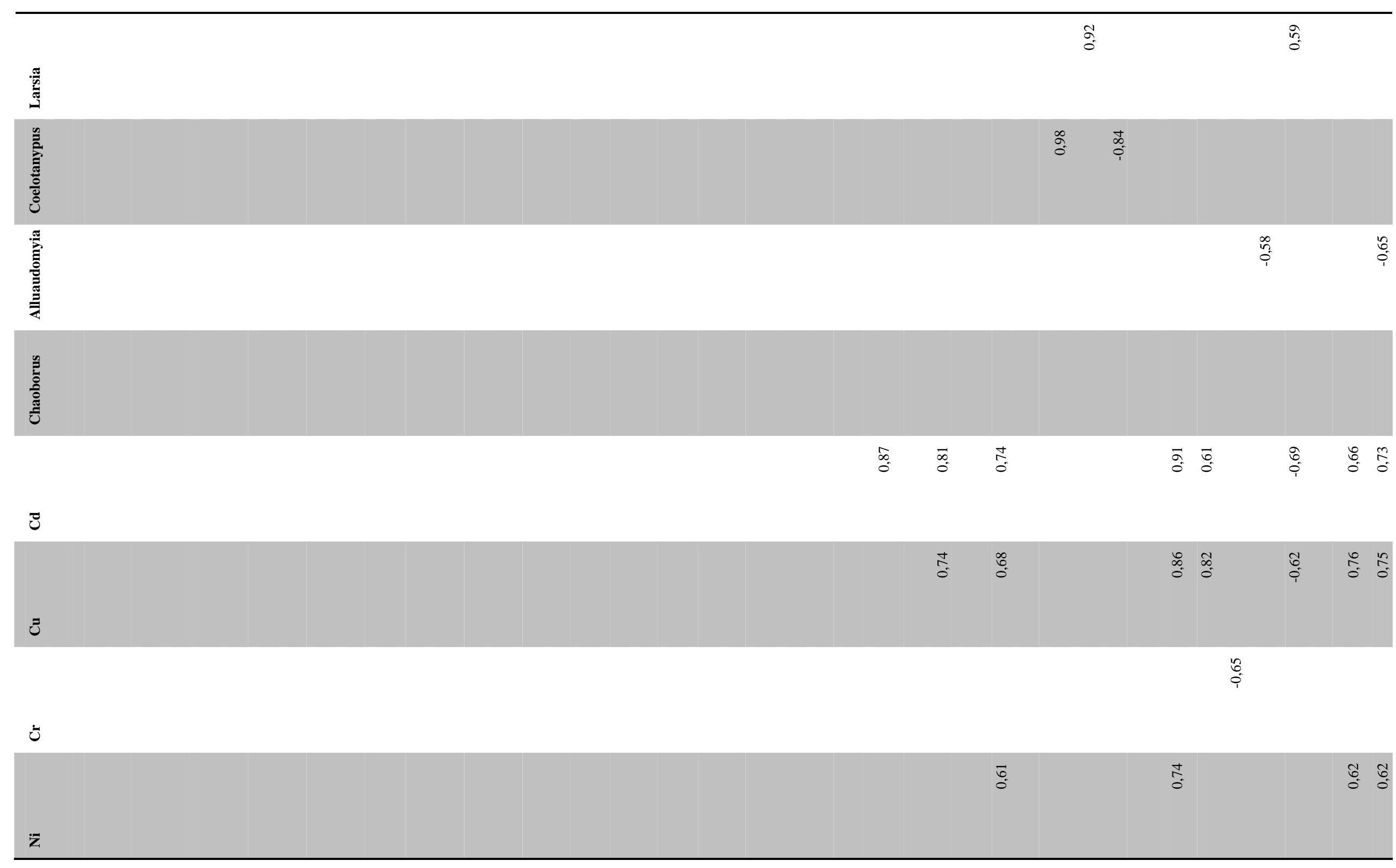


ร

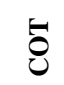

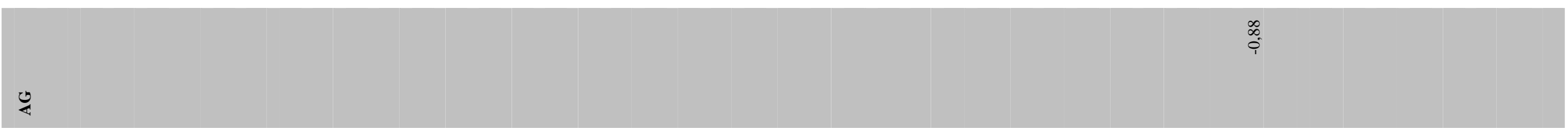

委

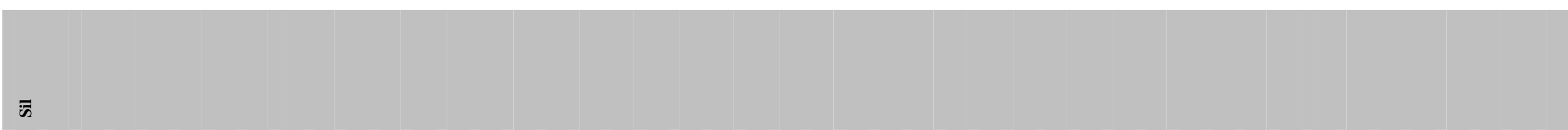

哭

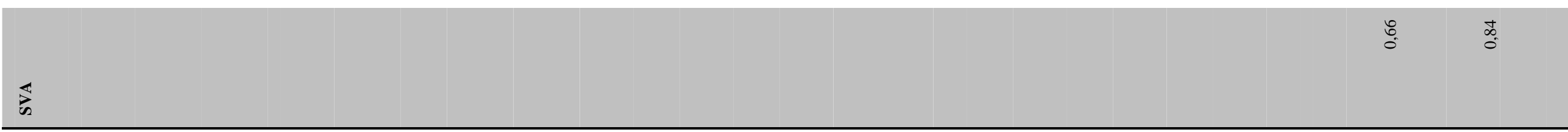


$\bar{g}$

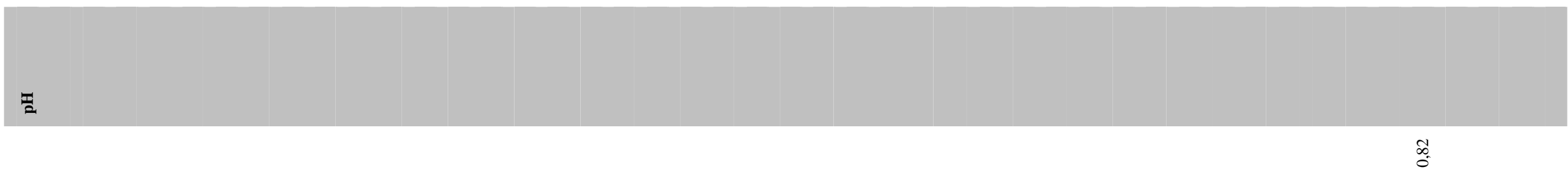

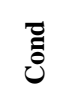

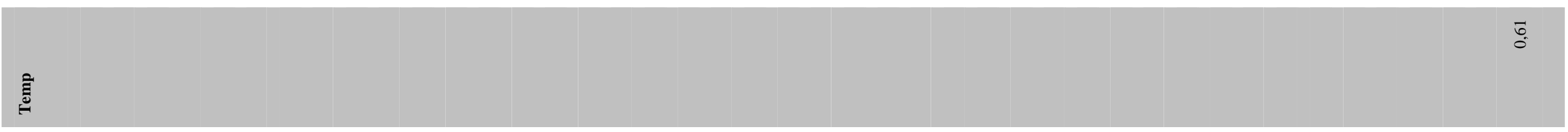

雷

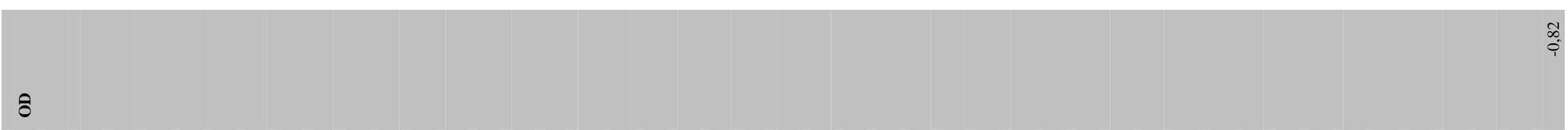

$\frac{5}{2}$

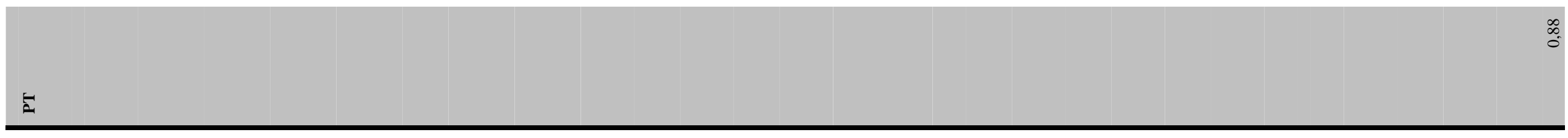

